Dataset S2. Illustration of the 84 microclones identified in samples 1-1 and 1-2.

A. Tables displaying the antigenic profile of the microclone and cell counts for each positive section, using the same scheme as in legend to Figure 2. B. Panel of images displaying the staining of each microclone. Independently identified cellular clusters are tagged with a flag; absence of a flag indicates that no cluster is present (if allocated a score of 0 in the table above) or that clusters were identified in the post hoc analysis (if allocated a score of $0^{*}$ in the table above). Scale bars: $100 \mu \mathrm{m}$. 
Clone no. 1-1_C1

A

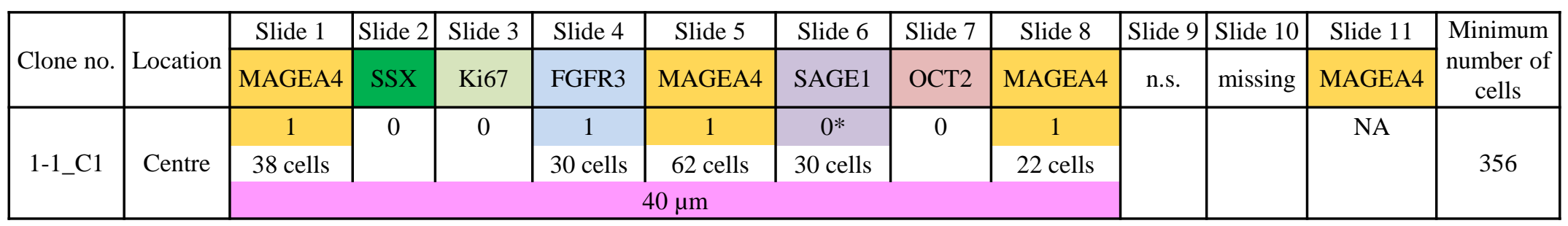

B

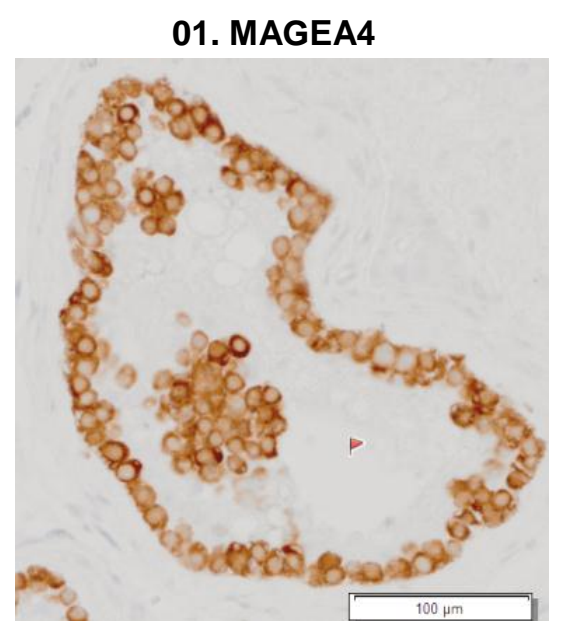

05. MAGEA4

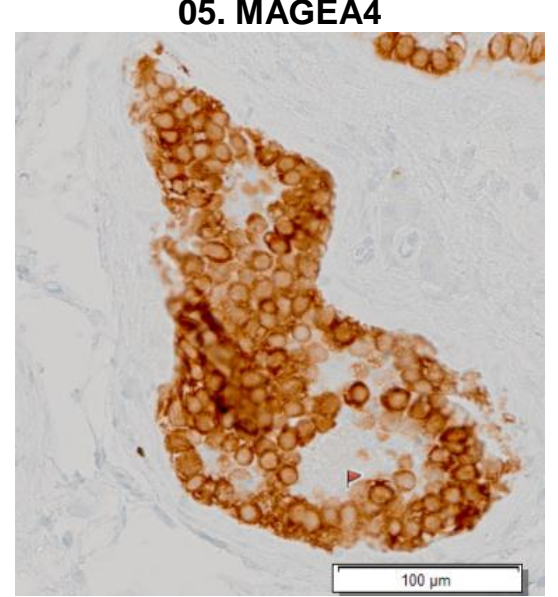

02. SSX

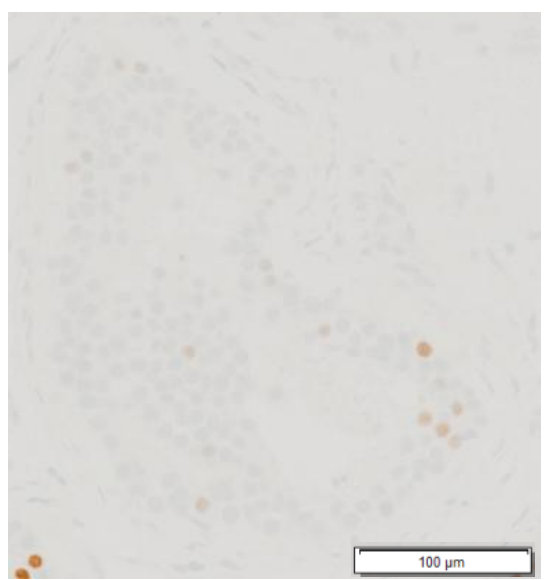

06. SAGE1

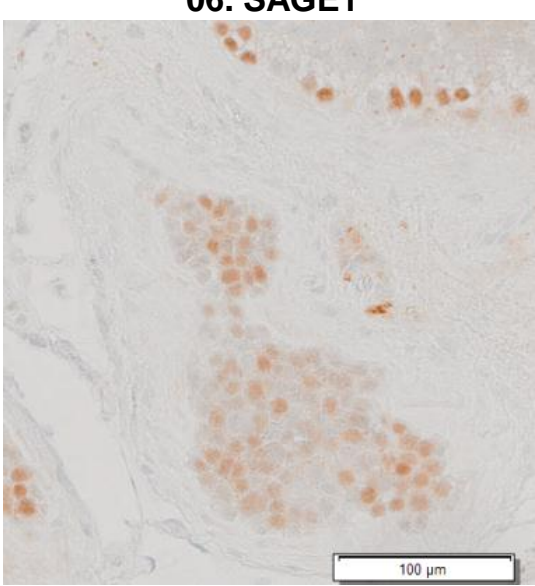

03. Ki67

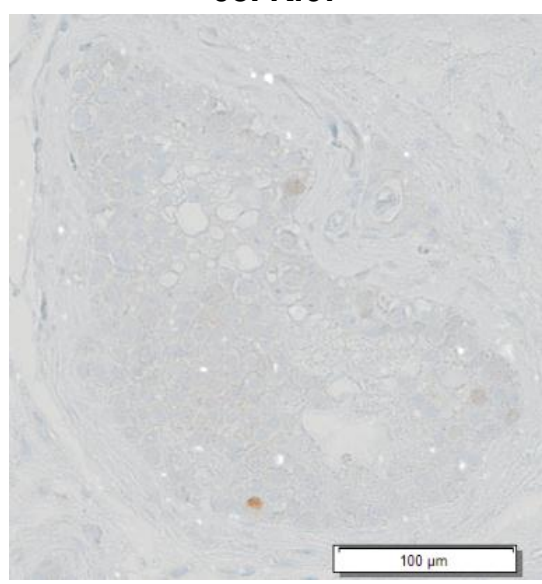

07. ОСТ2

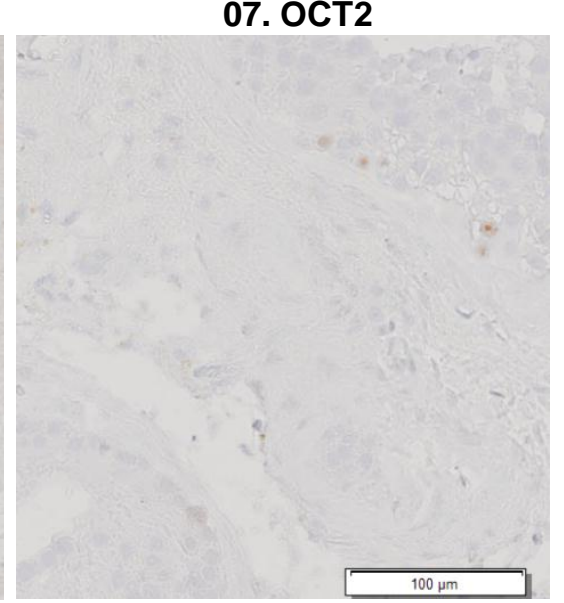

04. FGFR3

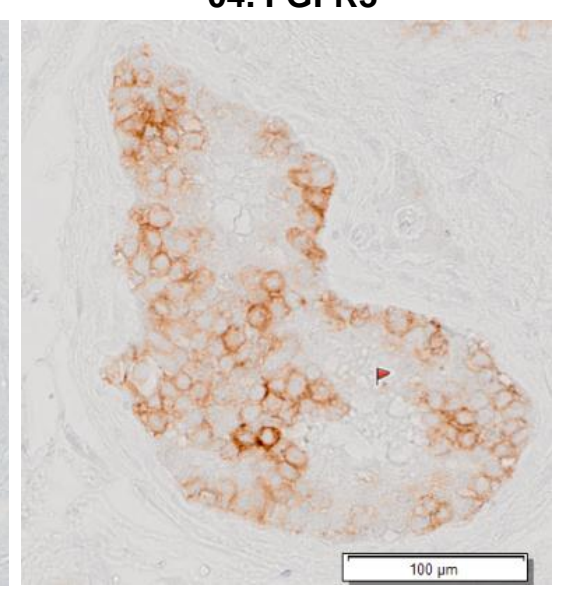

08. MAGEA4

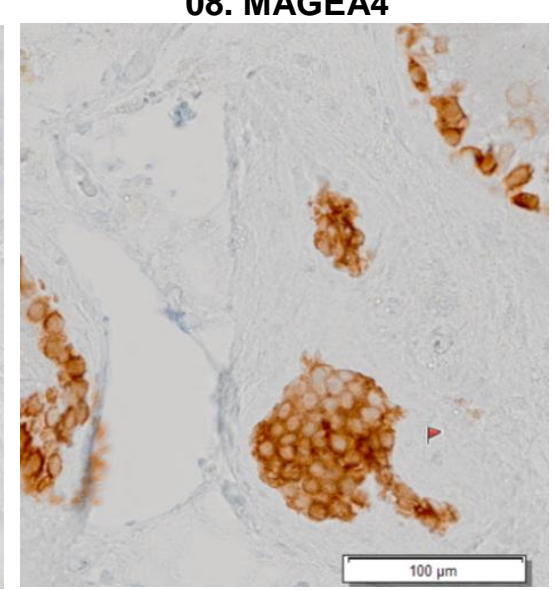




\section{Clone no.1-1_C2}

A

\begin{tabular}{|c|c|c|c|c|c|c|c|c|c|c|}
\hline \multirow{2}{*}{ Clone no. } & \multirow{2}{*}{ Location } & Slide 1 & Slide 2 & Slide 3 & Slide 4 & Slide 5 & Slide 6 & Slide 7 & Slide 8 & \multirow{2}{*}{$\begin{array}{c}\text { Minimum } \\
\text { number of cells }\end{array}$} \\
\hline & & MAGEA4 & SSX & Ki67 & FGFR3 & MAGEA4 & SAGE1 & OCT2 & MAGEA4 & \\
\hline \multirow{3}{*}{ 1-1_C2 } & \multirow{3}{*}{ Periphery } & 1 & 0 & 0 & 1 & 1 & 0 & 0 & $0^{*}$ & \multirow{3}{*}{287} \\
\hline & & 80 cells & & & 10 cells & 23 cells & & & 3 cells & \\
\hline & & \multicolumn{8}{|c|}{$40 \mu \mathrm{m}$} & \\
\hline
\end{tabular}

B

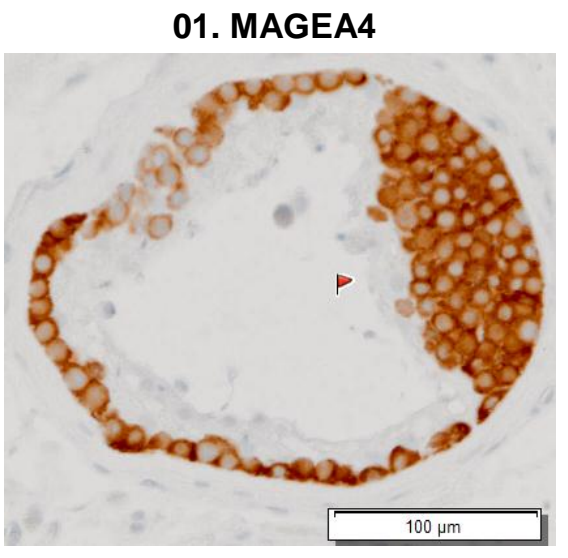

05. MAGEA4

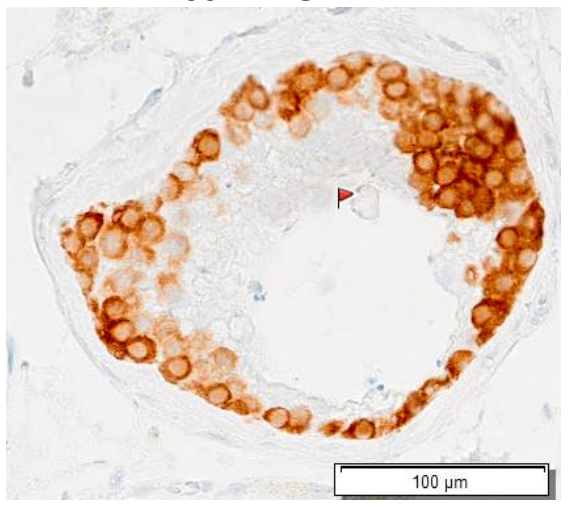

02. SSX

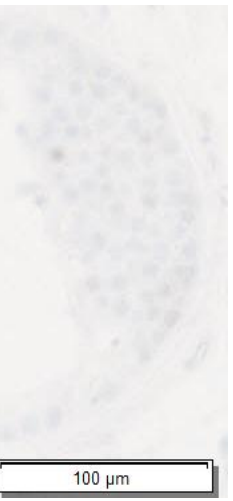

06. SAGE1

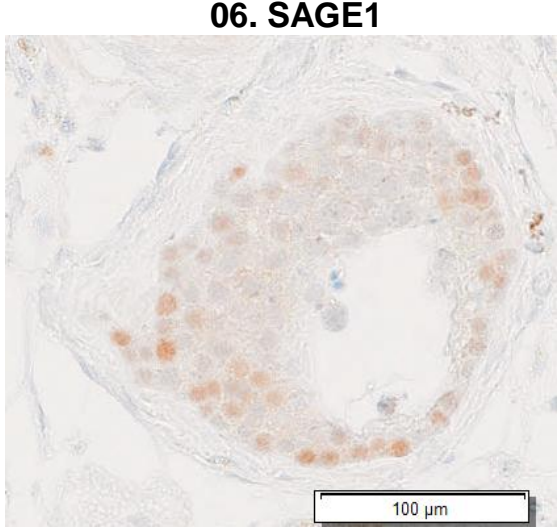

03. Ki67

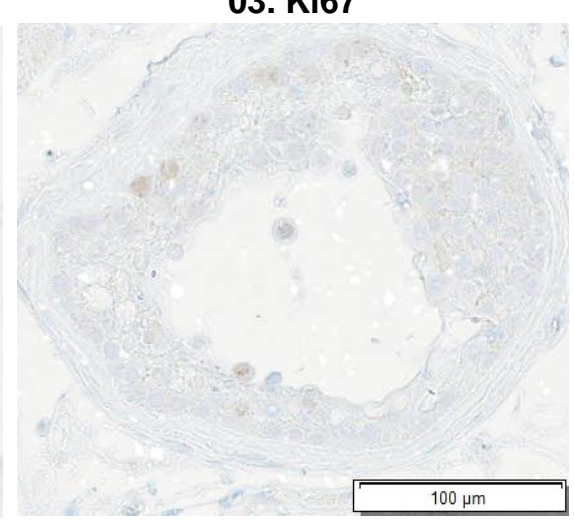

07. ОСТ2
04. FGFR3

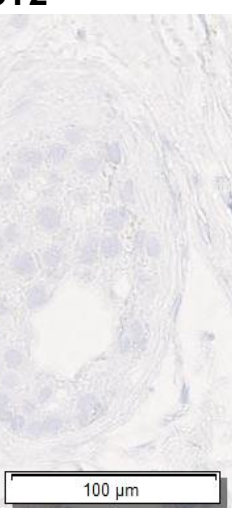

08. MAGEA4

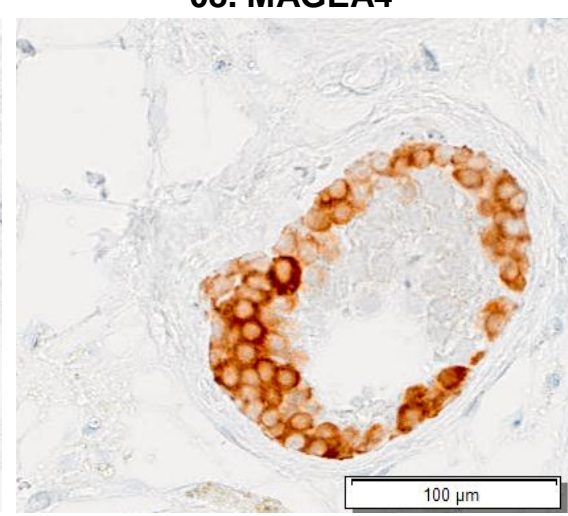




\section{Clone no.1-1_C3}

A

\begin{tabular}{|c|c|c|c|c|c|c|c|c|c|c|}
\hline \multirow{2}{*}{ Clone no. } & \multirow{2}{*}{ Location } & Slide 1 & Slide 2 & Slide 3 & Slide 4 & Slide 5 & Slide 6 & Slide 7 & Slide 8 & \multirow{2}{*}{$\begin{array}{c}\text { Minimum } \\
\text { number of cells }\end{array}$} \\
\hline & & MAGEA4 & SSX & Ki67 & FGFR3 & MAGEA4 & SAGE1 & OCT2 & MAGEA4 & \\
\hline \multirow{3}{*}{ 1-1_C3 } & \multirow{3}{*}{$\begin{array}{c}\text { Near } \\
\text { Periphery }\end{array}$} & 1 & 0 & 0 & 0 & 1 & 0 & 0 & $0^{*}$ & \multirow{3}{*}{58} \\
\hline & & 9 cells & & & & 9 cells & & & 2 cells & \\
\hline & & \multicolumn{8}{|c|}{$40 \mu \mathrm{m}$} & \\
\hline
\end{tabular}

B

01. MAGEA4

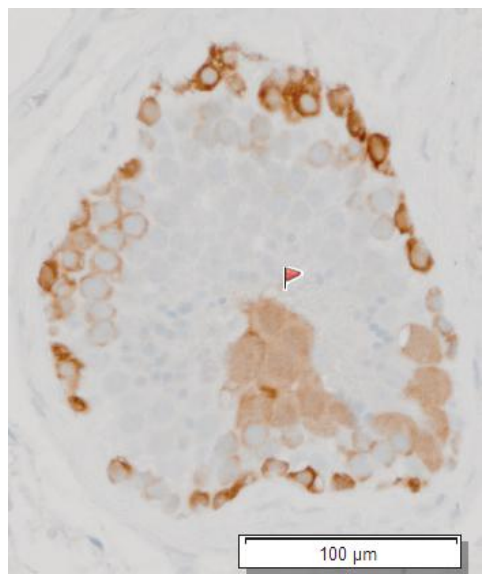

05. MAGEA4

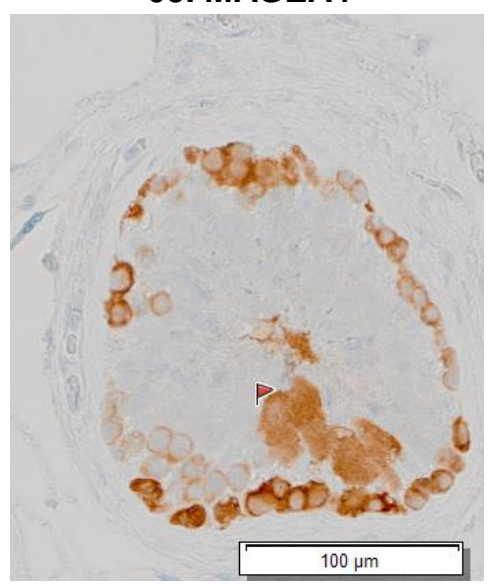

02. SSX

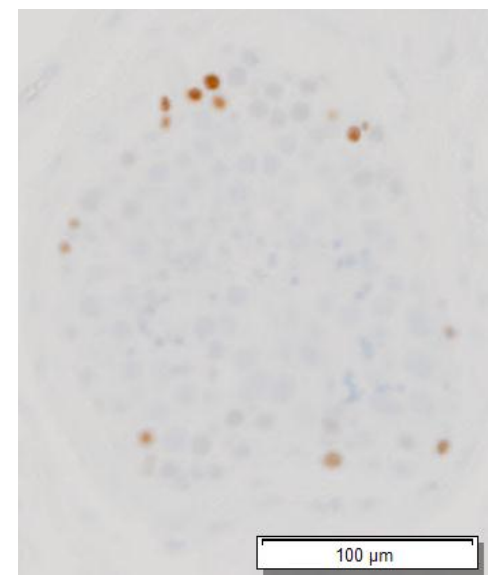

06. SAGE1

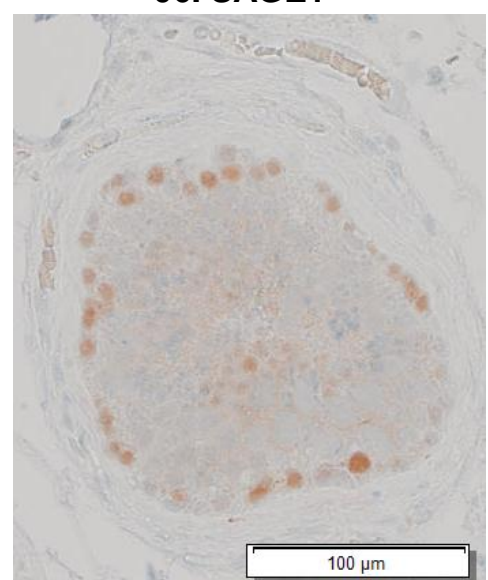

03. Ki67

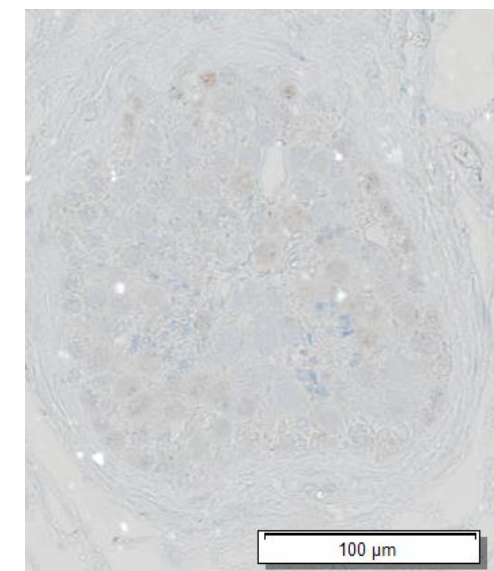

07. ОСТ2

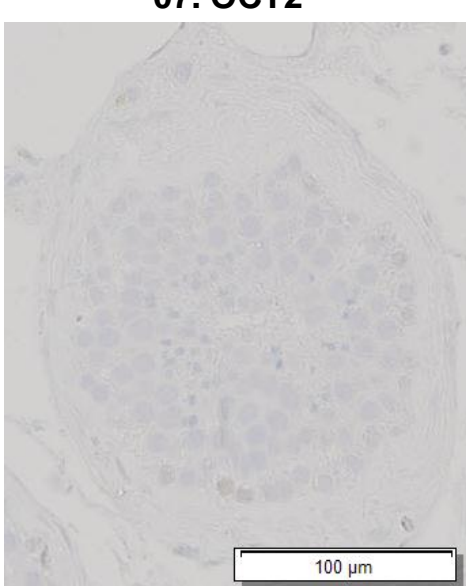

04. FGFR3

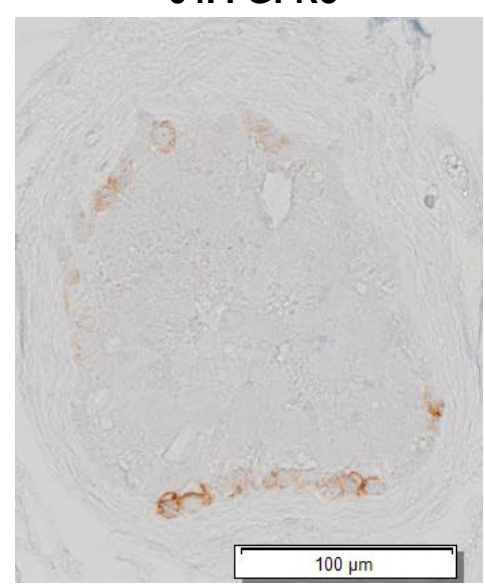

08. MAGEA4

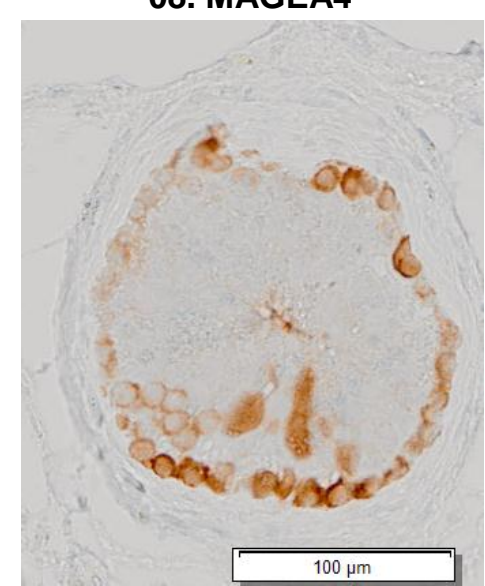


Clone no.1-1_C4

A

\begin{tabular}{|c|c|c|c|c|c|c|c|c|c|c|c|c|c|}
\hline \multirow{2}{*}{ Clone no. } & \multirow{2}{*}{ Location } & Slide 1 & Slide 2 & Slide 3 & Slide 4 & Slide 5 & Slide 6 & Slide 7 & Slide 8 & Slide 9 & Slide 10 & Slide 11 & \multirow{2}{*}{$\begin{array}{c}\text { Minimum } \\
\text { number of } \\
\text { cells }\end{array}$} \\
\hline & & MAGEA4 & SSX & Ki67 & FGFR3 & MAGEA4 & SAGE1 & ОСТ2 & MAGEA4 & n.s. & missing & MAGEA4 & \\
\hline \multirow{3}{*}{ 1-1_C4 } & \multirow{3}{*}{ Centre } & $0^{*}$ & 1 & $0^{*}$ & 1 & 1 & 1 & \multirow[t]{2}{*}{0} & 1 & & & 0 & \multirow{3}{*}{78} \\
\hline & & 6 cells & 3 cells & 2 cells & 5 cells & 14 cells & 12 cells & & 7 cells & & & & \\
\hline & & \multicolumn{8}{|c|}{$40 \mu \mathrm{m}$} & & & & \\
\hline
\end{tabular}

B

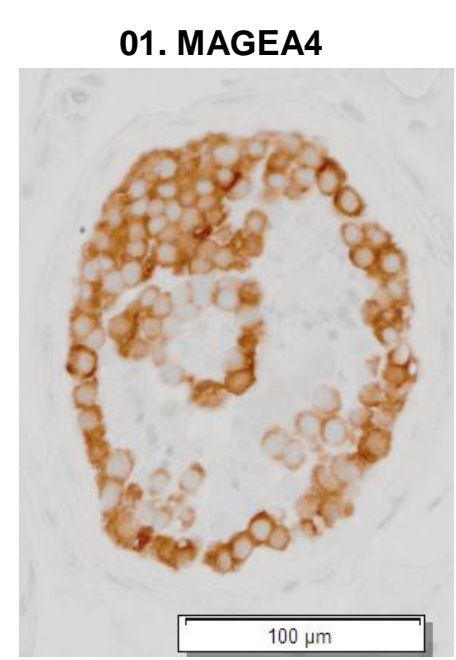

05. MAGEA4

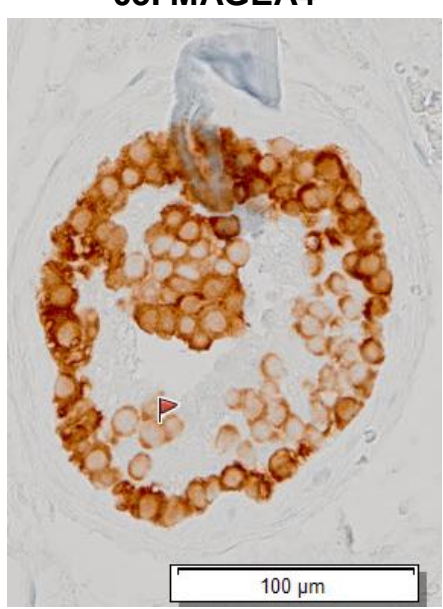

02. SSX

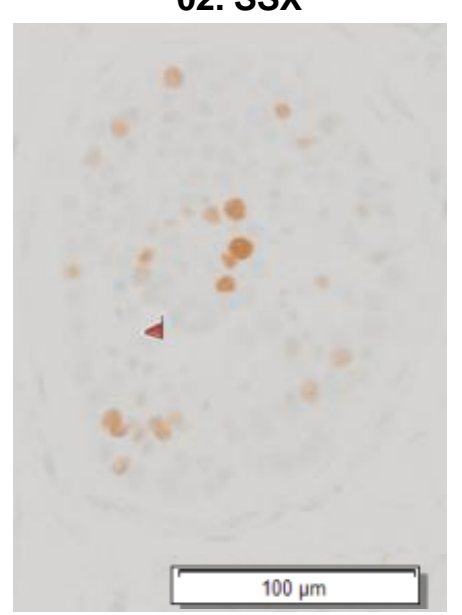

06. SAGE1

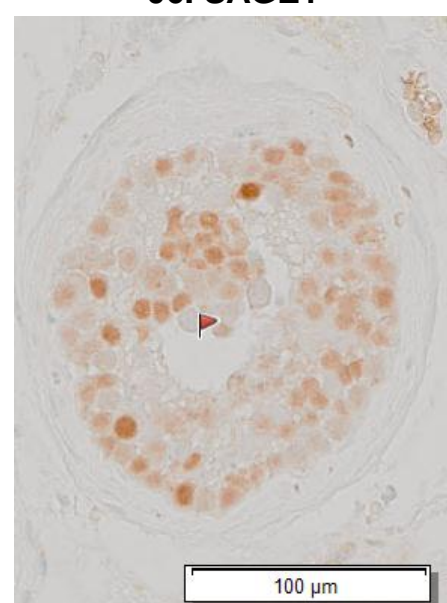

03. Ki67

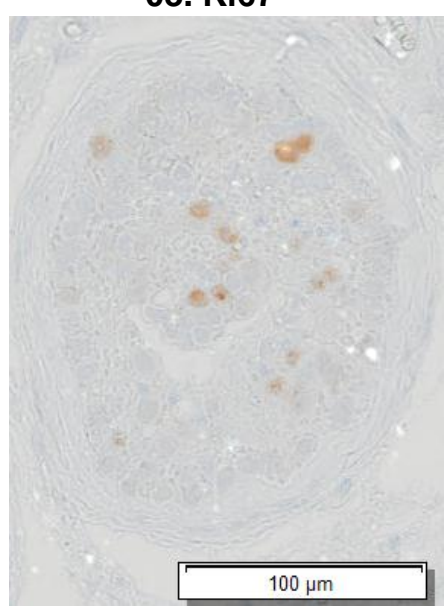

07. OCT2

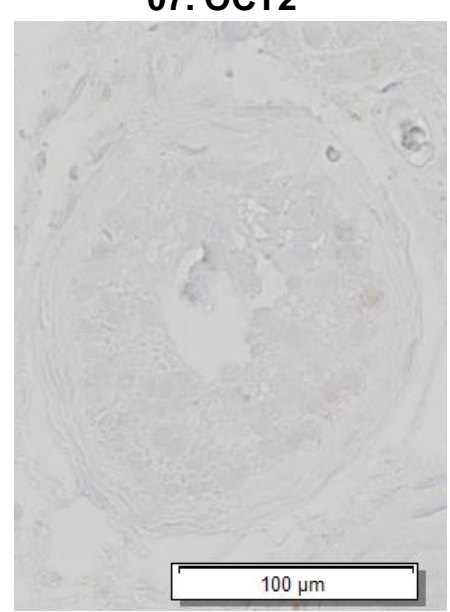

04. FGFR3

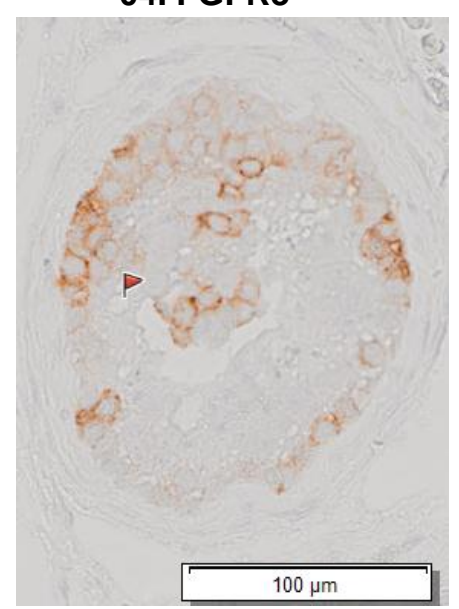

08. MAGEA4

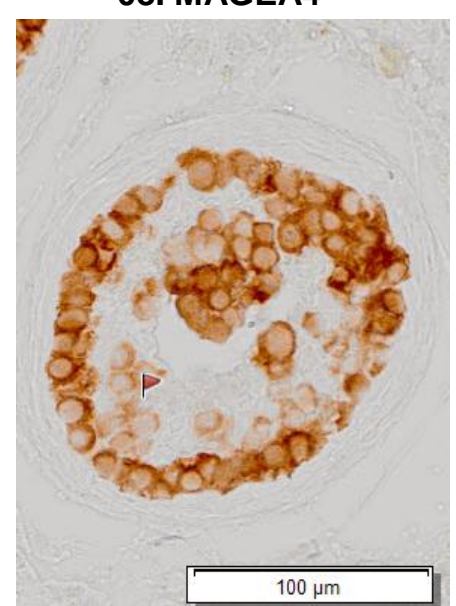




\section{Clone no.1-1_C5}

A

\begin{tabular}{|c|c|c|c|c|c|c|c|c|c|c|c|c|c|}
\hline \multirow[b]{2}{*}{ Clone no. } & \multirow[b]{2}{*}{ Location } & Slide 1 & Slide 2 & Slide 3 & Slide 4 & Slide 5 & Slide 6 & Slide 7 & Slide 8 & Slide 9 & Slide 10 & Slide 11 & \multirow{2}{*}{$\begin{array}{l}\text { Minimum } \\
\text { number of } \\
\text { cells }\end{array}$} \\
\hline & & MAGEA4 & SSX & Ki67 & FGFR3 & MAGEA4 & SAGE1 & ОСТ2 & MAGEA4 & n.s. & missing & MAGEA4 & \\
\hline \multirow{3}{*}{ 1-1_C5 } & \multirow{3}{*}{ Periphery } & \multirow[t]{3}{*}{ NA } & \multirow[t]{3}{*}{0} & \multirow[t]{3}{*}{0} & \multirow[t]{3}{*}{0} & 1 & $0^{*}$ & \multirow[t]{2}{*}{0} & 1 & & & 1 & \multirow{3}{*}{120} \\
\hline & & & & & & 13 cells & 4 cells & & 18 cells & & & 20 cells & \\
\hline & & & & & & \multicolumn{7}{|c|}{$35 \mu \mathrm{m}$} & \\
\hline
\end{tabular}

B

02. SSX

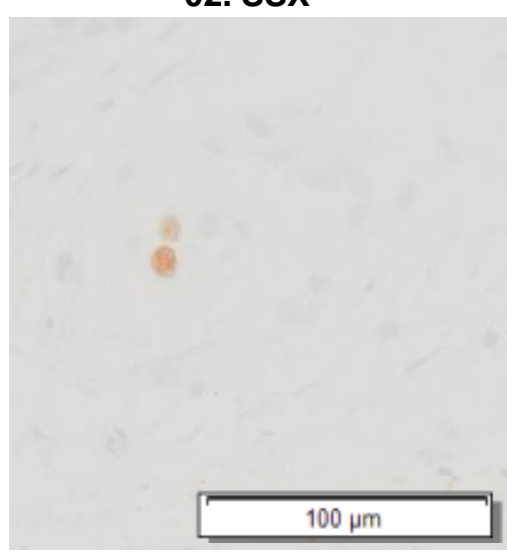

06. SAGE1

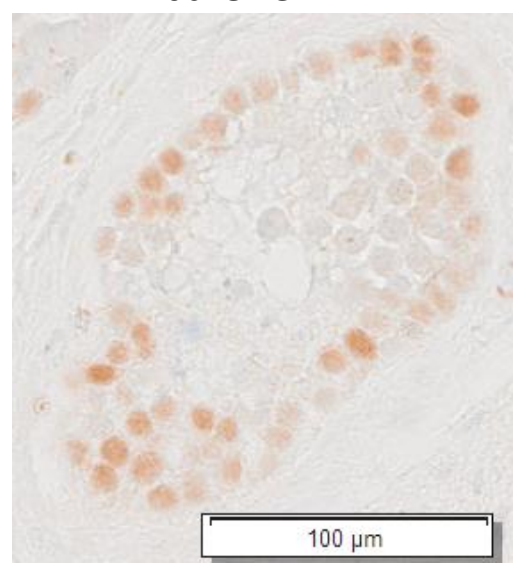

03. Ki67

$100 \mu \mathrm{m}$

07. ОСТ2

$100 \mu \mathrm{m}$
04. FGFR3

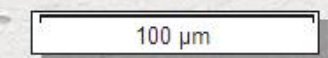

08. MAGEA4

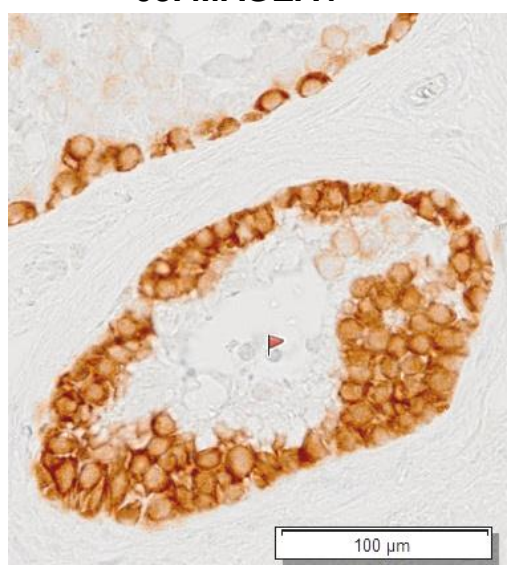

05. MAGEA4

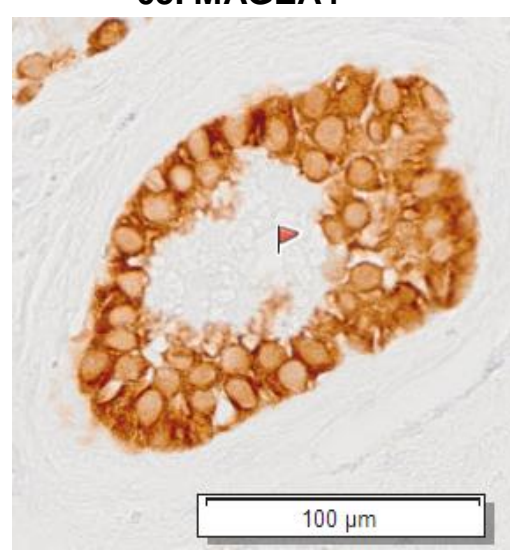

11. MAGEA4

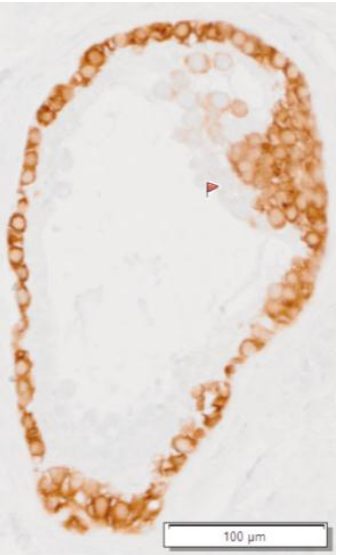




\section{Clone no. 1-1_C6}

A

\begin{tabular}{|c|c|c|c|c|c|c|c|c|c|c|c|c|c|}
\hline \multirow[b]{2}{*}{ Clone no } & \multirow[b]{2}{*}{ Locatior } & Slide 1 & Slide 2 & Slide 3 & \begin{tabular}{|l|} 
Slide 4 \\
\end{tabular} & Slide 5 & Slide 6 & Slide 7 & Slide 8 & Slides & Slide 10 & \begin{tabular}{|l|} 
Slide 11 \\
\end{tabular} & \multirow{2}{*}{$\begin{array}{l}\text { Minimum } \\
\text { number of } \\
\text { cells }\end{array}$} \\
\hline & & MAGEA4 & ss $x$ & Ki67 & FGFR3 & MAGEA4 & SAGE1 & OCT2 & MAGEA4 & n.s. & missing & MAGEA4 & \\
\hline \multirow{3}{*}{ 1-1_C6 } & \multirow{3}{*}{ Centre } & $0^{*}$ & \multirow[t]{2}{*}{0} & \multirow[t]{3}{*}{0} & \multirow[t]{3}{*}{0} & 1 & 1 & \multirow[t]{3}{*}{0} & 1 & & & \multirow[t]{3}{*}{0} & \multirow{3}{*}{40} \\
\hline & & 1 cell & & & & 9 cells & 3 cells & & 3 cells & & & & \\
\hline & & & & & & $40 \mu \mathrm{m}$ & & & & & & & \\
\hline
\end{tabular}

B

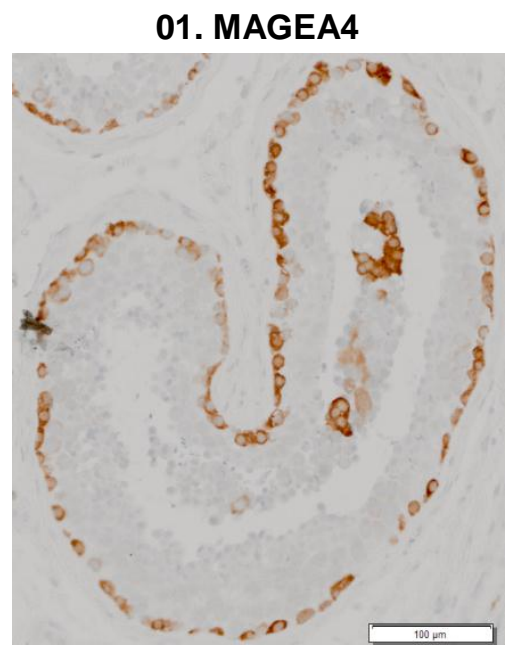

02. SSX

03. Ki67

04. FGFR3

05. MAGEA4

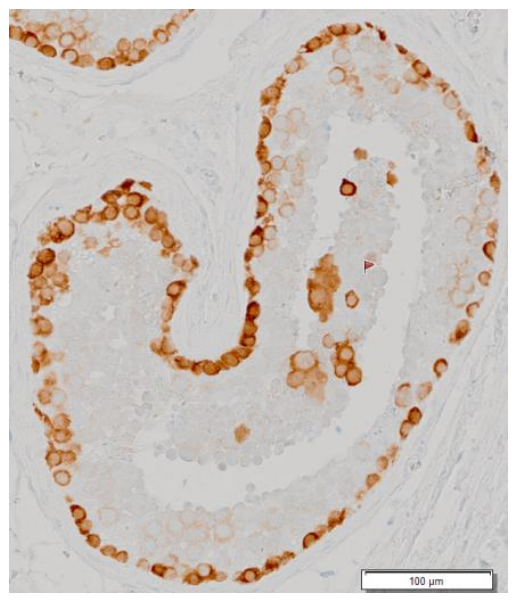

06. SAGE1

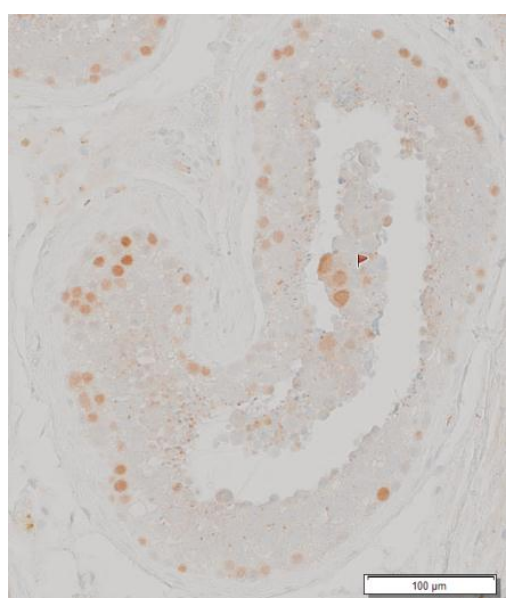

07. ОСT2

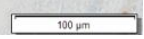

08. MAGEA4

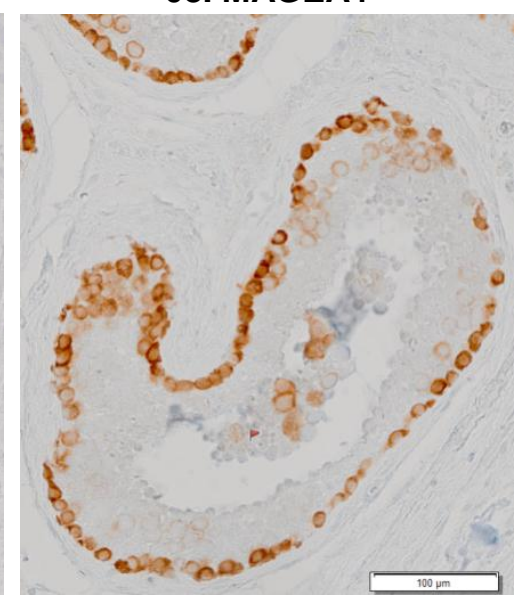


Clone no. 1-1_C7

A

\begin{tabular}{|c|c|c|c|c|c|c|c|c|c|c|c|c|}
\hline \multirow{2}{*}{ Clone no. } & Location & Slide 1 & Slide 2 & Slide 3 & Slide 4 & Slide 5 & Slide 6 & Slide 7 & Slide 8 & Slide 9 & Slide 10 & Slide 11 \\
\cline { 2 - 11 } & MAGEA4 & SSX & Ki67 & FGFR3 & MAGEA4 & SAGE1 & OCT2 & MAGEA4 & n.s. & missing & MAGEA4 & $\begin{array}{c}\text { Mumber of } \\
\text { cells }\end{array}$ \\
\hline 1-1_C7 & Periphery & & 0 & 0 & 0 & 0 & 1 & 0 & 0 & 1 & & \\
\end{tabular}

B
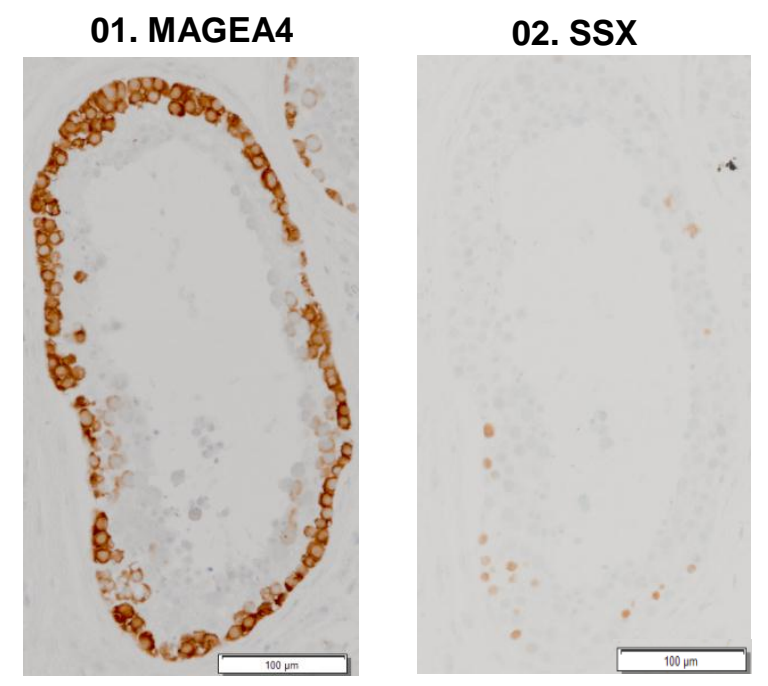

03. Ki67

04. FGFR3
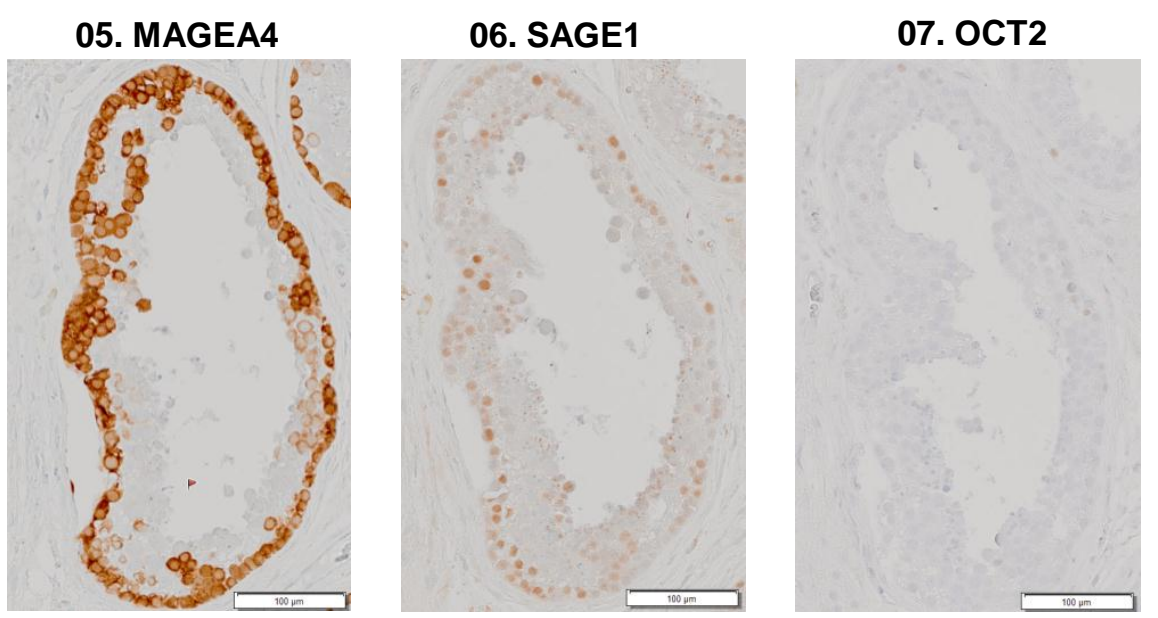

08. MAGEA4

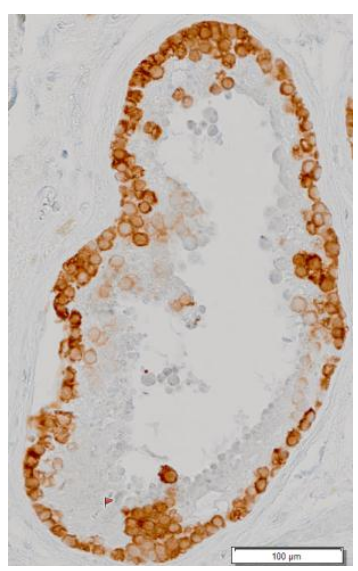




\section{Clone no. 1-1_C8}

A

\begin{tabular}{|c|c|c|c|c|c|c|c|c|c|c|c|c|c|}
\hline \multirow{2}{*}{ Clone no. } & \multirow{2}{*}{ Location } & Slide 1 & Slide 2 & Slide 3 & Slide 4 & Slide 5 & Slide 6 & Slide 7 & Slide 8 & Slide 9 & Slide 10 & Slide 11 & \multirow{2}{*}{$\begin{array}{c}\text { Minimum } \\
\text { number o } \\
\text { cells }\end{array}$} \\
\hline & & MAGEA4 & SSX & Ki67 & FGFR3 & MAGEA4 & SAGE1 & ОСТ2 & MAGEA4 & n.s. & missing & MAGEA4 & \\
\hline \multirow{3}{*}{ 1-1_C8 } & \multirow{3}{*}{ Centre } & \multirow[t]{3}{*}{ NA } & \multirow[t]{3}{*}{ NA } & \multirow[t]{3}{*}{ NA } & \multirow[t]{3}{*}{ NA } & 1 & 1 & \multirow[t]{2}{*}{ NA } & 1 & & & \multirow[t]{3}{*}{ NA } & \multirow{3}{*}{26} \\
\hline & & & & & & 6 cells & 7 cells & & 7 cells & & & & \\
\hline & & & & & & \multicolumn{4}{|c|}{$20 \mu \mathrm{m}$} & & & & \\
\hline
\end{tabular}

B

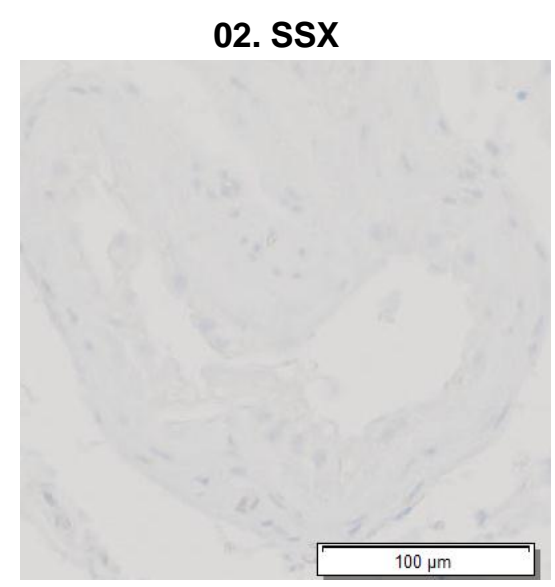

06. SAGE1

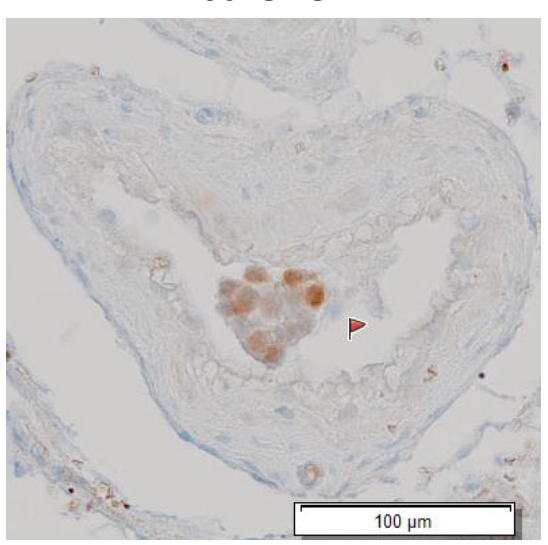

03. Ki67

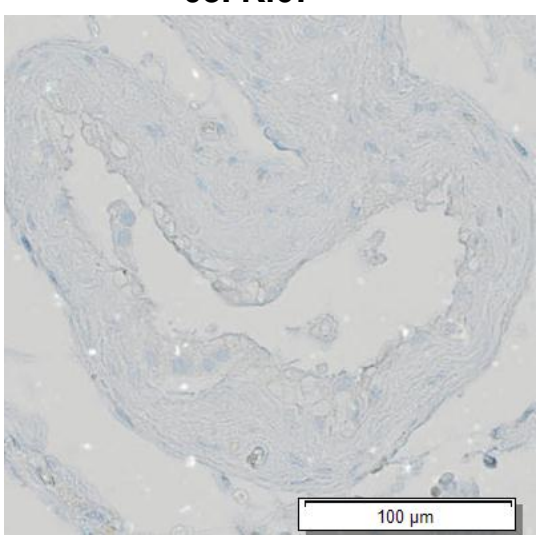

07. ОСт2

$100 \mu \mathrm{m}$
04. FGFR3

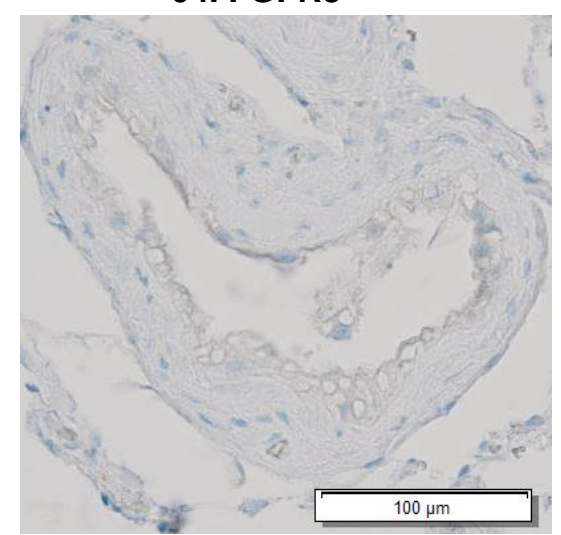

08. MAGEA4

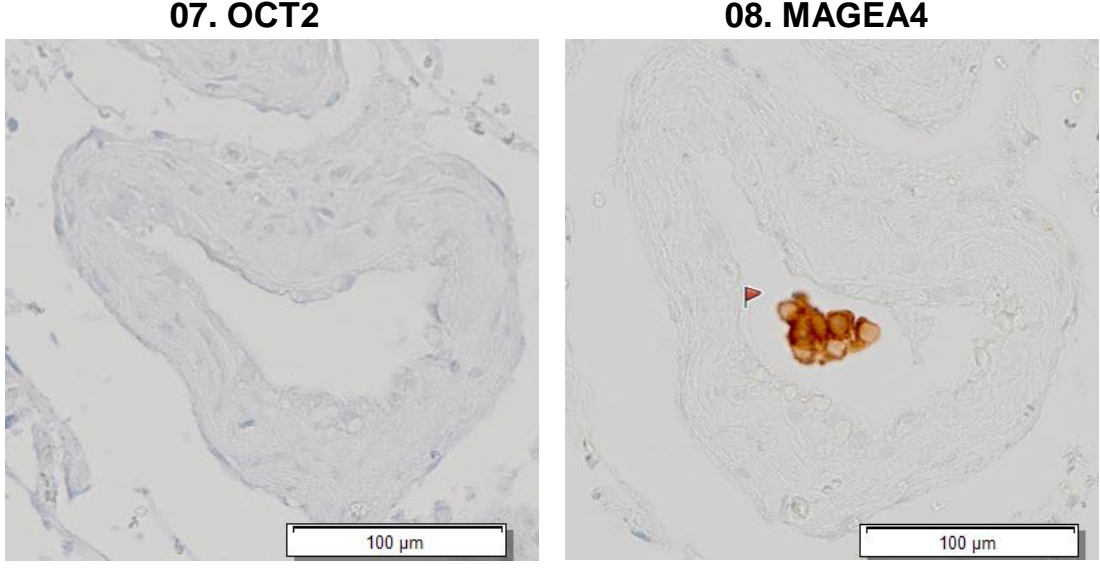

05. MAGEA4

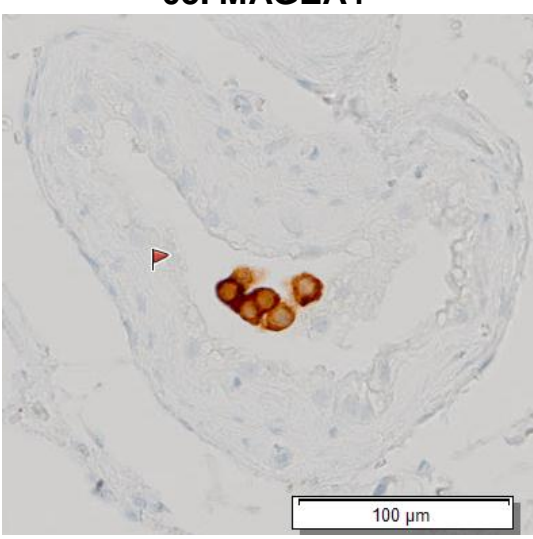

11. MAGEA4

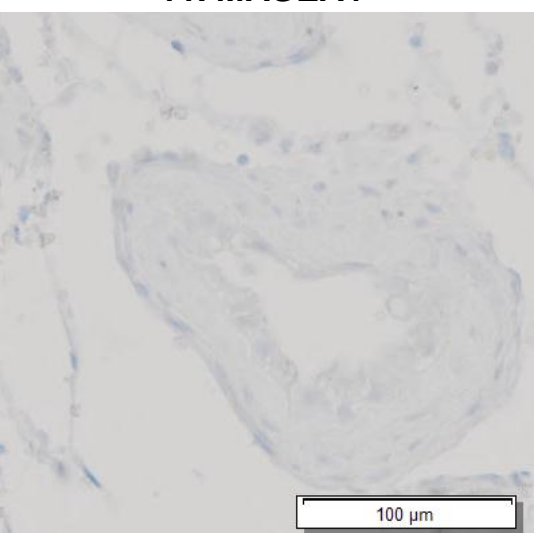




\section{Clone no.1-1_c9}

A

\begin{tabular}{|c|c|c|c|c|c|c|c|c|c|c|c|c|c|}
\hline \multirow{2}{*}{ Clone no. } & Location & Slide 1 & Slide 2 & Slide 3 & Slide 4 & Slide 5 & Slide 6 & Slide 7 & Slide 8 & Slide 9 & Slide 10 & Slide 11 & $\begin{array}{c}\text { Minimum } \\
\text { number of } \\
\text { cells }\end{array}$ \\
\hline \multirow{2}{*}{ 1-1_C9 } & $\begin{array}{c}\text { Near } \\
\text { Periphery }\end{array}$ & 0 & 0 & 0 & 0 & 1 & $0^{*}$ & 0 & 1 & & & 0 & \\
\end{tabular}

B

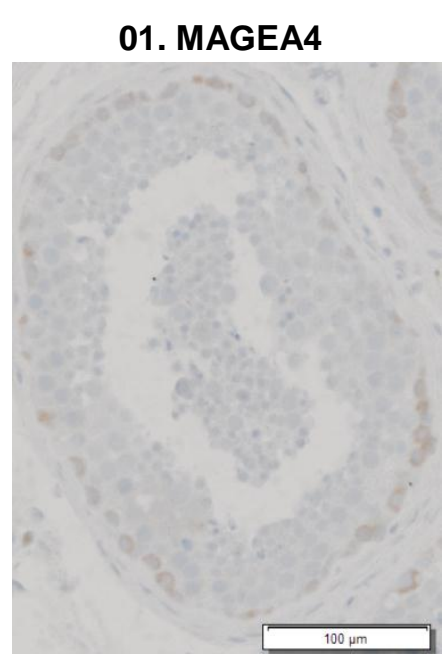

02. SSX

03. Ki67

04. FGFR3

05. MAGEA4

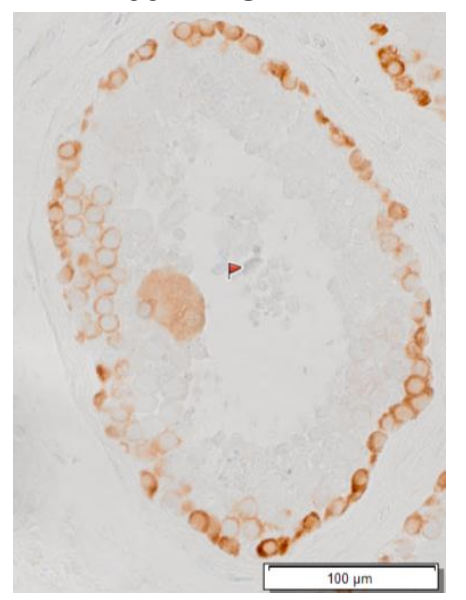

06. SAGE1

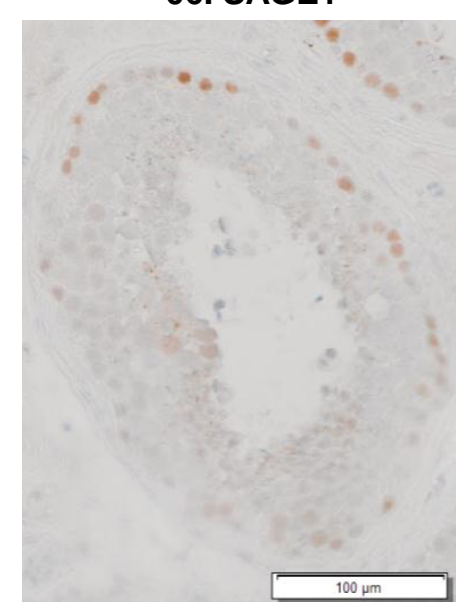

07. Ост2

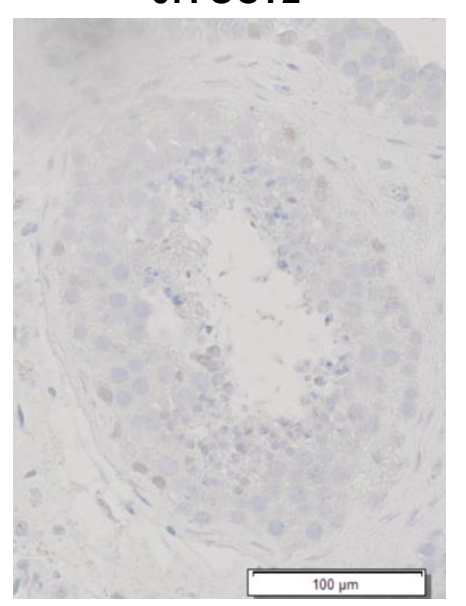

08. MAGEA4

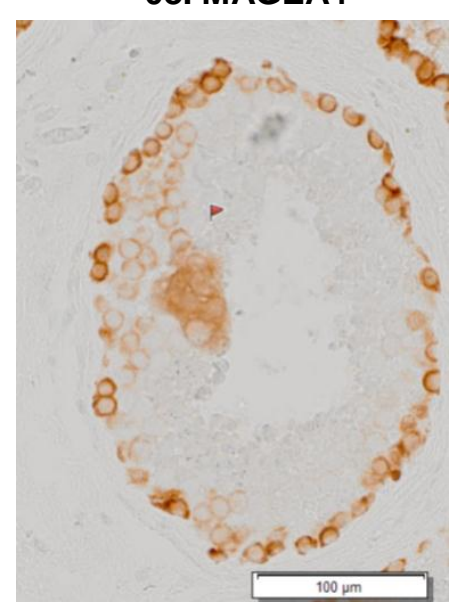


Clone no.1-1_C10

A

\begin{tabular}{|c|c|c|c|c|c|c|c|c|c|c|c|c|c|}
\hline \multirow{2}{*}{ Clone no. } & \multirow{2}{*}{ Location } & Slide 1 & Slide 2 & Slide 3 & Slide 4 & Slide 5 & Slide 6 & Slide 7 & Slide 8 & Slide 9 & Slide 10 & Slide 11 & \multirow{2}{*}{$\begin{array}{c}\text { Minimum } \\
\text { number o } \\
\text { cells }\end{array}$} \\
\hline & & MAGEA4 & SSX & Ki67 & FGFR3 & MAGEA4 & SAGE 1 & OCT2 & MAGEA4 & n.s. & missing & MAGEA4 & \\
\hline \multirow{3}{*}{ 1-1_C10 } & \multirow{3}{*}{$\begin{array}{c}\text { Near } \\
\text { Periphery }\end{array}$} & \multirow[t]{3}{*}{0} & \multirow[t]{3}{*}{0} & \multirow[t]{3}{*}{0} & \multirow[t]{3}{*}{0} & 1 & \multirow[t]{2}{*}{0} & \multirow[t]{2}{*}{0} & 1 & & & \multirow[t]{3}{*}{0} & \multirow{3}{*}{24} \\
\hline & & & & & & 7 cells & & & 5 cells & & & & \\
\hline & & & & & & \multicolumn{4}{|c|}{$20 \mu \mathrm{m}$} & & & & \\
\hline
\end{tabular}

B

01. MAGEA4

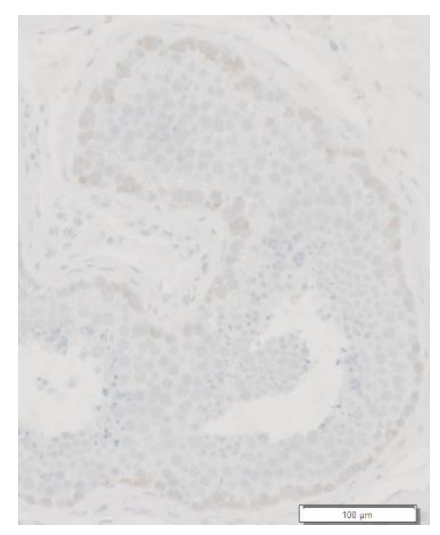

05. MAGEA4

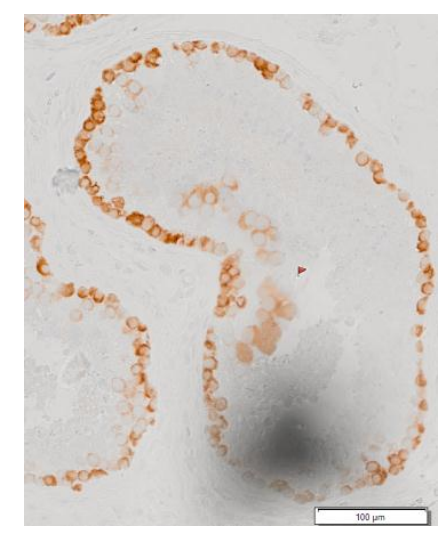

02. SSX

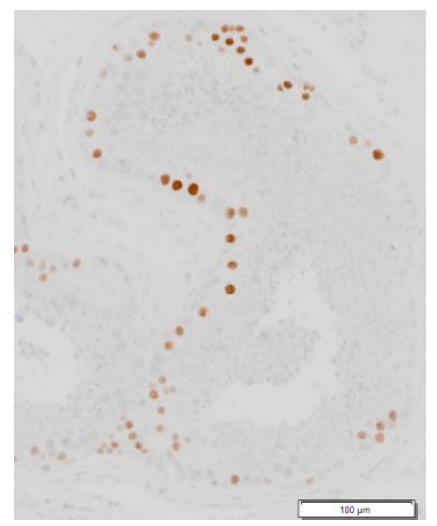

06. SAGE1

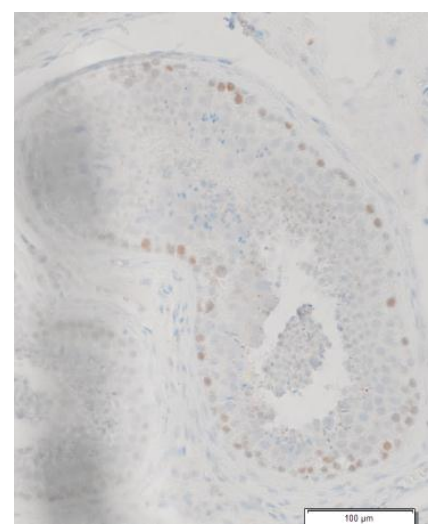

03. Ki67

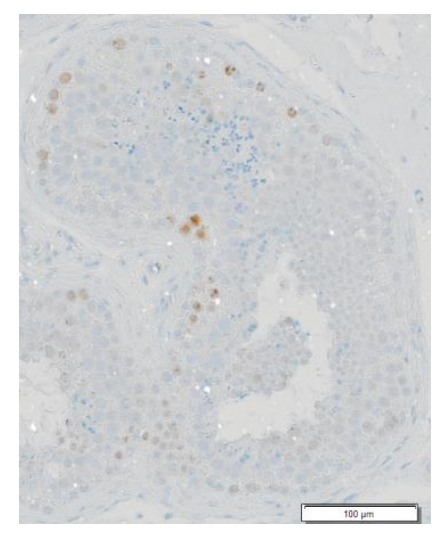

07. ОсT2

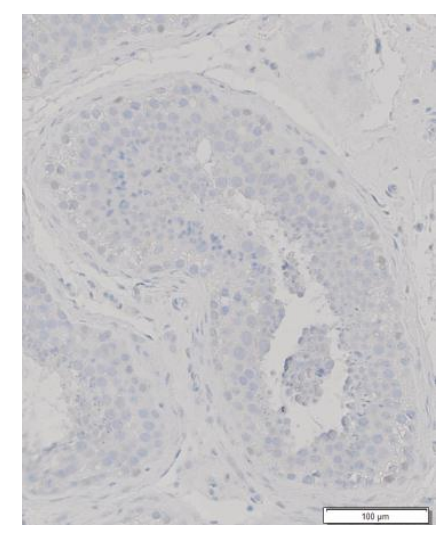

04. FGFR3

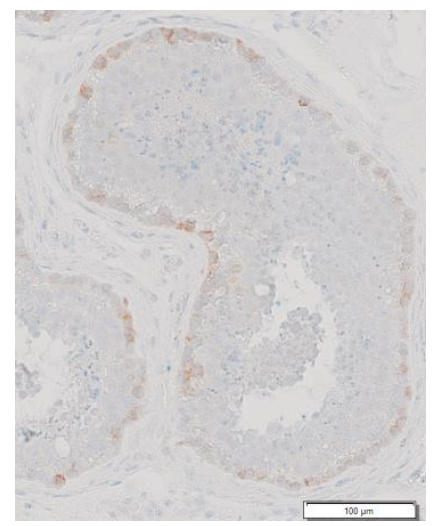

08. MAGEA4

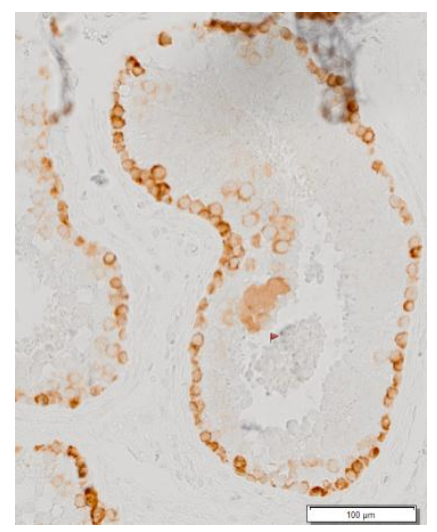


Clone no. 1-1_C11

A

\begin{tabular}{|c|c|c|c|c|c|c|c|c|c|c|c|c|c|}
\hline \multirow{2}{*}{ Clone no } & \multirow{2}{*}{ Location } & Slide 1 & Slide 2 & Slide 3 & Slide 4 & Slide 5 & Slide 6 & Slide 7 & Slide 8 & Slide 9 & Slide 10 & Slide 11 & \multirow{2}{*}{$\begin{array}{c}\text { Minimum } \\
\text { number of } \\
\text { cells }\end{array}$} \\
\hline & & MAGEA4 & SSX & Ki67 & FGFR3 & MAGEA4 & SAGE 1 & OCT2 & MAGEA4 & n.s & missing & MAGEA4 & \\
\hline \multirow{3}{*}{ 1-1_C11 } & \multirow{3}{*}{ Periphery } & \multirow[t]{3}{*}{0} & \multirow[t]{3}{*}{0} & \multirow[t]{3}{*}{0} & $0^{*}$ & 1 & \multirow[t]{2}{*}{0} & \multirow[t]{2}{*}{0} & 1 & & & $0^{*}$ & \multirow{3}{*}{57} \\
\hline & & & & & 5 cells & 9 cells & & & 6 cells & & & 8 cells & \\
\hline & & & & & \multicolumn{8}{|c|}{$40 \mu \mathrm{m}$} & \\
\hline
\end{tabular}

B

02. SSX

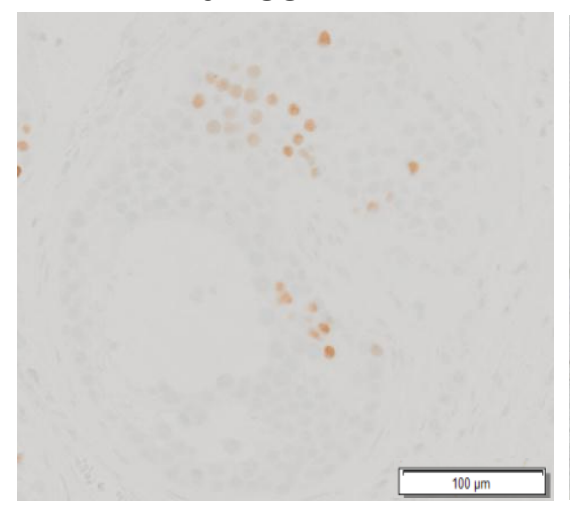

06. SAGE1

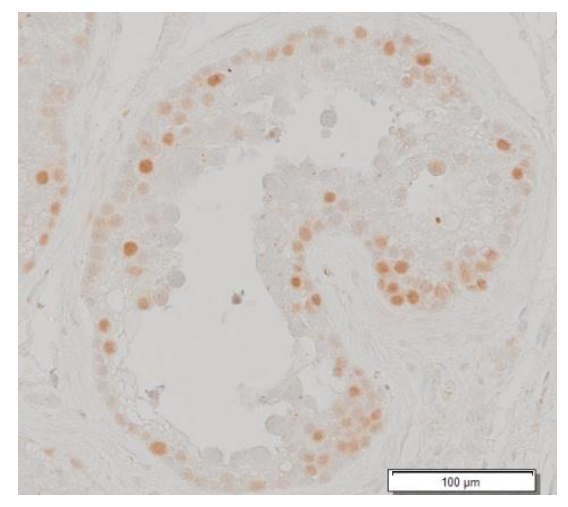

03. Ki67

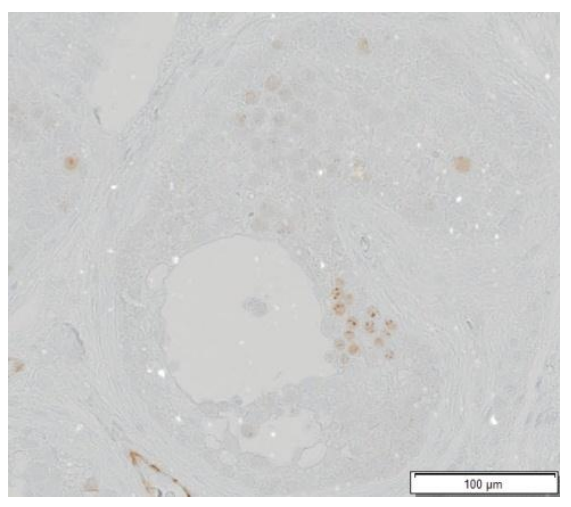

07. ОСT2

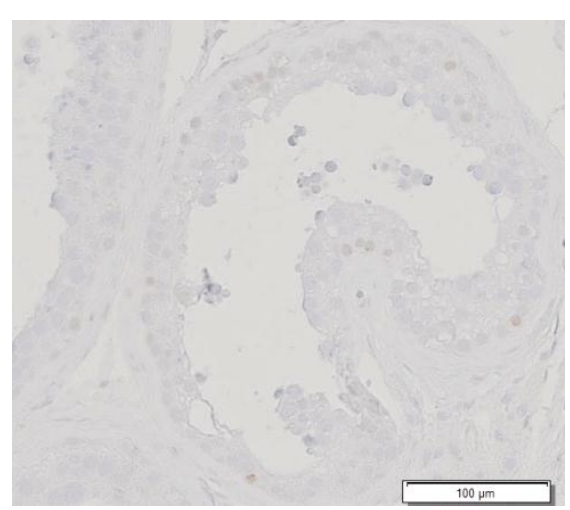

04. FGFR3

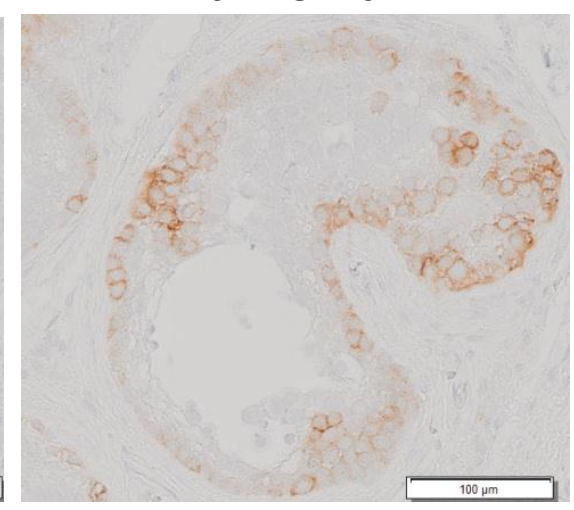

08. MAGEA4

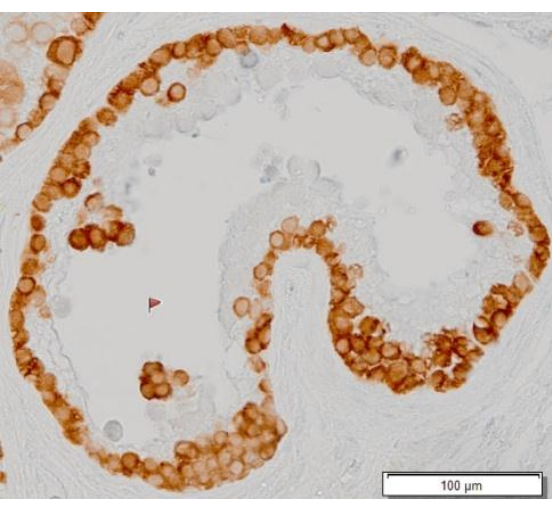

05. MAGEA4

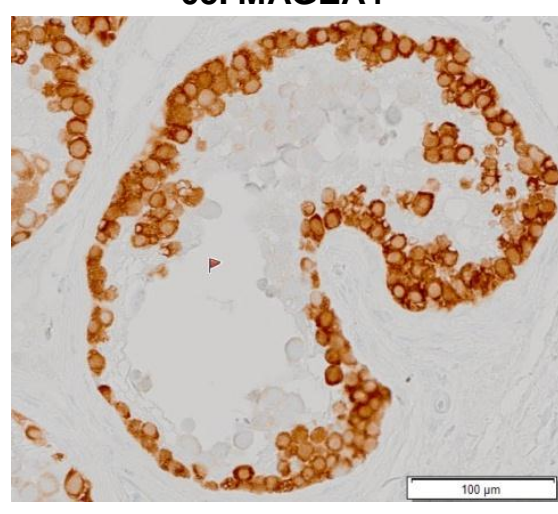

11. MAGEA4

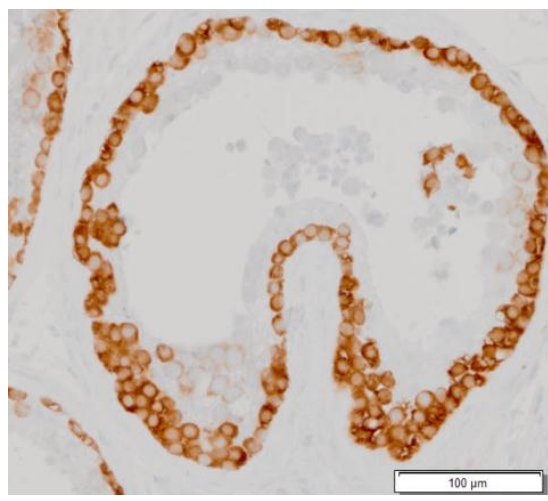




\section{Clone no. 1-1_C12}

A

\begin{tabular}{|c|c|c|c|c|c|c|c|c|c|c|c|c|c|}
\hline \multirow[b]{2}{*}{ Clone no. } & \multirow[b]{2}{*}{ Location } & Slide 1 & Slide 2 & Slide 3 & Slide 4 & Slide 5 & Slide 6 & Slide 7 & Slide 8 & Slide 9 & Slide 10 & Slide 11 & \multirow{2}{*}{$\begin{array}{c}\text { Minimum } \\
\text { number of } \\
\text { cells }\end{array}$} \\
\hline & & MAGEA4 & SSX & Ki67 & FGFR3 & MAGEA4 & SAGE1 & ОСТ2 & MAGEA4 & n.s & missing & MAGEA4 & \\
\hline \multirow{3}{*}{ 1-1_C12 } & \multirow{3}{*}{ Centre } & \multirow[t]{3}{*}{0} & \multirow[t]{3}{*}{0} & \multirow[t]{3}{*}{0} & \multirow[t]{3}{*}{0} & 1 & \multirow[t]{2}{*}{0} & \multirow[t]{2}{*}{0} & 1 & & & \multirow[t]{3}{*}{0} & \multirow{3}{*}{32} \\
\hline & & & & & & 6 cells & & & 10 cells & & & & \\
\hline & & & & & & \multicolumn{4}{|c|}{$20 \mu \mathrm{m}$} & & & & \\
\hline
\end{tabular}

B

02. SSX

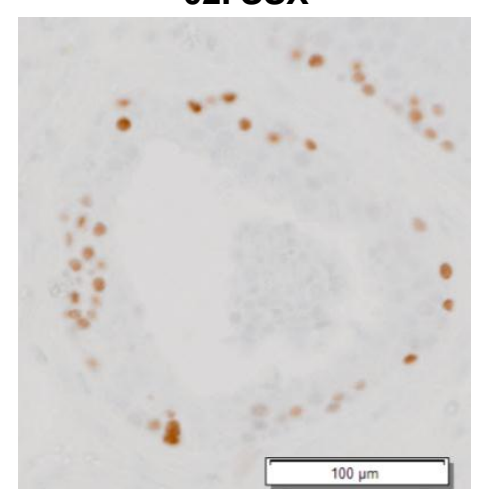

06. SAGE1

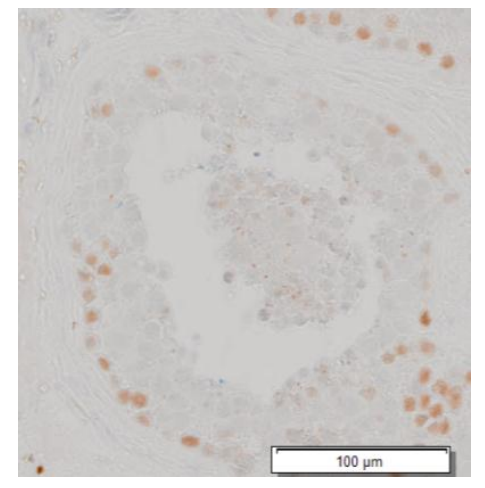

03. Ki67

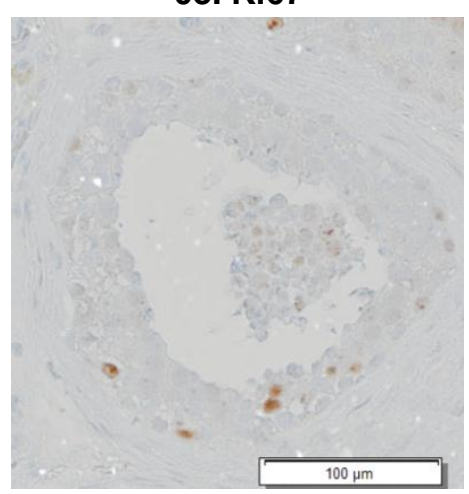

07. OCT2

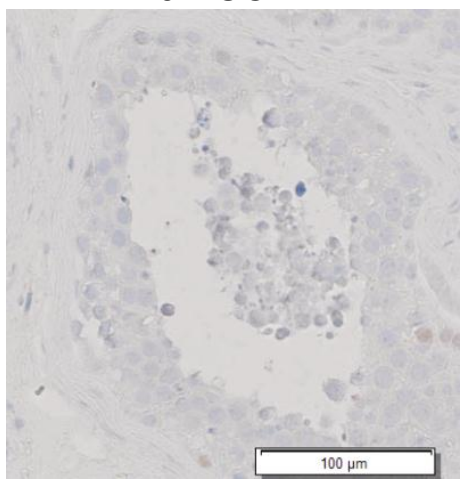

04. FGFR3

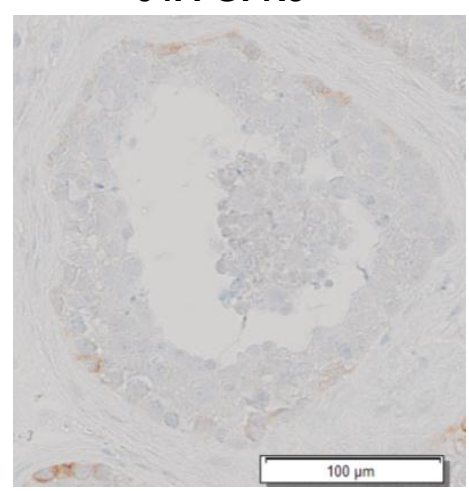

08. MAGEA4

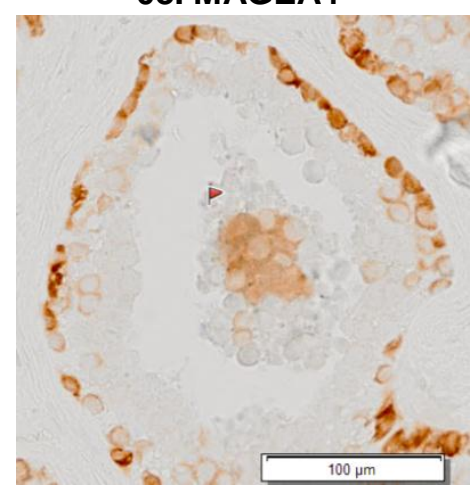

05. MAGEA4

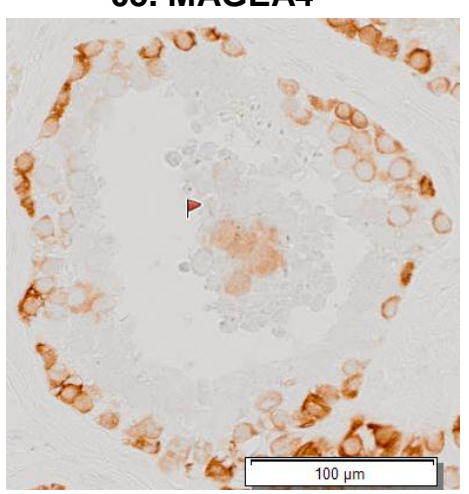

11. MAGEA4

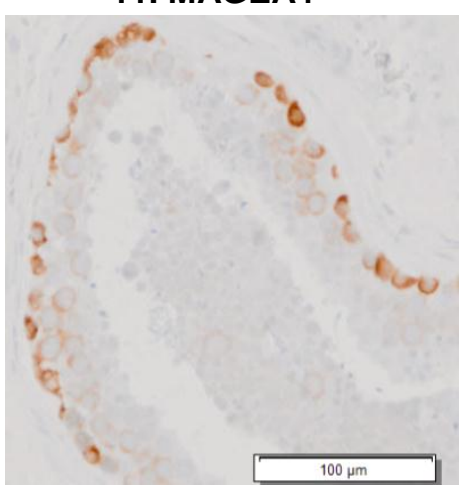




\section{Clone no.1-1_C13}

A

\begin{tabular}{|c|c|c|c|c|c|c|c|c|c|c|c|c|c|}
\hline \multirow[b]{2}{*}{ Clone no. } & \multirow{2}{*}{ Location } & Slide 1 & Slide 2 & Slide 3 & Slide 4 & Slide 5 & Slide 6 & Slide 7 & Slide 8 & Slide 9 & Slide 10 & Slide 11 & \multirow{2}{*}{$\begin{array}{l}\text { Minimum } \\
\text { number of } \\
\text { cells }\end{array}$} \\
\hline & & MAGEA4 & SSX & Ki67 & FGFR3 & MAGEA4 & SAGE1 & OCT2 & MAGEA4 & n.s & missing & MAGEA4 & \\
\hline \multirow{3}{*}{ 1-1_C13 } & \multirow{3}{*}{$\begin{array}{c}\text { Near } \\
\text { Periphery }\end{array}$} & \multirow[t]{3}{*}{0} & \multirow[t]{3}{*}{0} & \multirow[t]{3}{*}{0} & \multirow[t]{3}{*}{0} & 1 & $0^{*}$ & \multirow[t]{3}{*}{0} & 1 & & & \multirow[t]{3}{*}{0} & \multirow{3}{*}{28} \\
\hline & & & & & & 7 cells & 4 cells & & 7 cells & & & & \\
\hline & & & & & & \multicolumn{3}{|c|}{$20 \mu \mathrm{m}$} & & & & & \\
\hline
\end{tabular}

B

01. MAGEA4

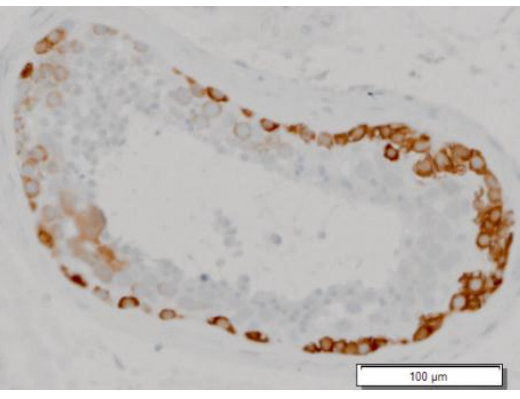

05. MAGEA4

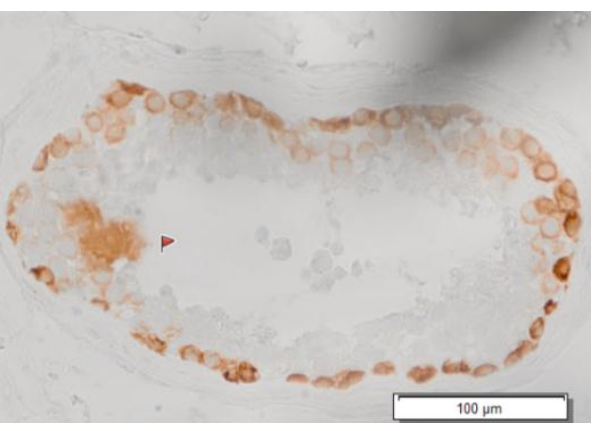

02. SSX

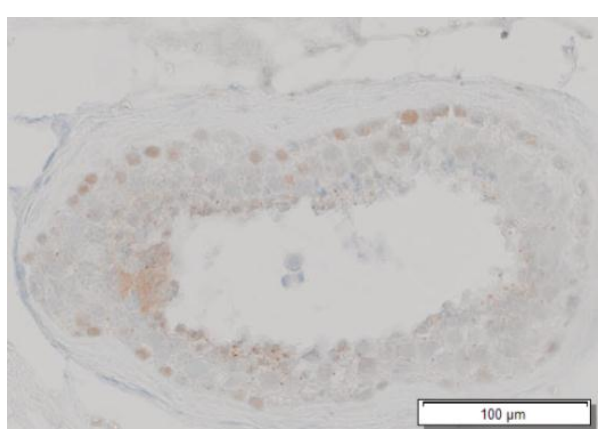

03. Ki67

04. FGFR3

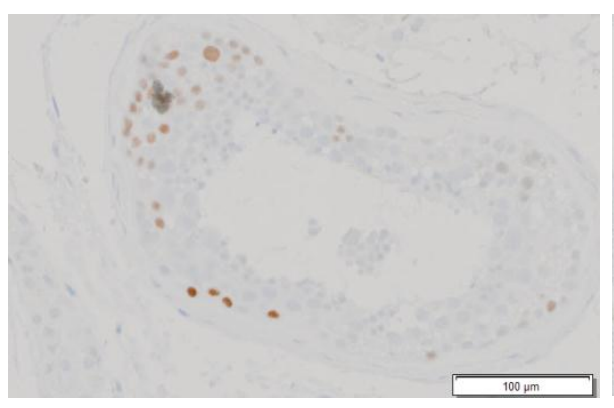

06. SAGE1

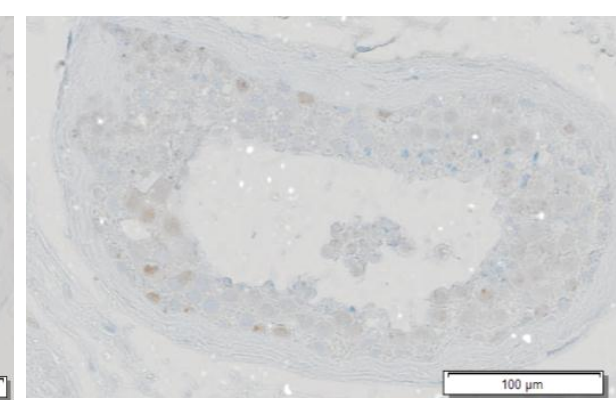

07. ОСТ2

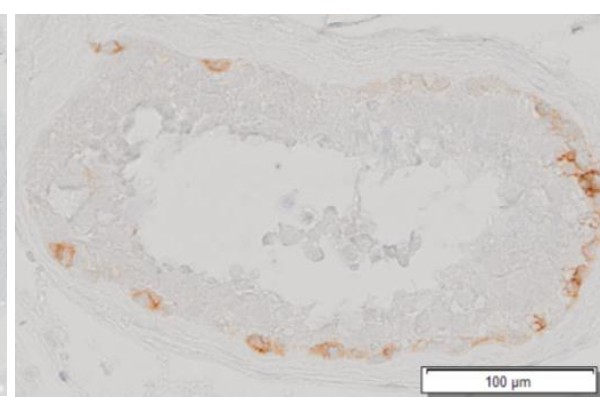

08. MAGEA4
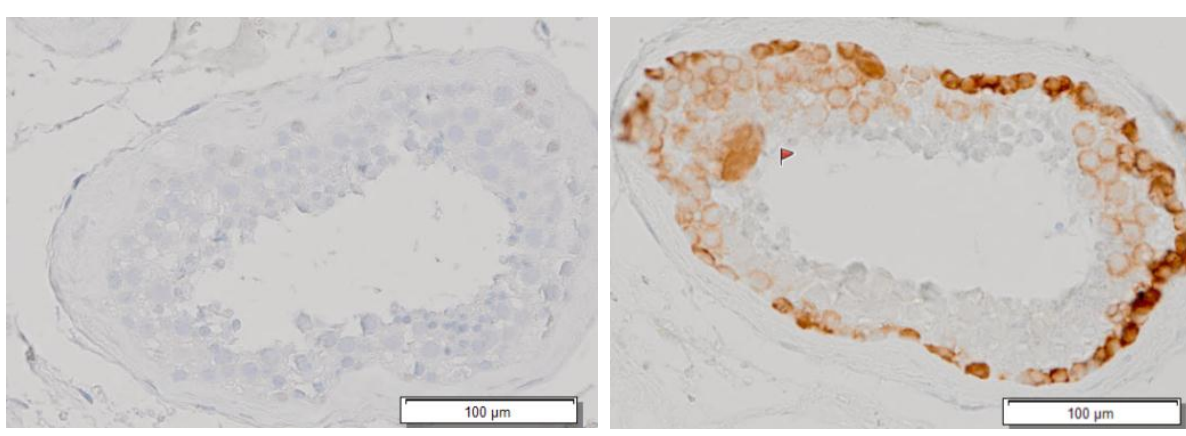


\section{Clone no. 1-1_C14}

A

\begin{tabular}{|c|c|c|c|c|c|c|c|c|c|c|c|}
\hline \multirow{2}{*}{ Clone no. } & \multirow{2}{*}{ Location } & Slide 21 & Slide 22 & Slide 23 & Slide 24 & Slide 25 & Slide 26 & Slide 27 & Slide 28 & Slide 29 & \multirow{2}{*}{$\begin{array}{c}\text { Minimum } \\
\text { number of } \\
\text { cells }\end{array}$} \\
\hline & & MAGEA4 & SSX & MAGEA4 & Ki67 & $H \& E$ & MAGEA4 & OCT2 & MAGEA4 & FGFR3 & \\
\hline \multirow{3}{*}{ 1-1_C14 } & \multirow{3}{*}{ Centre } & \multirow[t]{3}{*}{ NA } & \multirow[t]{3}{*}{0} & 1 & \multirow[t]{2}{*}{0} & & 1 & \multirow[t]{2}{*}{0} & 1 & \multirow[t]{3}{*}{ NA } & \multirow{3}{*}{72} \\
\hline & & & & 13 cells & & & 16 cells & & 4 cells & & \\
\hline & & & & \multicolumn{6}{|c|}{$30 \mu \mathrm{m}$} & & \\
\hline
\end{tabular}

B

\section{SSX}

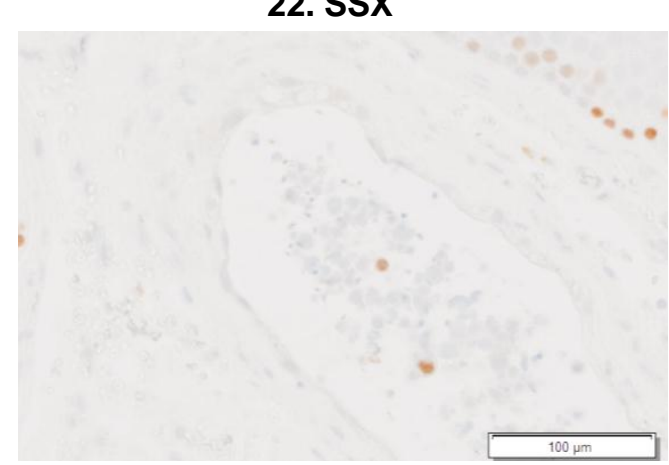

23. MAGEA4

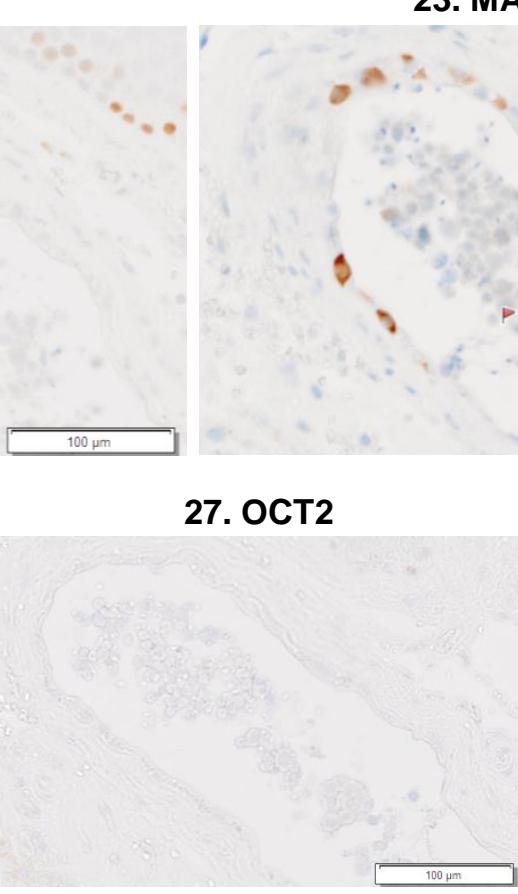

24. Ki67

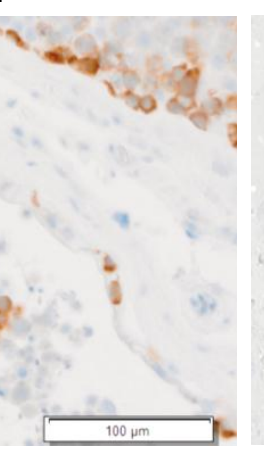

28. MAGEA4

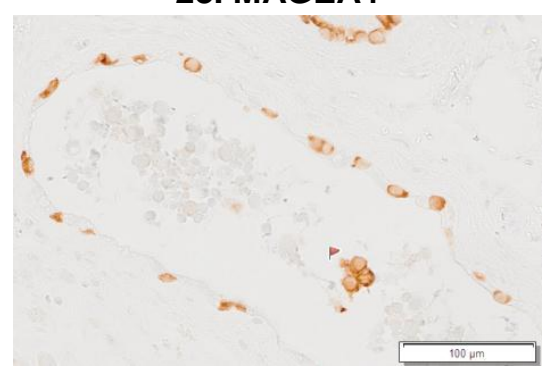

29. FGFR3

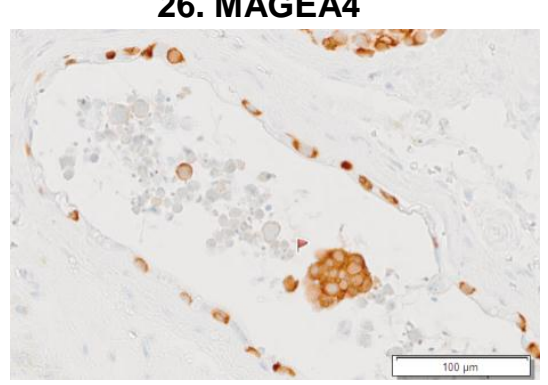




\section{Clone no.1-1_C15}

A

\begin{tabular}{|c|c|c|c|c|c|c|c|c|c|c|c|c|c|c|c|}
\hline \multirow{2}{*}{ Clone no. } & \multirow{2}{*}{ Location } & Slide 23 & $\begin{array}{c}\text { Slide } \\
24\end{array}$ & Slide 25 & Slide 26 & Slide 27 & Slide 28 & Slide 29 & Slide 30 & Slide 31 & Slide 32 & Slide 33 & Slide 34 & Slide 35 & \multirow{2}{*}{$\begin{array}{l}\text { Minimum } \\
\text { number of } \\
\text { cells }\end{array}$} \\
\hline & & MAGEA4 & Ki67 & $\mathrm{H} \& \mathrm{E}$ & MAGEA4 & ОСТ2 & MAGEA4 & FGFR3 & Ki67 & MAGEA4 & ssx & SAGE1 & ОСТ2 & MAGEA4 & \\
\hline \multirow{3}{*}{ 1-1_C15 } & \multirow{3}{*}{ Centre } & $0^{*}$ & 0 & & 1 & 0 & 1 & 0 & 0 & $0^{*}$ & 0 & 0 & 0 & $0^{*}$ & \multirow{3}{*}{58} \\
\hline & & 2 cells & & & 7 cells & & 8 cells & & & 3 cells & & & & 2 cells & \\
\hline & & \multicolumn{13}{|c|}{$65 \mu \mathrm{m}$} & \\
\hline
\end{tabular}

B

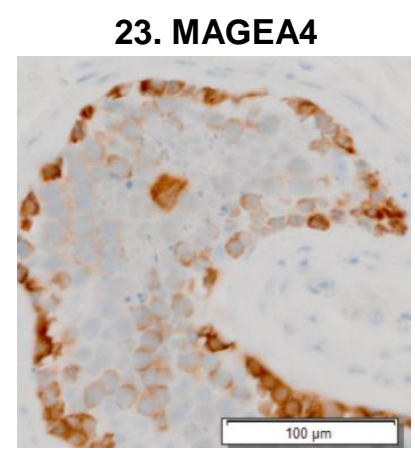

29. FGFR3

31. MAGEA4

Ki67
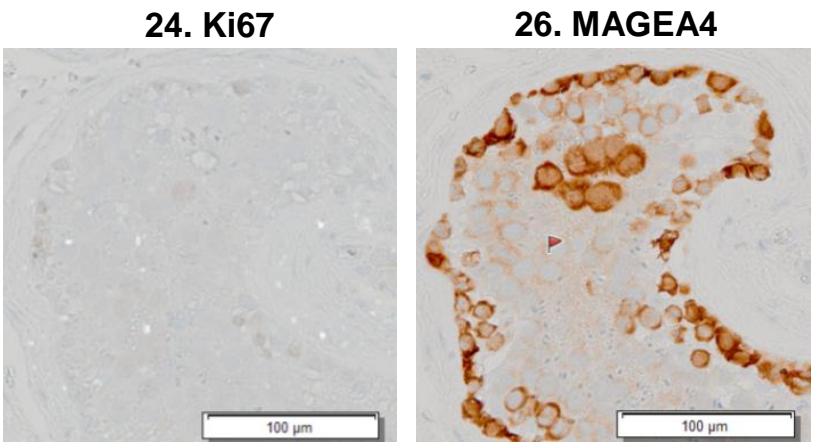

27. ОСТ2

32. SSX

33. SAGE1

28. MAGEA4
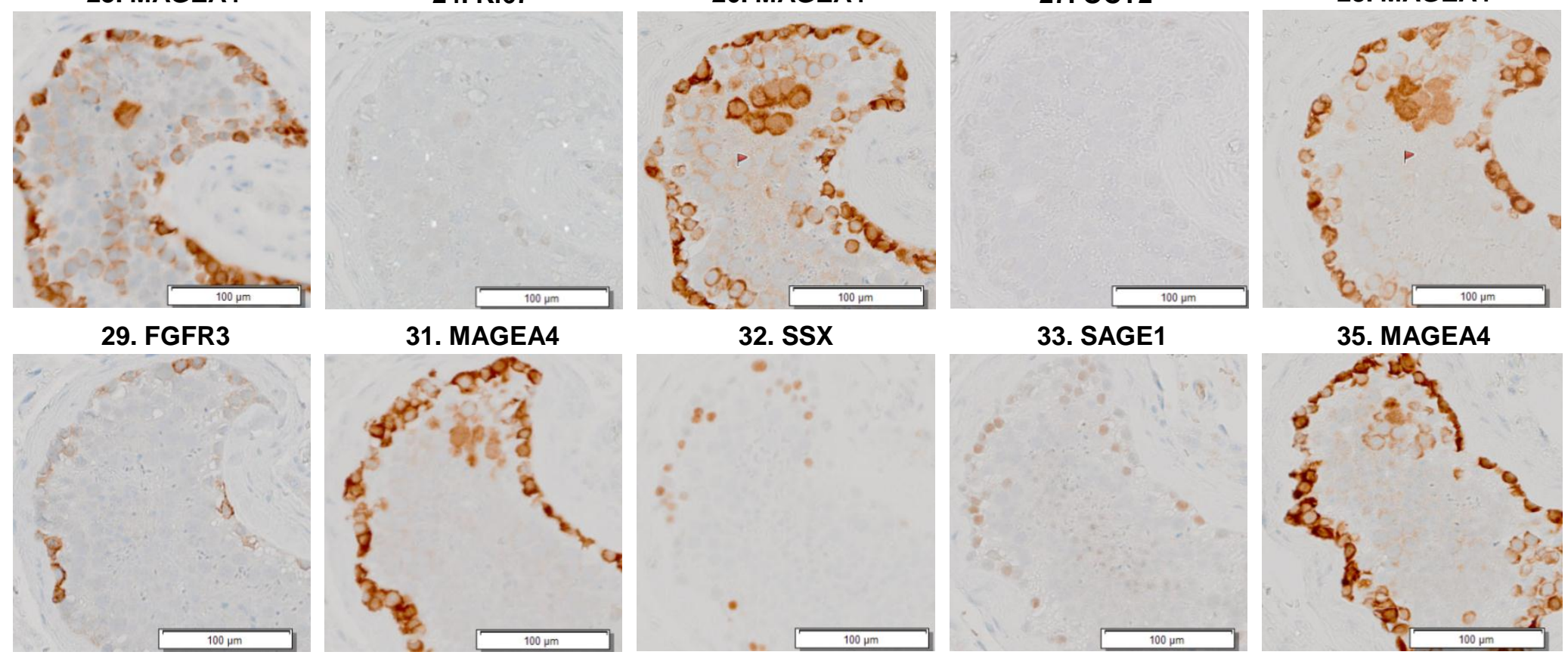

35. MAGEA4

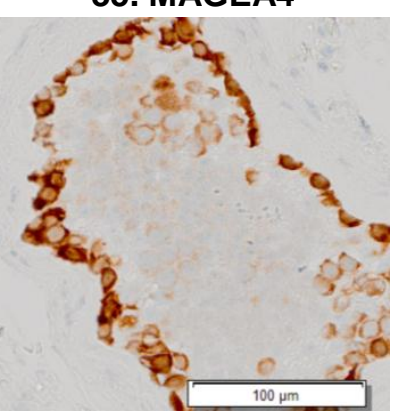




\section{Clone no.1-1_C16}

A

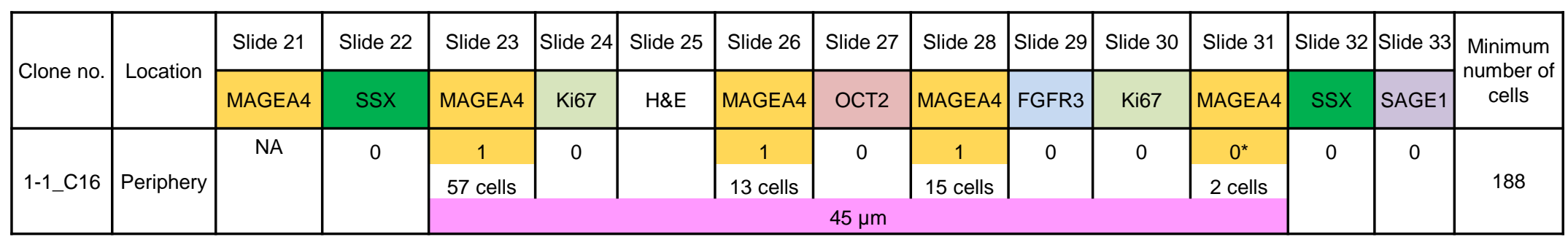

B
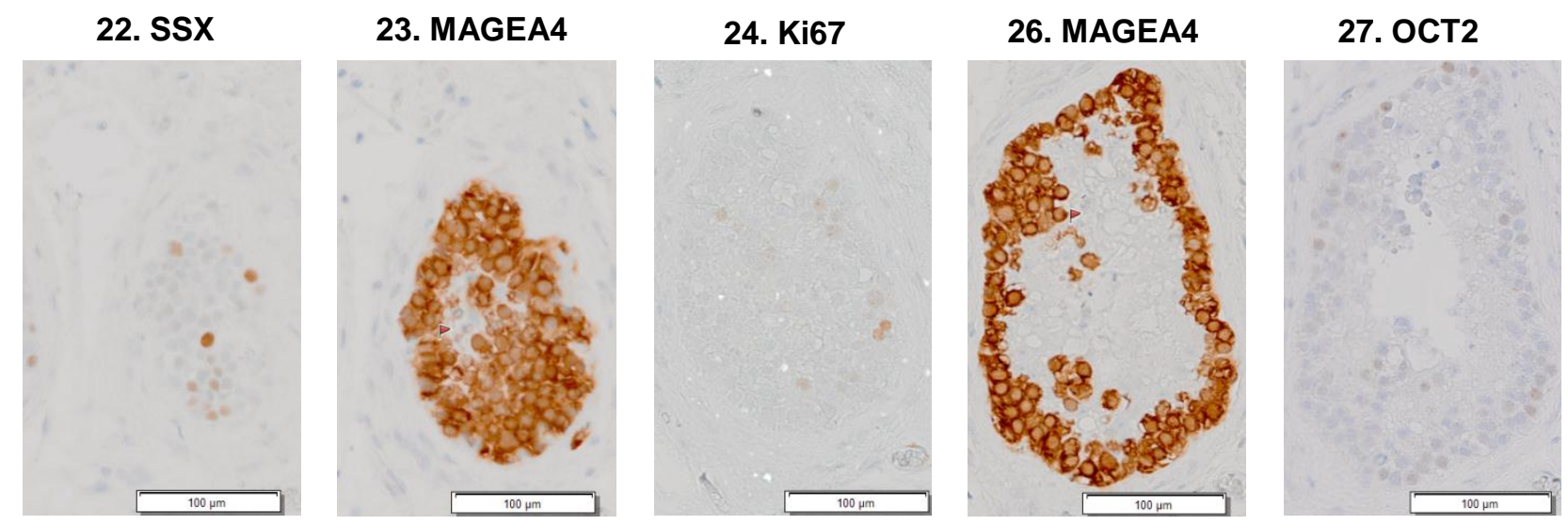

\section{MAGEA4}

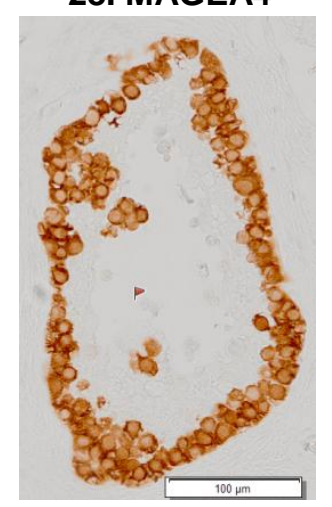

29. FGFR3
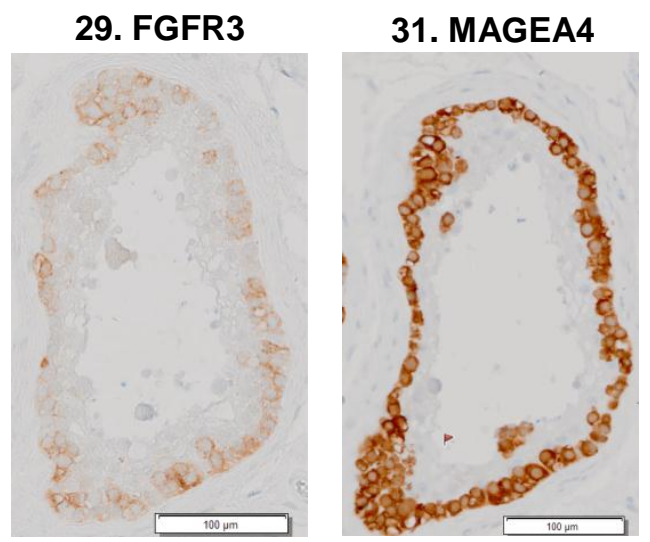

32. SSX

33. SAGE1
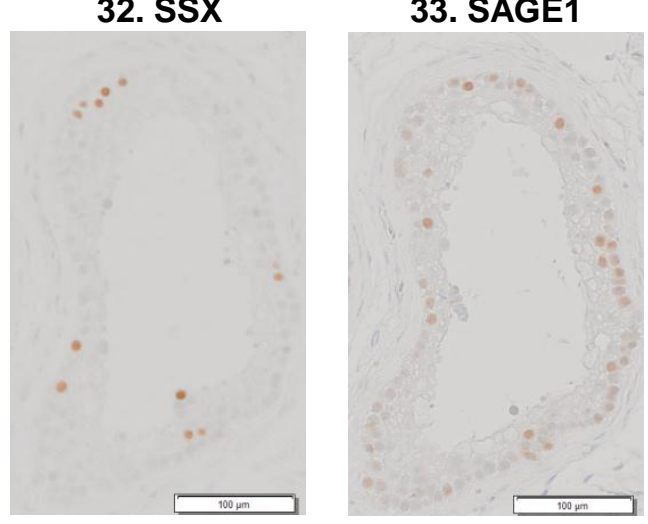
Clone no.1-1_C17

A

\begin{tabular}{|c|c|c|c|c|c|c|c|c|c|c|c|c|c|}
\hline \multirow{2}{*}{ Clone no. } & \multirow{2}{*}{ Location } & Slide 23 & Slide 24 & Slide 25 & Slide 26 & Slide 27 & Slide 28 & Slide 29 & Slide 30 & Slide 31 & Slide 32 & Slide 33 & \multirow{2}{*}{$\begin{array}{l}\text { Minimum } \\
\text { number of } \\
\text { cells }\end{array}$} \\
\hline & & MAGEA4 & Ki67 & $H \& E$ & MAGEA4 & Ост2 & MAGEA4 & FGFR3 & Ki67 & MAGEA4 & ssX & SAGE1 & \\
\hline \multirow{3}{*}{ 1-1_C17 } & \multirow{3}{*}{ Periphery } & \multirow[t]{3}{*}{0} & \multirow[t]{3}{*}{0} & & 1 & \multirow[t]{2}{*}{0} & 1 & \multirow[t]{2}{*}{0} & \multirow[t]{2}{*}{0} & $0^{*}$ & \multirow[t]{3}{*}{0} & \multirow[t]{3}{*}{0} & \multirow{3}{*}{22} \\
\hline & & & & & 5 cells & & 4 cells & & & 2 cells & & & \\
\hline & & & & & \multicolumn{6}{|c|}{$30 \mu \mathrm{m}$} & & & \\
\hline
\end{tabular}

B

23. MAGEA4

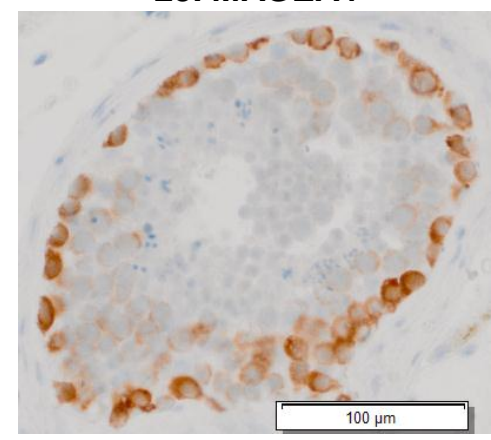

29. FGFR3
30. Ki67

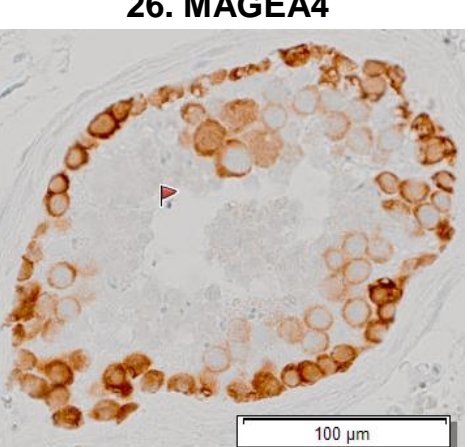

27. OCT2

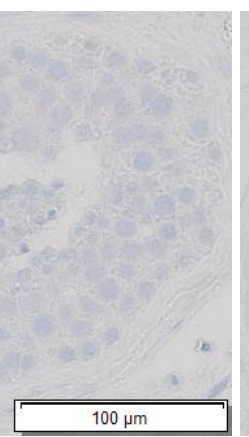

32. SSX
28. MAGEA4

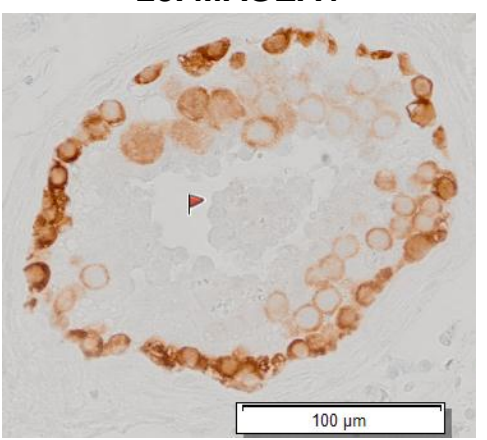

31. MAGEA4

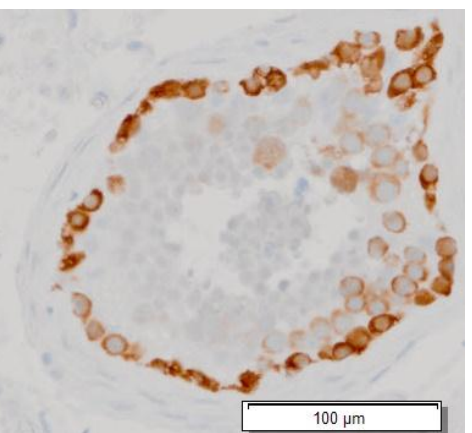

$100 \mu \mathrm{m}$

$100 \mu \mathrm{m}$
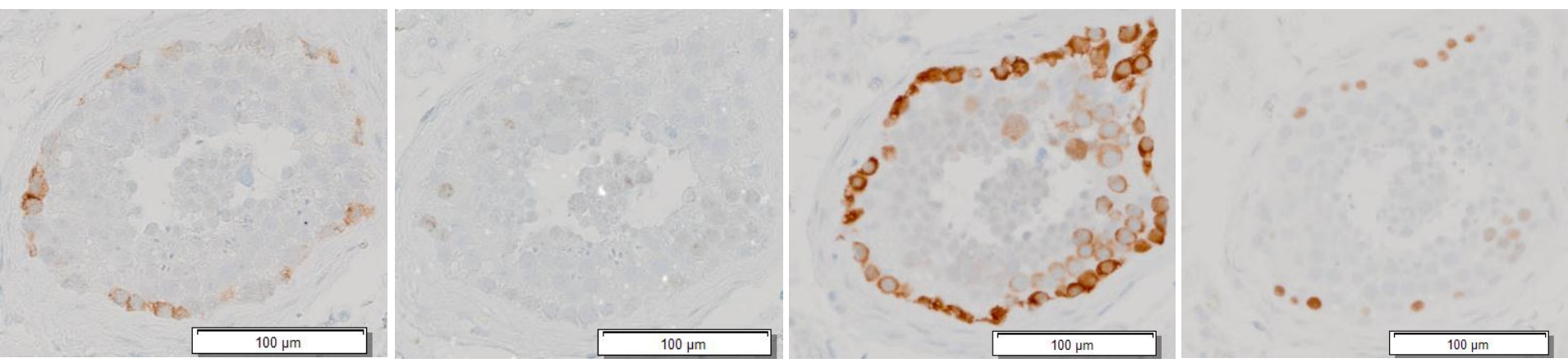

33. SAGE1 
Clone no.1-1_C18

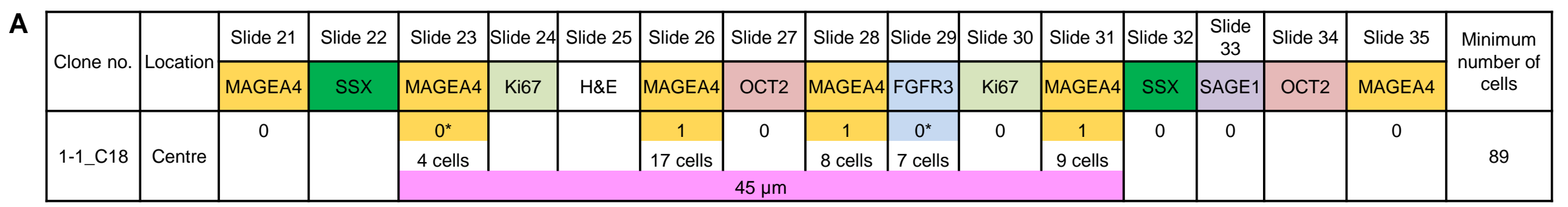

B

23. MAGEA4

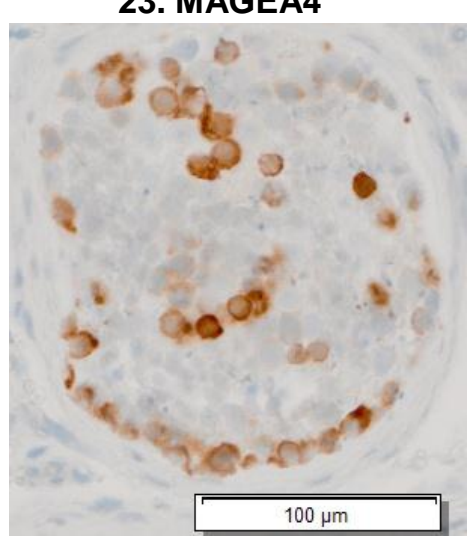

29. FGFR3

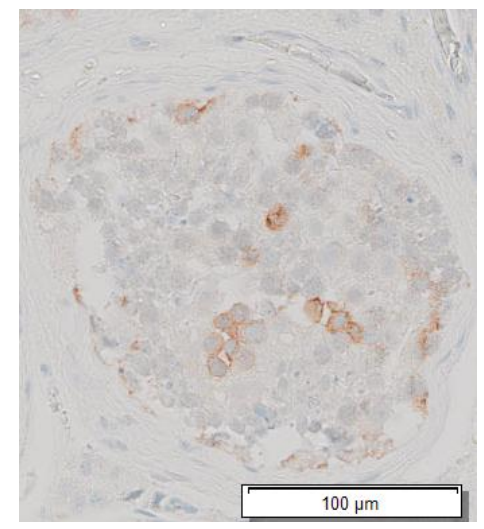

24. Ki67

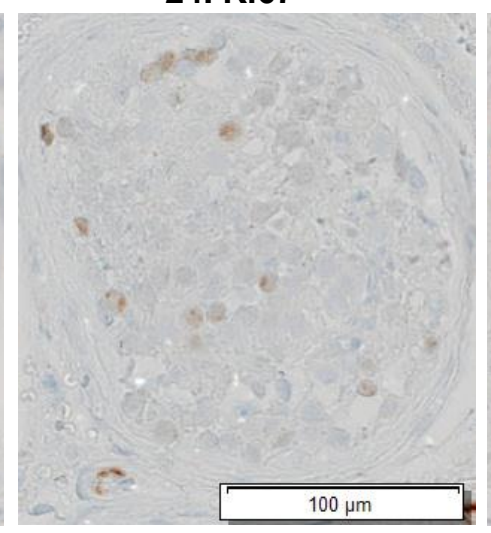

31. MAGEA4

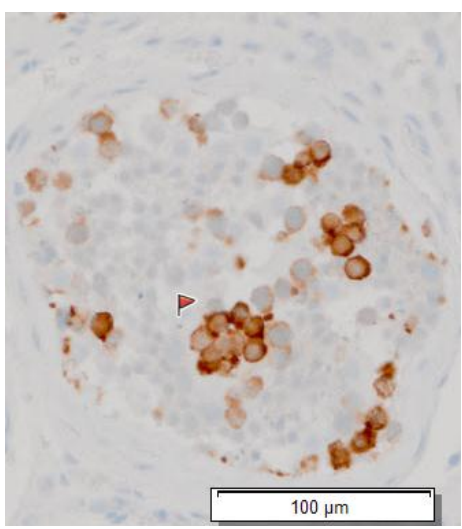

26. MAGEA4

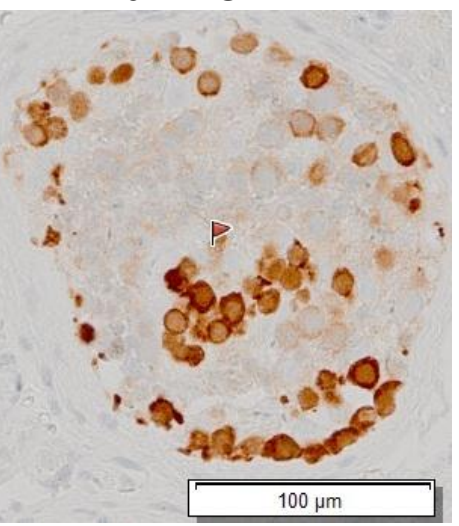

32. SSX

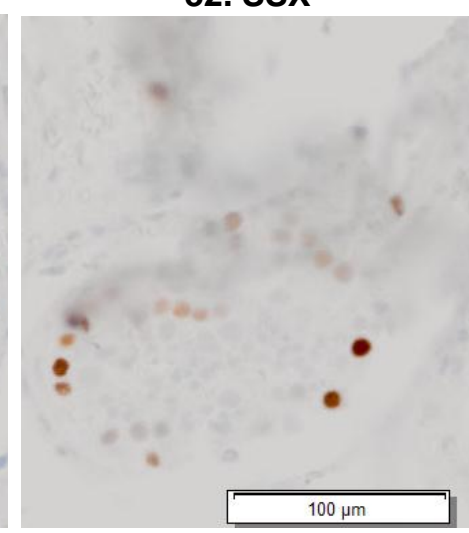

27. ОСТ2

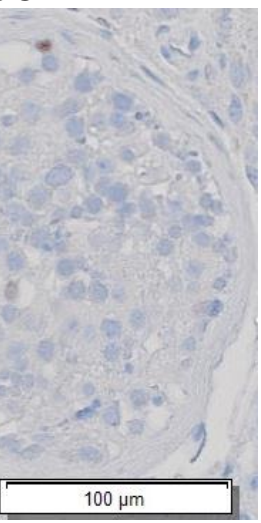

33. SAGE1

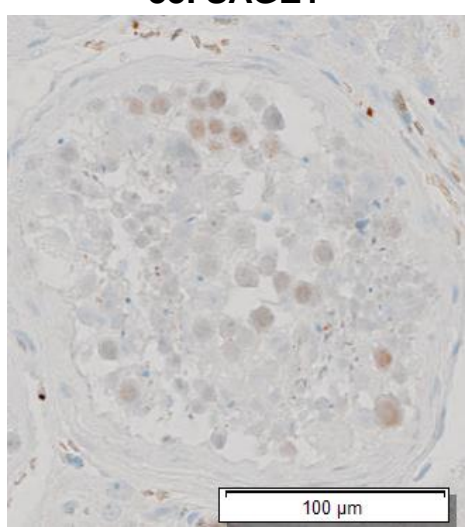

28. MAGEA4

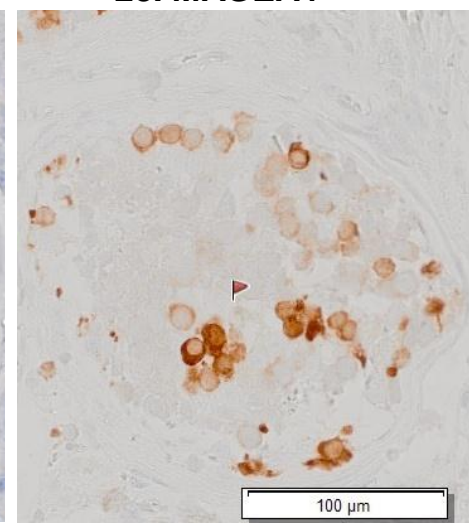

35. MAGEA4

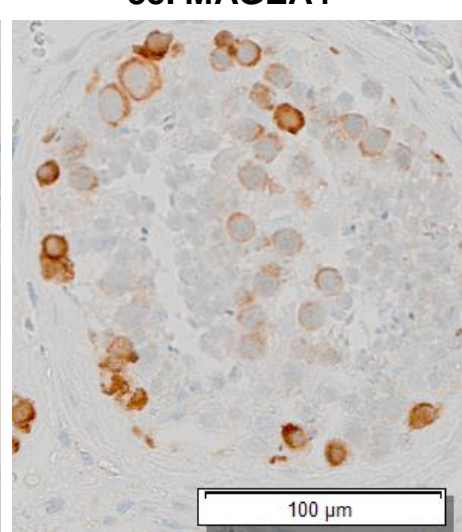


Clone no.1-1_C19

A

\begin{tabular}{|c|c|c|c|c|c|c|c|c|c|c|c|c|c|}
\hline \multirow{2}{*}{ Clone no. } & \multirow{2}{*}{ Location } & Slide 21 & Slide 22 & Slide 23 & Slide 24 & Slide 25 & Slide 26 & Slide 27 & Slide 28 & Slide 29 & Slide 30 & Slide 31 & \multirow{2}{*}{$\begin{array}{c}\text { Minimum } \\
\text { number of } \\
\text { cells }\end{array}$} \\
\hline & & MAGEA4 & SSX & MAGEA4 & Ki67 & $H \& E$ & MAGEA4 & OCT2 & MAGEA4 & FGFR3 & Ki67 & MAGEA4 & \\
\hline \multirow{3}{*}{ 1-1_C19 } & \multirow{3}{*}{ Centre } & \multirow[t]{3}{*}{0} & \multirow[t]{3}{*}{ NA } & 1 & \multirow[t]{2}{*}{0} & & 1 & \multirow[t]{2}{*}{0} & 1 & $0^{*}$ & \multirow[t]{3}{*}{0} & \multirow[t]{3}{*}{0} & \multirow{3}{*}{59} \\
\hline & & & & 4 cells & & & 17 cells & & 4 cells & 2 cells & & & \\
\hline & & & & & & & $35 \mu \mathrm{m}$ & & & & & & \\
\hline
\end{tabular}

B
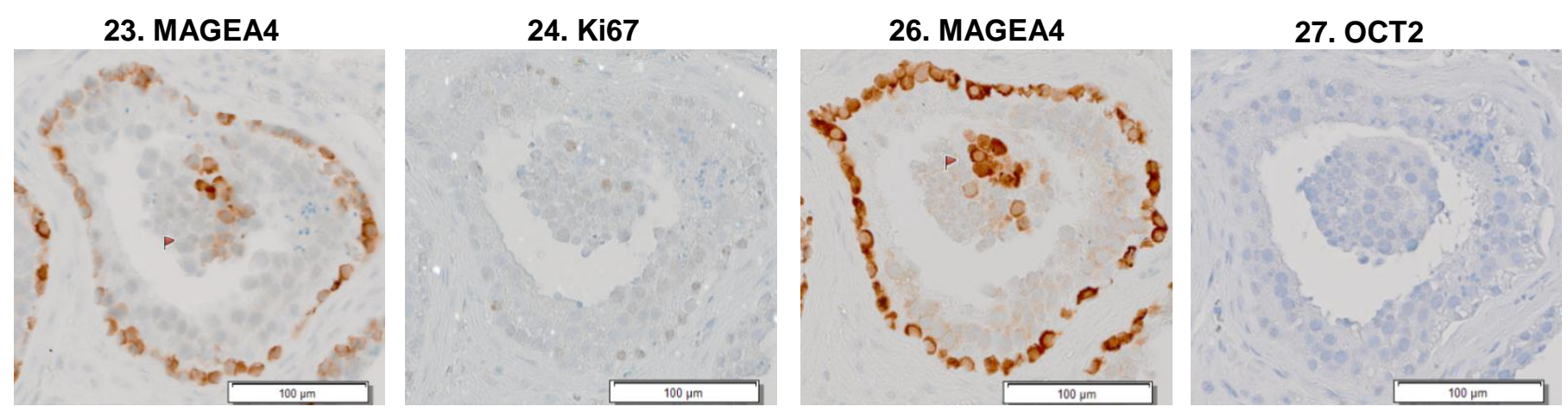

28. MAGEA4

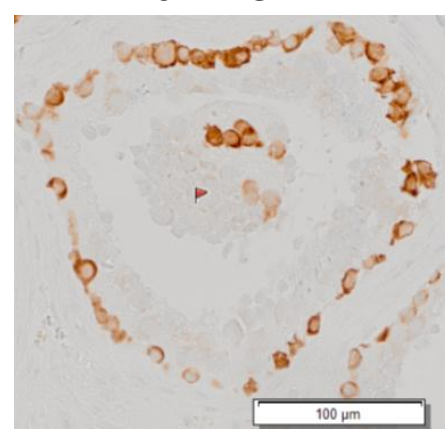

29. FGFR3

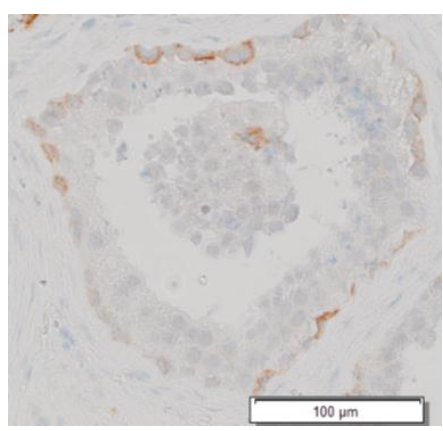

31. MAGEA4

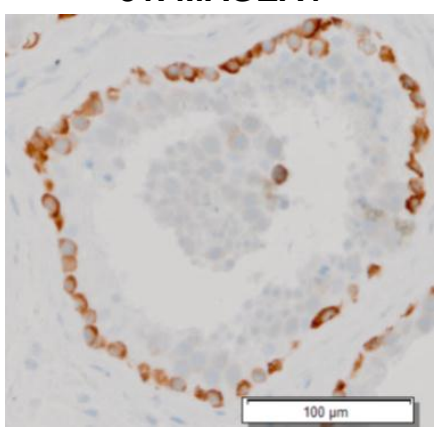


Clone no. 1-1_C20

A

\begin{tabular}{|c|c|c|c|c|c|c|c|c|c|c|c|}
\hline \multirow{2}{*}{ Clone no. } & \multirow{2}{*}{ Location } & Slide 23 & Slide 24 & Slide 25 & Slide 26 & Slide 27 & Slide 28 & Slide 29 & Slide 30 & Slide 31 & \multirow{2}{*}{$\begin{array}{l}\text { Minimum } \\
\text { number of } \\
\text { cells }\end{array}$} \\
\hline & & MAGEA4 & Ki67 & $H \& E$ & MAGEA4 & OCT2 & MAGEA4 & FGFR3 & Ki67 & MAGEA4 & \\
\hline \multirow{3}{*}{ 1-1_C20 } & \multirow{3}{*}{ Centre } & \multirow[t]{3}{*}{0} & \multirow[t]{3}{*}{0} & & 1 & \multirow[t]{2}{*}{0} & 1 & \multirow[t]{3}{*}{0} & \multirow[t]{3}{*}{0} & \multirow[t]{3}{*}{0} & \multirow{3}{*}{15} \\
\hline & & & & & 4 cells & & 6 cells & & & & \\
\hline & & & & \multicolumn{4}{|c|}{$15 \mu \mathrm{m}$} & & & & \\
\hline
\end{tabular}

B

\section{MAGEA4}

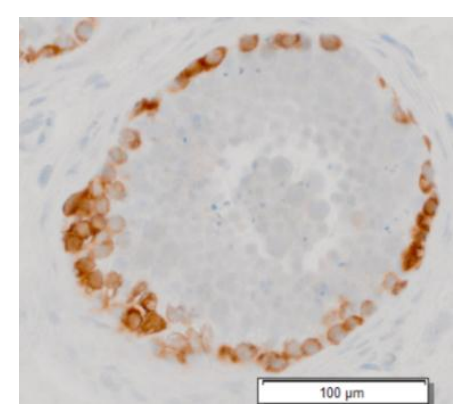

28. MAGEA4

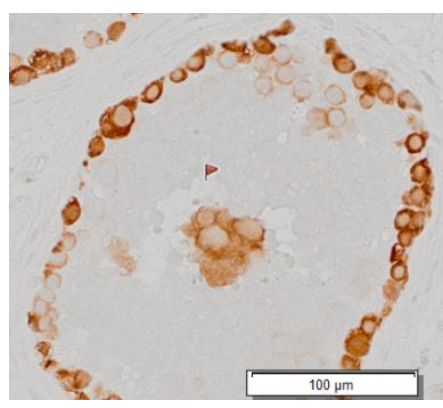

24. Ki67

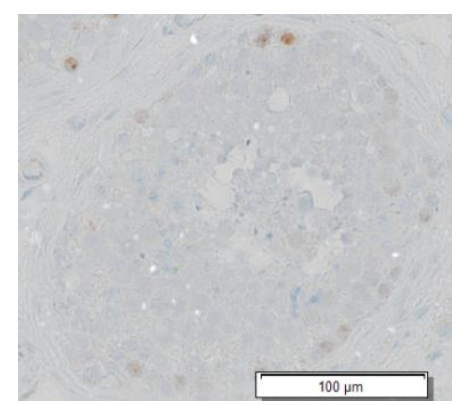

29. FGFR3

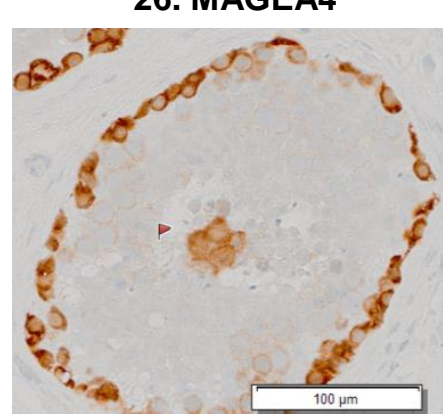

27. OCT2

31. MAGEA4

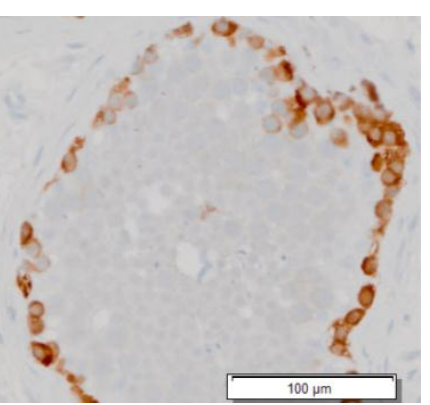




\section{Clone no. 1-1_C21}

A

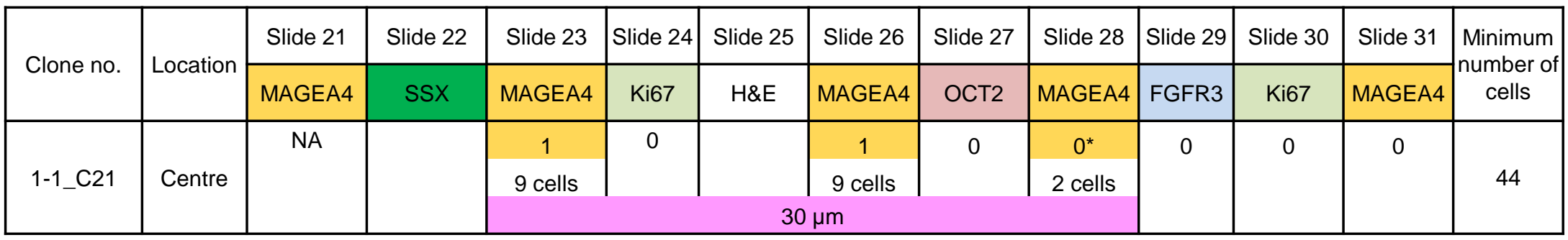

B

23. MAGEA4

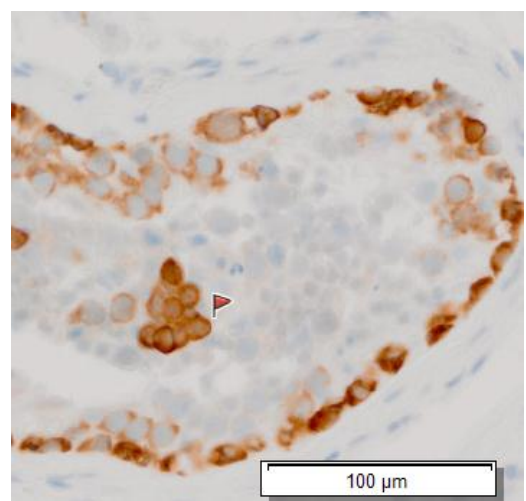

28. MAGEA4

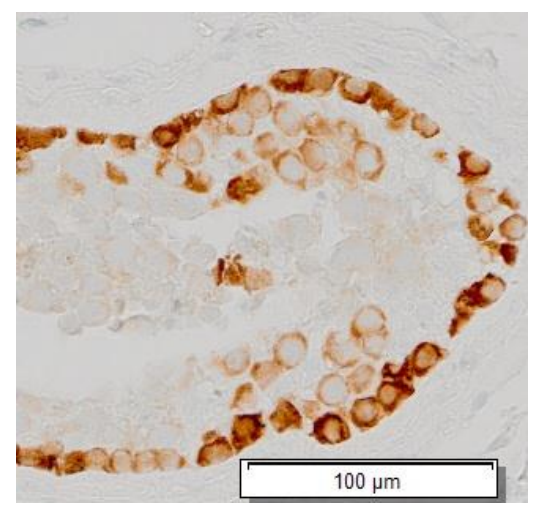

24. Ki67

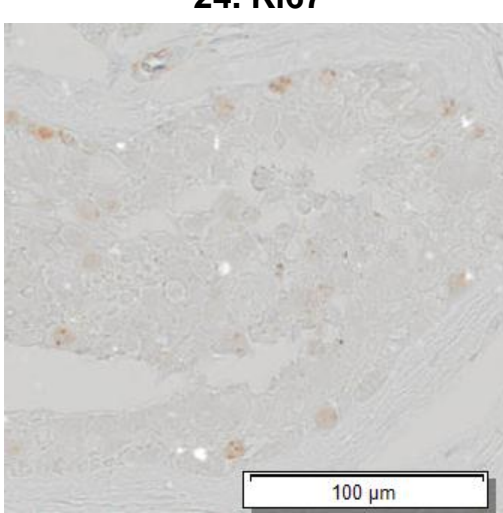

29. FGFR3

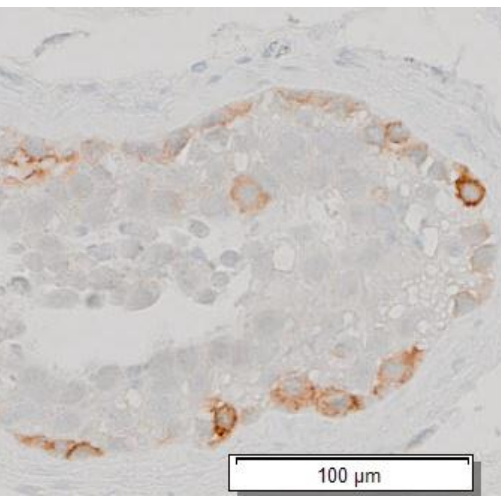

26. MAGEA4

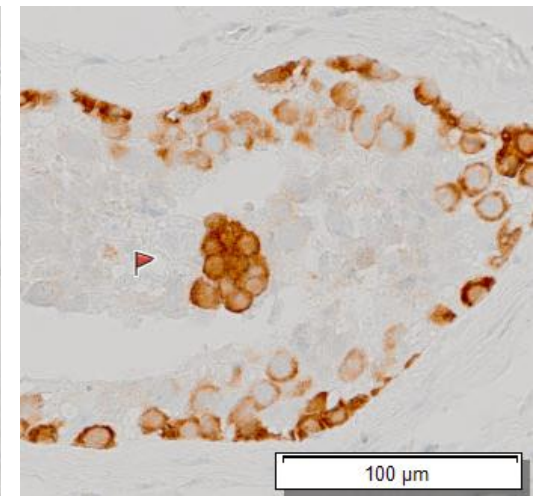

27. OCT2

31. MAGEA4

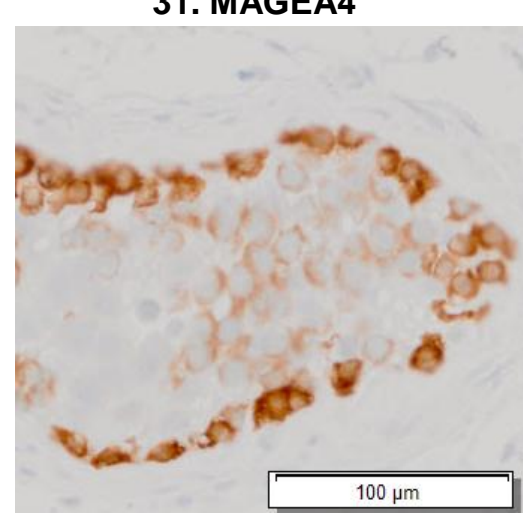




\section{Clone no. 1-1_C22}

A

\begin{tabular}{|c|c|c|c|c|c|c|c|c|c|c|c|}
\hline \multirow{2}{*}{ Clone no. } & \multirow{2}{*}{ Location } & Slide 23 & Slide 24 & Slide 25 & Slide 26 & Slide 27 & Slide 28 & Slide 29 & Slide 30 & Slide 31 & \multirow{2}{*}{$\begin{array}{c}\text { Minimum } \\
\text { number o } \\
\text { cells }\end{array}$} \\
\hline & & MAGEA4 & Ki67 & $H \& E$ & MAGEA4 & OCT2 & MAGEA4 & FGFR3 & Ki67 & MAGEA4 & \\
\hline \multirow{3}{*}{ 1-1_C22 } & \multirow{3}{*}{ Centre } & NA & 0 & & 1 & 0 & 1 & 0 & 0 & 0 & \multirow{3}{*}{15} \\
\hline & & & & & 5 cells & & 5 cells & & & & \\
\hline & & & & & & $15 \mu \mathrm{m}$ & & & & & \\
\hline
\end{tabular}

B
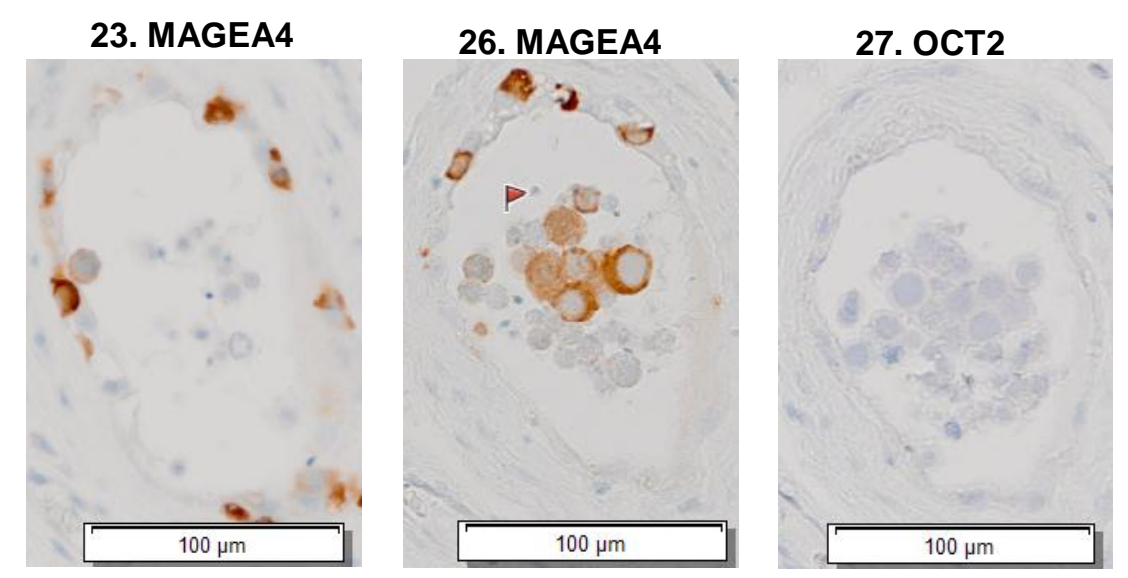

28. MAGEA4

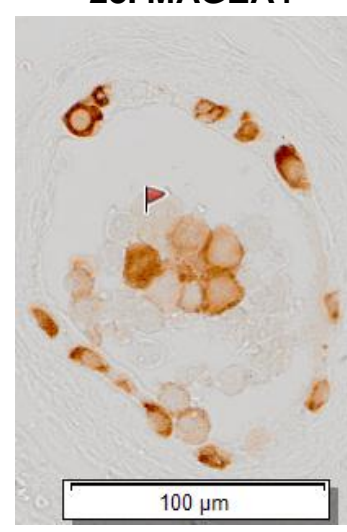

29. FGFR3

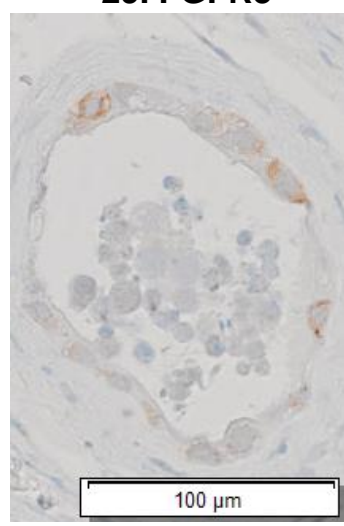

30. Ki67

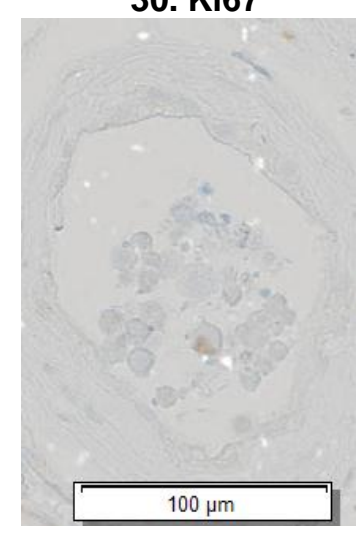

31. MAGEA4

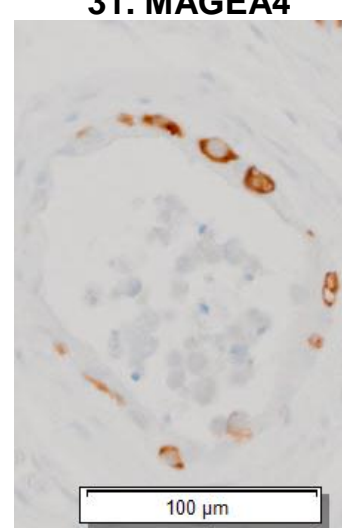




\section{Clone no.1-1_C23}

A

\begin{tabular}{|c|c|c|c|c|c|c|c|c|c|c|c|}
\hline \multirow{2}{*}{ Clone no. } & \multirow{2}{*}{ Location } & Slide 23 & Slide 24 & Slide 25 & Slide 26 & Slide 27 & Slide 28 & Slide 29 & Slide 30 & Slide 31 & \multirow{2}{*}{$\begin{array}{c}\text { Minimum } \\
\text { number of cells }\end{array}$} \\
\hline & & MAGEA4 & Ki67 & $H \& E$ & MAGEA4 & OCT2 & MAGEA4 & FGFR3 & Ki67 & MAGEA4 & \\
\hline \multirow{3}{*}{ 1-1_C23 } & \multirow{3}{*}{ Periphery } & \multirow[t]{3}{*}{0} & \multirow[t]{3}{*}{0} & & 1 & \multirow[t]{2}{*}{0} & 1 & \multirow[t]{3}{*}{0} & \multirow[t]{3}{*}{0} & \multirow[t]{3}{*}{0} & \multirow{3}{*}{27} \\
\hline & & & & & 10 cells & & 8 cells & & & & \\
\hline & & & & & \multicolumn{3}{|c|}{$15 \mu \mathrm{m}$} & & & & \\
\hline
\end{tabular}

B

23. MAGEA4

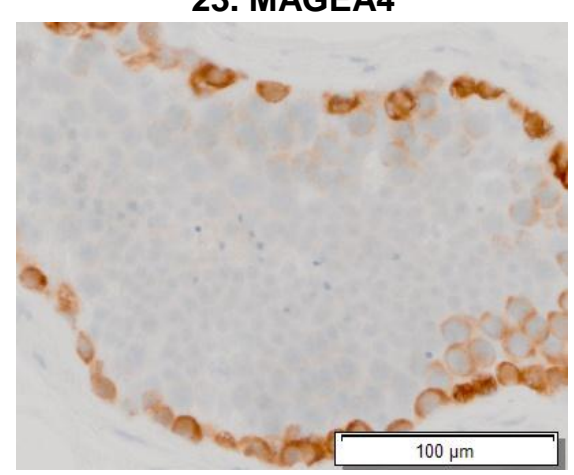

28. MAGEA4

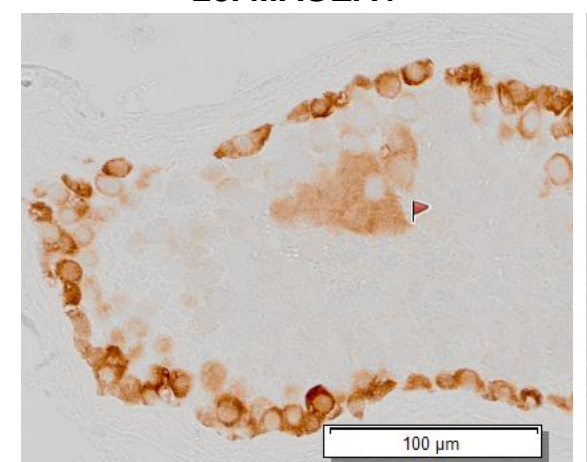

24. Ki67

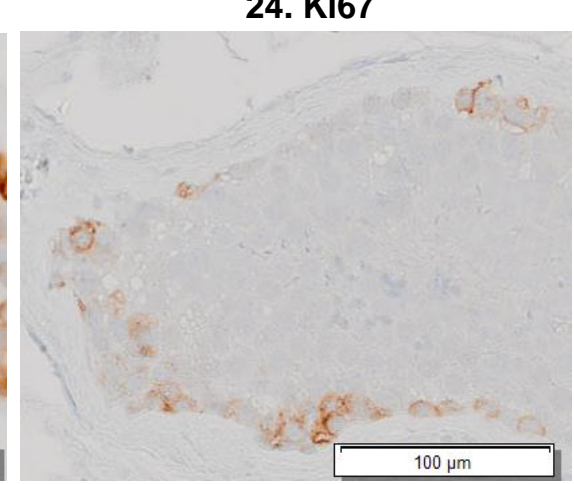

29. FGFR3

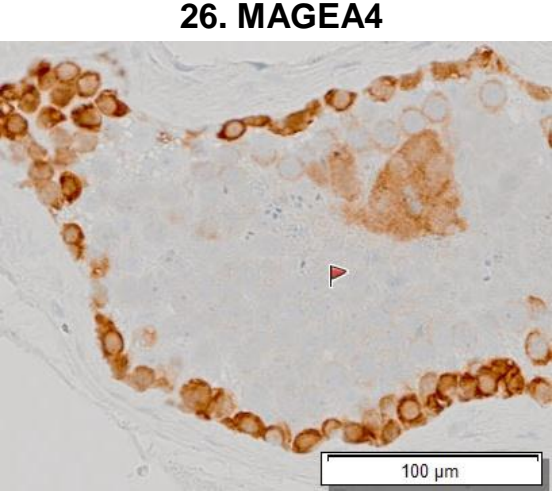

31. MAGEA4

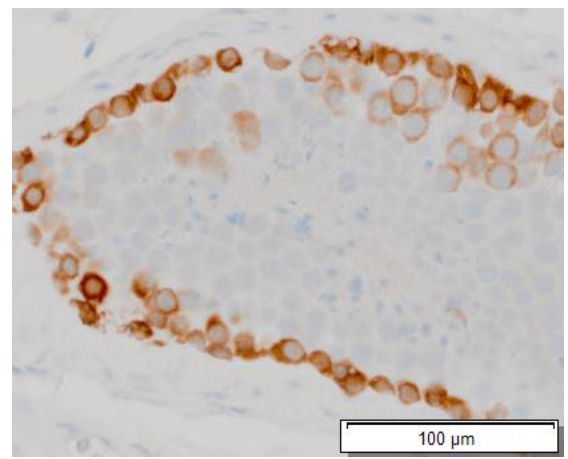

27. OCT2

$100 \mu \mathrm{m}$ 


\section{Clone no. 1-1_C24}

A

\begin{tabular}{|c|c|c|c|c|c|c|c|c|c|c|c|c|c|}
\hline \multirow[b]{2}{*}{ Clone no. } & \multirow[b]{2}{*}{ Location } & Slide 21 & Slide 22 & Slide 23 & Slide 24 & Slide 25 & Slide 26 & Slide 27 & Slide 28 & Slide 29 & Slide 30 & Slide 31 & \multirow{2}{*}{$\begin{array}{l}\text { Minimum } \\
\text { number of } \\
\text { cells }\end{array}$} \\
\hline & & MAGEA4 & SSX & MAGEA4 & Ki67 & $\mathrm{H} \& \mathrm{E}$ & MAGEA4 & ОСТ2 & MAGEA4 & FGFR3 & Ki67 & MAGEA4 & \\
\hline \multirow{3}{*}{ 1-1_C24 } & \multirow{3}{*}{ Periphery } & \multirow[t]{3}{*}{ NA } & \multirow[t]{3}{*}{0} & 1 & \multirow[t]{2}{*}{0} & & 1 & \multirow[t]{3}{*}{0} & $0^{*}$ & \multirow[t]{3}{*}{0} & \multirow[t]{3}{*}{0} & \multirow[t]{3}{*}{0} & \multirow{3}{*}{58} \\
\hline & & & & 7 cells & & & 15 cells & & 4 cells & & & & \\
\hline & & & & \multicolumn{5}{|c|}{$30 \mu \mathrm{m}$} & & & & & \\
\hline
\end{tabular}

B

22. SSX

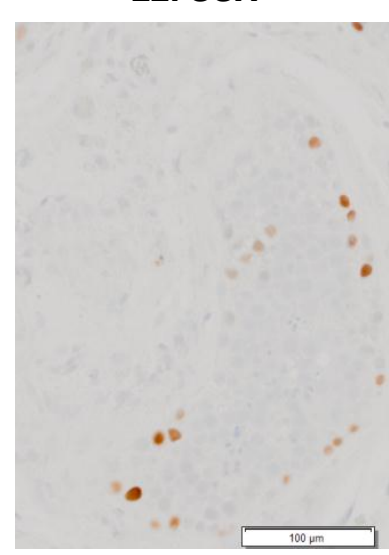

27. OCT2

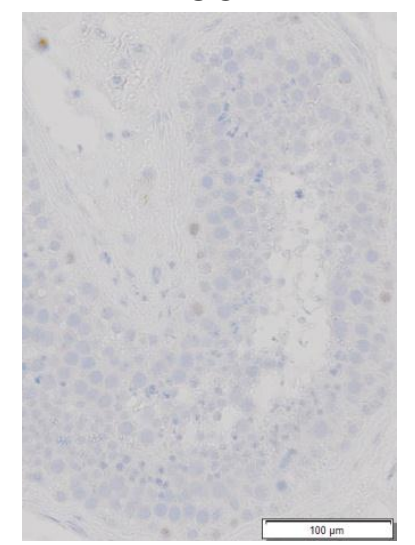

23. MAGEA4

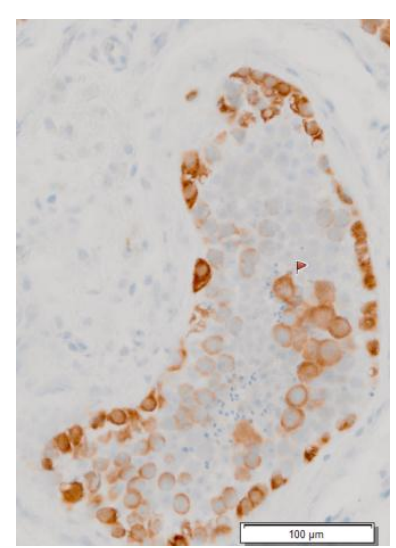

28. MAGEA4

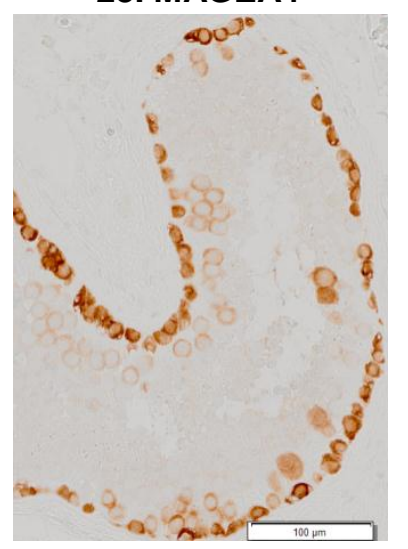

24. Ki67

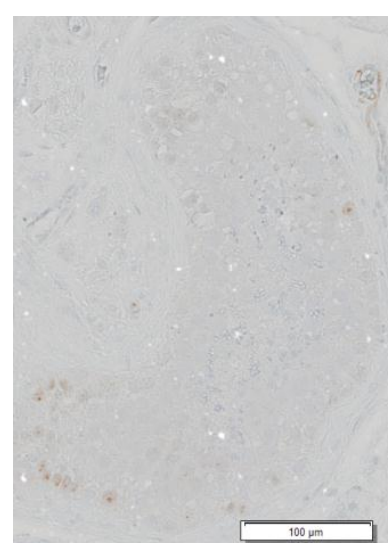

29. FGFR3

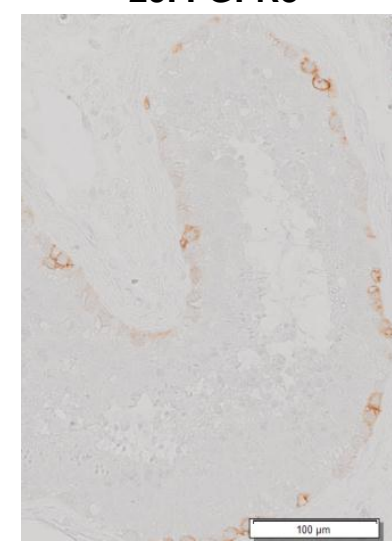

\section{MAGEA4}

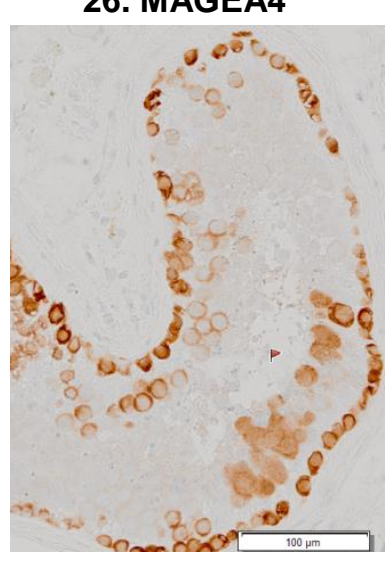

31. MAGEA4

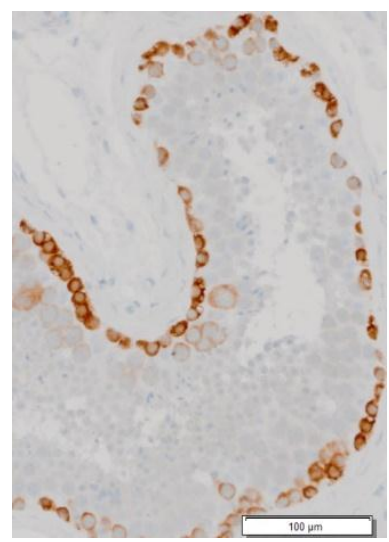


Clone no.1-1_C25

A

\begin{tabular}{|c|c|c|c|c|c|c|c|c|c|c|c|c|c|}
\hline \multirow{2}{*}{ Clone no. } & \multirow{2}{*}{ Location } & Slide 21 & Slide 22 & Slide 23 & Slide 24 & Slide 25 & Slide 26 & Slide 27 & Slide 28 & Slide 29 & $\begin{array}{c}\text { Slide } \\
30\end{array}$ & Slide 31 & \multirow{2}{*}{$\begin{array}{l}\text { Minimum } \\
\text { number of } \\
\text { cells }\end{array}$} \\
\hline & & MAGEA4 & SSX & MAGEA4 & Ki67 & H\&E & MAGEA4 & ОСТ2 & MAGEA4 & FGFR3 & Ki67 & MAGEA4 & \\
\hline \multirow{3}{*}{ 1-1_C25 } & \multirow{3}{*}{$\begin{array}{c}\text { Near } \\
\text { Peripher } \\
y\end{array}$} & & \multirow[t]{3}{*}{0} & $0^{*}$ & \multirow[t]{2}{*}{0} & & 1 & \multirow[t]{2}{*}{0} & 1 & \multirow[t]{3}{*}{0} & \multirow[t]{3}{*}{0} & \multirow[t]{3}{*}{0} & \multirow{3}{*}{26} \\
\hline & & & & 1 cell & & & 7 cells & & 4 cells & & & & \\
\hline & & & & \multicolumn{6}{|c|}{$30 \mu \mathrm{m}$} & & & & \\
\hline
\end{tabular}

B

22. SSX

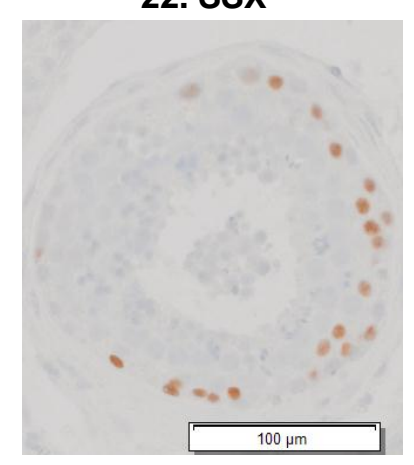

27. ОСТ2

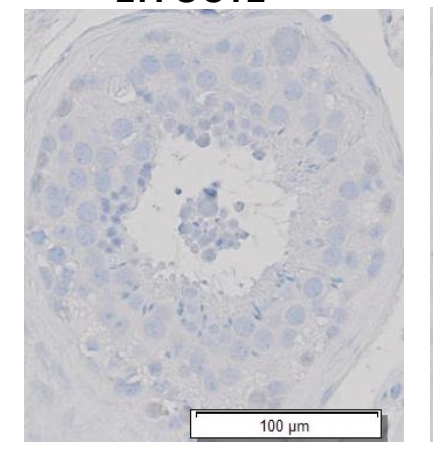

23. MAGEA4

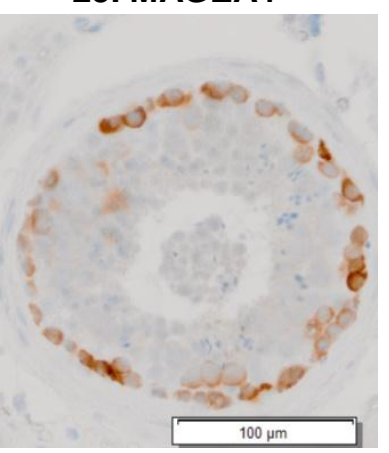

28. MAGEA4

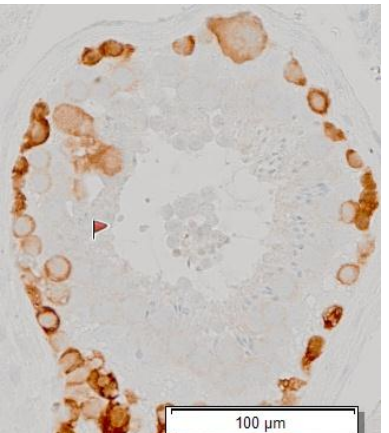

24. Ki67

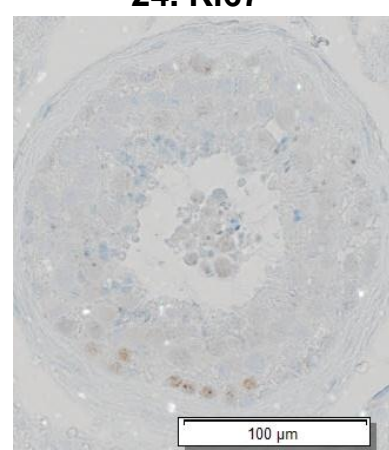

29. FGFR3

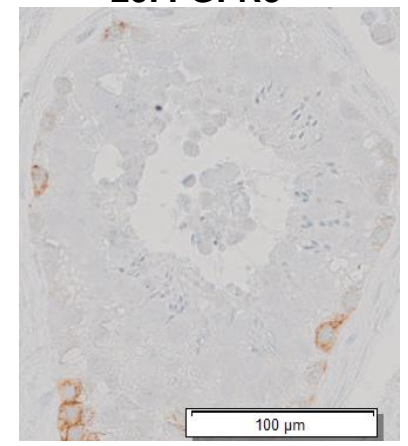

26. MAGEA4

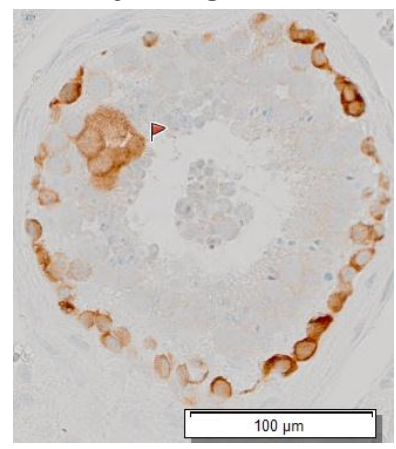

31. MAGEA4

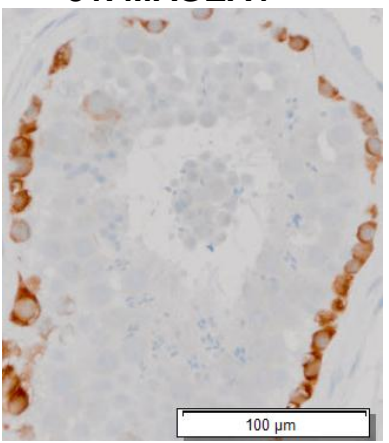




\section{Clone no.1-1_C26}

A

\begin{tabular}{|c|c|c|c|c|c|c|c|c|c|c|c|c|c|}
\hline \multirow[b]{2}{*}{ Clone no. } & \multirow[b]{2}{*}{ Location } & Slide 21 & Slide 22 & Slide 23 & Slide 24 & Slide 25 & Slide 26 & Slide 27 & Slide 28 & Slide 29 & Slide 30 & Slide 31 & \multirow{2}{*}{$\begin{array}{l}\text { Minimum } \\
\text { number of } \\
\text { cells }\end{array}$} \\
\hline & & MAGEA4 & sSX & MAGEA4 & Ki67 & $\mathrm{H} \& \mathrm{E}$ & MAGEA4 & ОСТ2 & MAGEA4 & FGFR3 & Ki67 & MAGEA4 & \\
\hline \multirow{3}{*}{ 1-1_C26 } & \multirow{3}{*}{$\begin{array}{c}\text { Near } \\
\text { Periphery }\end{array}$} & \multirow[t]{3}{*}{0} & \multirow[t]{3}{*}{0} & $0^{*}$ & \multirow[t]{2}{*}{0} & & 1 & \multirow[t]{2}{*}{0} & 1 & \multirow[t]{3}{*}{0} & \multirow[t]{3}{*}{0} & \multirow[t]{3}{*}{0} & \multirow{3}{*}{43} \\
\hline & & & & 7 cells & & & 8 cells & & 6 cells & & & & \\
\hline & & & & \multicolumn{6}{|c|}{$30 \mu \mathrm{m}$} & & & & \\
\hline
\end{tabular}

B

22. SSX

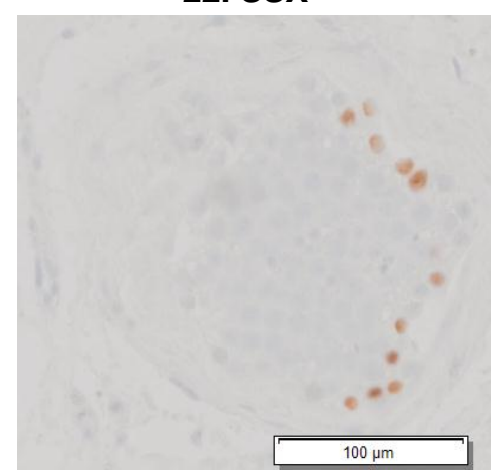

\section{OCT2}

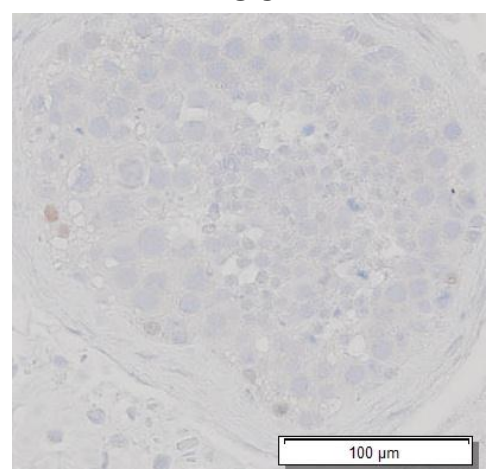

23. MAGEA4

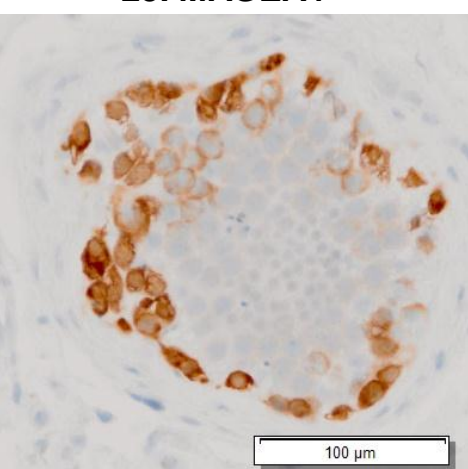

28. MAGEA4

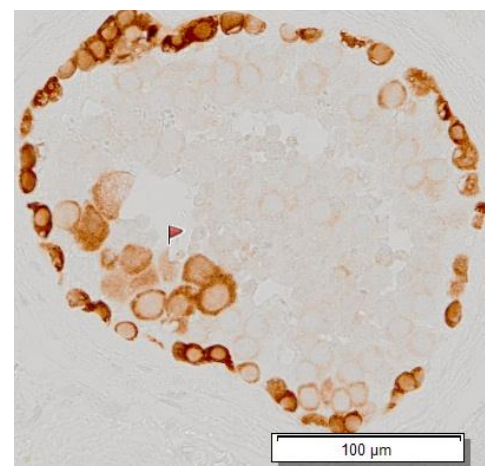

24. Ki67

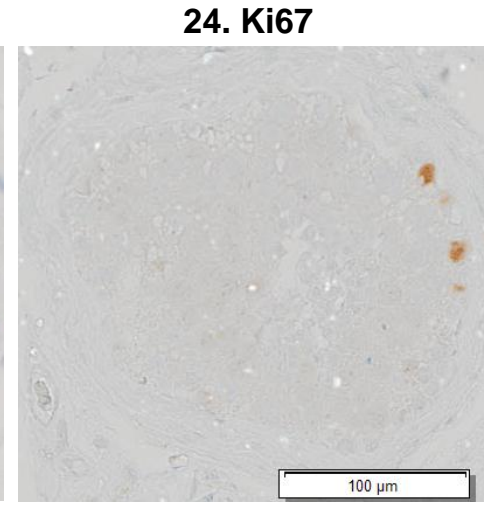

29. FGFR3

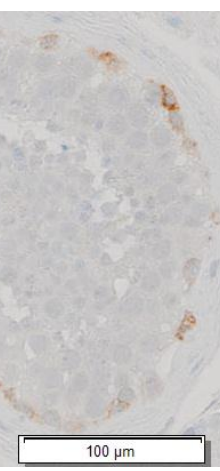

26. MAGEA4

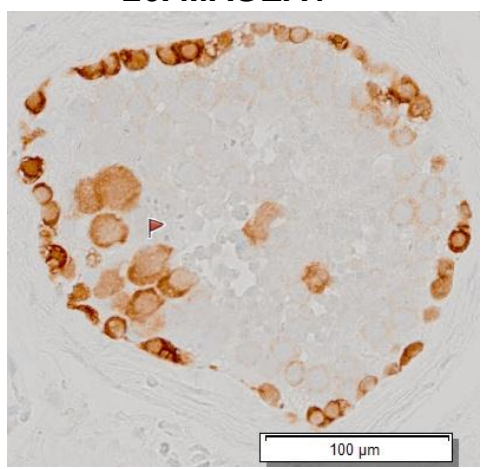

31. MAGEA4

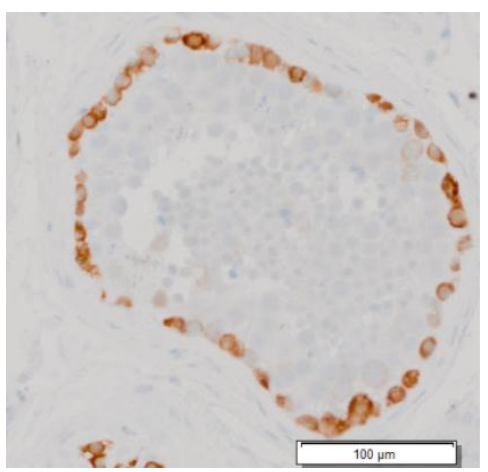


Clone no.1-1_C27

A

\begin{tabular}{|c|c|c|c|c|c|c|c|c|c|c|c|c|c|c|c|c|c|c|c|c|c|c|c|}
\hline \multirow{2}{*}{ Clone no. } & \multirow{2}{*}{ Location } & Slide 21 & Slide 22 & Slide 23 & Slide 24 & Slide 25 & Slide 26 & Slide 27 & Slide 28 & Slide 29 & Slide 30 & Slide 31 & Slide 32 & Slide 33 & Slide 34 & Slide 35 & $\begin{array}{c}\text { Sldie } \\
36\end{array}$ & SIdie 37 & SIdie 38 & SIdie 39 & SIdie 40 & Slide 41 & \multirow{2}{*}{$\begin{array}{c}\text { Minimum } \\
\text { number of } \\
\text { cells }\end{array}$} \\
\hline & & MAGEA4 & ssx & MAGEA4 & Ki67 & H\&E & MAGEA4 & ост2 & MAGEA4 & FGFR3 & Ki67 & MAGEA4 & ssx & SAGE1 & ост2 & MAGEA4 & n.s & n.s & n.s & n.s & n.s & MAGEA4 & \\
\hline \multirow[t]{2}{*}{ 1-1_C27 } & \multirow[t]{2}{*}{ Centre } & NA & 0 & $\begin{array}{c}1 \\
4 \text { cells }\end{array}$ & & & 1 & 0 & $\begin{array}{c}1 \\
22 \text { cells }\end{array}$ & 0 & 0 & $\begin{array}{c}0^{*} \\
5 \text { cells }\end{array}$ & 0 & 0 & 0 & $\begin{array}{c}1 \\
13 \text { cells }\end{array}$ & & & & & & 0 & \multirow[t]{2}{*}{163} \\
\hline & & & & & & & & & & $65 \mu \mathrm{m}$ & & & & & & & & & & & & & \\
\hline
\end{tabular}

B
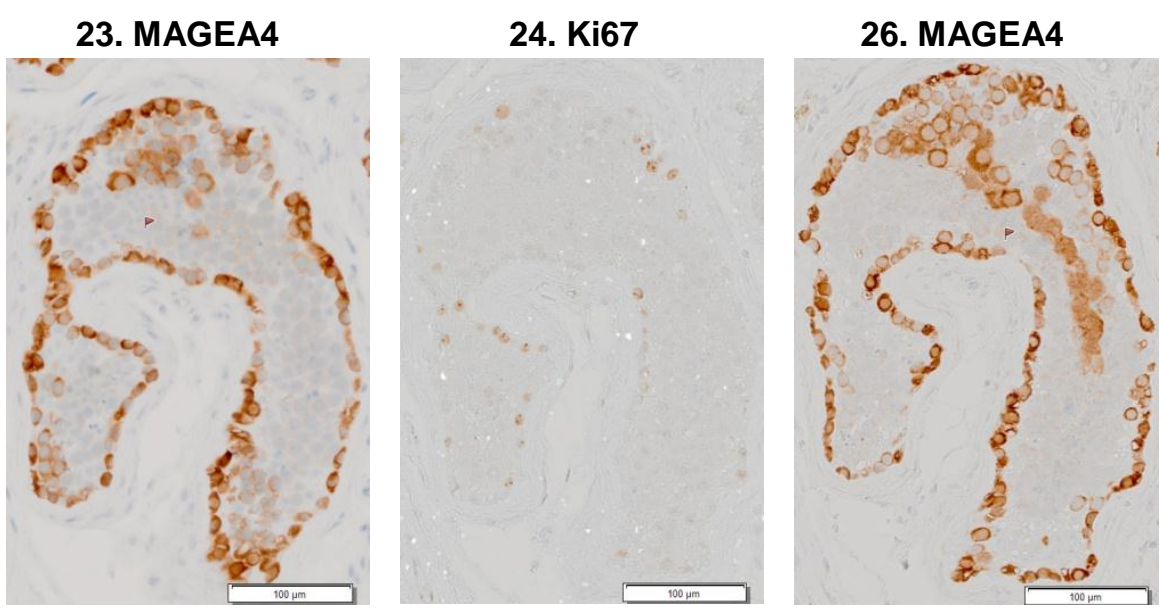

29. FGFR3

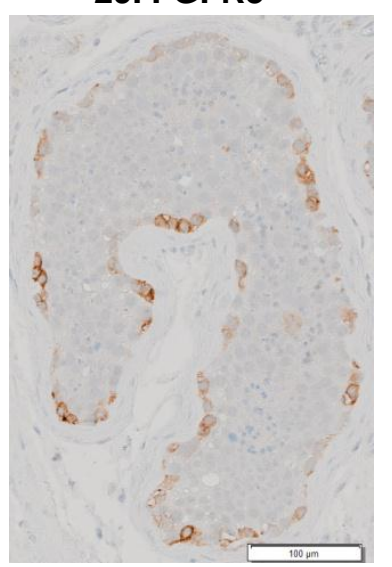

31. MAGEA4

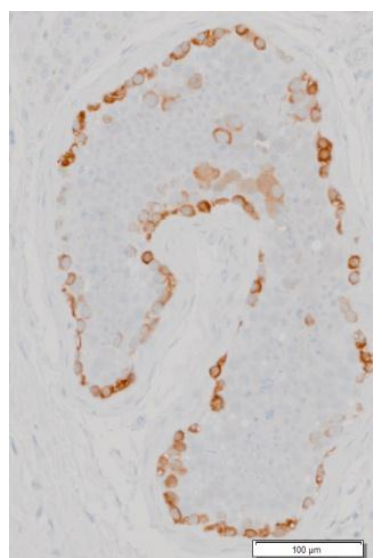

32. SSX

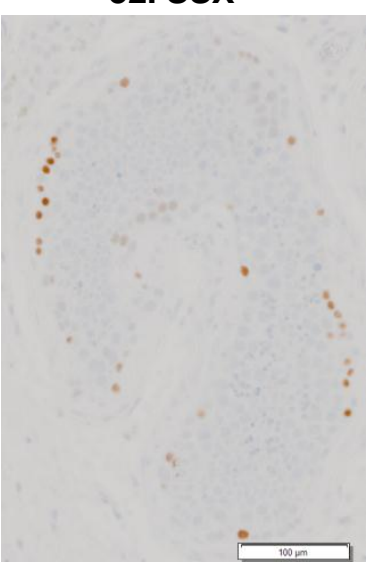

27. OCT2

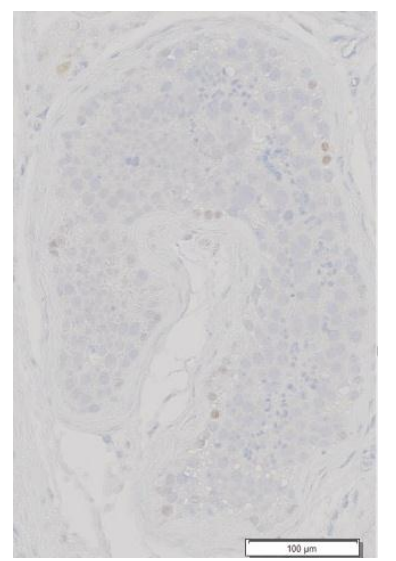

33. SAGE1

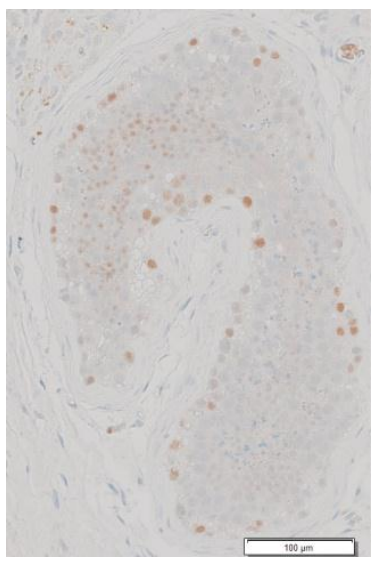

28. MAGEA4

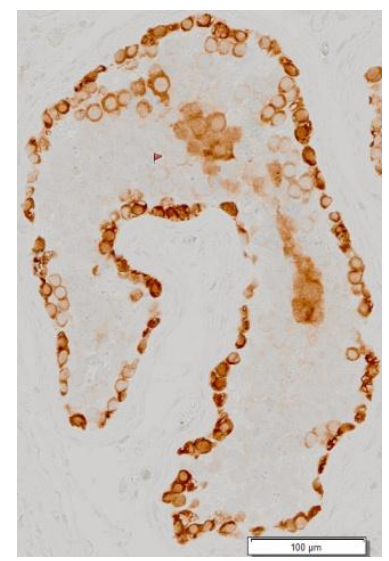

35. MAGEA4

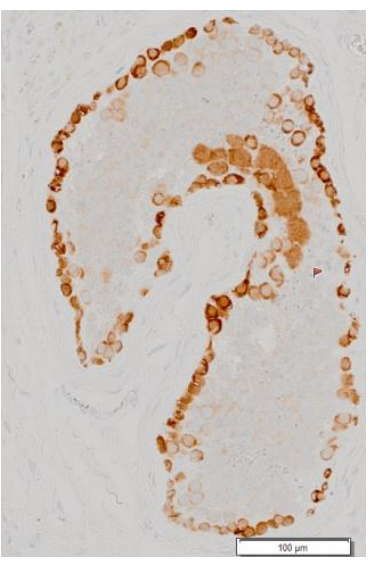




\section{Clone no.1-1_C28}

A

\begin{tabular}{|c|c|c|c|c|c|c|c|c|c|c|c|c|c|}
\hline \multirow{2}{*}{ Clone no. } & \multirow{2}{*}{ Location } & Slide 21 & Slide 22 & Slide 23 & Slide 24 & Slide 25 & Slide 26 & Slide 27 & Slide 28 & Slide 29 & Slide 30 & Slide 31 & \multirow{2}{*}{$\begin{array}{l}\text { Minimum } \\
\text { number of } \\
\text { cells }\end{array}$} \\
\hline & & MAGEA4 & ssx & MAGEA4 & Ki67 & $\mathrm{H} \& \mathrm{E}$ & MAGEA4 & ОСТ2 & MAGEA4 & FGFR3 & Ki67 & MAGEA4 & \\
\hline \multirow{3}{*}{ 1-1_C28 } & \multirow{3}{*}{ Centre } & \multirow[t]{3}{*}{0} & \multirow[t]{3}{*}{0} & 1 & \multirow[t]{2}{*}{0} & & 1 & \multirow[t]{3}{*}{0} & $0^{*}$ & \multirow[t]{3}{*}{0} & \multirow[t]{3}{*}{0} & \multirow[t]{3}{*}{ NA } & \multirow{3}{*}{24} \\
\hline & & & & 4 cells & & & 5 cells & & 2 cells & & & & \\
\hline & & & & \multicolumn{5}{|c|}{$30 \mu \mathrm{m}$} & & & & & \\
\hline
\end{tabular}

B

22. SSX

$100 \mu \mathrm{m}$

27. OCT2

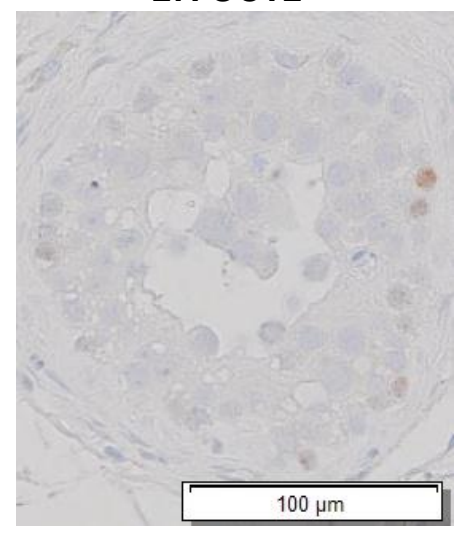

23. MAGEA4

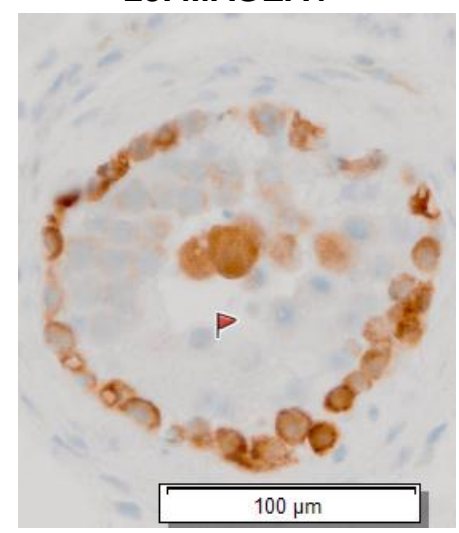

28. MAGEA4

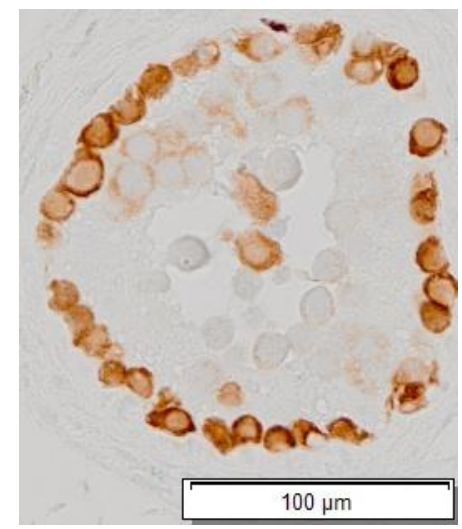

24. Ki67

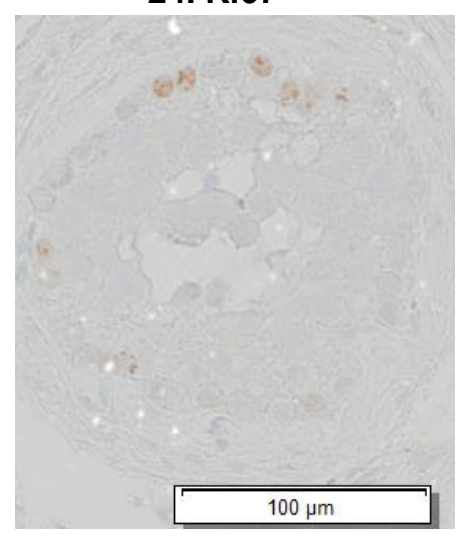

29. FGFR3

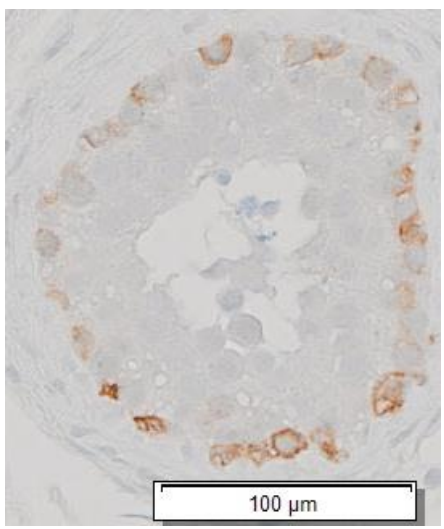

26. MAGEA4

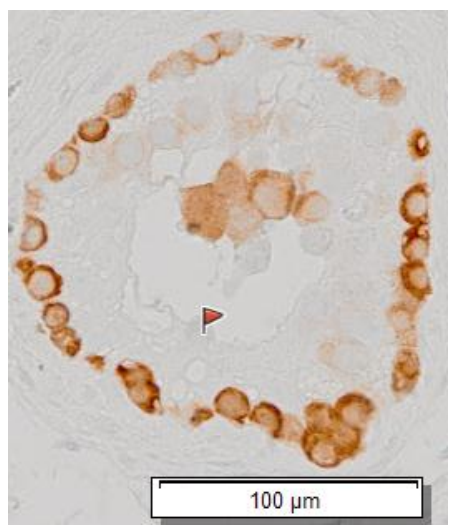

31. MAGEA4

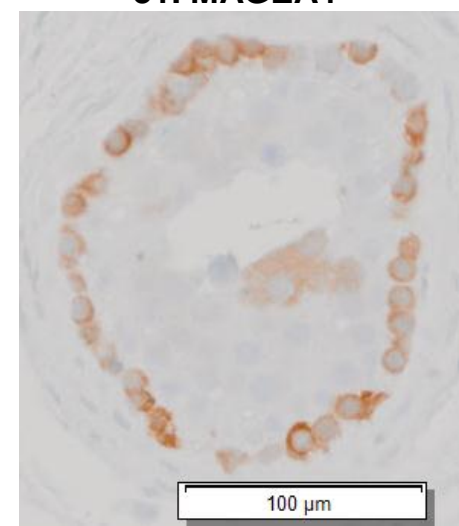


Clone no.1-1_C29

A

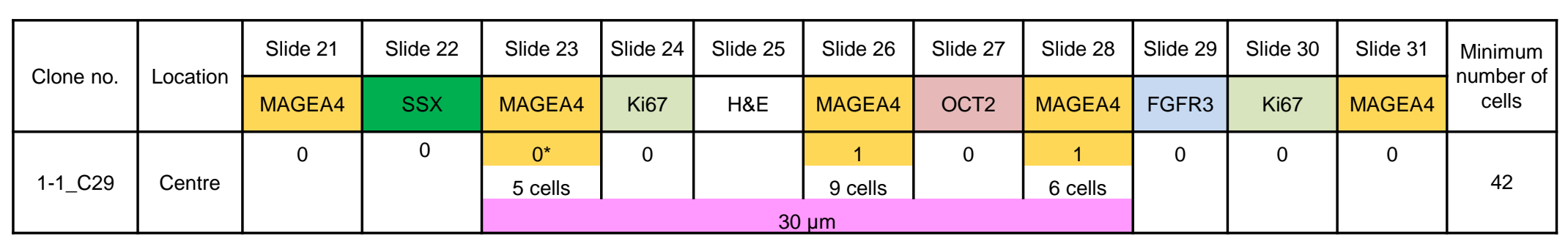

B

22. SSX

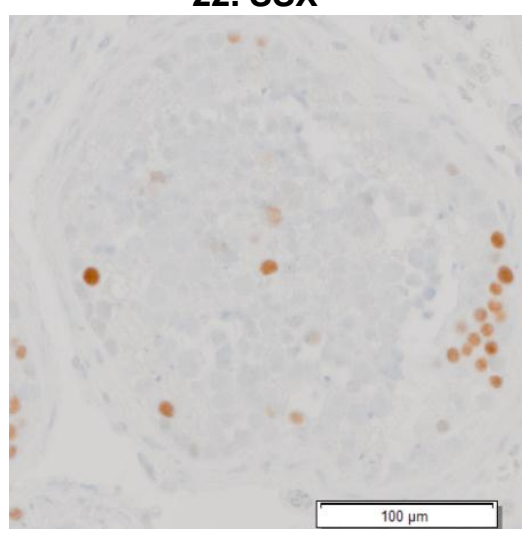

27. OCT2

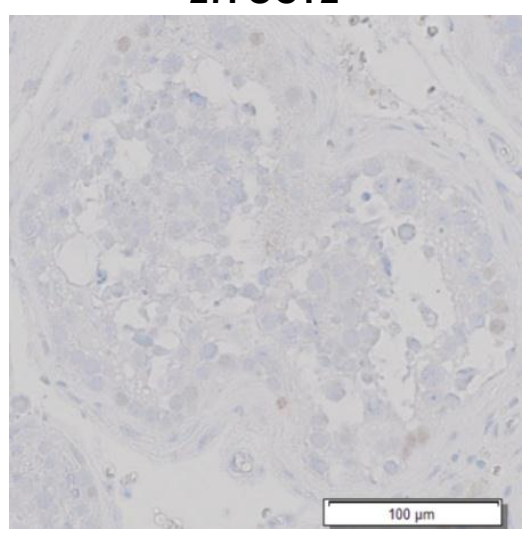

23. MAGEA4

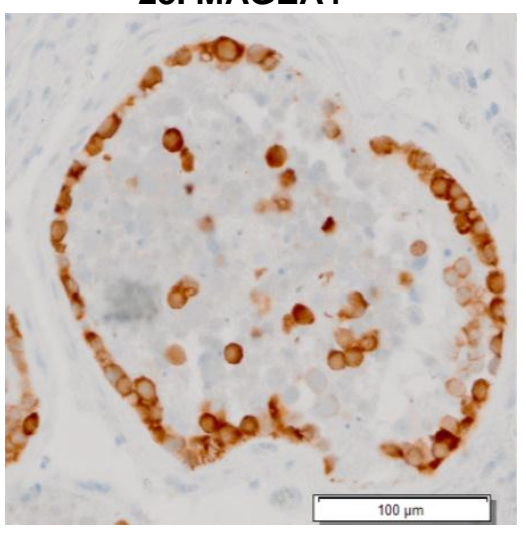

28. MAGEA4

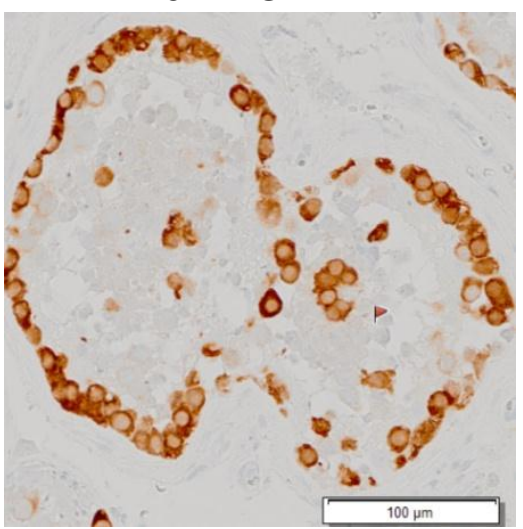

24. Ki67

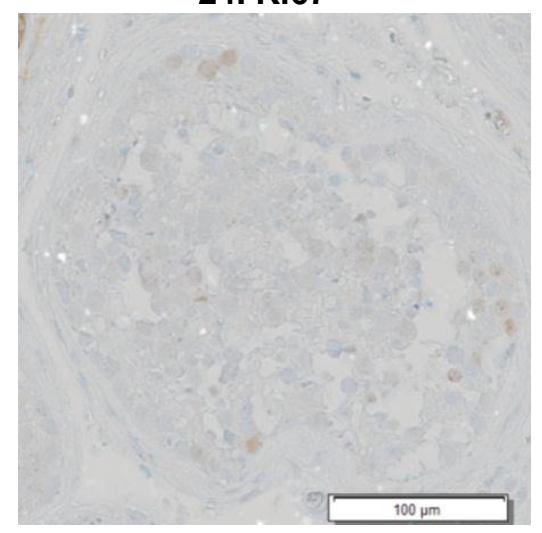

29. FGFR3

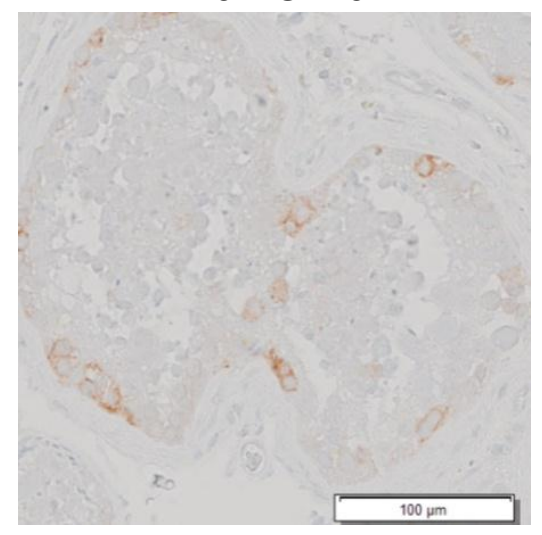

26. MAGEA4

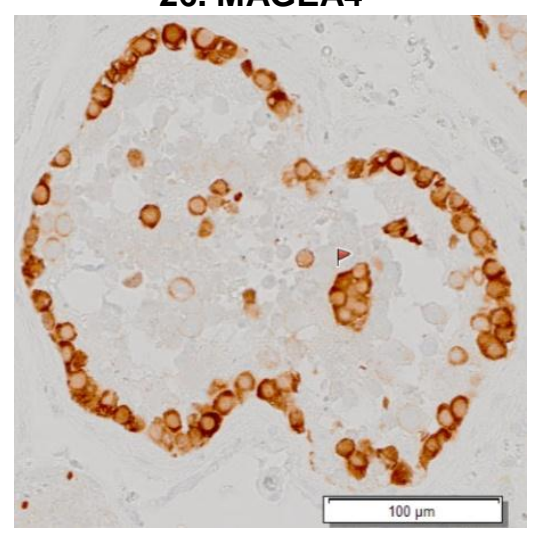

31. MAGEA4

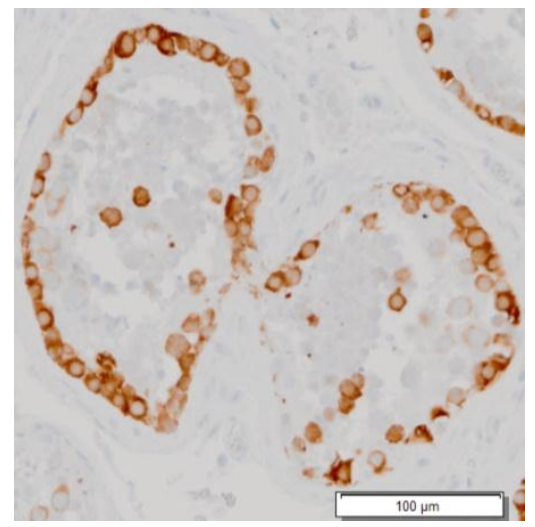


Clone no. 1-1_C30

A

\begin{tabular}{|c|c|c|c|c|c|c|c|c|c|c|c|}
\hline \multirow{2}{*}{ Clone no. } & \multirow{2}{*}{ Location } & Slide 23 & Slide 24 & Slide 25 & Slide 26 & Slide 27 & Slide 28 & Slide 29 & Slide 30 & Slide 31 & \begin{tabular}{c} 
Minimum \\
\cline { 3 - 11 }
\end{tabular} \\
\cline { 3 - 12 } & MAGEA4 & Ki67 & H\&E & MAGEA4 & OCT2 & MAGEA4 & FGFR3 & Ki67 & MAGEA4 & number of cells \\
\hline \multirow{2}{*}{ 1-1_C30 } & Centre & & 0 & & 1 & 0 & 1 & 0 & 0 & 0 & 15 \\
\hline
\end{tabular}

B
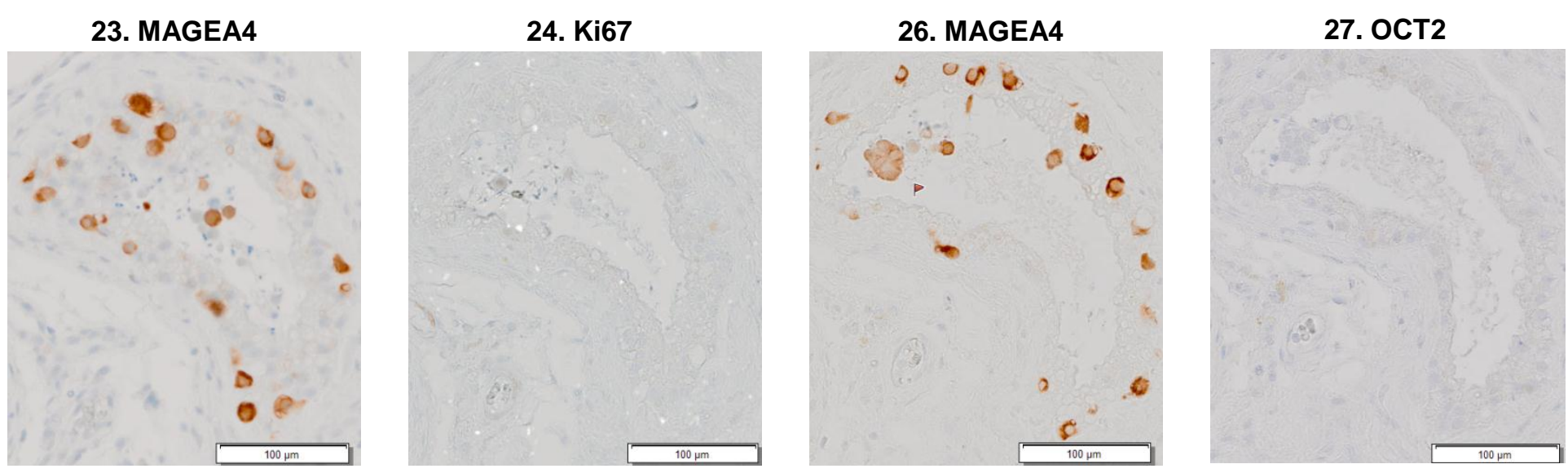

28. MAGEA4

29. FGFR3

31. MAGEA4
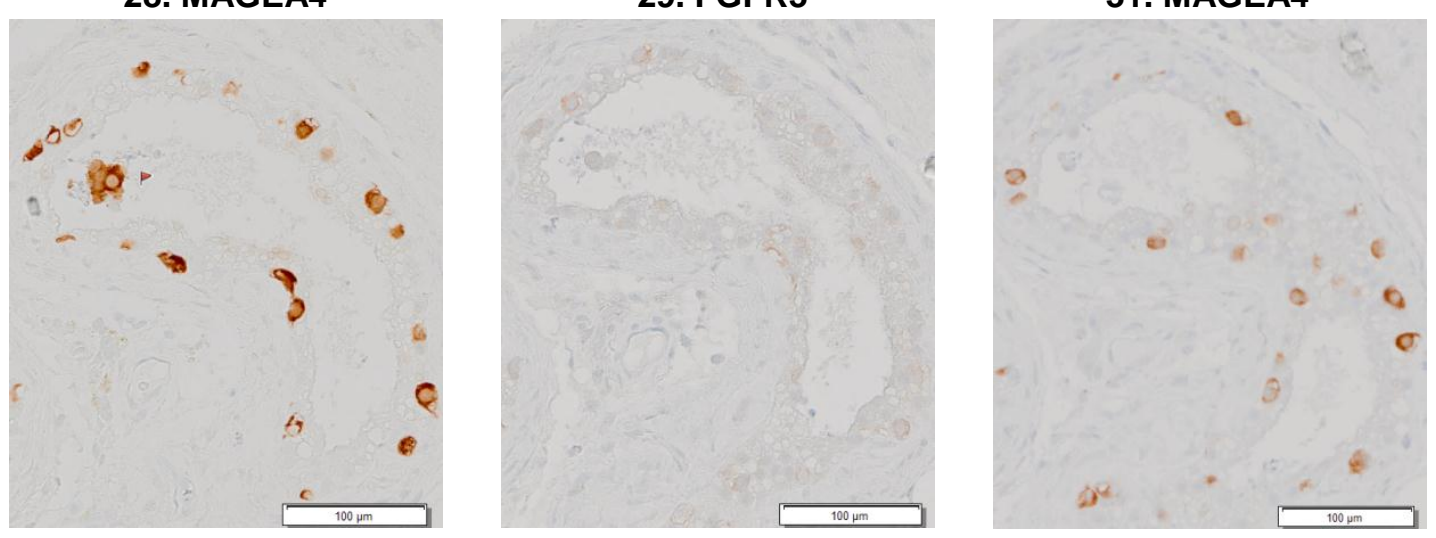
Clone no.1-1_C31

A

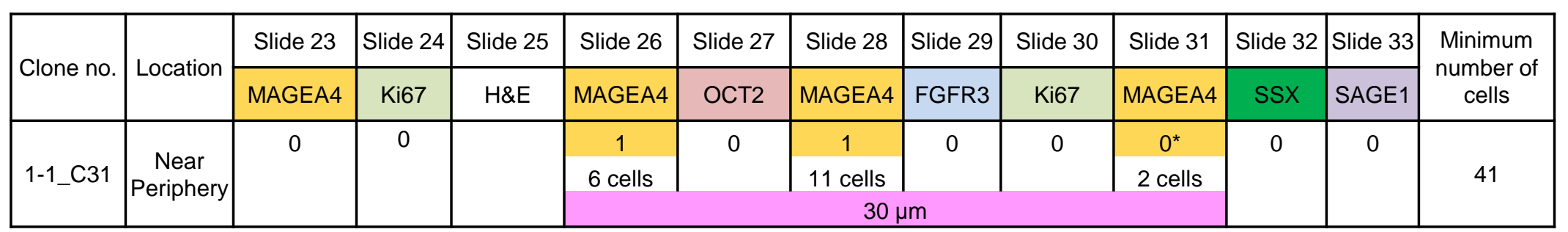

B

23. MAGEA4

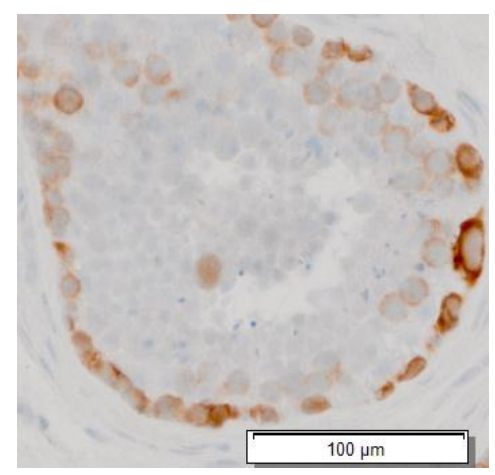

29. FGFR3
30. Ki67
26. MAGEA4

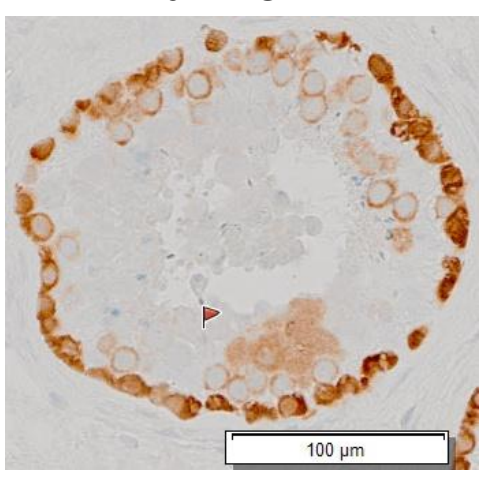

27. ОСТ2

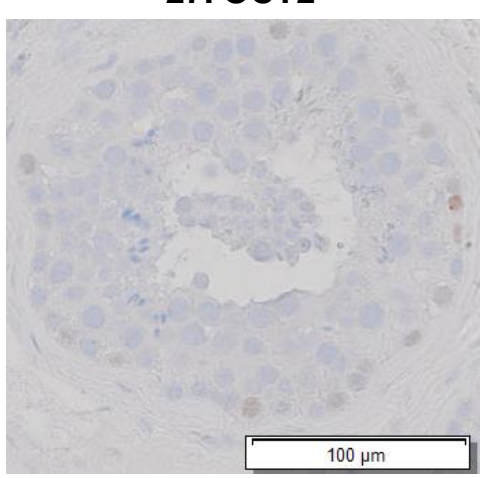

32. SSX
28. MAGEA4

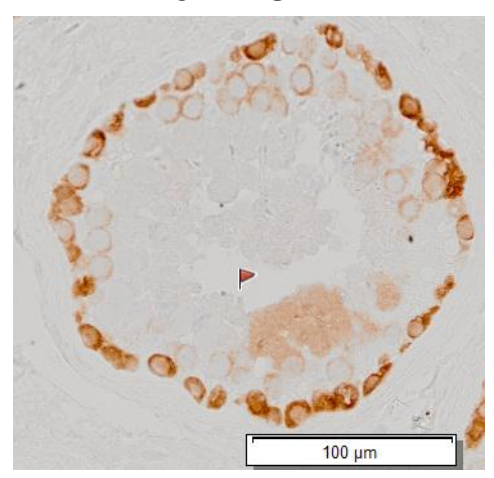

33. SAGE1
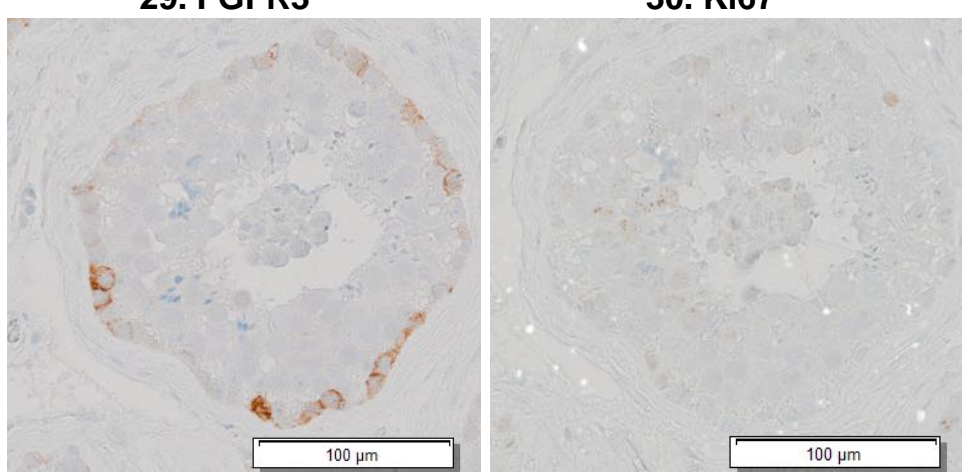

31. MAGEA4

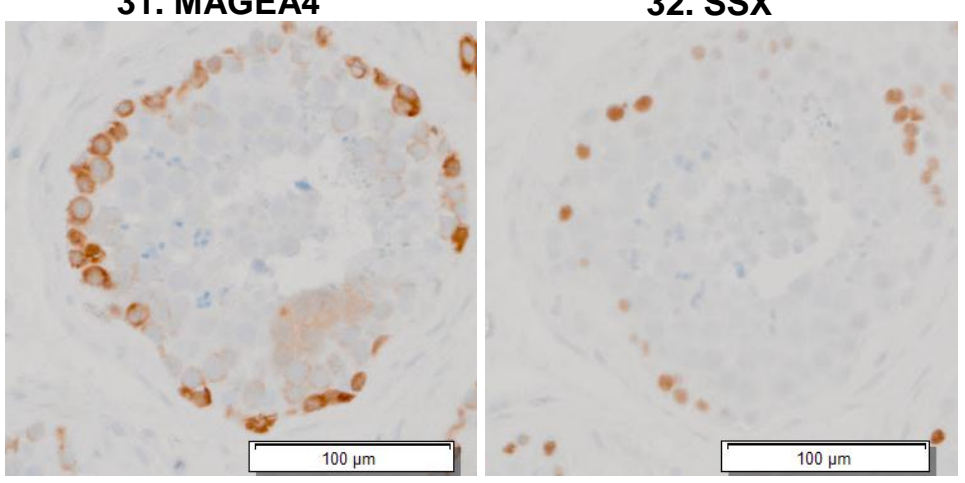




\section{Clone no.1-1_C32}

A

\begin{tabular}{|c|c|c|c|c|c|c|c|c|c|c|c|c|c|}
\hline Clone no. & Location & Slide 21 & Slide 22 & Slide 23 & Slide 24 & Slide 25 & Slide 26 & Slide 27 & Slide 28 & Slide 29 & Slide 30 & Slide 31 & $\begin{array}{l}\text { Minimum } \\
\text { number of } \\
\text { cells }\end{array}$ \\
\hline \multirow{3}{*}{ 1-1_C32 } & \multirow{3}{*}{$\begin{array}{c}\text { Near } \\
\text { Periphery }\end{array}$} & \multirow[t]{3}{*}{0} & \multirow[t]{3}{*}{0} & 1 & & & 1 & \multirow[t]{2}{*}{0} & 1 & \multirow[t]{3}{*}{0} & \multirow[t]{3}{*}{0} & \multirow[t]{3}{*}{0} & \multirow{3}{*}{40} \\
\hline & & & & 7 cells & & & 6 cells & & 7 cells & & & & \\
\hline & & & & \multicolumn{6}{|c|}{$30 \mu \mathrm{m}$} & & & & \\
\hline
\end{tabular}

B
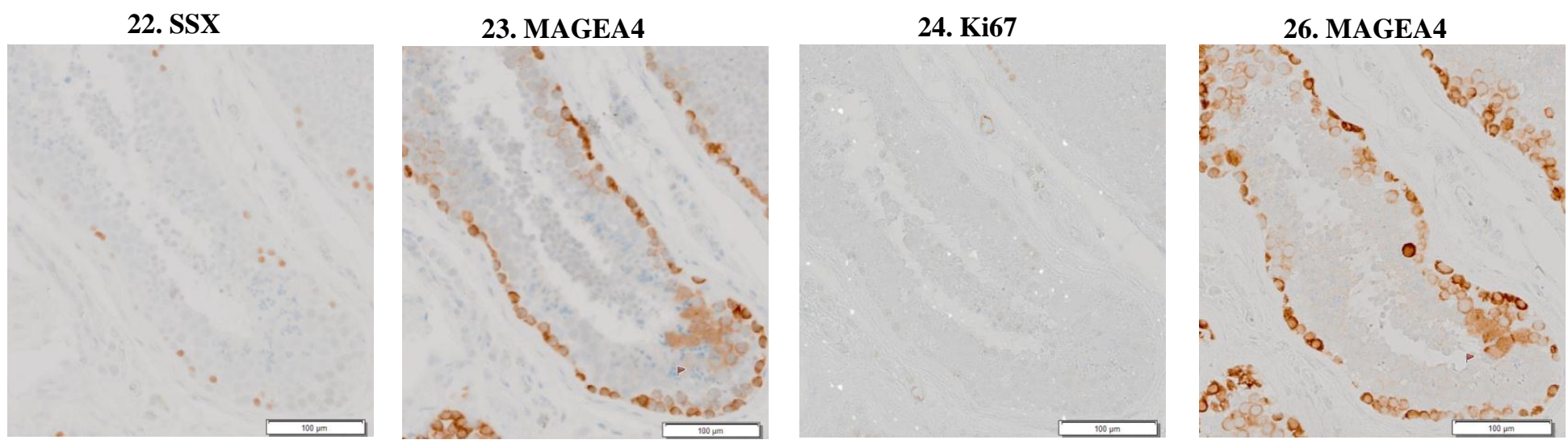

27. OCT2

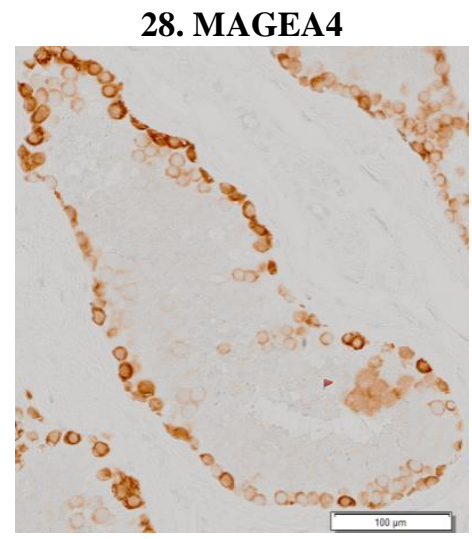

29. FGFR3

31. MAGEA4
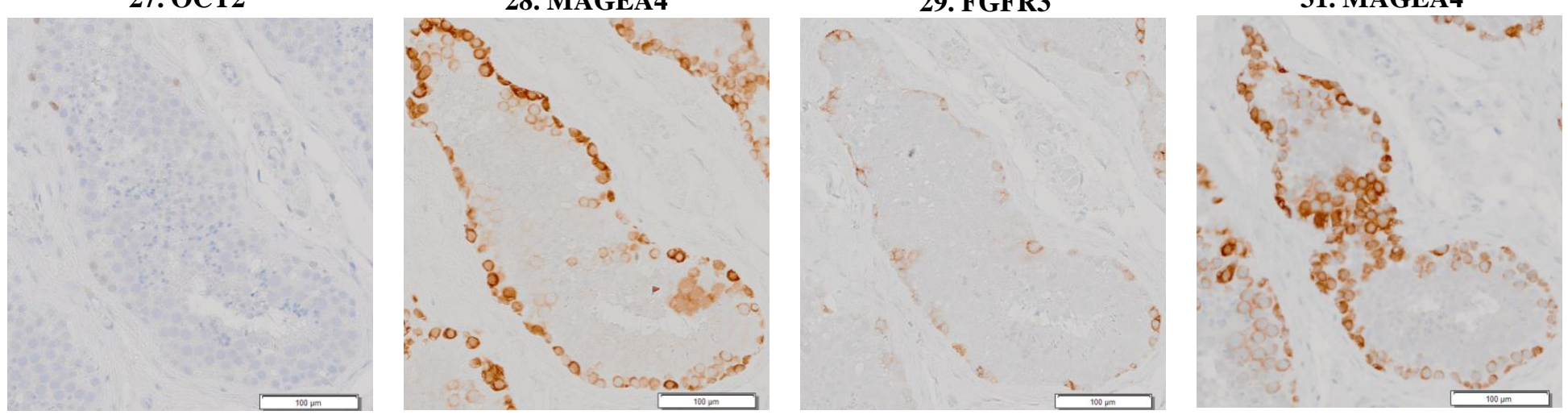
Clone no. 1-1_C33

A

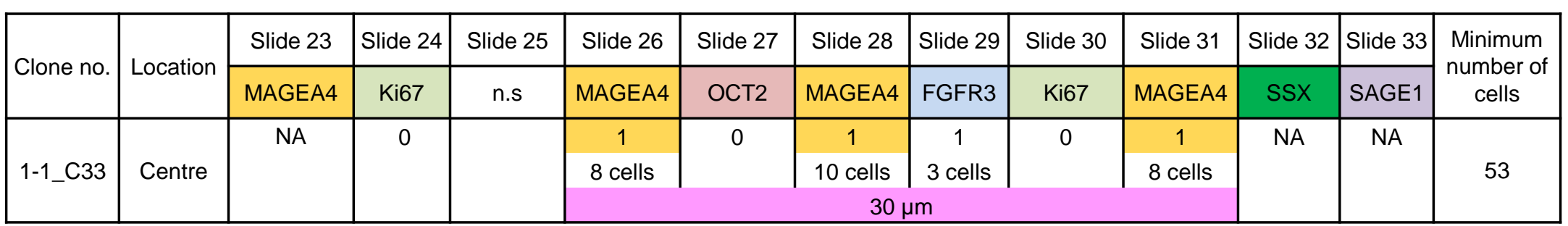

B

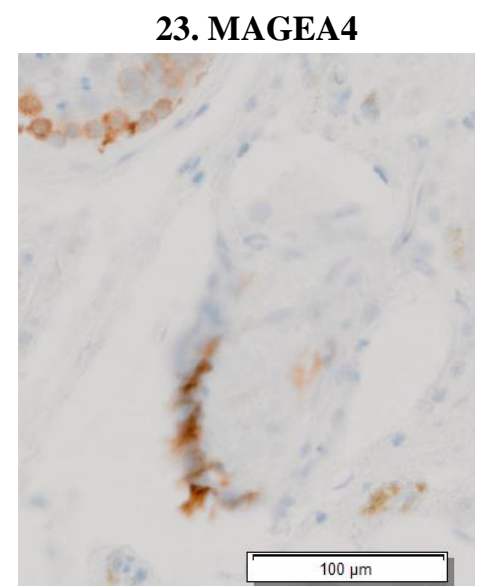

29. FGFR3

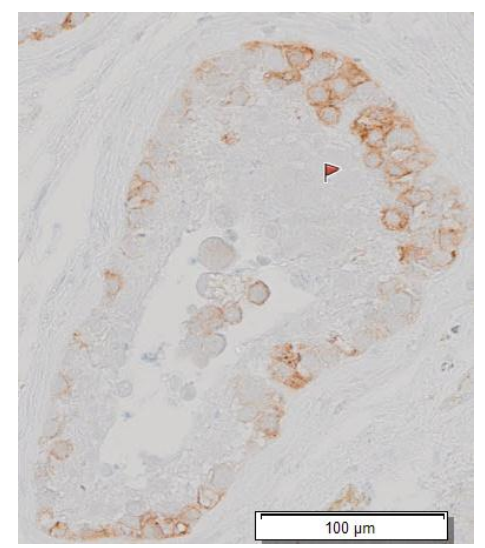

26. MAGEA4

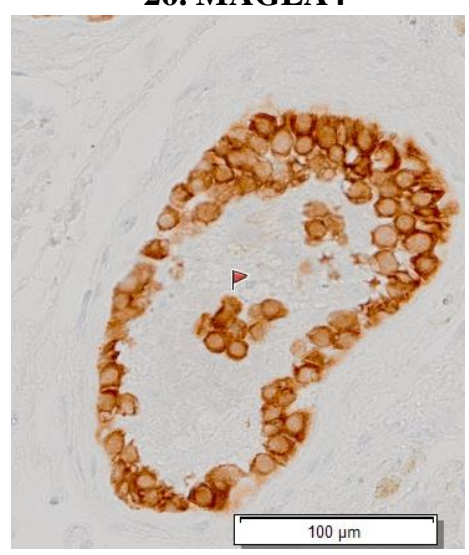

30. Ki67

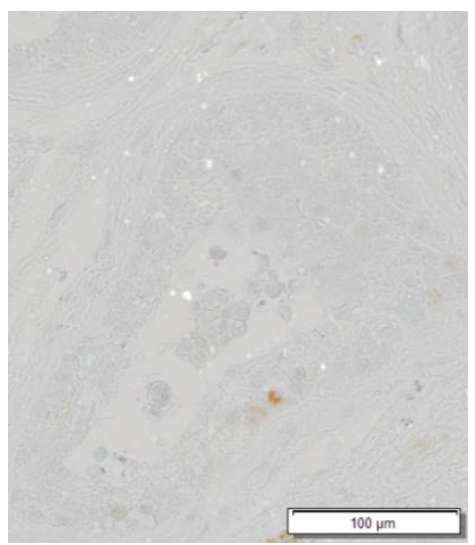

27. OCT2

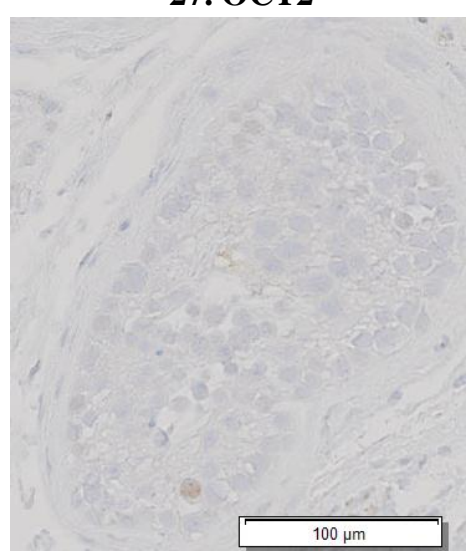

31. MAGEA4

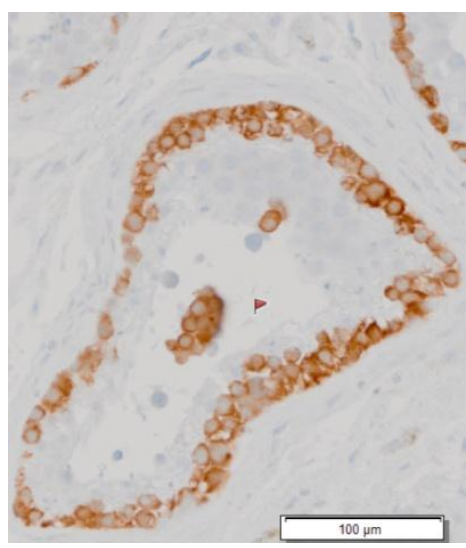

28. MAGEA4

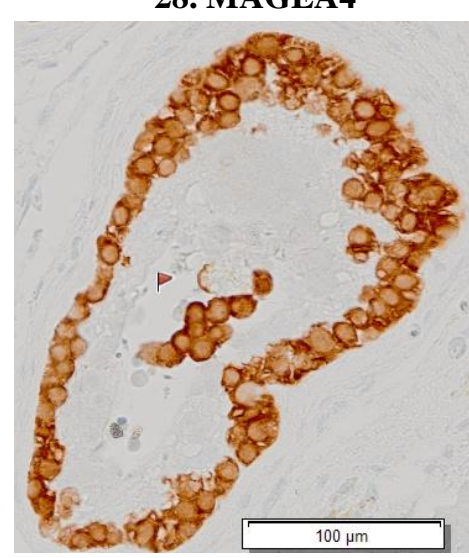

32. SSX

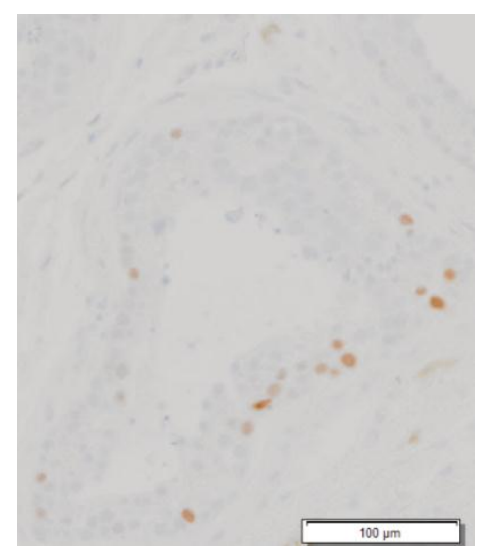




\section{Clone no. 1-}

A

\begin{tabular}{|c|c|c|c|c|c|c|c|c|c|c|c|c|c|c|c|}
\hline \multirow{2}{*}{ Clone no. } & \multirow{2}{*}{ Location } & Slide 23 & Slide 24 & Slide 25 & Slide 26 & Slide $\overline{27}$ & Slide 28 & Slide 29 & Slide 30 & Slide 31 & Slide 32 & Slide 33 & Slide 34 & Slide 35 & \multirow{2}{*}{$\begin{array}{l}\text { Minimum } \\
\text { number of } \\
\text { cells }\end{array}$} \\
\hline & & MAGEA4 & Ki67 & $\mathrm{H} \& \mathrm{E}$ & MAGEA4 & ОСТ2 & MAGEA4 & FGFR3 & Ki67 & MAGEA4 & SSX & SAGE1 & OCT2 & MAGEA4 & \\
\hline \multirow{3}{*}{ 1-1_C34 } & \multirow{3}{*}{$\begin{array}{c}\text { Near } \\
\text { Periphery }\end{array}$} & \multirow[t]{3}{*}{0} & & & $0^{*}$ & \multirow[t]{2}{*}{0} & 1 & \multirow[t]{2}{*}{0} & \multirow[t]{2}{*}{0} & 1 & \multirow[t]{2}{*}{0} & \multirow[t]{2}{*}{0} & \multirow[t]{2}{*}{0} & $0^{*}$ & \multirow{3}{*}{51} \\
\hline & & & & & 3 cells & & 5 cells & & & 8 cells & & & & 2 cells & \\
\hline & & & & & \multicolumn{10}{|c|}{$50 \mu \mathrm{m}$} & \\
\hline
\end{tabular}

B

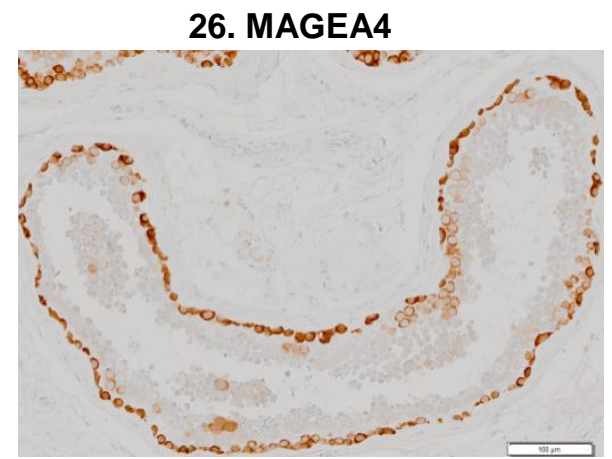

30. Ki67

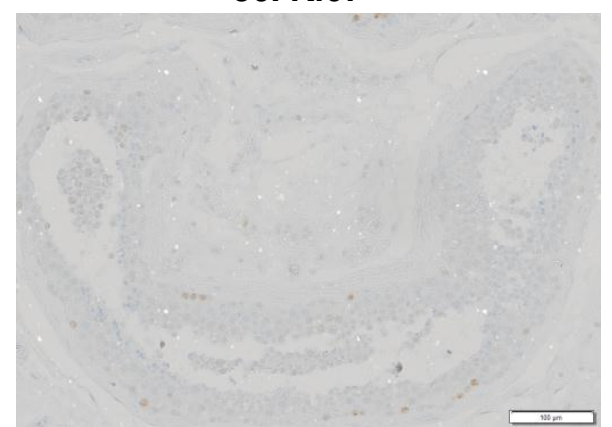

33. SAGE1

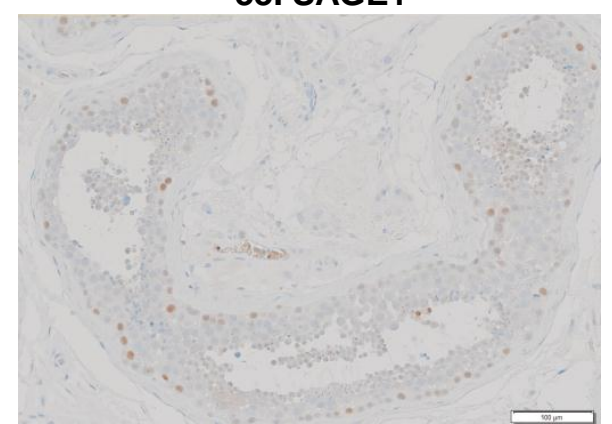

28. MAGEA4

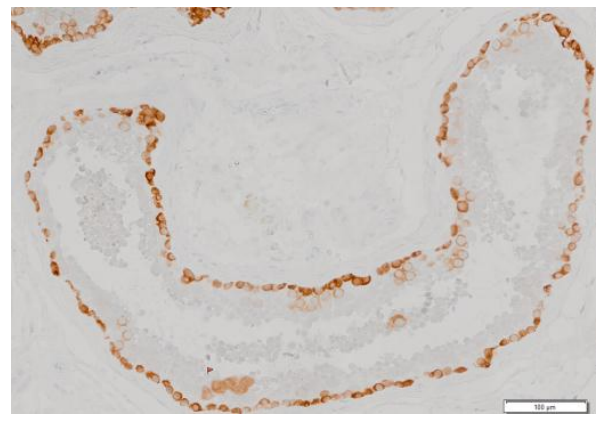

31. MAGEA4

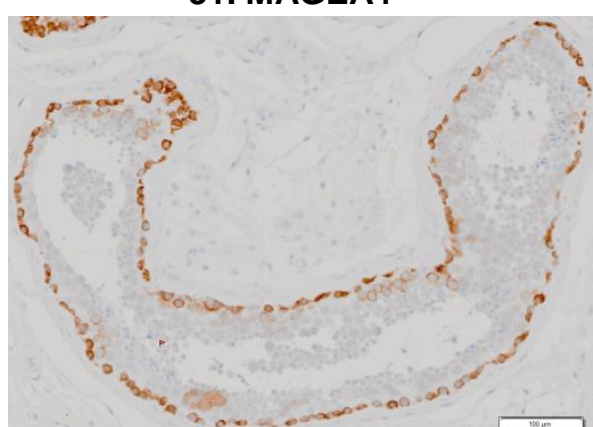

34. ОСТ2

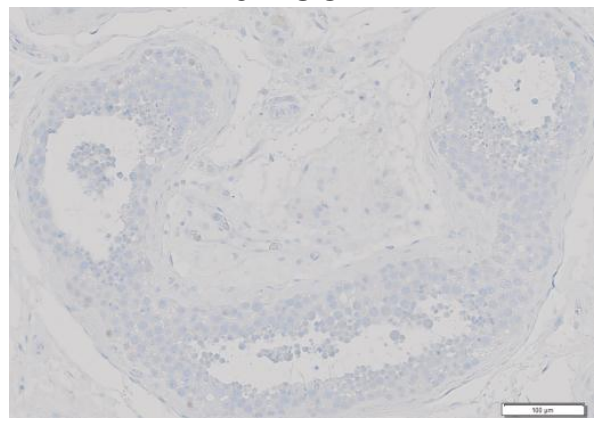

29. FGFR3

32. SSX

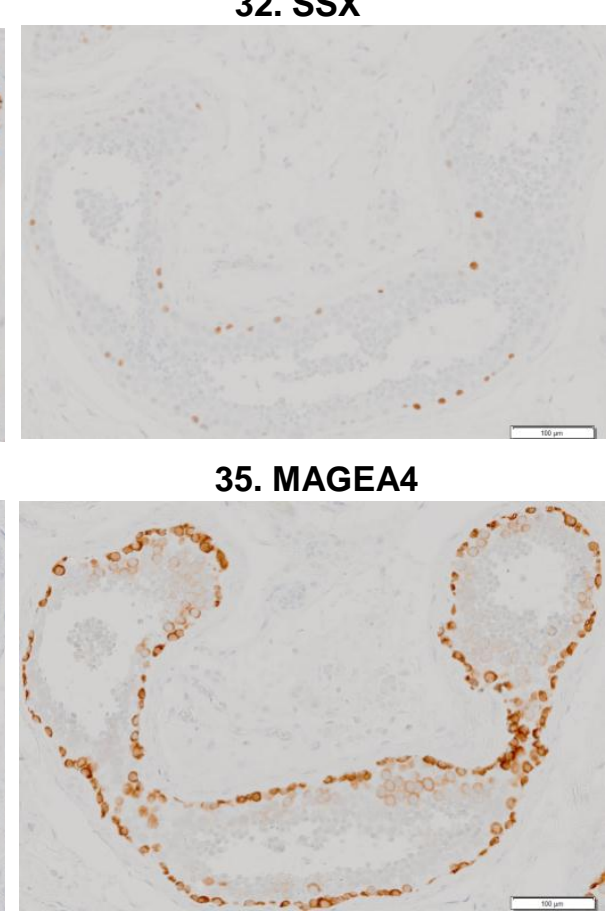




\section{Clone no. 1-}

\section{C35}

A

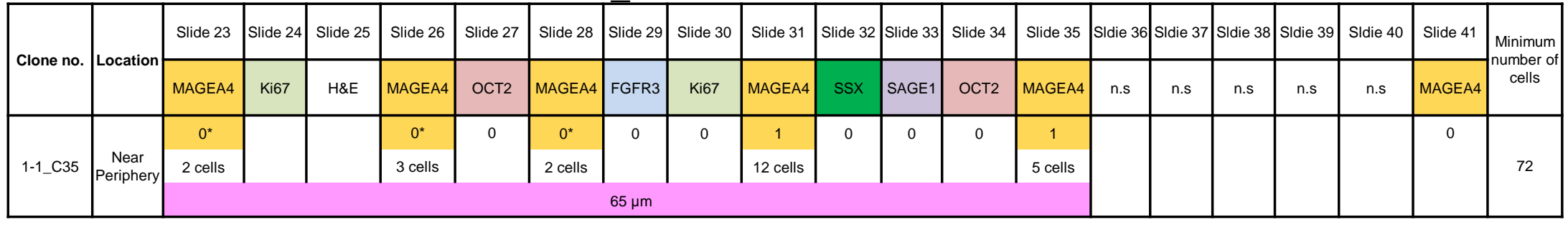

B

\section{MAGEA4}

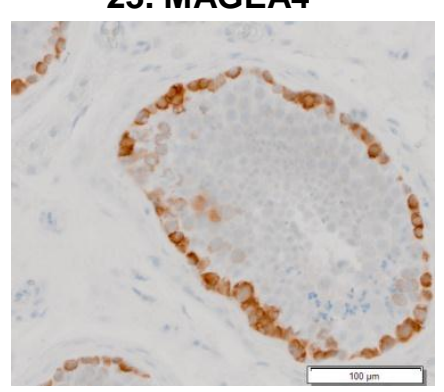

31. MAGEA4

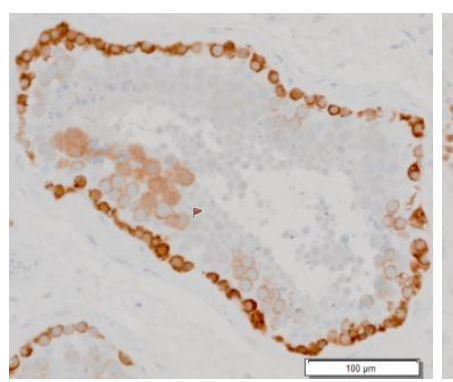

26. MAGEA4

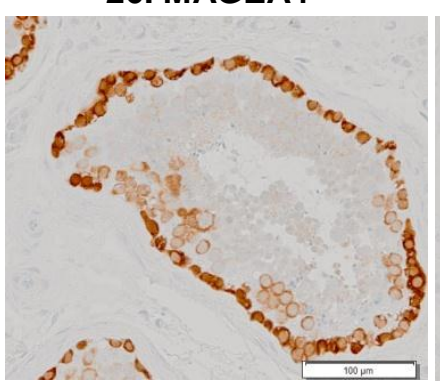

32. SSX

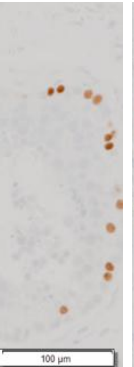

28. MAGEA4

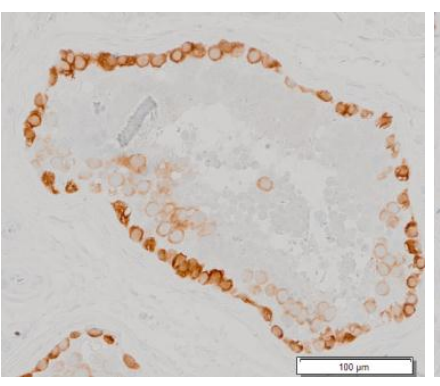

33. SAGE1
29. FGFR3

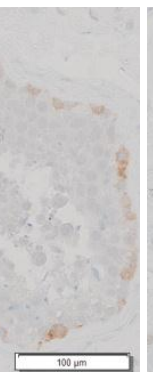

34. OCT2

35. MAGEA4

\section{Ki67}
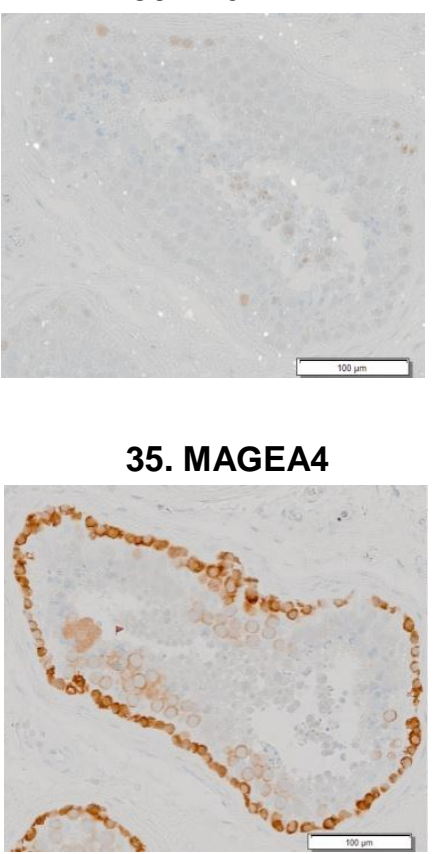


\section{Clone no.1-1_C36}

A

\begin{tabular}{|c|c|c|c|c|c|c|c|c|c|c|c|c|}
\hline \multirow{2}{*}{ Clone no. } & \multirow{2}{*}{ Location } & Slide 26 & Slide 27 & Slide 28 & Slide 29 & Slide 30 & Slide 31 & Slide 32 & Slide 33 & Slide 34 & Slide 35 & \multirow{2}{*}{$\begin{array}{l}\text { Minimum } \\
\text { number of } \\
\text { cells }\end{array}$} \\
\hline & & MAGEA4 & OCT2 & MAGEA4 & FGFR3 & Ki67 & MAGEA4 & SSX & SAGE1 & OCT2 & MAGEA4 & \\
\hline \multirow{3}{*}{ 1-1_C36 } & \multirow{3}{*}{ Centre } & $0^{*}$ & 0 & 1 & $0^{*}$ & 1 & 1 & 1 & 1 & 0 & 0 & \multirow{3}{*}{98} \\
\hline & & 4 cells & & 7 cells & 1 cell & 9 cells & 21 cells & 17 cells & 15 cells & & & \\
\hline & & \multicolumn{8}{|c|}{$40 \mu \mathrm{m}$} & & & \\
\hline
\end{tabular}

B

26. MAGEA4

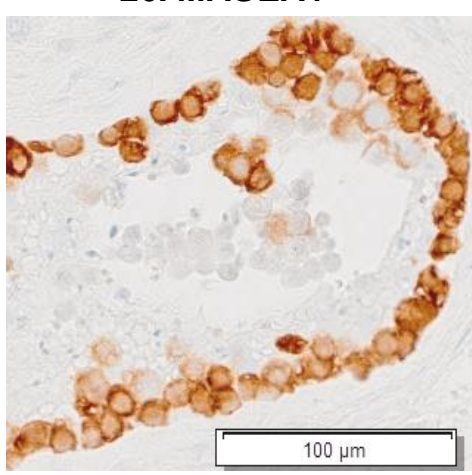

31. MAGEA4

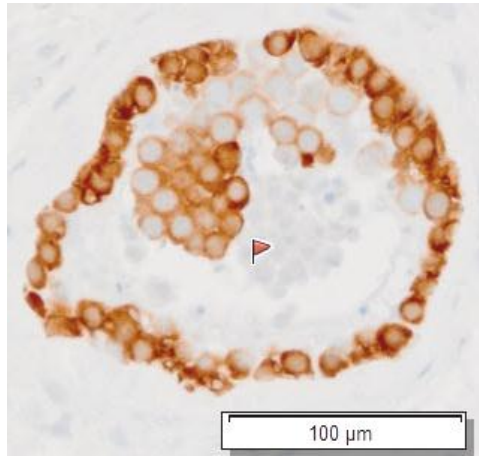

27. OCT2

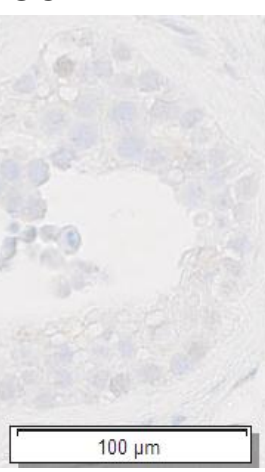

32. SSX
33. SAGE1

28. MAGEA4

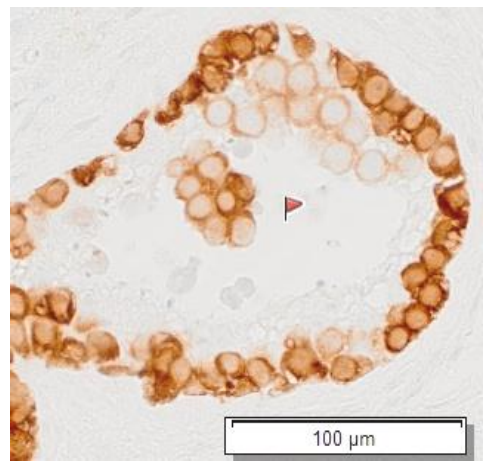

29. FGFR3

30. Ki67

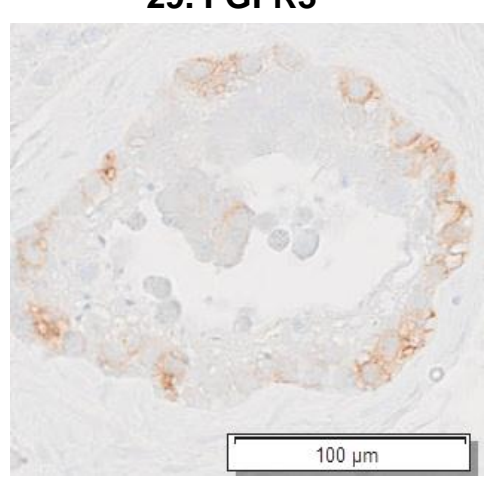

34. ОСT2

35. MAGEA4

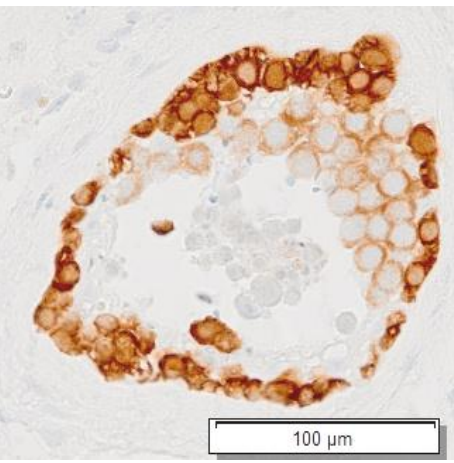




\section{Clone no.1-1_C37}

A

\begin{tabular}{|c|c|c|c|c|c|c|c|c|c|c|c|c|}
\hline \multirow{2}{*}{ Clone no. } & \multirow{2}{*}{ Location } & Slide 26 & Slide 27 & Slide 28 & Slide 29 & Slide 30 & Slide 31 & Slide 32 & Slide 33 & Slide 34 & Slide 35 & \multirow{2}{*}{$\begin{array}{c}\text { Minimum } \\
\text { number o } \\
\text { cells }\end{array}$} \\
\hline & & MAGEA4 & Ост2 & MAGEA4 & FGFR3 & Ki67 & MAGEA4 & SSX & SAGE1 & Ост2 & MAGEA4 & \\
\hline \multirow{3}{*}{ 1-1_C37 } & \multirow{3}{*}{ Centre } & \multirow[t]{3}{*}{0} & \multirow[t]{3}{*}{0} & 1 & $0^{*}$ & \multirow[t]{2}{*}{0} & 1 & \multirow[t]{2}{*}{0} & 1 & \multirow[t]{3}{*}{0} & \multirow[t]{3}{*}{0} & \multirow{3}{*}{55} \\
\hline & & & & 9 cells & 2 cells & & 13 cells & & 3 cells & & & \\
\hline & & & & \multicolumn{6}{|c|}{$30 \mu \mathrm{m}$} & & & \\
\hline
\end{tabular}

B

26. MAGEA4

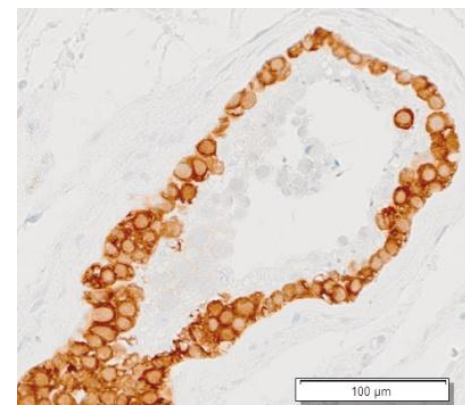

31. MAGEA4

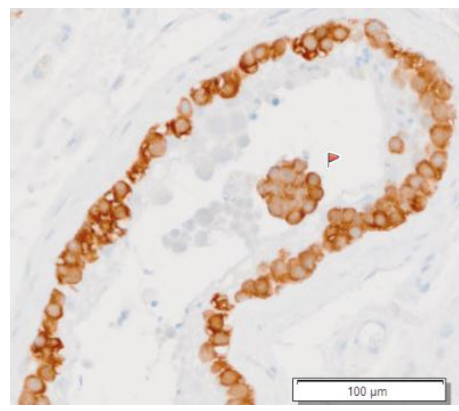

27. OCT2

32. SSX
28. MAGEA4

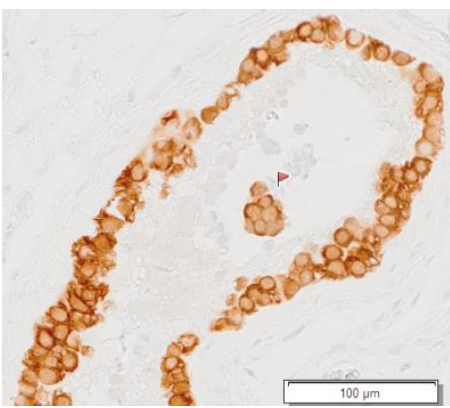

33. SAGE1
29. FGFR3

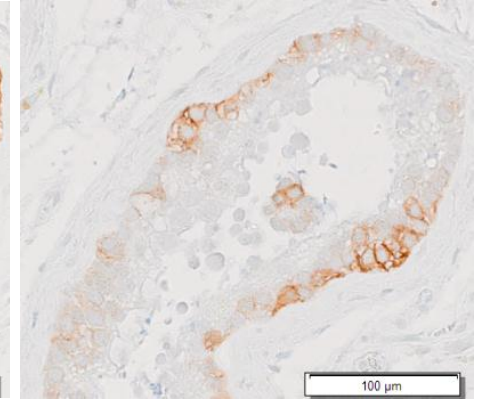

34. OCT2
30. Ki67

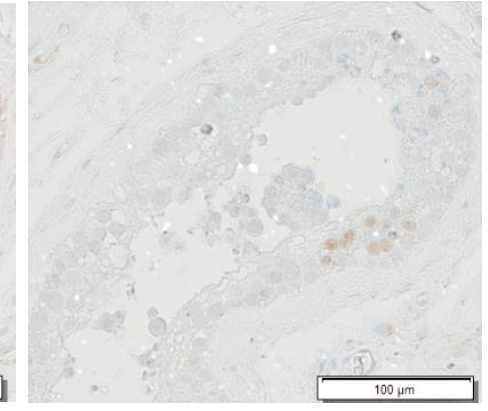

35. MAGEA4

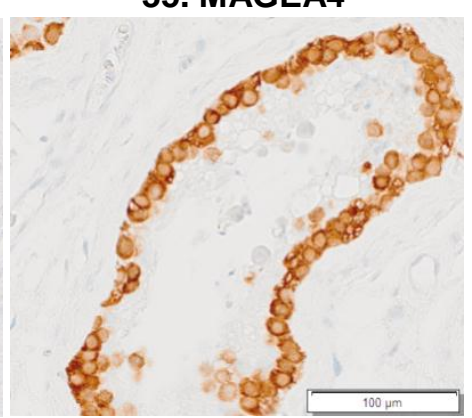




\section{Clone no. 1-1_C38}

A

\begin{tabular}{|c|c|c|c|c|c|c|c|c|c|c|c|c|}
\hline \multirow{2}{*}{ Clone no. } & \multirow{2}{*}{ Location } & Slide 26 & Slide 27 & Slide 28 & Slide 29 & Slide 30 & Slide 31 & Slide 32 & Slide 33 & Slide 34 & Slide 35 & $\begin{array}{c}\text { Minimum } \\
\text { number of } \\
\text { cells }\end{array}$ \\
\cline { 2 - 12 } & MAGEA4 & OCT2 & MAGEA4 & FGFR3 & Ki67 & MAGEA4 & SSX & SAGE1 & OCT2 & MAGEA4 \\
\hline \multirow{2}{*}{ 1-1_C38 } & $\begin{array}{c}\text { Near } \\
\text { Periphery }\end{array}$ & $\begin{array}{c}0^{*} \\
2 \text { cells }\end{array}$ & 0 & $\begin{array}{c}1 \\
6 \text { cells }\end{array}$ & 0 & 0 & 1 & 0 & 0 & 0 & 0 & 28 \\
\hline
\end{tabular}

B
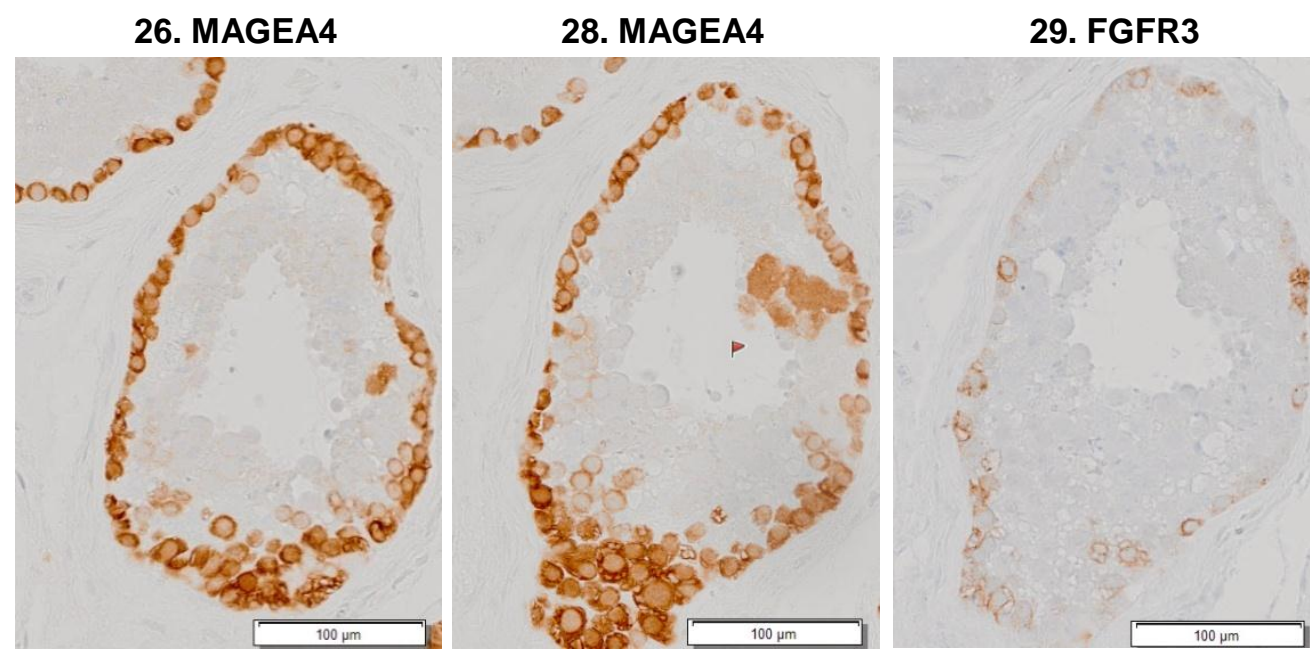

30. Ki67

31. MAGEA4

32. SSX

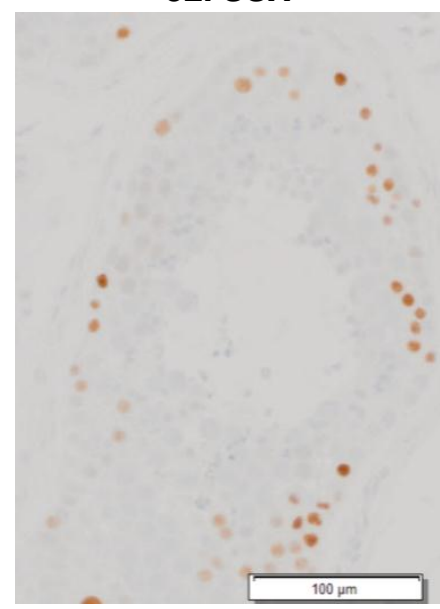

33. SAGE1

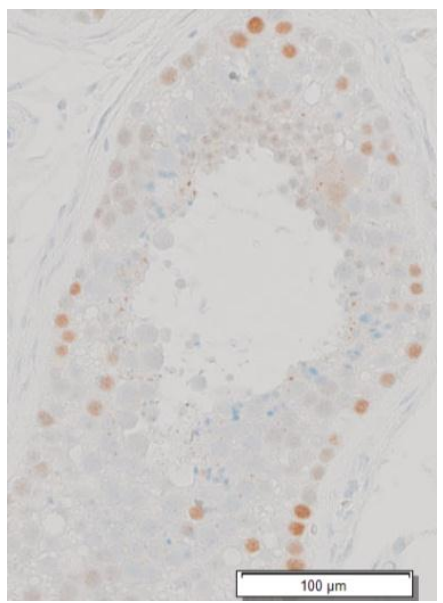

34. ОСT2

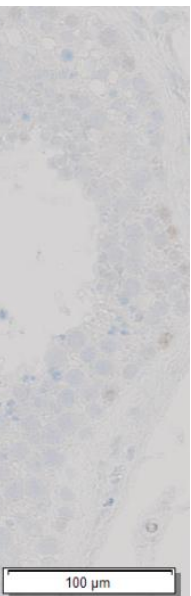

35. MAGEA4

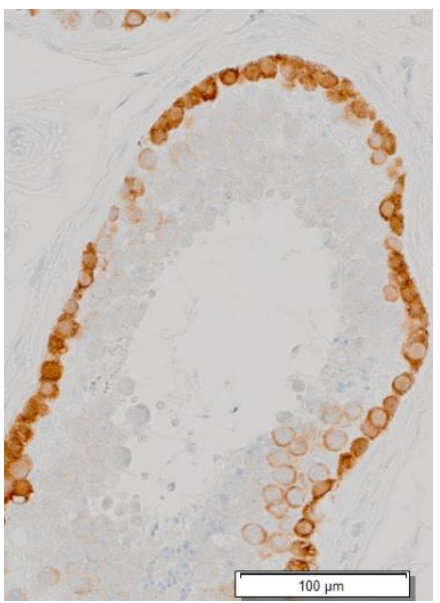


Clone no.1-1_C39

A

\begin{tabular}{|c|c|c|c|c|c|c|c|c|c|c|}
\hline \multirow{2}{*}{$\begin{array}{c}\text { Clone } \\
\text { no. }\end{array}$} & Location & Slide 28 & Slide 29 & Slide 30 & Slide 31 & Slide 32 & Slide 33 & Slide 34 & Slide 35 & $\begin{array}{c}\text { Minimum } \\
\text { number of } \\
\text { cells }\end{array}$ \\
\cline { 2 - 11 } & MAGEA4 & FGFR3 & Ki67 & MAGEA4 & SSX & SAGE1 & OCT2 & MAGEA4 & NA & \\
\hline 1-1_C39 & Periphery & 0 & 0 & 0 & 0 & 1 & 1 & 0 & 35 \\
\hline
\end{tabular}

B

\section{MAGEA4}

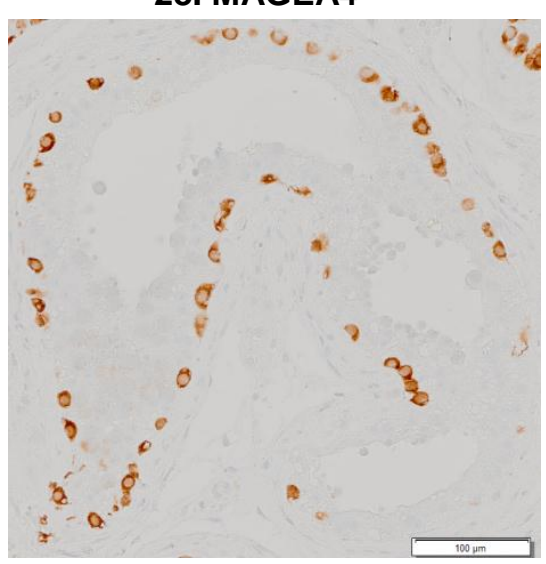

32. SSX
29. FGFR3

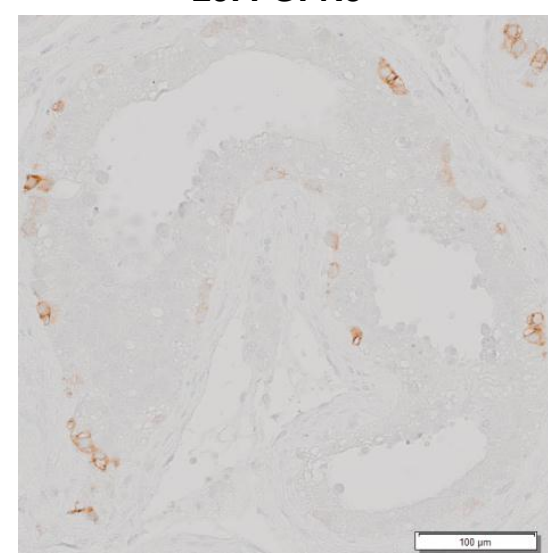

33. SAGE1
30. Ki67

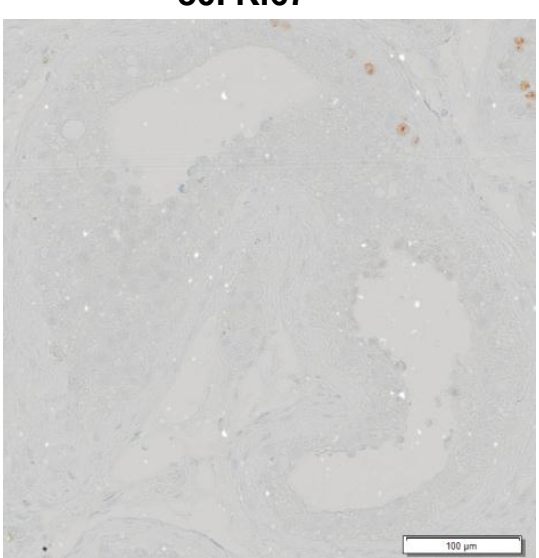

34. ОСТ2

31. MAGEA4

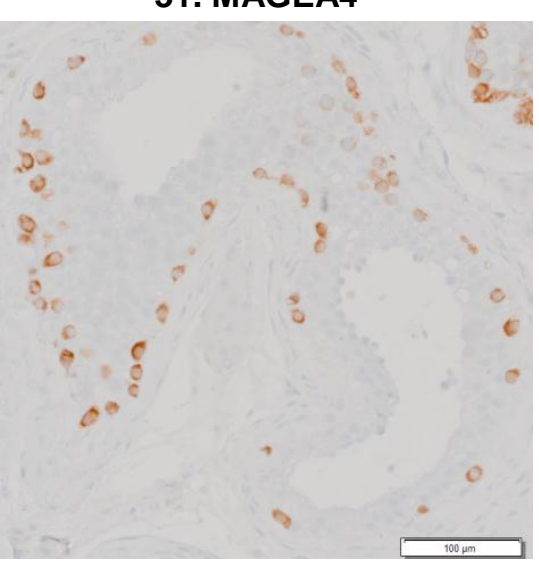

35. MAGEA4

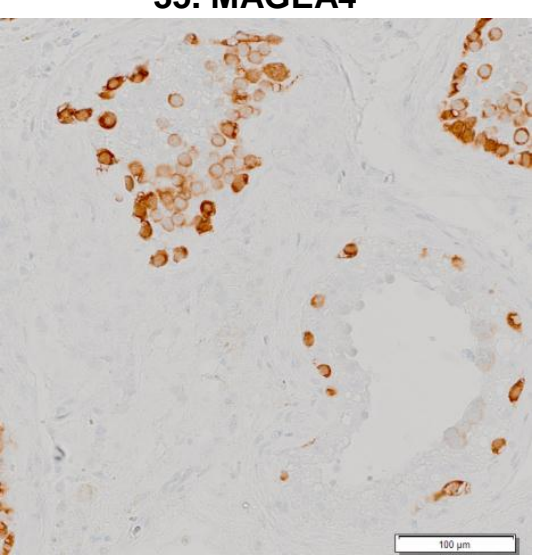




\section{Clone no.1-1_C40}

A

\begin{tabular}{|c|c|c|c|c|c|c|c|c|c|c|c|c|c|c|c|c|}
\hline \multirow{2}{*}{ Clone no. } & \multirow{2}{*}{ Location } & Slide 28 & Slide 29 & Slide 30 & Slide 31 & Slide 32 & Slide 33 & Slide 34 & Slide 35 & $\begin{array}{c}\text { Sldie } \\
36\end{array}$ & SIdie 37 & SIdie 38 & SIdie 39 & SIdie 40 & Slide 41 & \multirow{2}{*}{$\begin{array}{l}\text { Minimum } \\
\text { number of } \\
\text { cells }\end{array}$} \\
\hline & & MAGEA4 & FGFR3 & Ki67 & MAGEA4 & SSX & SAGE1 & ОСТ2 & MAGEA4 & n.s & n.s & n.s & n.s & n.s & MAGEA4 & \\
\hline \multirow{3}{*}{ 1-1_C40 } & \multirow{3}{*}{ Periphery } & 0 & $0^{*}$ & 0 & $0^{*}$ & 1 & 1 & 0 & 1 & & & & & & 0 & \multirow{3}{*}{124} \\
\hline & & & 14 cells & & 15 cells & 38 cells & 20 cells & & 23 cells & & & & & & & \\
\hline & & & & & & $35 \mu \mathrm{m}$ & & & & & & & & & & \\
\hline
\end{tabular}

B

28. MAGEA4

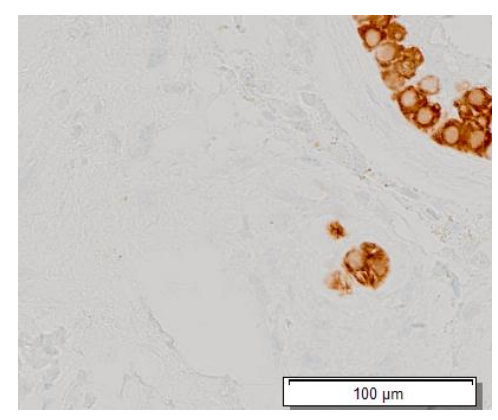

31. MAGEA4

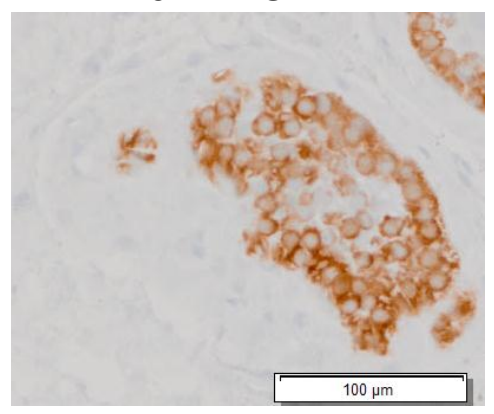

34. ОСT2

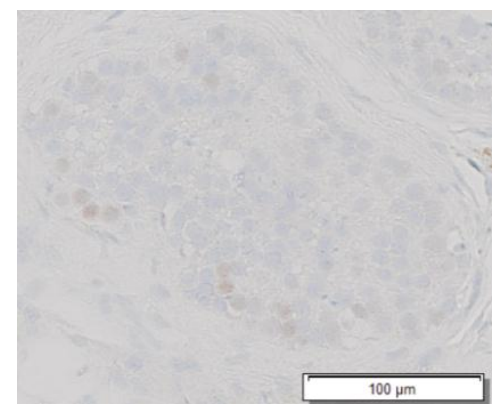

29. FGFR3

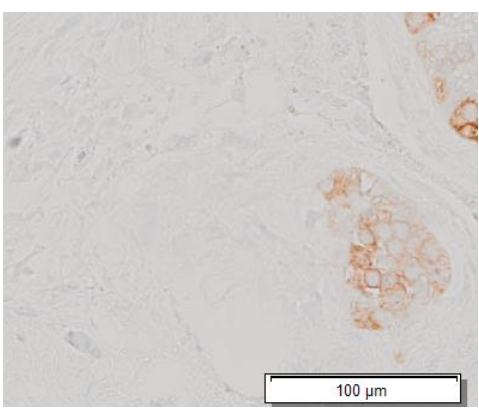

32. SSX

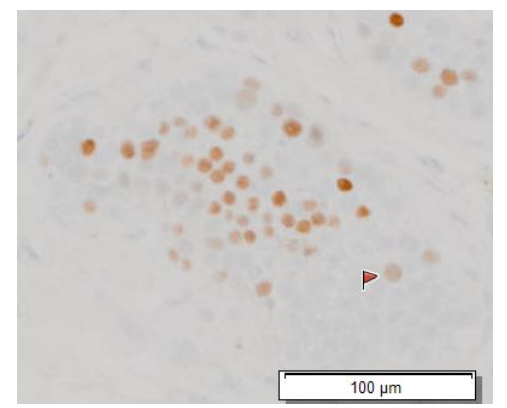

35. MAGEA4

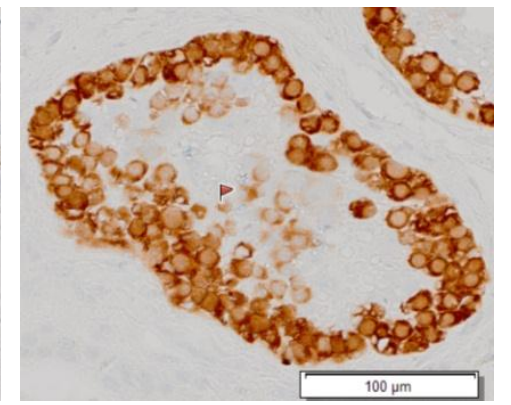

30. Ki67

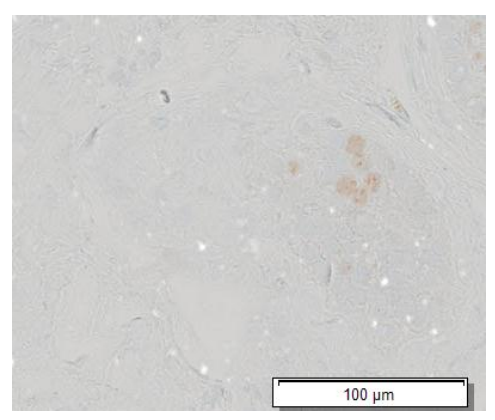

33. SAGE1

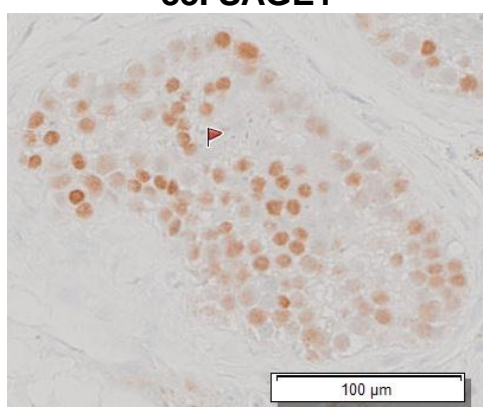

41 MAGEA4

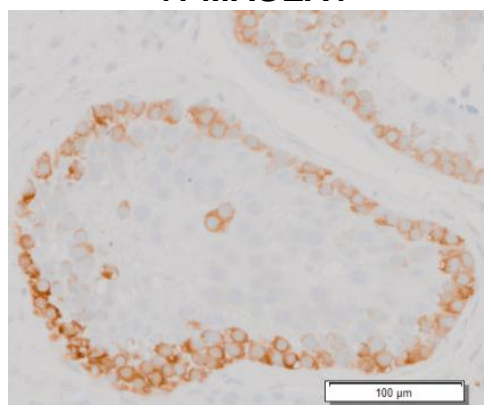


Clone no. 1-1_C41

A

\begin{tabular}{|c|c|c|c|c|c|c|c|c|}
\hline \multirow{2}{*}{ Clone no. } & \multirow{2}{*}{ Location } & Slide 29 & Slide 30 & Slide 31 & Slide 32 & Slide 33 & Slide 34 & $\begin{array}{c}\text { Minimum } \\
\text { number of cells }\end{array}$ \\
\cline { 3 - 9 } & & FGFR3 & Ki67 & MAGEA4 & SSX & SAGE1 & OCT2 & 1-1_C41 \\
\cline { 3 - 8 } & Centre & 0 & 0 & 0 & $\begin{array}{c}1 \\
10 \text { cells }\end{array}$ & 14 cells & & 24 \\
\hline
\end{tabular}

B

29. FGFR3

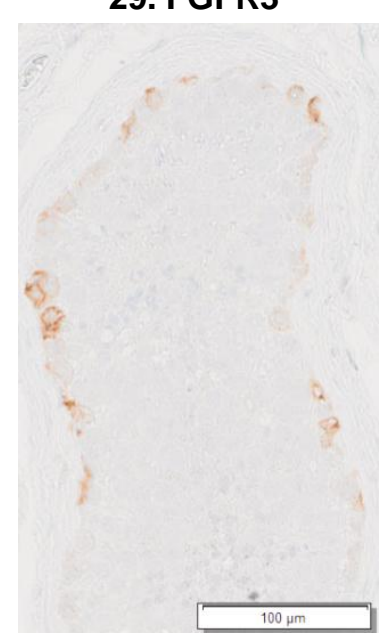

30. Ki67

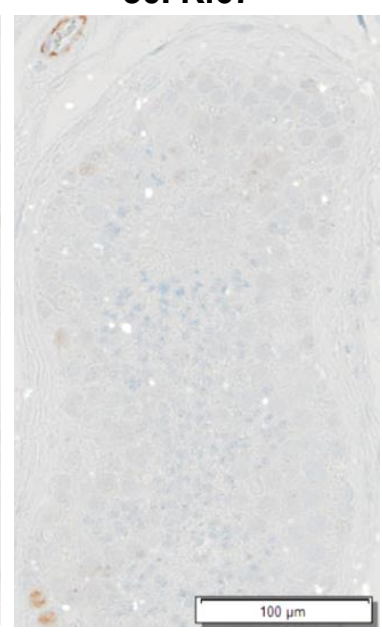

31. MAGEA4

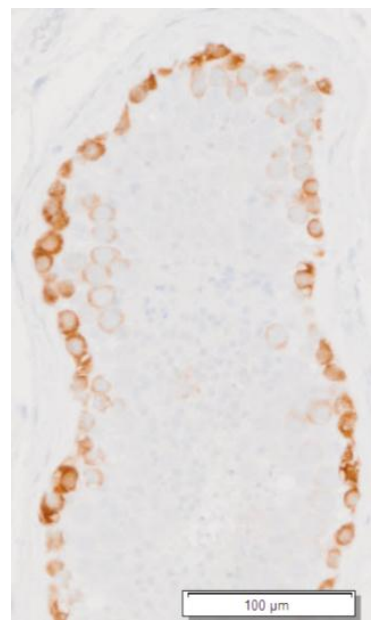

32. SSX

33. SAGE1

34. OCT2 


\section{Clone no.1-1_C42}

A

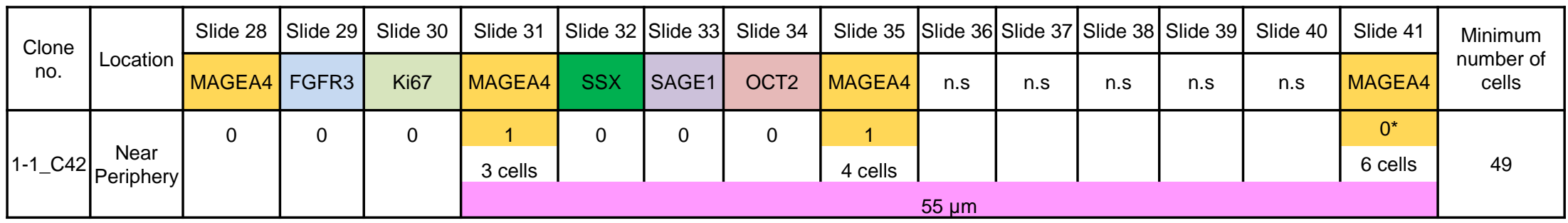

B

28. MAGEA4

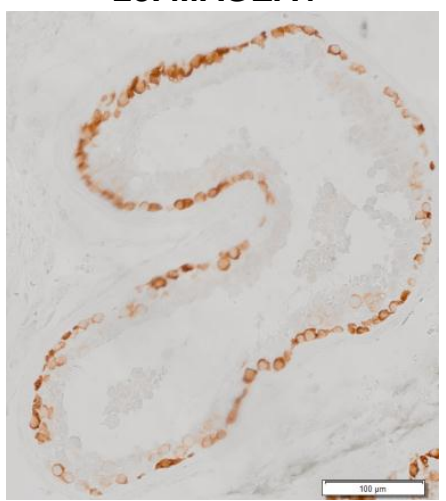

33. SAGE1

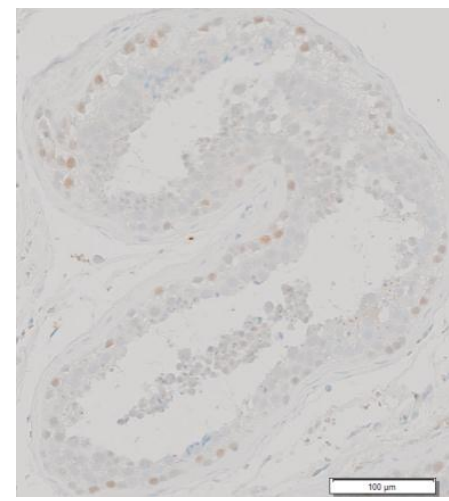

29. FGFR3

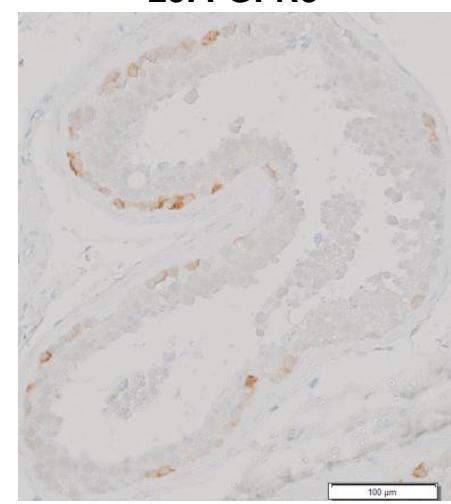

34. OCT2

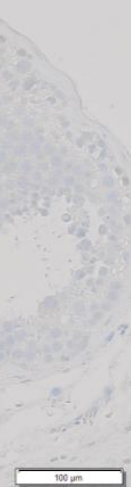

30. Ki67

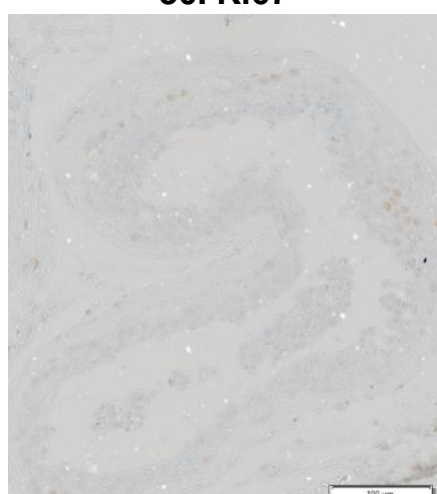

35. MAGEA4

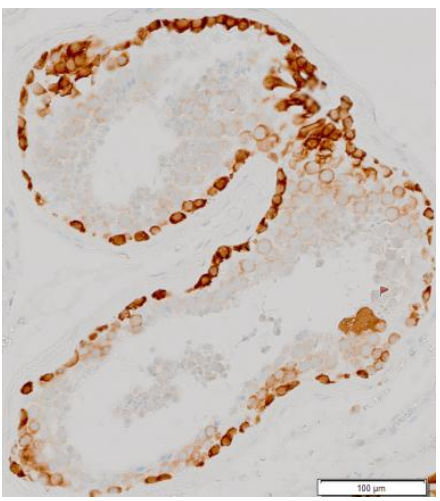

31. MAGEA4

32. SSX

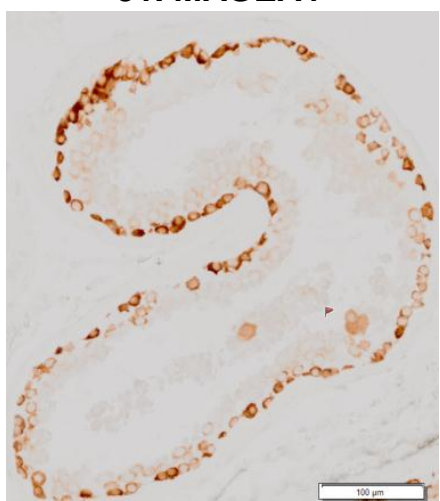

\section{MAGEA4}

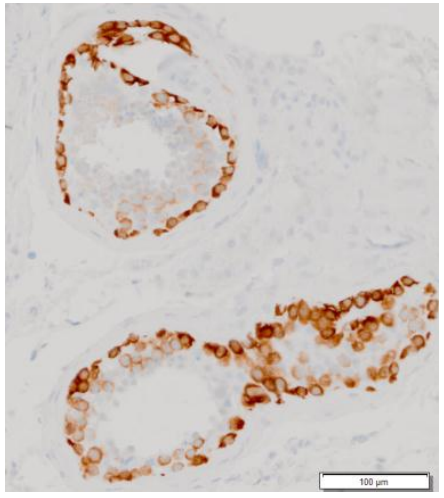




\section{Clone no.1-1_C43}

A

\begin{tabular}{|c|c|c|c|c|c|c|c|c|c|c|c|c|c|}
\hline \multirow{2}{*}{ Clone no. } & \multirow{2}{*}{ Location } & Slide 31 & Slide 32 & Slide 33 & Slide 34 & Slide 35 & Slide 36 & Slide 37 & Slide 38 & Slide 39 & Slide 40 & Slide 41 & $\begin{array}{c}\text { Minimum } \\
\text { number of } \\
\text { cells }\end{array}$ \\
\hline & MAGEA4 & SSX & SAGE1 & OCT2 & MAGEA4 & n.s & n.s & n.s & n.s & n.s & MAGEA4 & \\
\hline 1-1_C43 & $\begin{array}{c}\text { Near } \\
\text { Periphery }\end{array}$ & 0 & 0 & 0 & 0 & 1 & & & & & 1 & 5 cells \\
\end{tabular}

31. MAGEA4

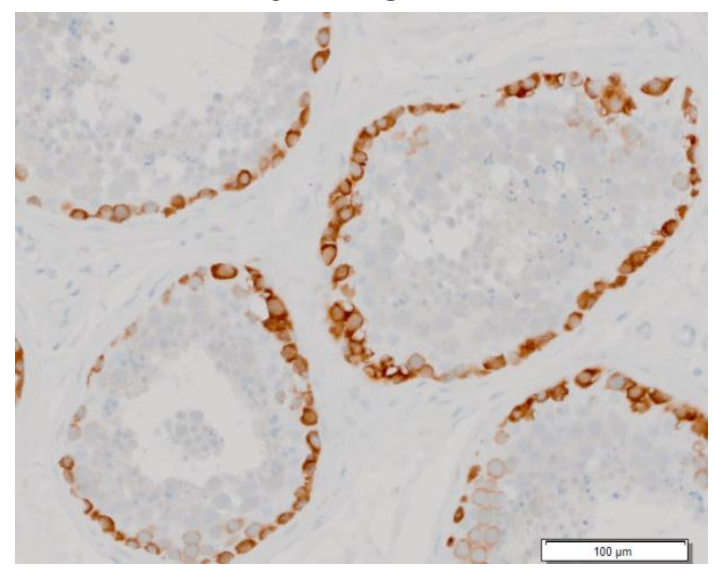

34. OCT2

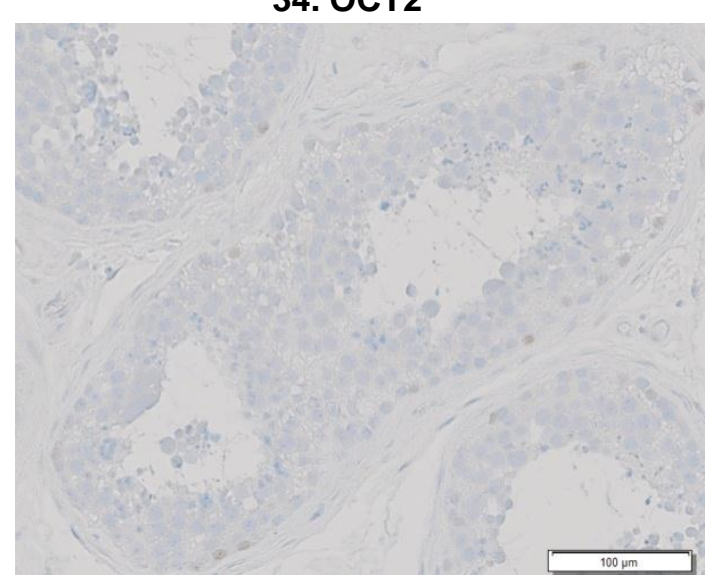

32. SSX

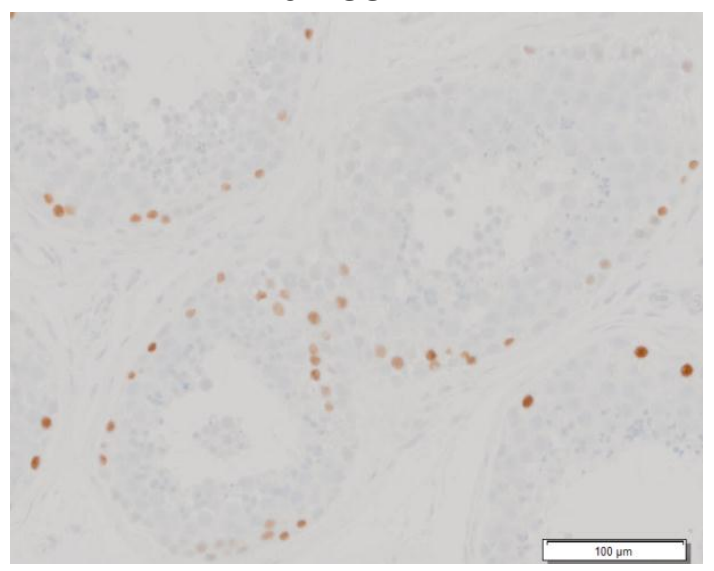

35. MAGEA4

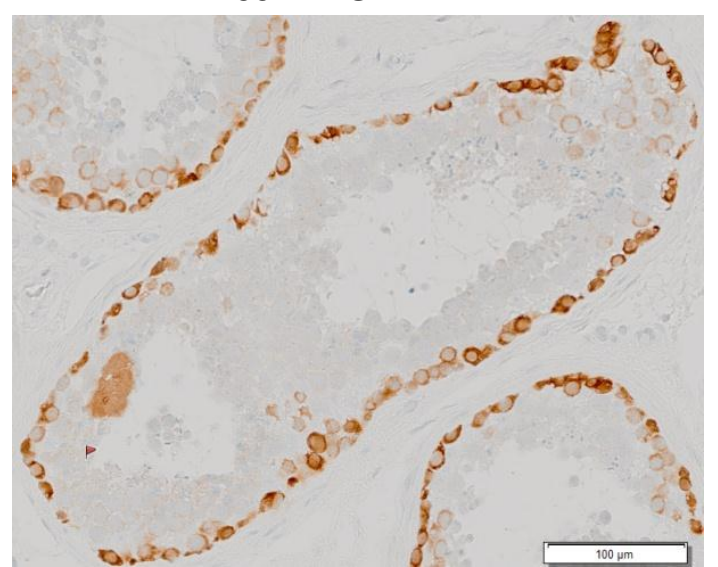

33. SAGE1

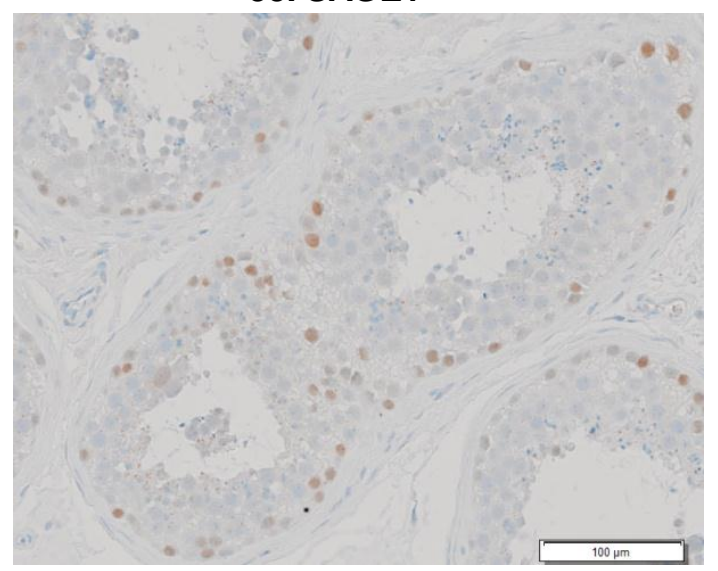

41. MAGEA4

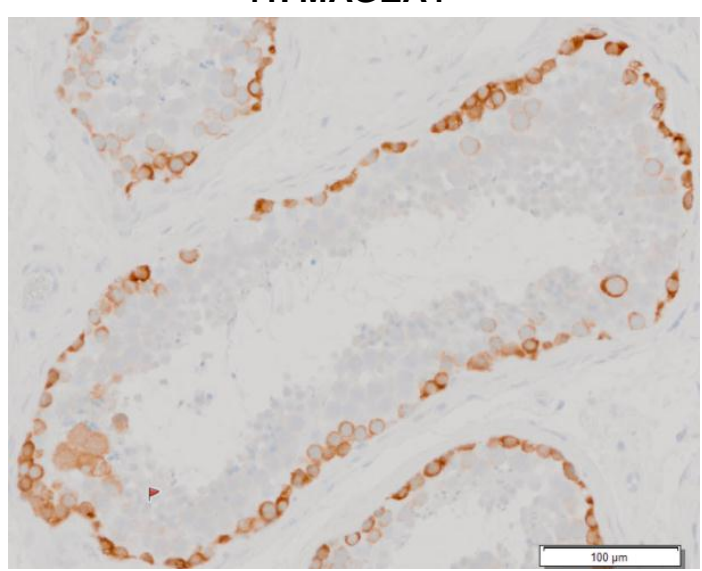




\section{Clone no. 1-1_C44}

A

\begin{tabular}{|c|c|c|c|c|c|c|c|c|c|c|c|c|c|c|c|c|c|c|c|c|c|}
\hline \multirow{2}{*}{$\begin{array}{c}\text { Clone } \\
\text { no. }\end{array}$} & \multirow{2}{*}{ Location } & Slide 23 & $\begin{array}{c}\text { Slide } \\
24\end{array}$ & Slide 25 & Slide 26 & Slide 27 & Slide 28 & Slide 29 & Slide 30 & Slide 31 & Slide 32 & \begin{tabular}{|c|} 
Slide \\
33 \\
\end{tabular} & Slide 34 & Slide 35 & $\begin{array}{c}\text { Slide } \\
36 \\
\end{array}$ & $\begin{array}{c}\text { Slide } \\
37\end{array}$ & $\begin{array}{c}\text { Slide } \\
38 \\
\end{array}$ & Slide 39 & SIdie 40 & Slide 41 & \multirow{2}{*}{$\begin{array}{c}\text { Minimum } \\
\text { number of } \\
\text { cells }\end{array}$} \\
\hline & & MAGEA4 & Ki67 & $\mathrm{H} \& \mathrm{E}$ & MAGEA4 & Ост2 & MAGEA4 & FGFR3 & Ki67 & MAGEA4 & SSX & SAGE1 & Ост2 & MAGEA4 & n.s & n.s & n.s & n.s & n.s & MAGEA4 & \\
\hline \multirow{3}{*}{ 1-1_C44 } & \multirow{3}{*}{$\begin{array}{c}\text { Near } \\
\text { Periphery }\end{array}$} & NA & & & $0^{*}$ & 0 & $0^{*}$ & 0 & 0 & 1 & 0 & 0 & 0 & 1 & & & & & & 1 & \multirow{3}{*}{187} \\
\hline & & & & & 2 cells & & 3 cells & & & 10 cells & & & & 21 cells & & & & & & 10 cells & \\
\hline & & & & & \multicolumn{16}{|c|}{$80 \mu \mathrm{m}$} & \\
\hline
\end{tabular}

B

26. MAGEA4

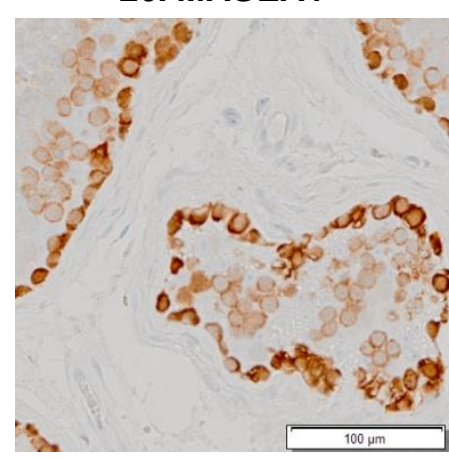

32. SSX

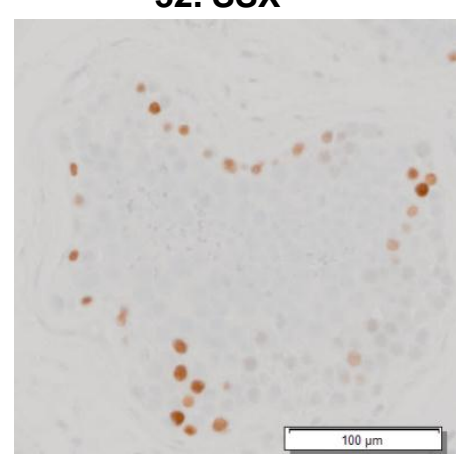

28. MAGEA4

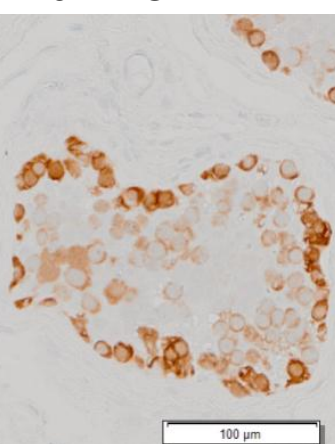

33. SAGE1

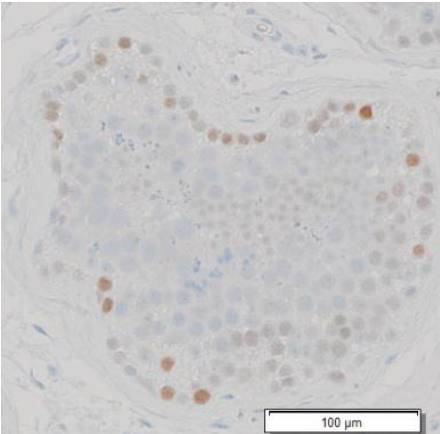

29. FGFR3

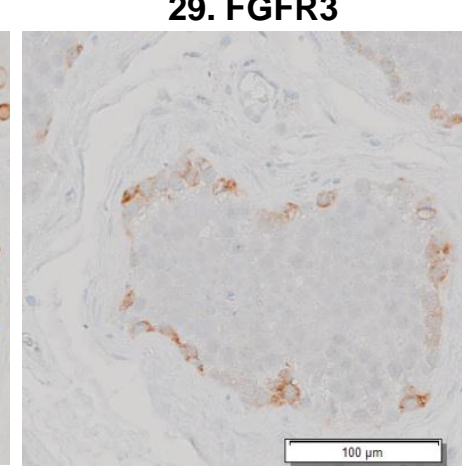

34. OCT2

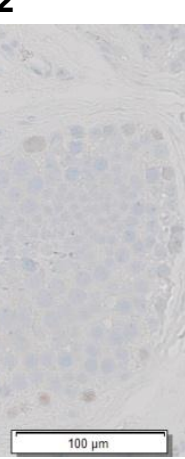

30. Ki67

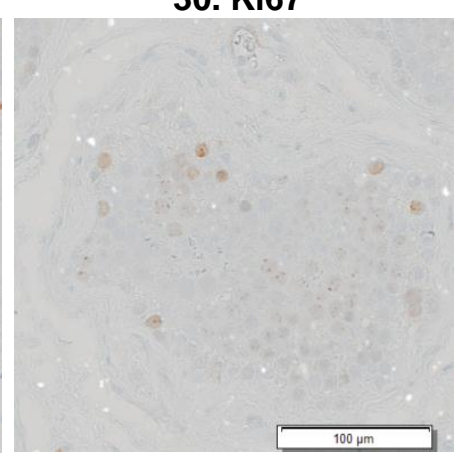

35. MAGEA4

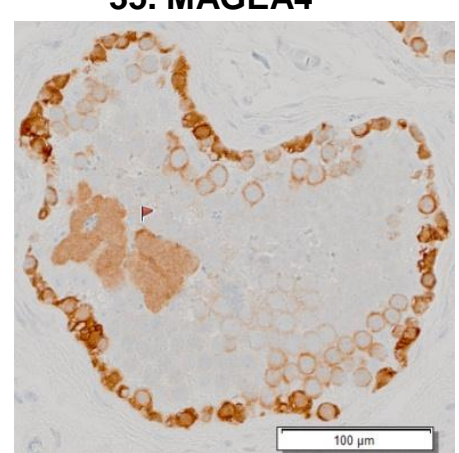

31. MAGEA4

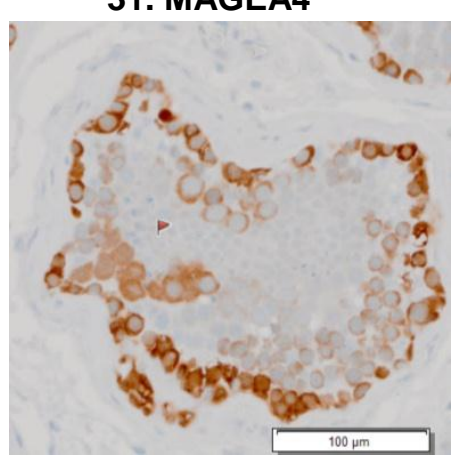

41. MAGEA4

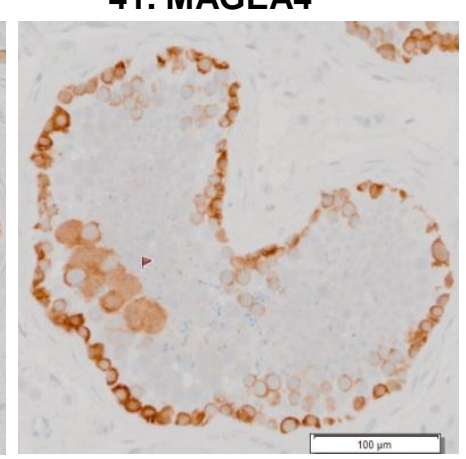




\section{Clone no.1-1_C45}

A

\begin{tabular}{|c|c|c|c|c|c|c|c|c|c|c|c|c|c|}
\hline \multirow{2}{*}{ Clone no. } & \multirow{2}{*}{ Location } & Slide 31 & Slide 32 & Slide 33 & Slide 34 & Slide 35 & Slide 36 & Slide 37 & Slide 38 & Slide 39 & Slide 40 & Slide 41 & \multirow{2}{*}{$\begin{array}{c}\text { Minimum } \\
\text { number o } \\
\text { cells }\end{array}$} \\
\hline & & MAGEA4 & SSX & SAGE1 & OCT2 & MAGEA4 & n.s & n.s & n.s & n.s & n.s & MAGEA4 & \\
\hline \multirow{3}{*}{ 1-1_C45 } & \multirow{3}{*}{ Centre } & \multirow[t]{3}{*}{0} & \multirow[t]{3}{*}{0} & 1 & \multirow[t]{2}{*}{0} & 1 & & & & & & 1 & \multirow{3}{*}{72} \\
\hline & & & & 4 cells & & 12 cells & & & & & & 5 cells & \\
\hline & & & & \multicolumn{9}{|c|}{$45 \mu \mathrm{m}$} & \\
\hline
\end{tabular}

B
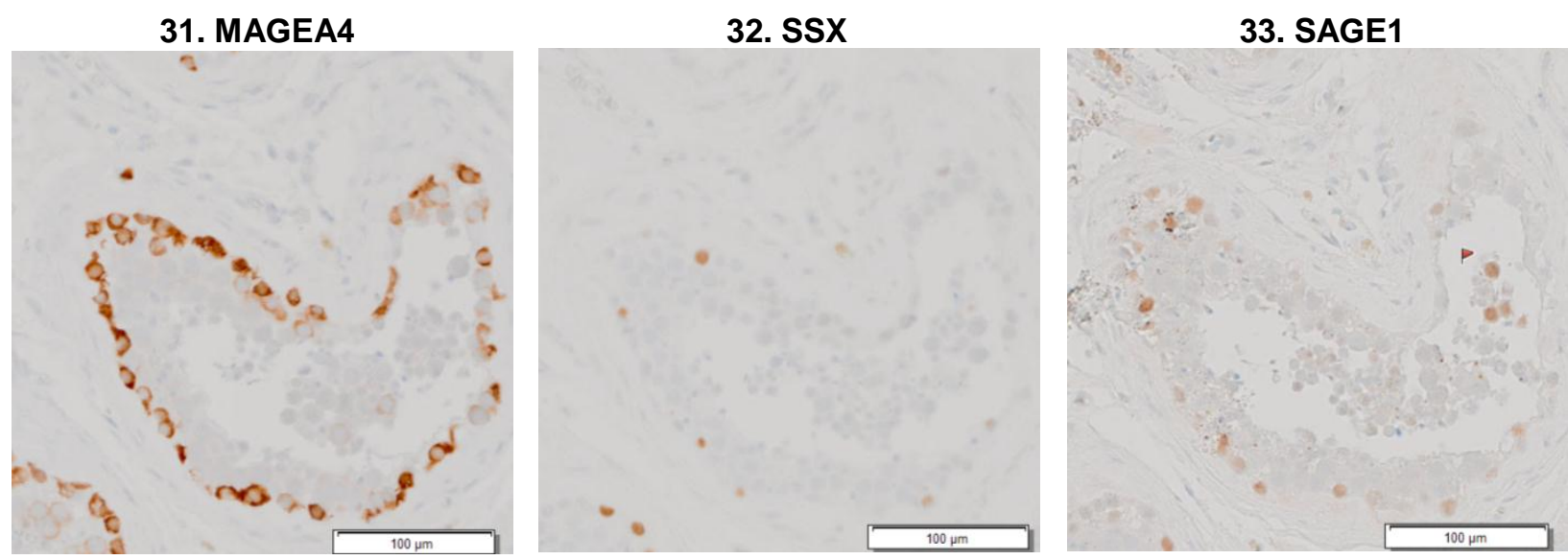

34. OCT2

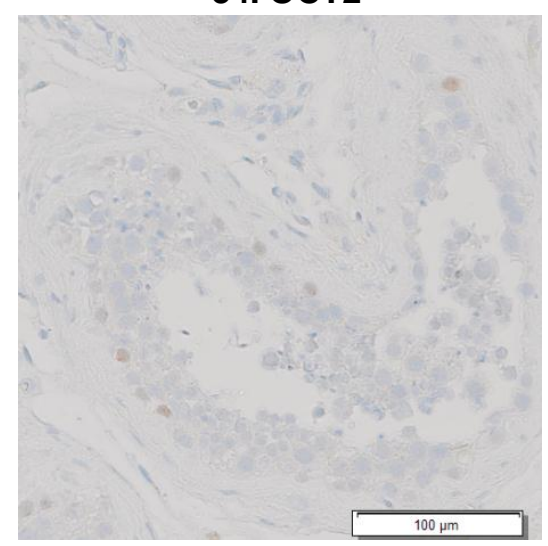

35. MAGEA4

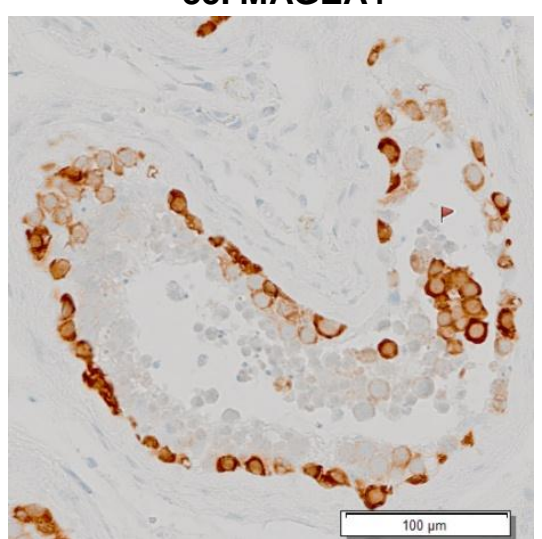

41. MAGEA4

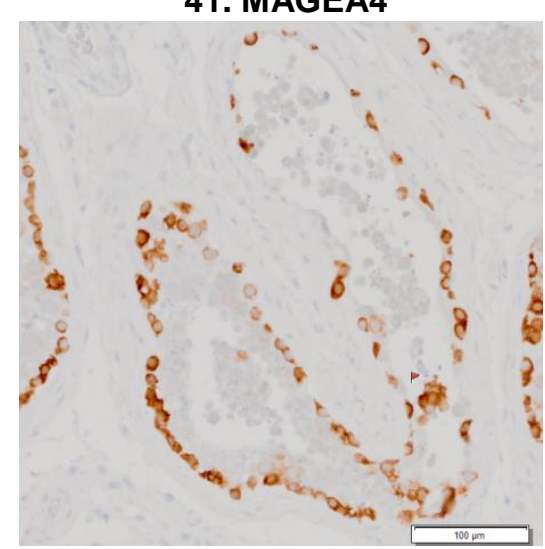


Clone no. 1-2_C1

A

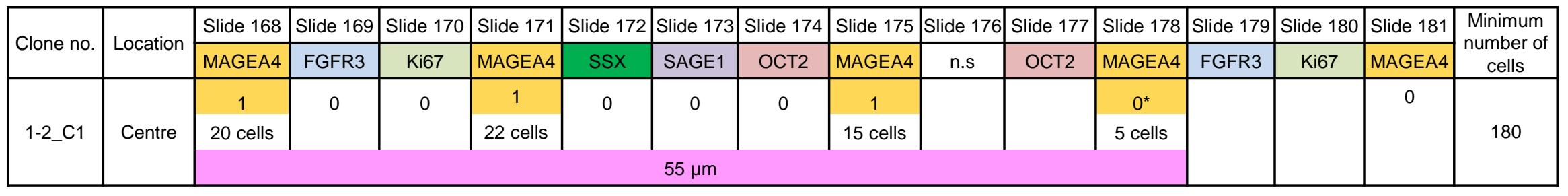

B

168. MAGEA4

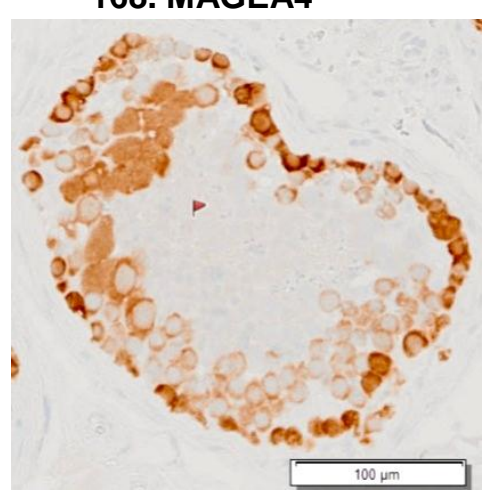

173. SAGE1
169. FGFR3

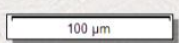

174. OCT2
170. Ki67

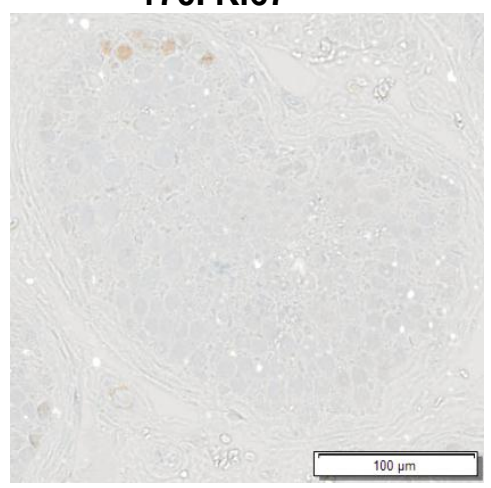

175. MAGEA4

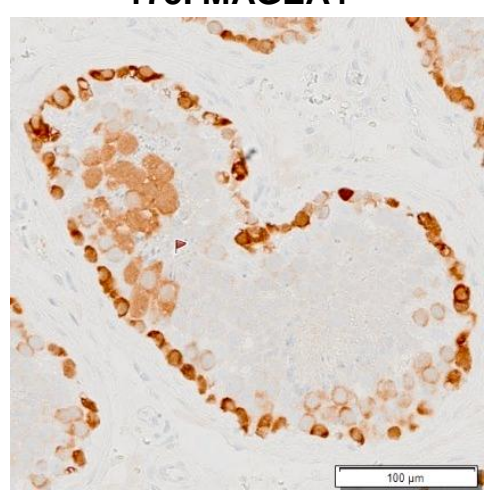

171. MAGEA4

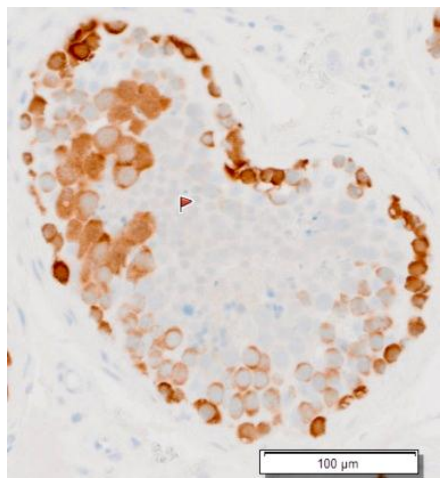

178. MAGEA4
172. SSX

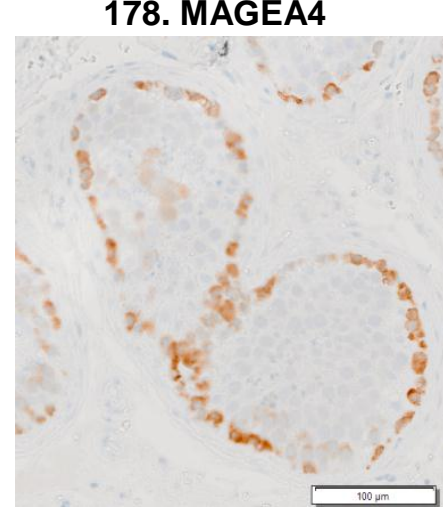

181. MAGEA4

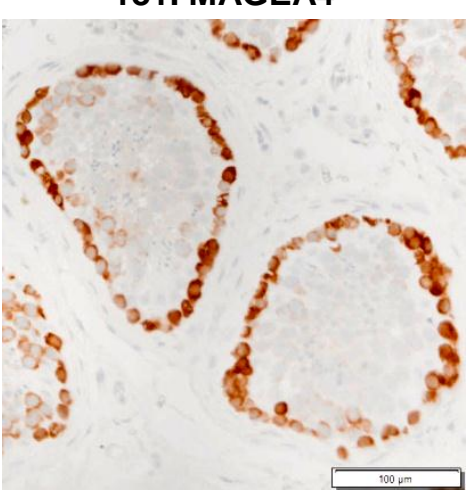




\section{Clone no. 1-2_C2}

A

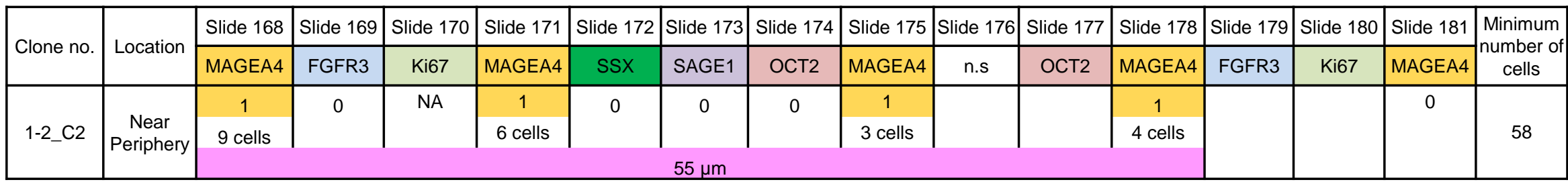

B

168. MAGEA4

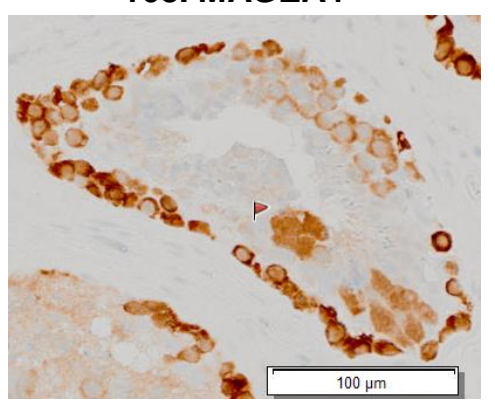

173. SAGE1

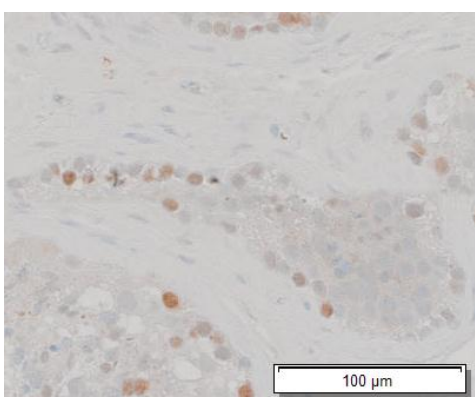

169. FGFR3

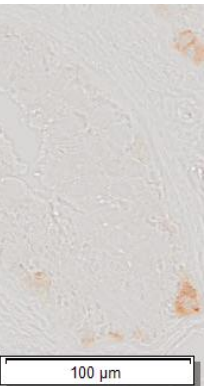

174. ОСТ2
171. MAGEA4

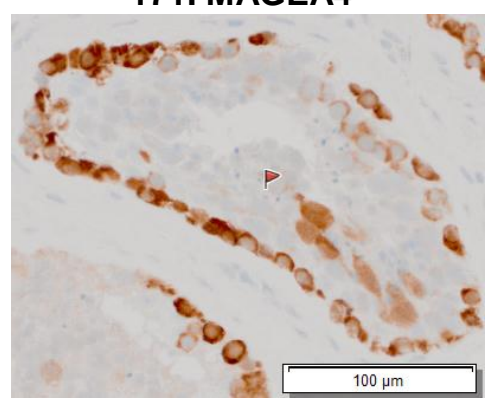

175. MAGEA4

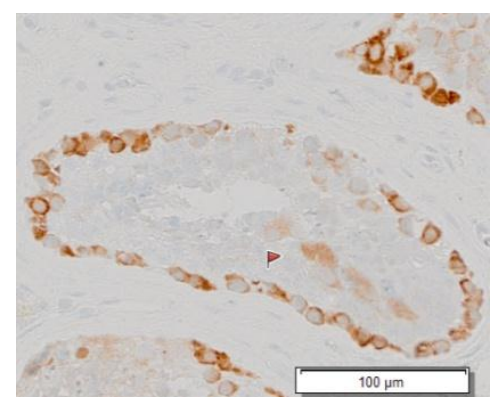

172. SSX

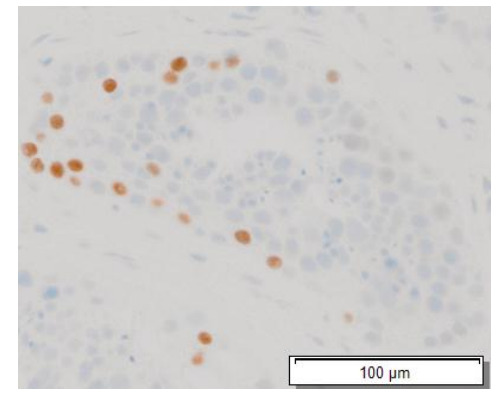

178. MAGEA4

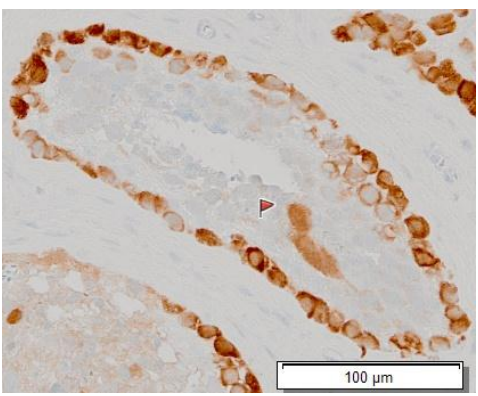




\section{Clone no. 1-2_C3}

A

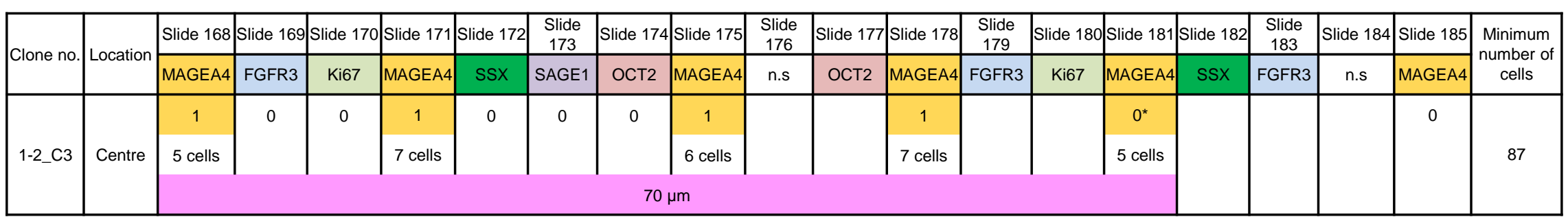

B

168. MAGEA4

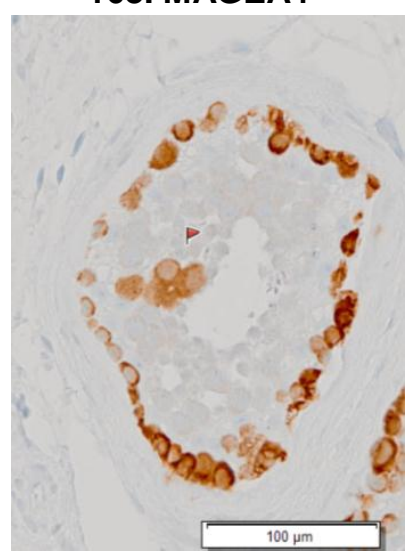

173. SAGE1
169. FGFR3

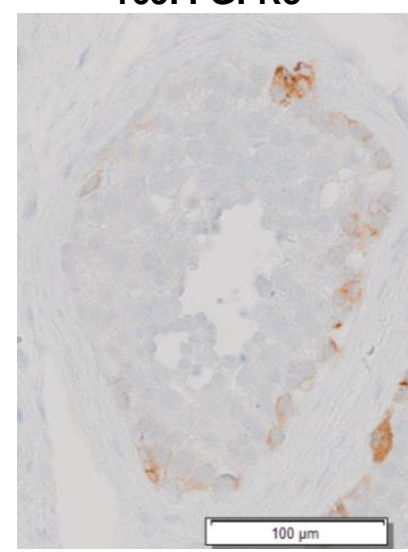

174. ОСТ2
170. Ki67

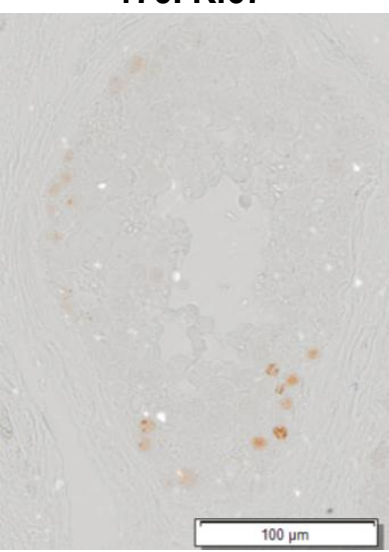

175. MAGEA4

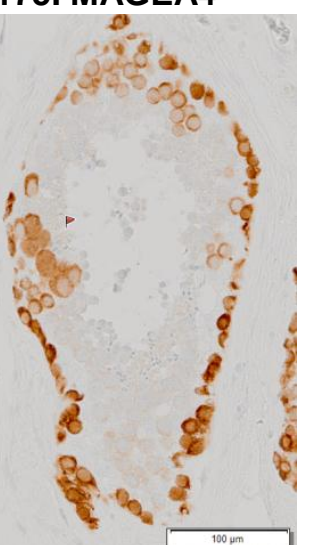

171. MAGEA4

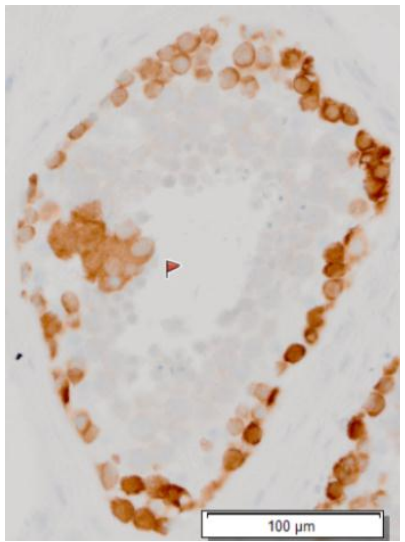

178. MAGEA4

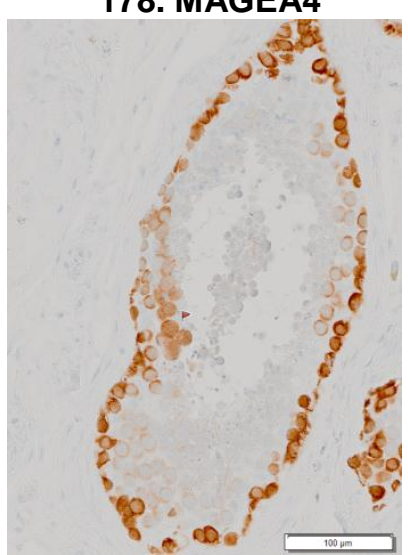

172. SSX

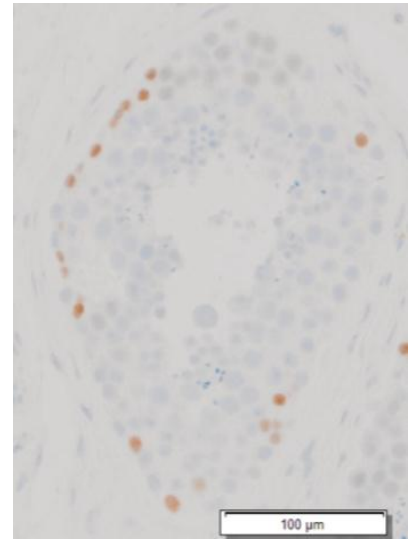

181. MAGEA4

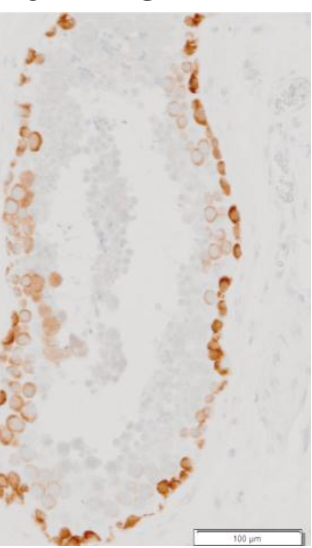




\section{Clone no. 1-2_C4}

A

\begin{tabular}{|c|c|c|c|c|c|c|c|c|c|c|c|c|c|}
\hline \multirow{2}{*}{ Clone no. } & \multirow{2}{*}{ Location } & Slide 168 & Slide 169 & Slide 170 & Slide 171 & Slide 172 & Slide 173 & Slide 174 & Slide 175 & Slide 176 & Slide 177 & Slide 178 & \multirow{2}{*}{$\begin{array}{l}\text { Minimum } \\
\text { number of } \\
\text { cells }\end{array}$} \\
\hline & & MAGEA4 & FGFR3 & Ki67 & MAGEA4 & SSX & SAGE1 & Ост2 & MAGEA4 & n.s & ост2 & MAGEA4 & \\
\hline \multirow{2}{*}{ 1-2_C4 } & \multirow{2}{*}{ Periphery } & 1 & 0 & 0 & 1 & 0 & 0 & 0 & 1 & & & \multirow[t]{2}{*}{0} & \multirow{2}{*}{50} \\
\hline & & \multicolumn{8}{|c|}{$40 \mu \mathrm{m}$} & & & & \\
\hline
\end{tabular}

B
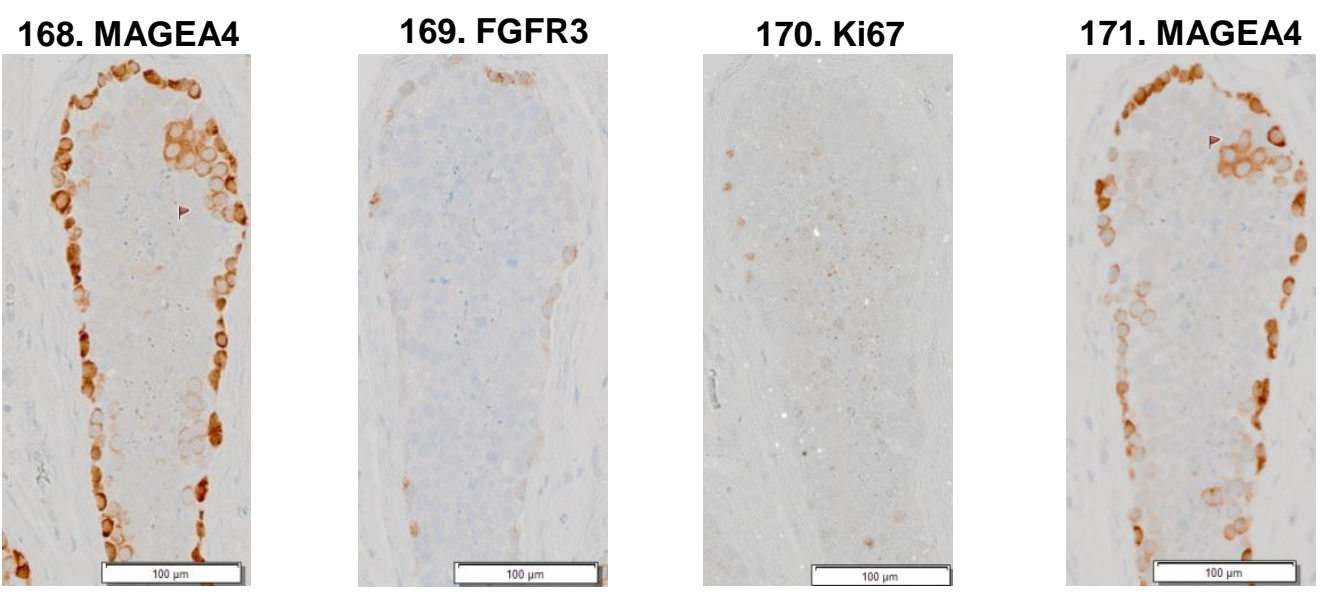

172. SSX
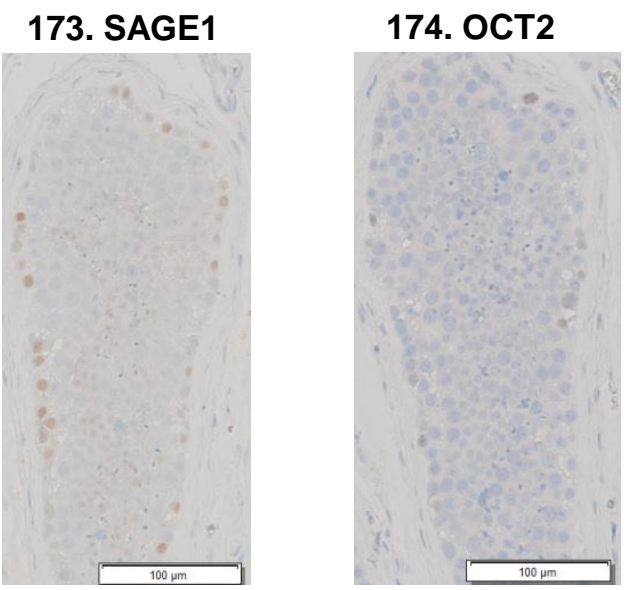

175. MAGEA4

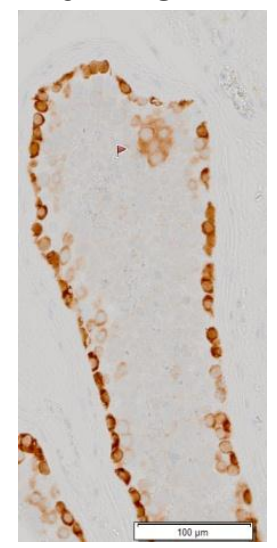

178. MAGEA4

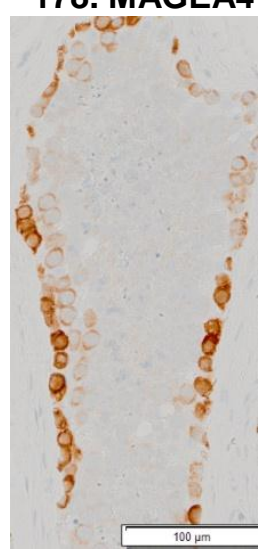


Clone no. 1-2_C5

A

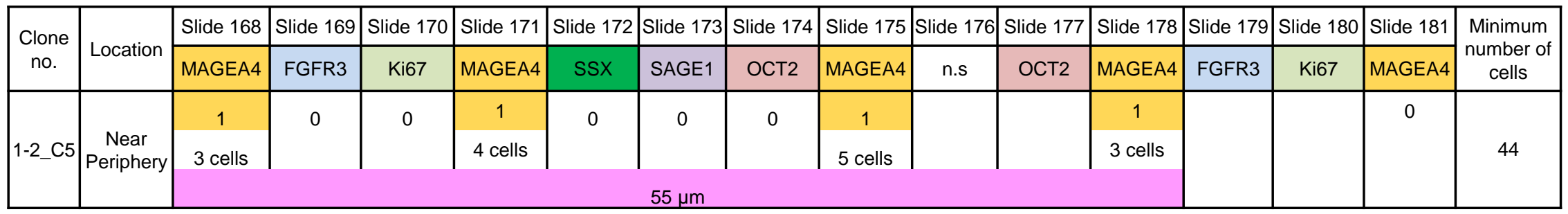

B

168. MAGEA4

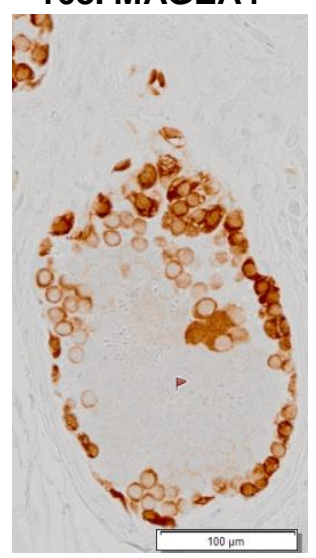

173. SAGE1

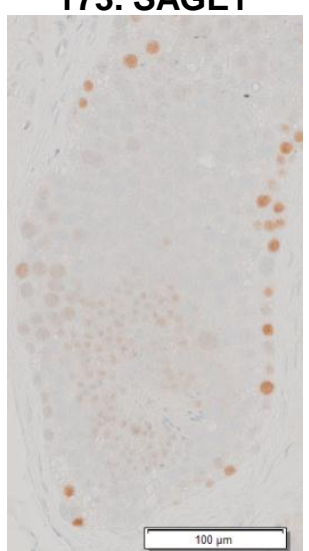

169. FGFR3

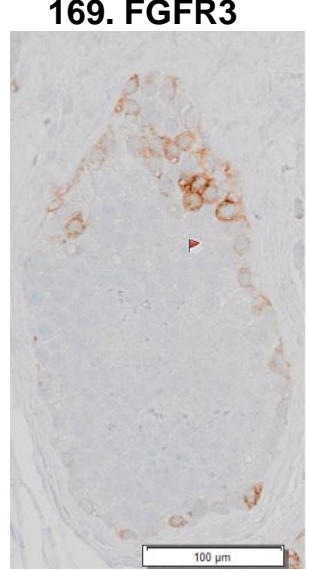

174. ОСТ2

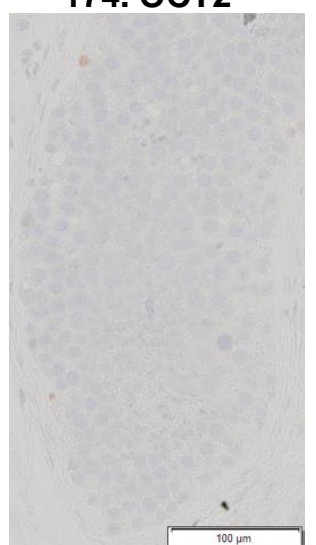

170. Ki67

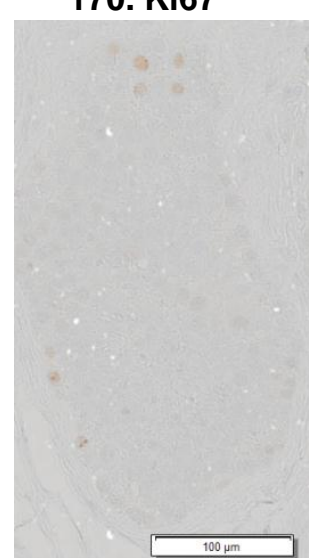

175. MAGEA4

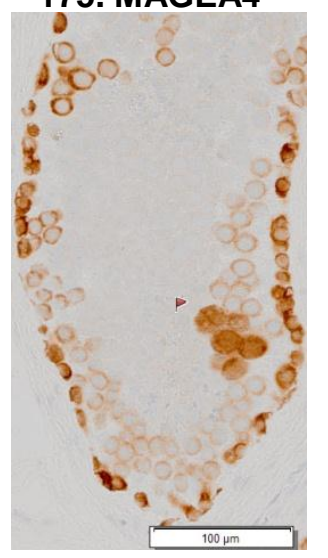

171. MAGEA4

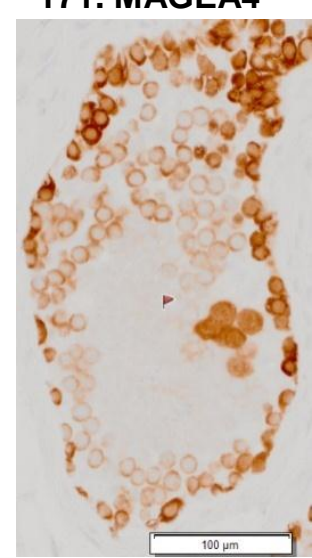

178. MAGEA4

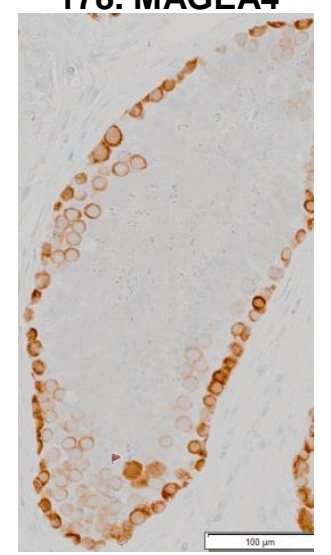

172. SSX

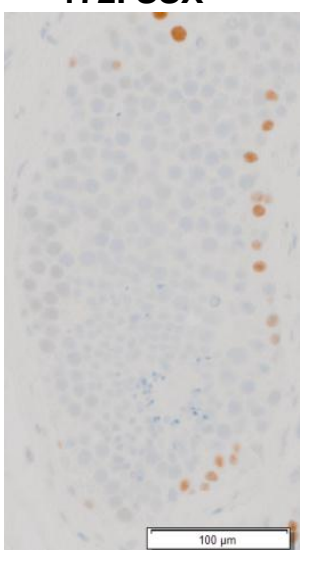

181. MAGEA4

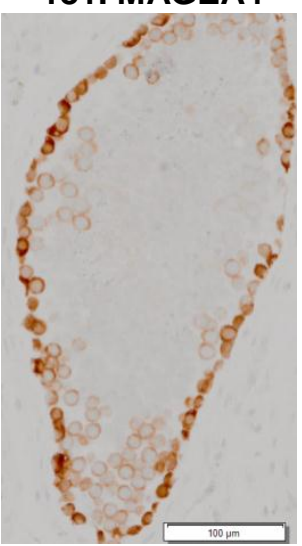




\section{Clone no. 1-2_C6}

A

\begin{tabular}{|c|c|c|c|c|c|c|c|c|c|c|c|c|c|c|c|c|}
\hline \multirow{2}{*}{ Clone no. } & \multirow{2}{*}{ Location } & Slide 168 & Slide 169 & Slide 170 & Slide 171 & Slide 172 & Slide 173 & Slide 174 & Slide 175 & Slide 176 & Slide 177 & Slide 178 & Slide 179 & Slide 180 & Slide 181 & \multirow{2}{*}{$\begin{array}{l}\text { Minimum } \\
\text { number of } \\
\text { cells }\end{array}$} \\
\hline & & MAGEA4 & FGFR3 & Ki67 & MAGEA4 & SSX & SAGE1 & OCT2 & MAGEA4 & n.s & OCT2 & MAGEA4 & FGFR3 & Ki67 & MAGEA4 & \\
\hline \multirow{3}{*}{ 1-2_C6 } & \multirow{3}{*}{$\begin{array}{l}\text { Near } \\
\text { Periphery }\end{array}$} & $0^{*}$ & \multirow[t]{2}{*}{0} & \multirow[t]{2}{*}{0} & 1 & \multirow[t]{2}{*}{0} & \multirow[t]{2}{*}{0} & \multirow[t]{2}{*}{0} & 1 & & & 1 & & & 0 & \multirow{3}{*}{65} \\
\hline & & 1 cell & & & 8 cells & & & & 7 cells & & & 5 cells & & & & \\
\hline & & & & & & & $55 \mu \mathrm{m}$ & & & & & & & & & \\
\hline
\end{tabular}

B

168. MAGEA4

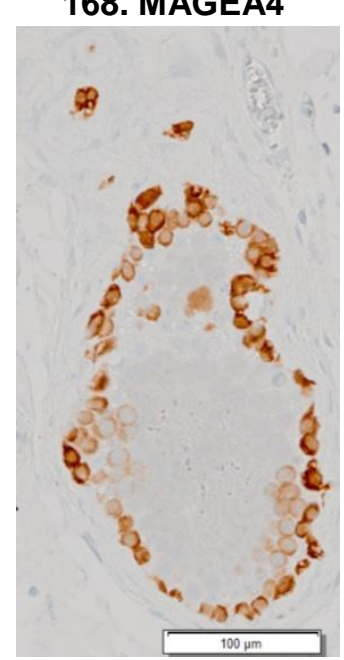

173. SAGE1

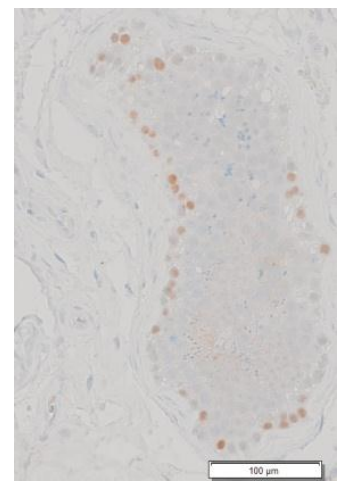

169. FGFR3

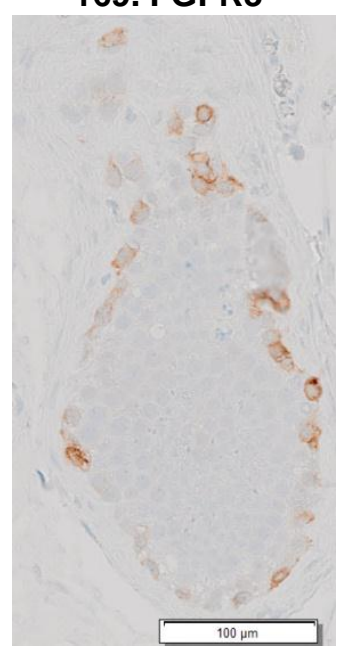

174. ОСТ2

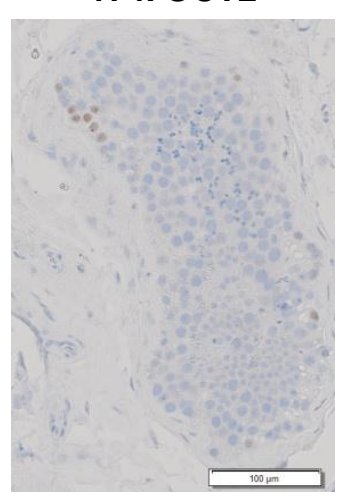

170. Ki67

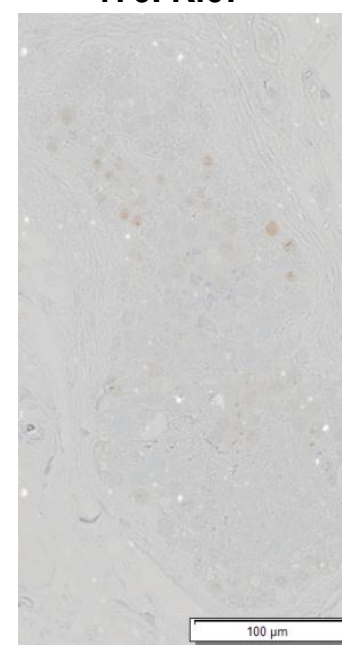

175. MAGEA4

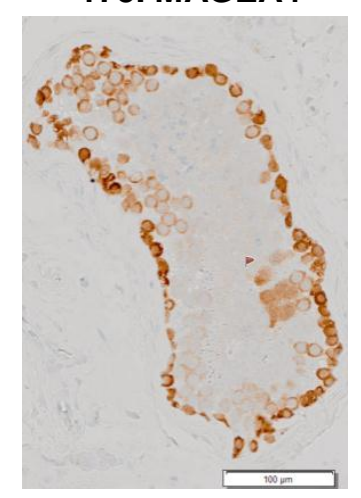

171. MAGEA4

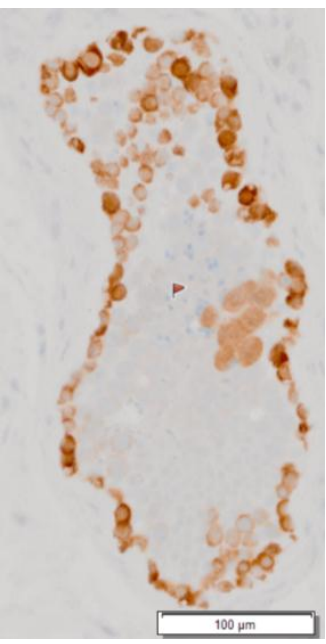

178. MAGEA4

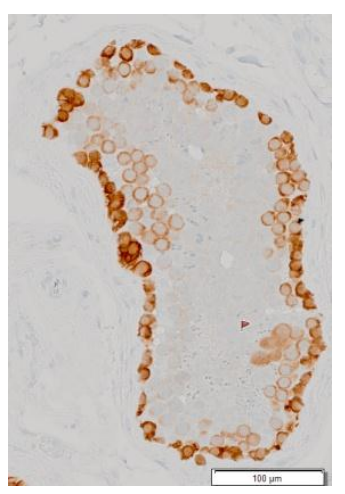

172. SSX

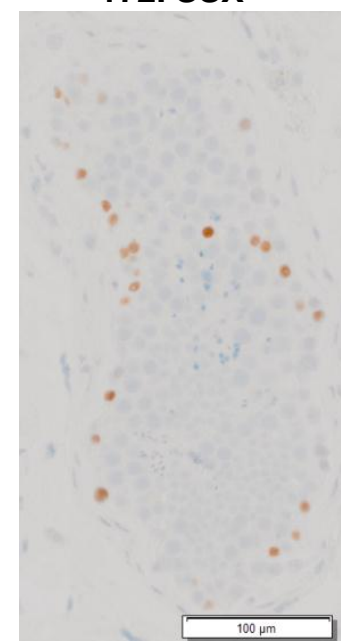

181. MAGEA4

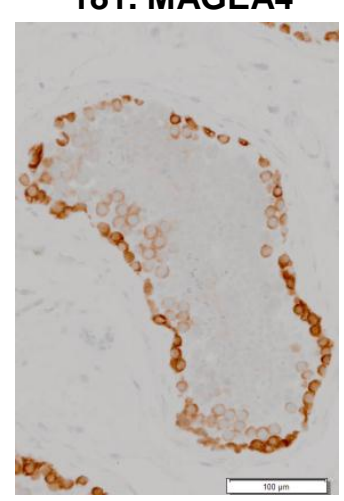




\section{Clone no. 1-2_C7}

A

\begin{tabular}{|c|c|c|c|c|c|c|c|c|c|c|c|c|c|c|c|c|}
\hline \multirow{2}{*}{$\begin{array}{c}\text { Clone } \\
\text { no. }\end{array}$} & \multirow{2}{*}{ Location } & Slide 168 & Slide 169 & Slide 170 & Slide 171 & Slide 172 & Slide 173 & Slide 174 & Slide 175 & Slide 176 & Slide 177 & Slide 178 & Slide 179 & Slide 180 & Slide 181 & \multirow{2}{*}{$\begin{array}{l}\text { Minimum } \\
\text { number of } \\
\text { cells }\end{array}$} \\
\hline & & MAGEA4 & FGFR3 & Ki67 & MAGEA4 & SSX & SAGE1 & ост2 & MAGEA4 & n.s & Ост2 & MAGEA4 & FGFR3 & Ki67 & MAGEA4 & \\
\hline \multirow{3}{*}{ 1-2_C7 } & \multirow{3}{*}{$\begin{array}{l}\text { Near } \\
\text { Periphery }\end{array}$} & 1 & \multirow[t]{2}{*}{0} & \multirow[t]{2}{*}{0} & 1 & \multirow[t]{2}{*}{0} & \multirow[t]{2}{*}{0} & \multirow[t]{2}{*}{0} & 1 & & & 1 & & & 1 & \multirow{3}{*}{152} \\
\hline & & 13 cells & & & 10 cells & & & & 19 cells & & & 6 cells & & & 3 cells & \\
\hline & & \multicolumn{14}{|c|}{$70 \mu \mathrm{m}$} & \\
\hline
\end{tabular}

B

168. MAGEA4

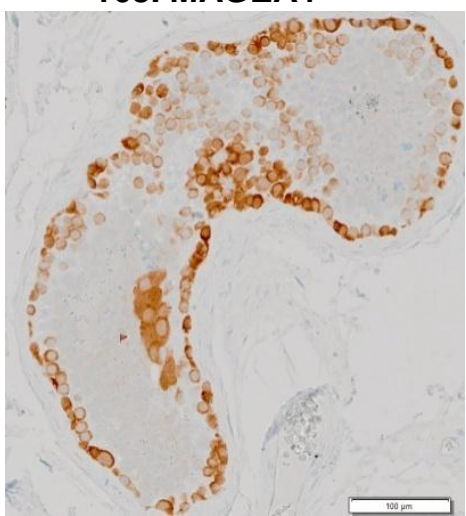

173. SAGE1
169. FGFR3

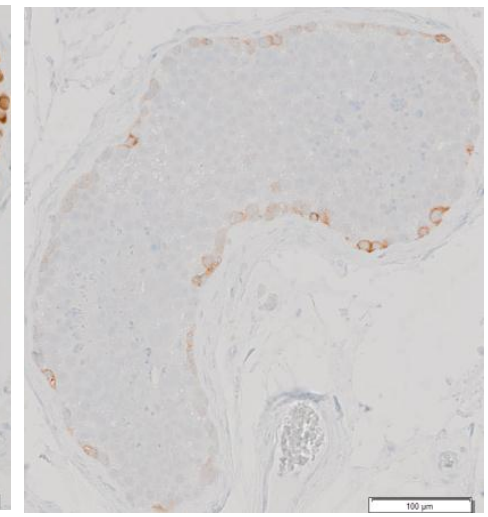

174. OCT2
170. Ki67

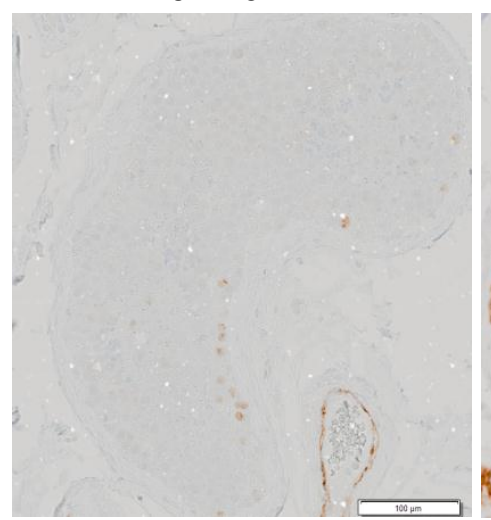

175. MAGEA4

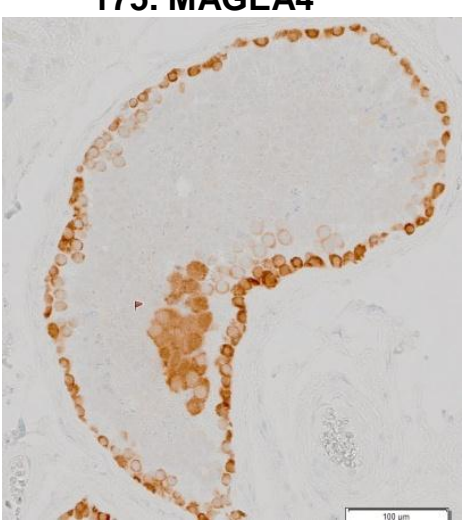

171. MAGEA4

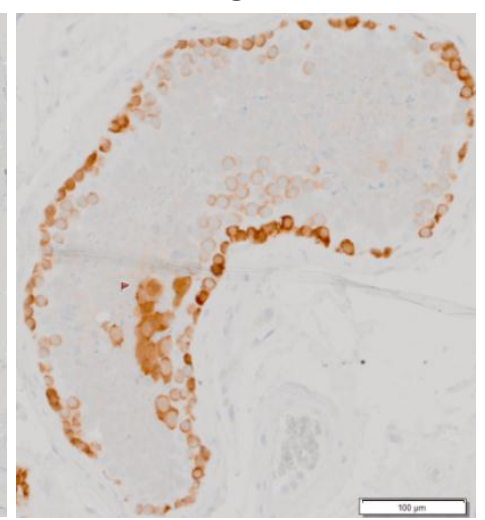

178. MAGEA4

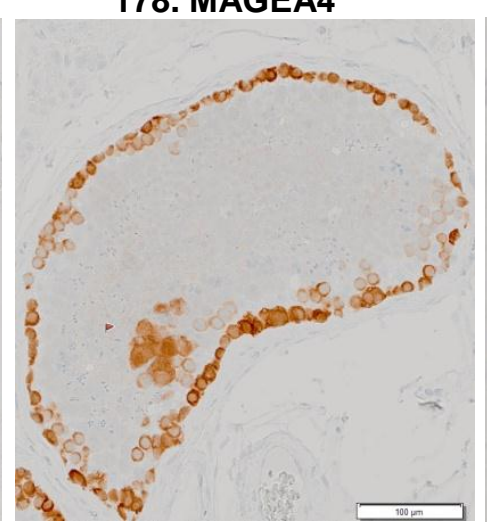

172. SSX
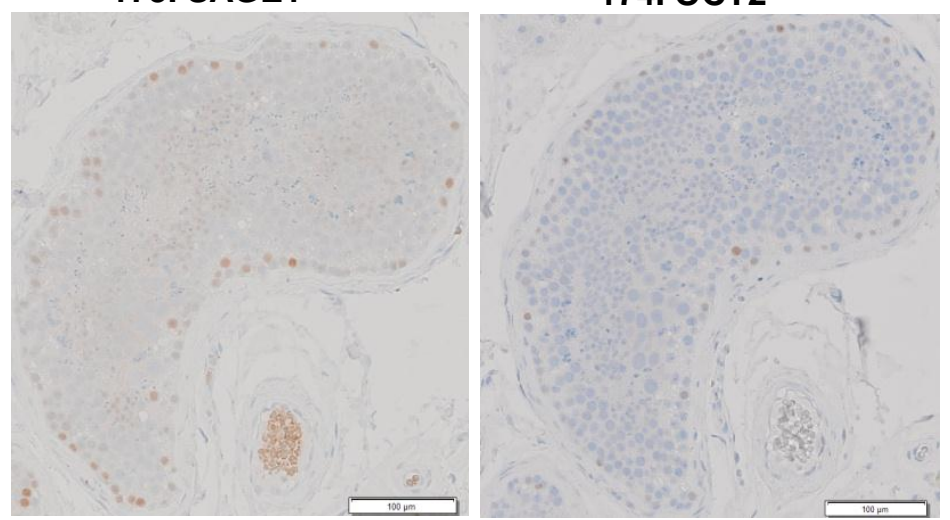

181. MAGEA4

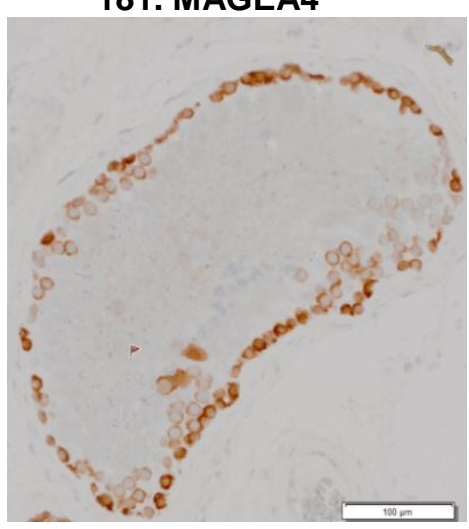




\section{Clone no. 1-2_C8}

A

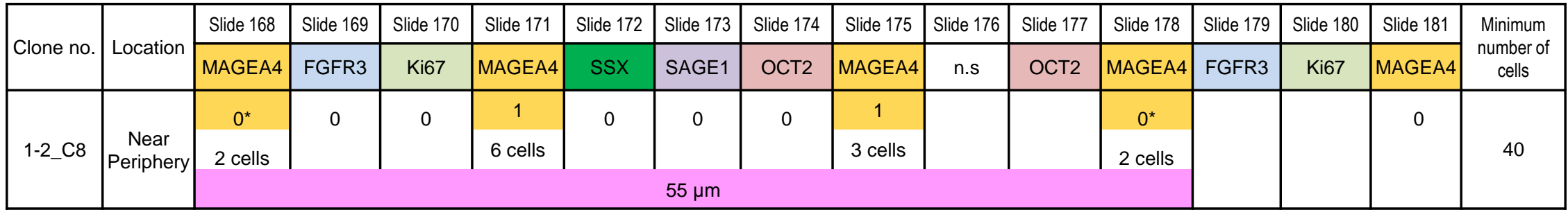

B

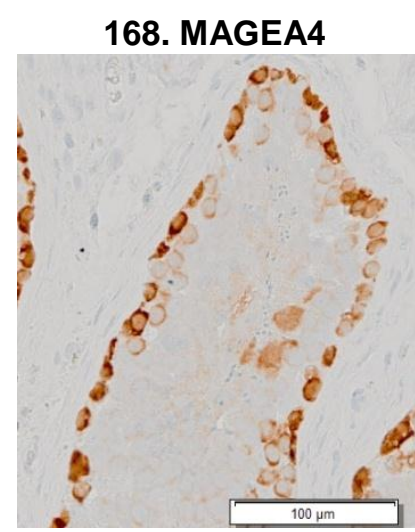

173. SAGE1

\section{OCT2}

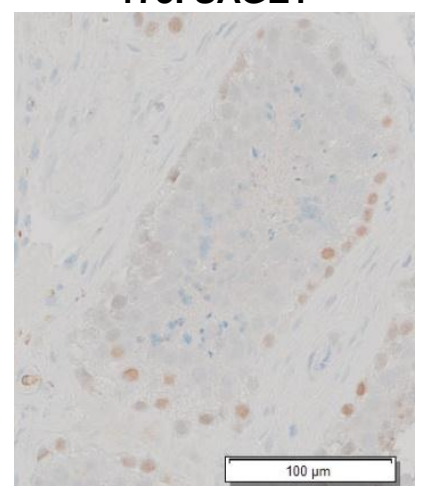

169. FGFR3

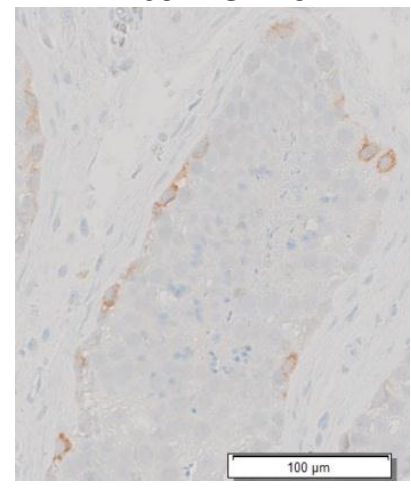

170. Ki67

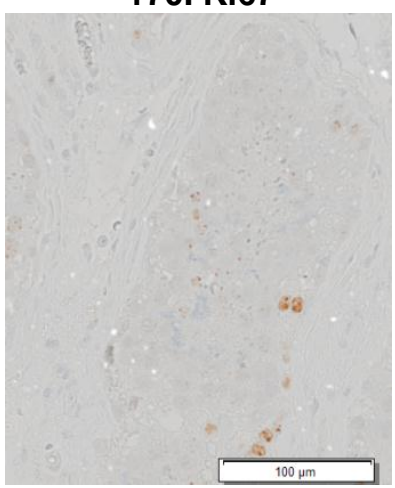

175. MAGEA4
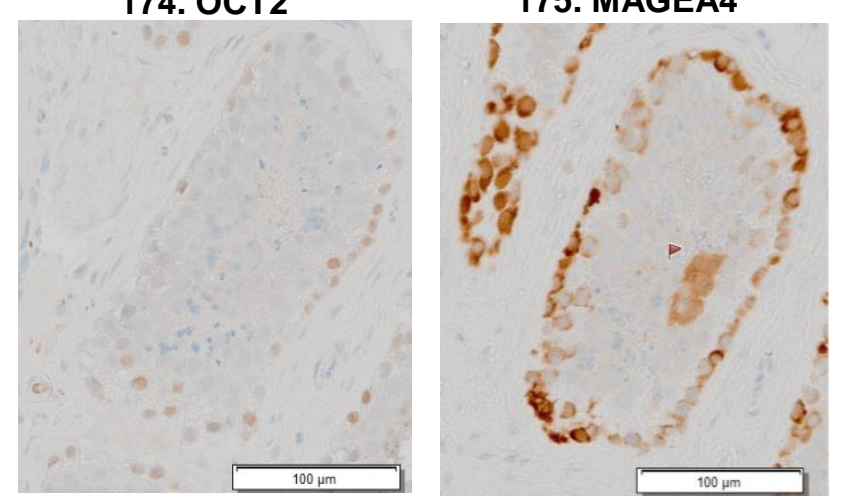

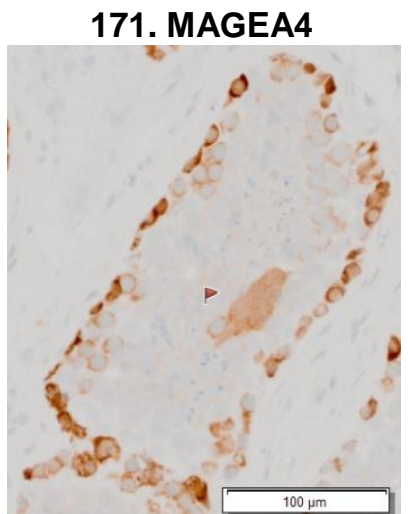

178. MAGEA4

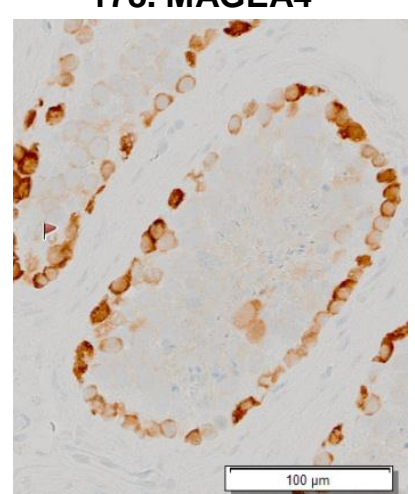

172. SSX

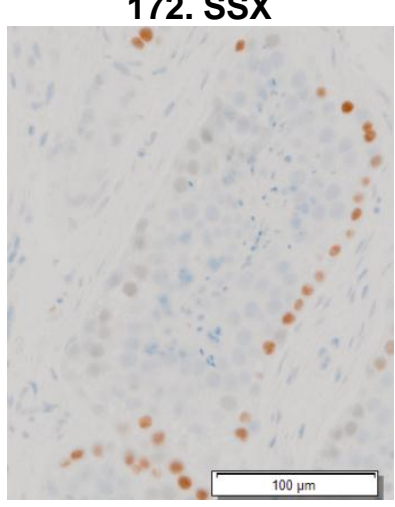

181. MAGEA4

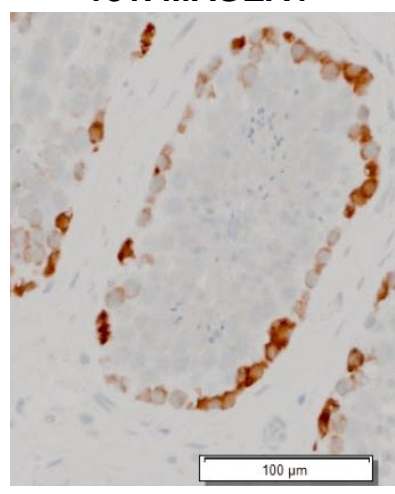




\section{Clone no. 1-2_c9}

A

\begin{tabular}{|c|c|c|c|c|c|c|c|c|c|c|c|c|c|}
\hline \multirow{2}{*}{ Clone no. } & \multirow{2}{*}{ Location } & Slide 168 & Slide 169 & Slide 170 & Slide 171 & Slide 172 & Slide 173 & Slide 174 & Slide 175 & Slide 176 & Slide 177 & Slide 178 & \multirow{2}{*}{$\begin{array}{c}\text { Minimum } \\
\text { number o } \\
\text { cells }\end{array}$} \\
\hline & & MAGEA4 & FGFR3 & Ki67 & MAGEA4 & SSX & SAGE1 & OCT2 & MAGEA4 & n.s & OCT2 & MAGEA4 & \\
\hline \multirow{3}{*}{ 1-2_C9 } & \multirow{3}{*}{ Centre } & $0^{*}$ & 0 & 0 & 1 & 0 & 0 & 0 & 1 & & & 1 & \multirow{3}{*}{54} \\
\hline & & 2 cells & & & 4 cells & & & & 6 cells & & & 7 cells & \\
\hline & & \multicolumn{11}{|c|}{$55 \mu \mathrm{m}$} & \\
\hline
\end{tabular}

B

168. MAGEA4

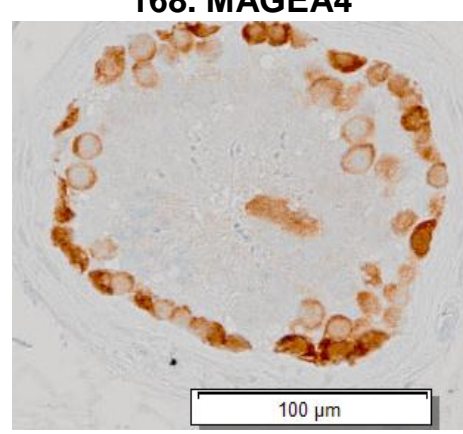

173. SAGE1

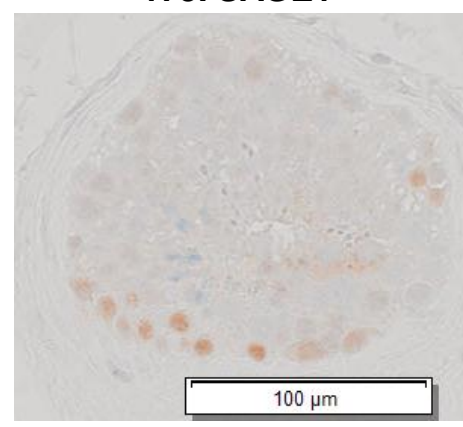

169. FGFR3

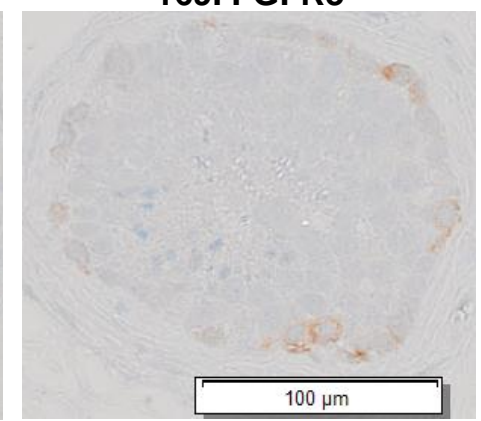

174. ОСТ2

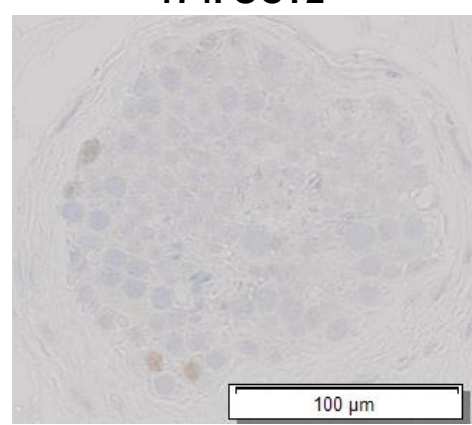

170. Ki67

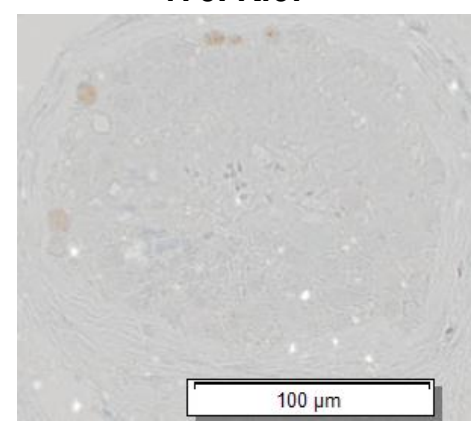

175. MAGEA4

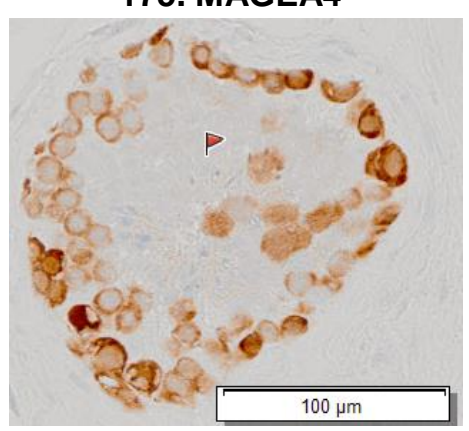

171. MAGEA4

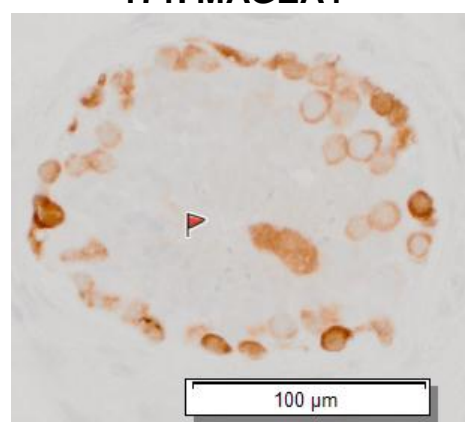

172. SSX

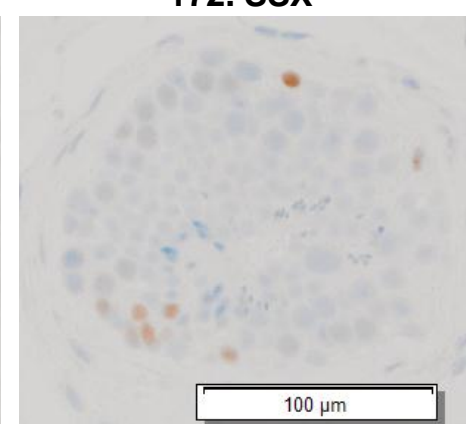

178. MAGEA4

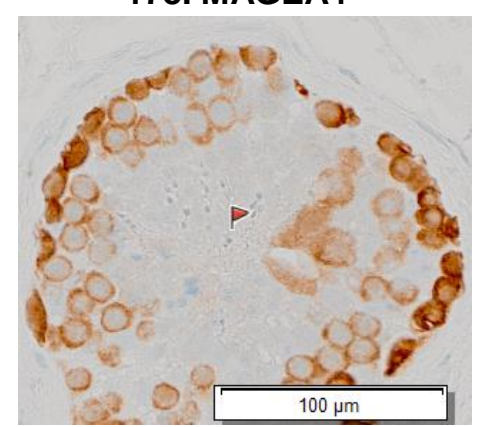


A

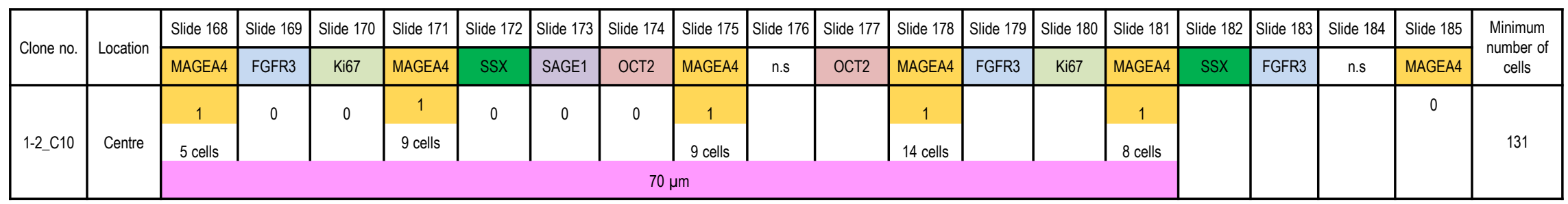

B

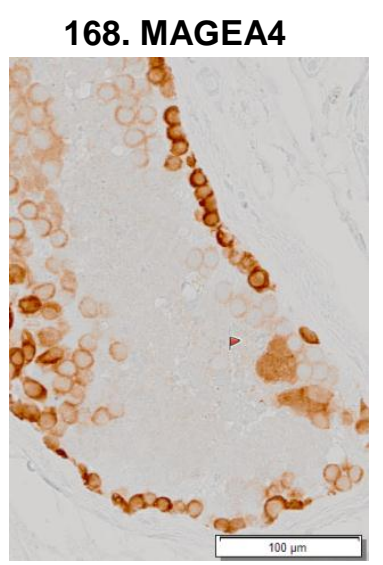

169. FGFR3

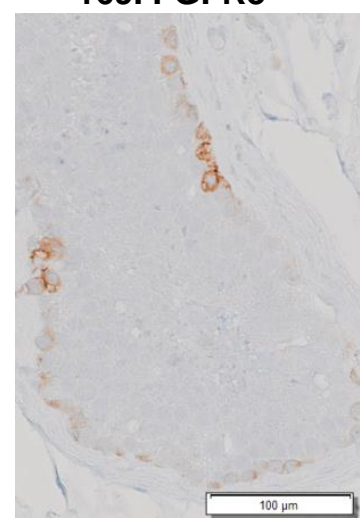

174. ОСТ2

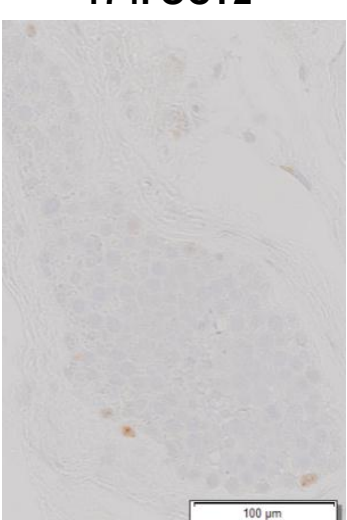

170. Ki67

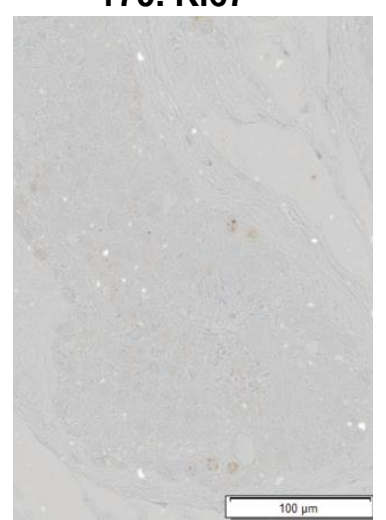

175. MAGEA4

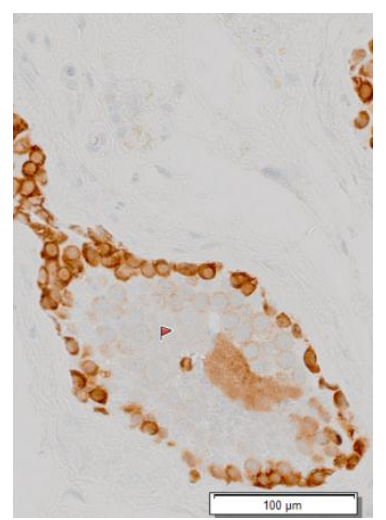

171. MAGEA4

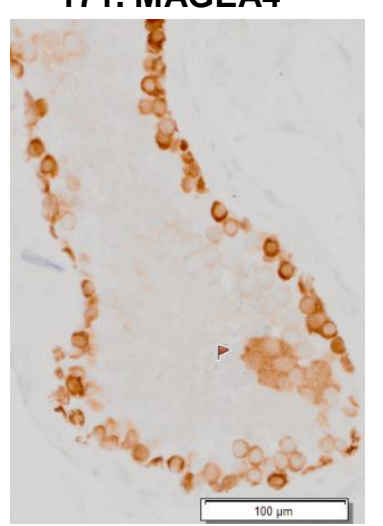

178. MAGEA4

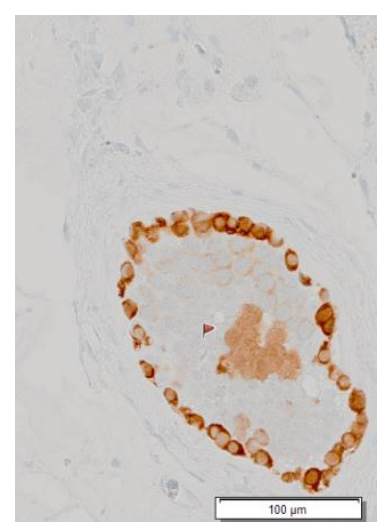

172. SSX

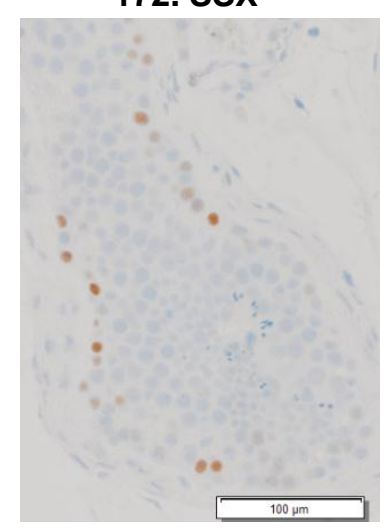

181. MAGEA4

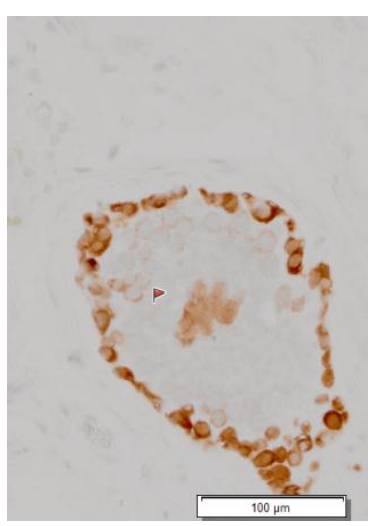


Clone no. 1-2_C11

A

\begin{tabular}{|c|c|c|c|c|c|c|c|c|c|c|c|c|c|}
\hline \multirow{2}{*}{ Clone no. } & \multirow{2}{*}{ Location } & Slide 168 & Slide 169 & Slide 170 & Slide 171 & Slide 172 & Slide 173 & Slide 174 & Slide 175 & Slide 176 & Slide 177 & Slide 178 & \multirow{2}{*}{$\begin{array}{l}\text { Minimum } \\
\text { number of } \\
\text { cells }\end{array}$} \\
\hline & & MAGEA4 & FGFR3 & Ki67 & MAGEA4 & SSX & SAGE1 & ОСТ2 & MAGEA4 & n.s & ОСТ2 & MAGEA4 & \\
\hline \multirow{3}{*}{ 1-2_C11 } & \multirow{3}{*}{$\begin{array}{l}\text { Centre \& } \\
\text { periphery }\end{array}$} & $0^{*}$ & \multirow[t]{2}{*}{0} & \multirow[t]{2}{*}{0} & 1 & \multirow[t]{2}{*}{0} & \multirow[t]{2}{*}{0} & \multirow[t]{2}{*}{0} & 1 & & & \multirow[t]{3}{*}{ NA } & \multirow{3}{*}{58} \\
\hline & & 2 cells & & & 11 cells & & & & 6 cells & & & & \\
\hline & & \multicolumn{8}{|c|}{$40 \mu \mathrm{m}$} & & & & \\
\hline
\end{tabular}

B

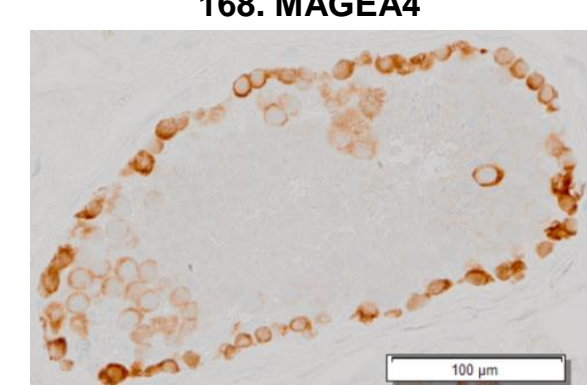

172. SSX

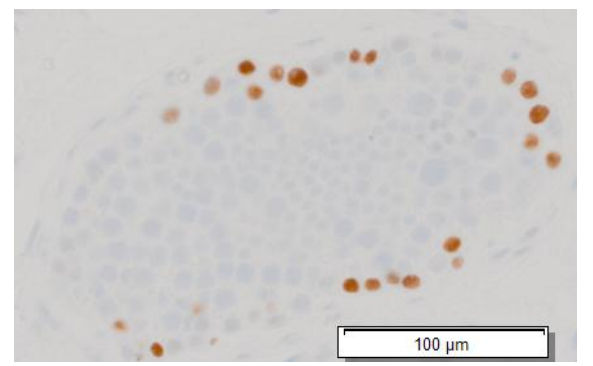

169. FGFR3

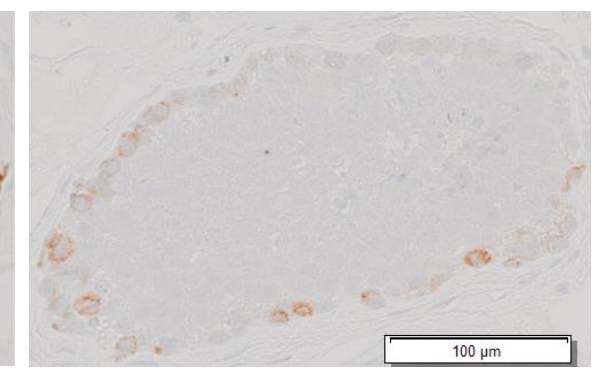

173. SAGE1

$100 \mu \mathrm{m}$
170. Ki67

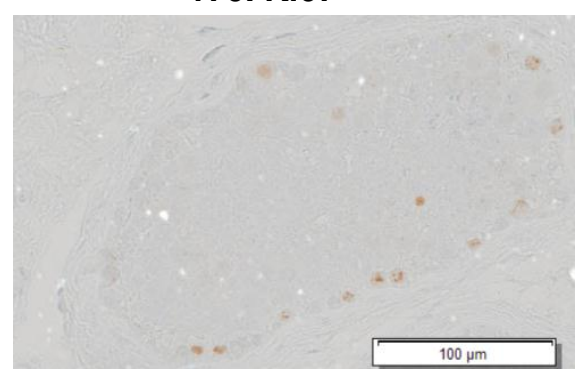

174. OCT2

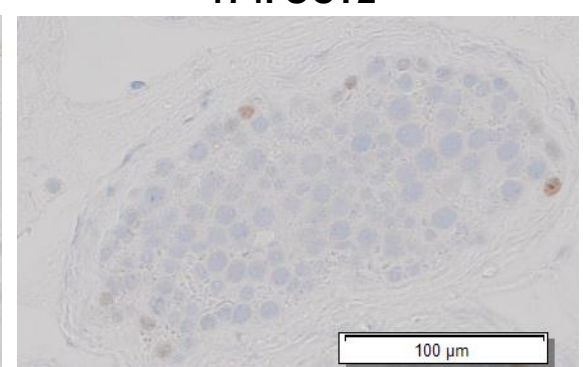

171. MAGEA4

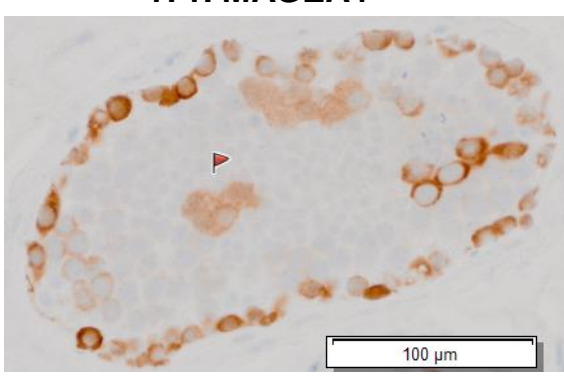

175. MAGEA4

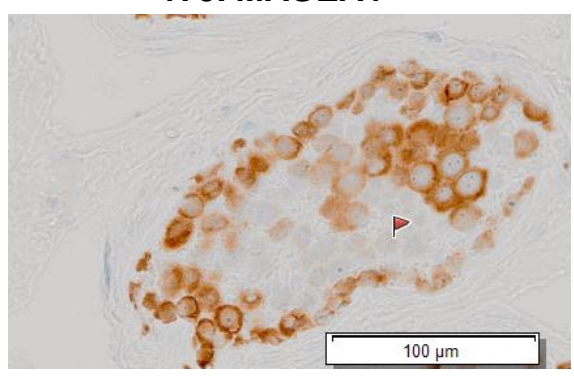




\section{Clone no. 1-2_C12}

A

\begin{tabular}{|c|c|c|c|c|c|c|c|c|c|c|c|c|c|}
\hline Clone no. & Location & Slide 168 & Slide 169 & Slide 170 & Slide 171 & Slide 172 & Slide 173 & Slide 174 & Slide 175 & Slide 176 & Slide 177 & Slide 178 & $\begin{array}{c}\text { Minimum } \\
\text { number of } \\
\text { cells }\end{array}$ \\
\hline \multirow{3}{*}{ 1-2_C12 } & \multirow{3}{*}{$\begin{array}{c}\text { Near } \\
\text { Periphery }\end{array}$} & $0^{*}$ & \multirow[t]{2}{*}{0} & \multirow[t]{2}{*}{0} & 1 & \multirow[t]{2}{*}{0} & \multirow[t]{2}{*}{0} & \multirow[t]{2}{*}{0} & 1 & & & \multirow[t]{3}{*}{ NA } & \multirow{3}{*}{41} \\
\hline & & 1 cell & & & 6 cells & & & & 7 cells & & & & \\
\hline & & \multicolumn{8}{|c|}{$40 \mu \mathrm{m}$} & & & & \\
\hline
\end{tabular}

B

168. MAGEA4

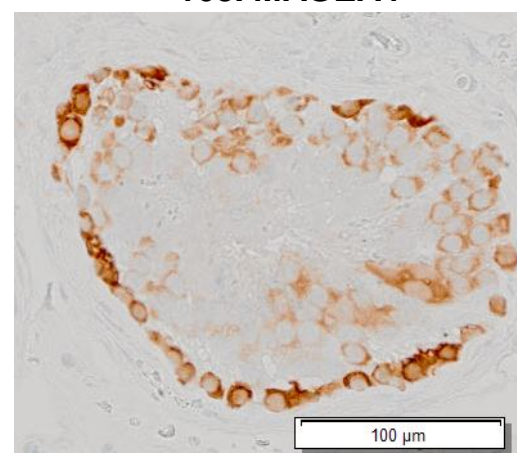

172. SSX

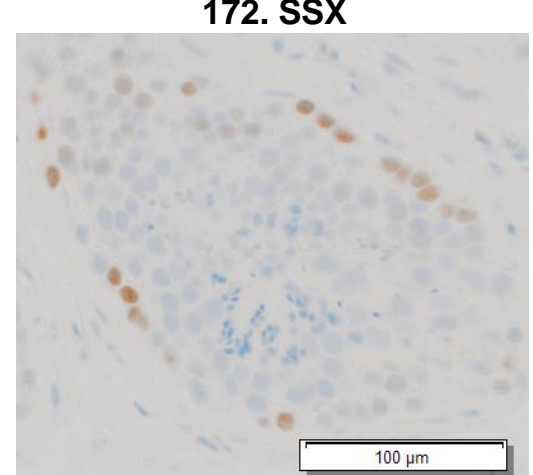

169. FGFR3

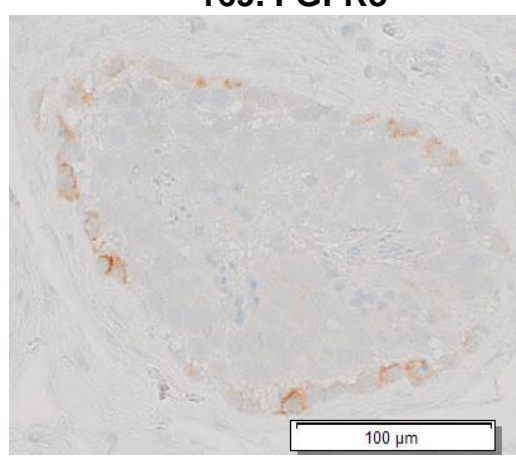

173. SAGE1

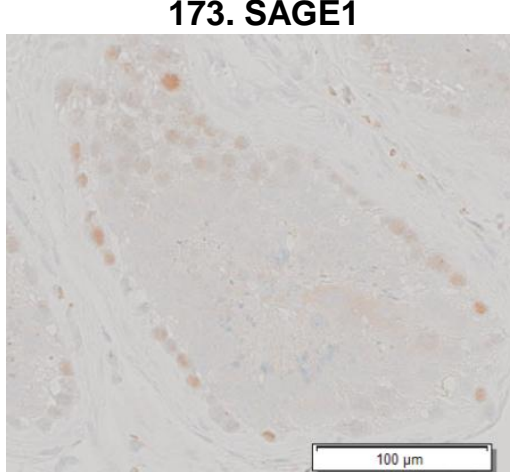

170. Ki67

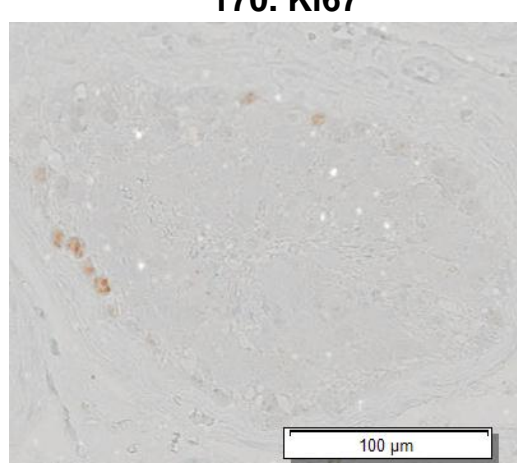

174. OCT2

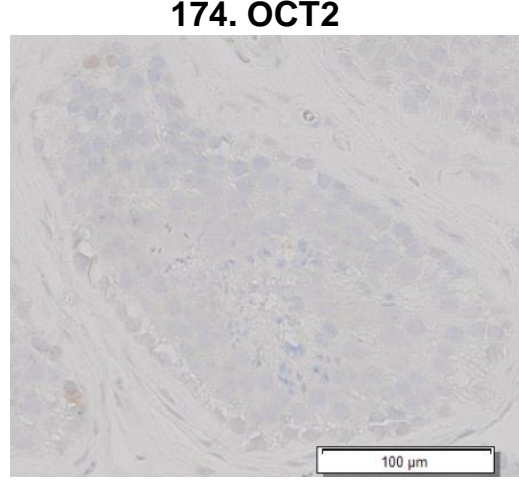

171. MAGEA4

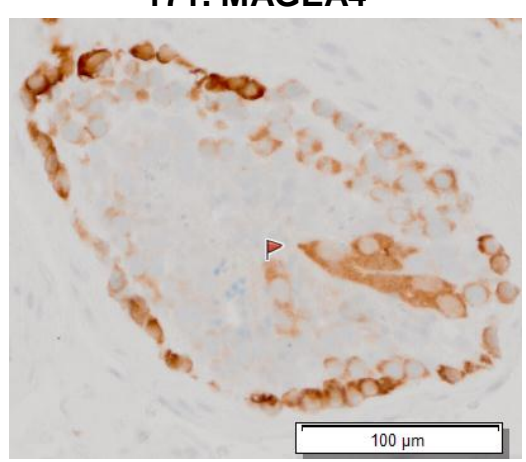

175. MAGEA4

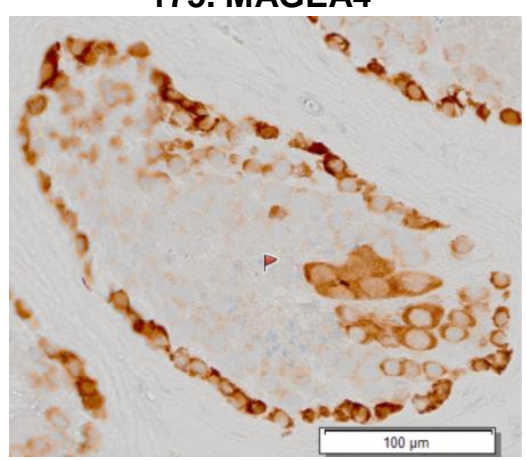




\section{Clone no. 1-2_C13}

A

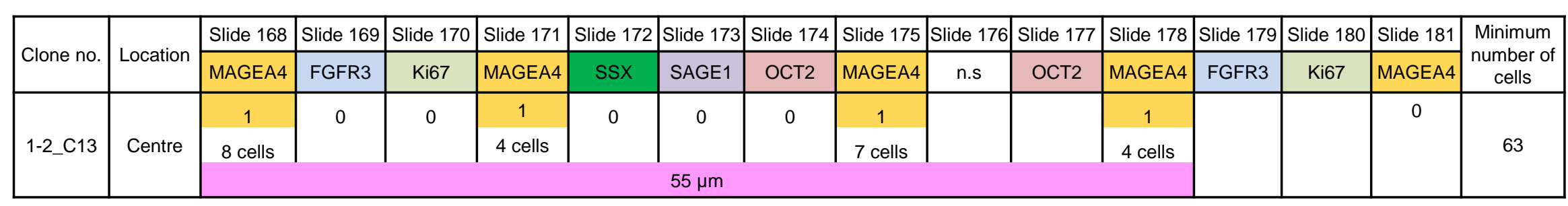

B

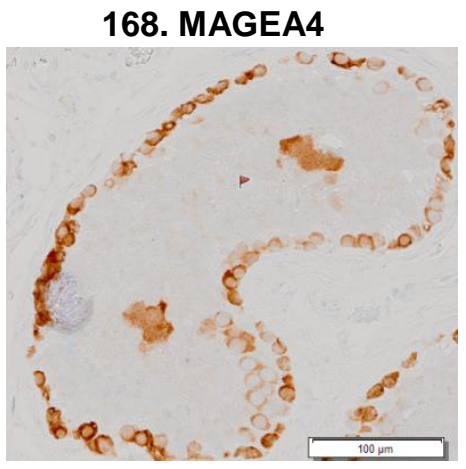

173. SAGE1

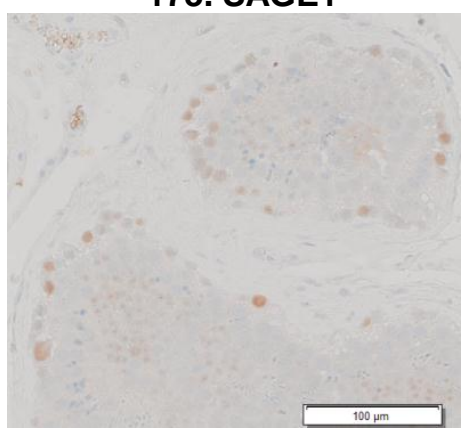

169. FGFR3

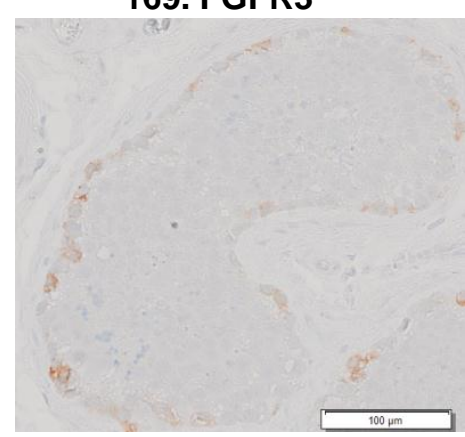

174. OCT2

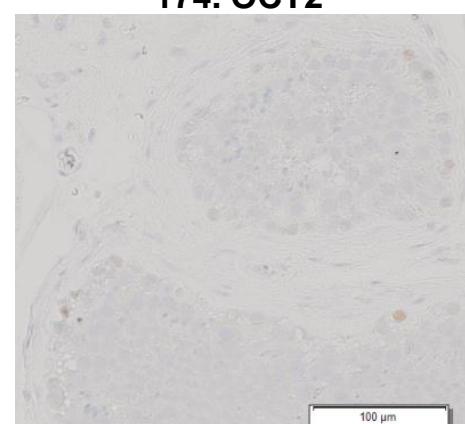

170. Ki67

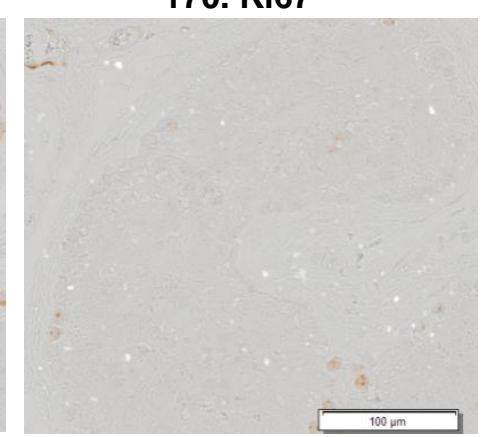

175. MAGEA4

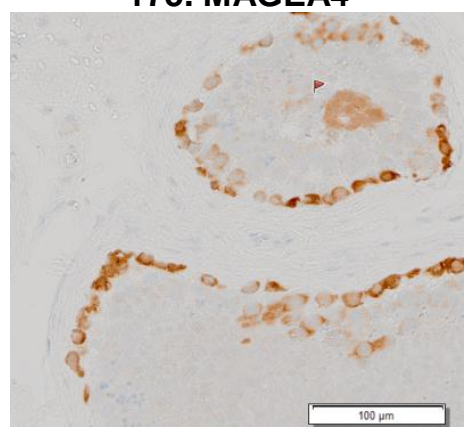

171. MAGEA4

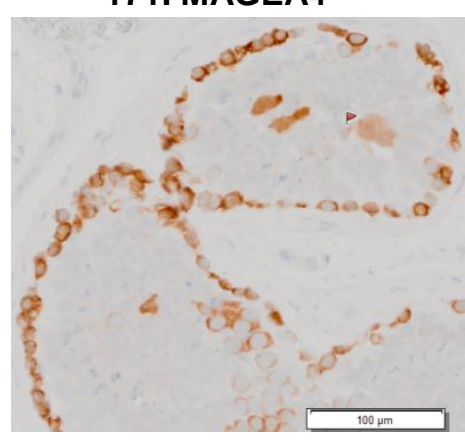

178. MAGEA4 s 8

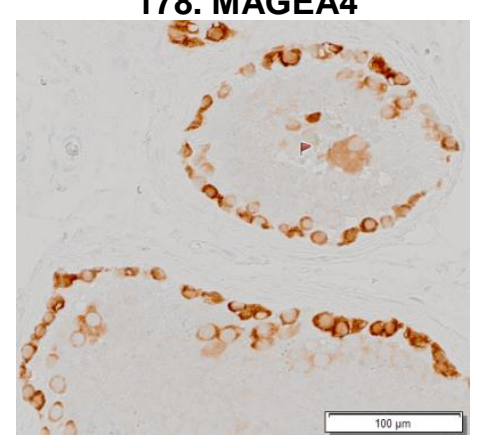

172. SSX

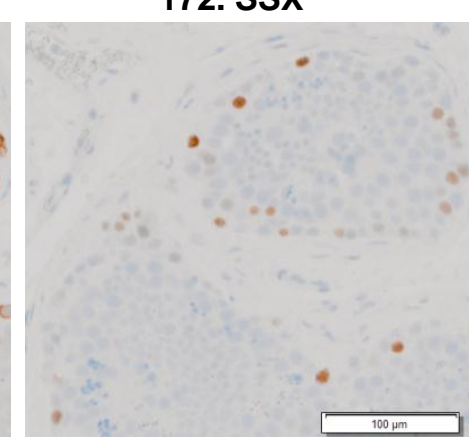

181. MAGEA4

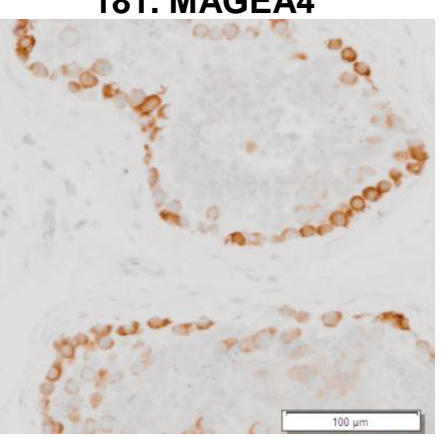




\section{Clone no. 1-2_C14}

A

\begin{tabular}{|c|c|c|c|c|c|c|c|c|c|c|}
\hline \multirow{2}{*}{ Clone no. } & \multirow{2}{*}{ Location } & Slide 168 & Slide 169 & Slide 170 & Slide 171 & Slide 172 & Slide 173 & Slide 174 & Slide 175 & \multirow{2}{*}{$\begin{array}{c}\text { Minimum } \\
\text { number of cells }\end{array}$} \\
\hline & & MAGEA4 & FGFR3 & Ki67 & MAGEA4 & SSX & SAGE1 & OCT2 & MAGEA4 & \\
\hline \multirow{3}{*}{ 1-2_C14 } & \multirow{3}{*}{ Centre } & $0^{*}$ & 0 & 0 & 1 & 1 & $0^{*}$ & 0 & NA & \multirow{3}{*}{58} \\
\hline & & 7 cells & & & 12 cells & 13 cells & 7 cells & & & \\
\hline & & \multicolumn{6}{|c|}{$30 \mu \mathrm{m}$} & & & \\
\hline
\end{tabular}

B

168. MAGEA4

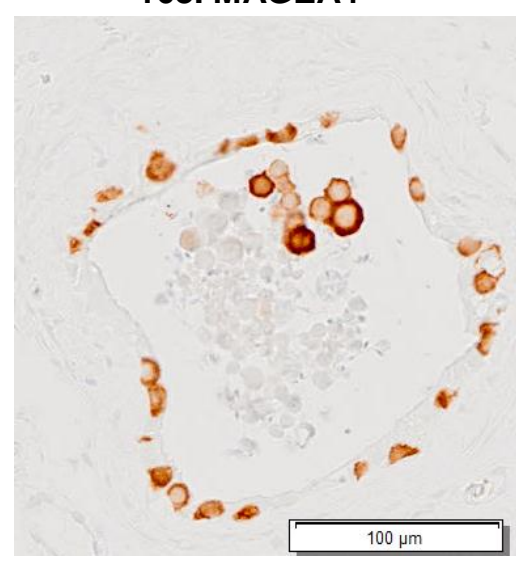

172. SSX

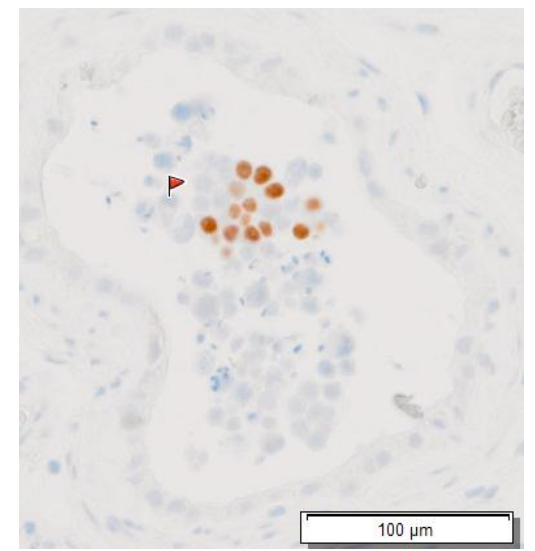

169. FGFR3

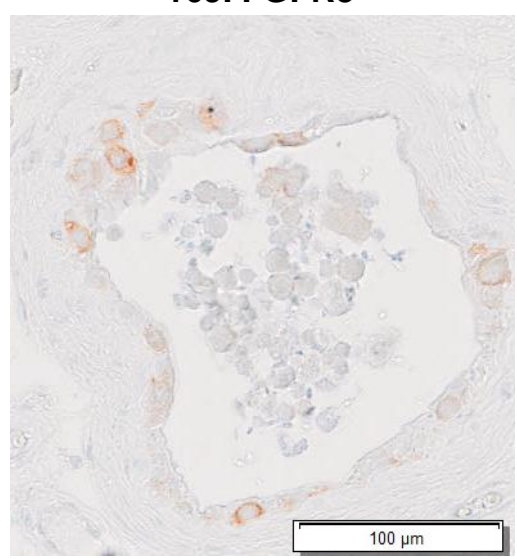

173. SAGE1

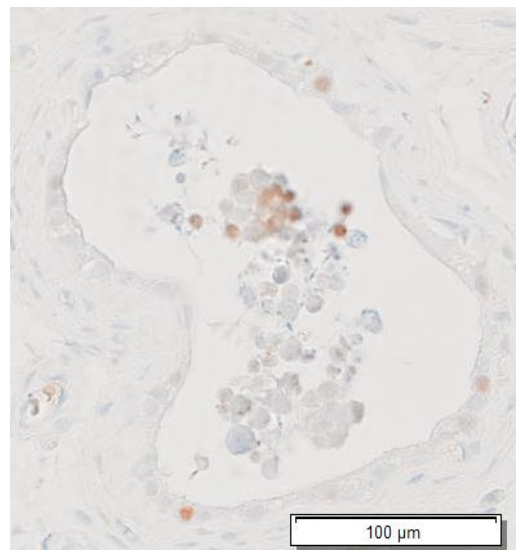

170. Ki67

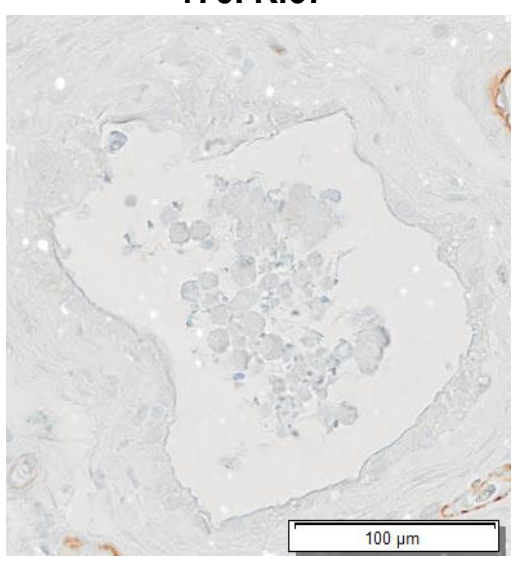

174. ОСТ2

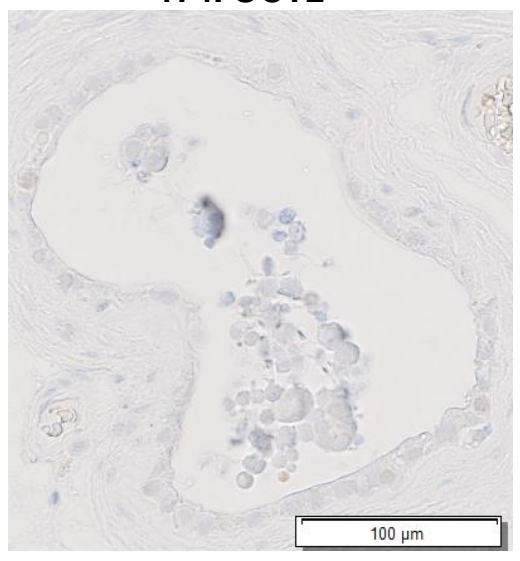

171. MAGEA4

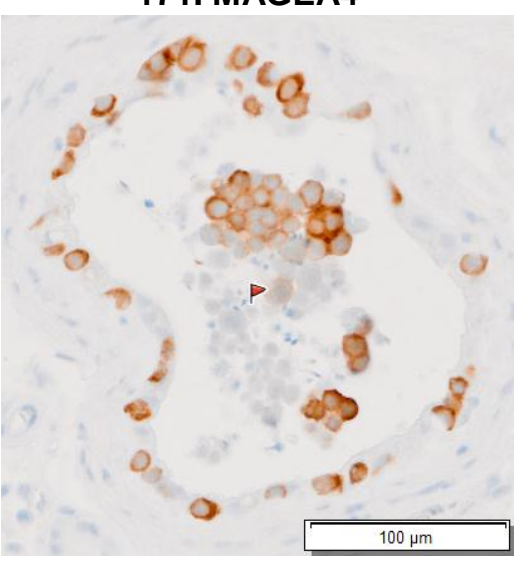

175. MAGEA4

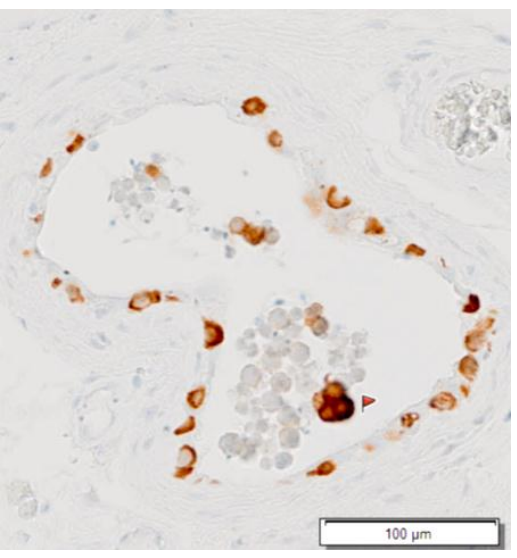




\section{Clone no. 1-2_C15}

A

\begin{tabular}{|c|c|c|c|c|c|c|c|c|c|c|c|c|c|}
\hline \multirow{2}{*}{ Clone no } & \multirow{2}{*}{ Location } & Slide 168 & Slide 169 & Slide 170 & Slide 171 & Slide 172 & Slide 173 & Slide 174 & Slide 175 & Slide 176 & Slide 177 & Slide 178 & \multirow{2}{*}{$\begin{array}{c}\text { Minimum } \\
\text { number o } \\
\text { cells }\end{array}$} \\
\hline & & MAGEA4 & FGFR3 & Ki67 & MAGEA4 & SSX & SAGE1 & OCT2 & MAGEA4 & n.s & OCT2 & MAGEA4 & \\
\hline \multirow[b]{2}{*}{ 1-2_C15 } & \multirow[b]{2}{*}{ Centre } & $0^{*}$ & \multirow{2}{*}{0} & \multirow{2}{*}{0} & 1 & \multirow{2}{*}{0} & \multirow[t]{2}{*}{0} & \multirow[t]{2}{*}{0} & . & & & $0^{*}$ & \multirow[b]{2}{*}{34} \\
\hline & & 2 cells & & & 4 cells & & & & 4 cells & & & 1 cell & \\
\hline
\end{tabular}

B

168. MAGEA4

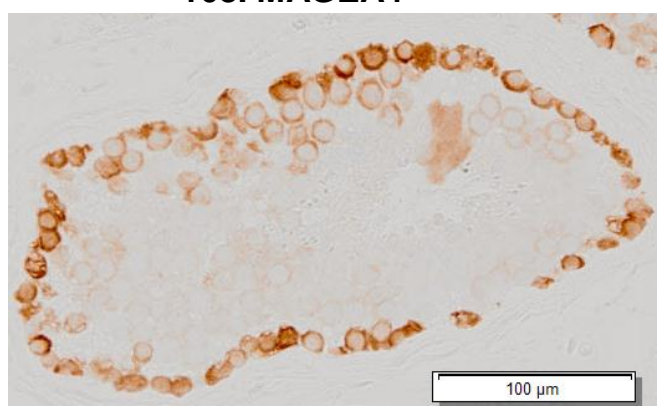

171. MAGEA4

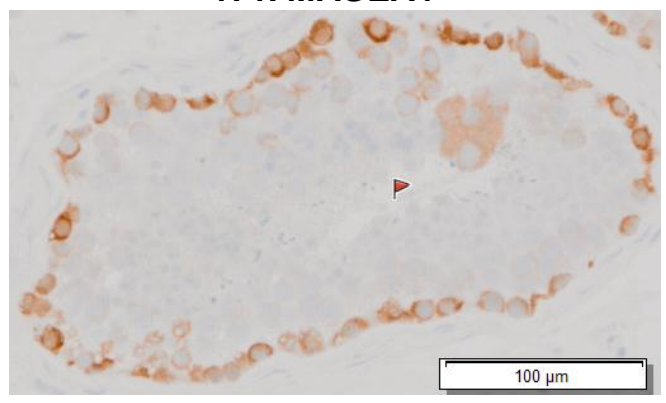

174. ОСТ2
169. FGFR3

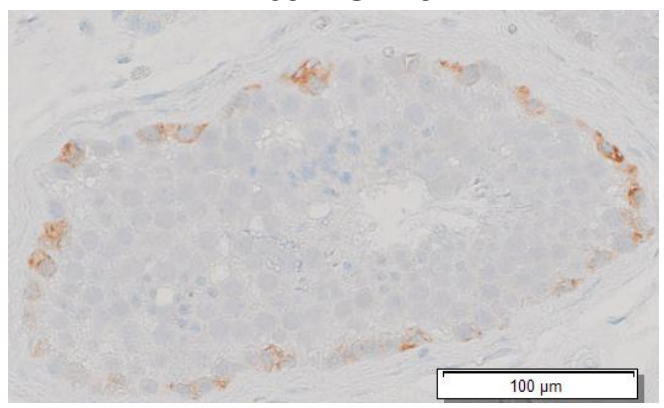

172. SSX

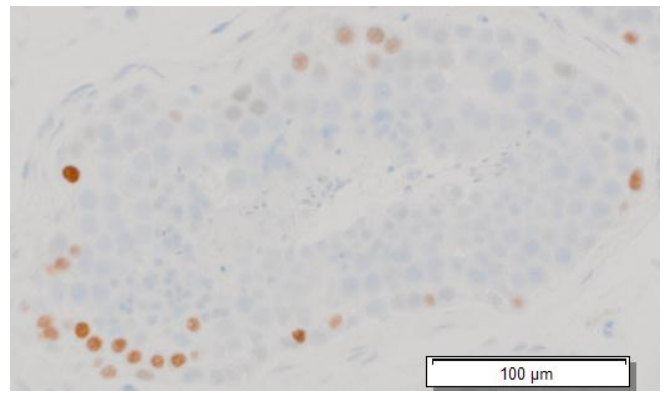

175. MAGEA4

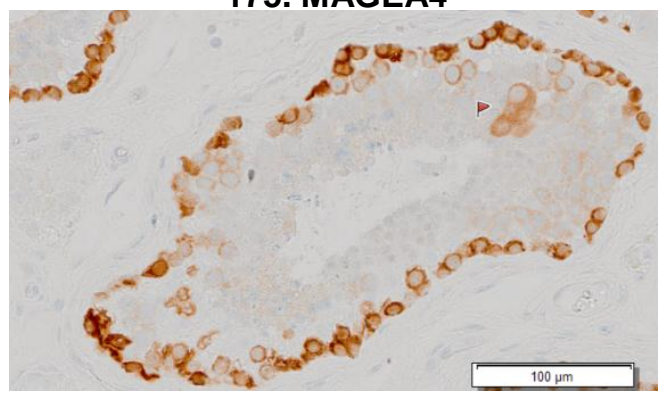

170. Ki67

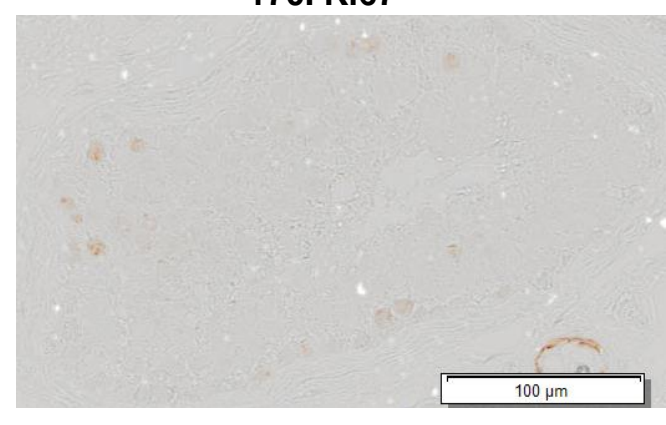

173. SAGE1

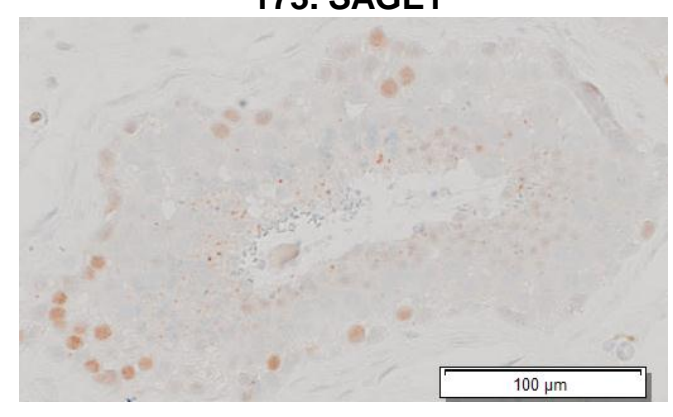

178. MAGEA4

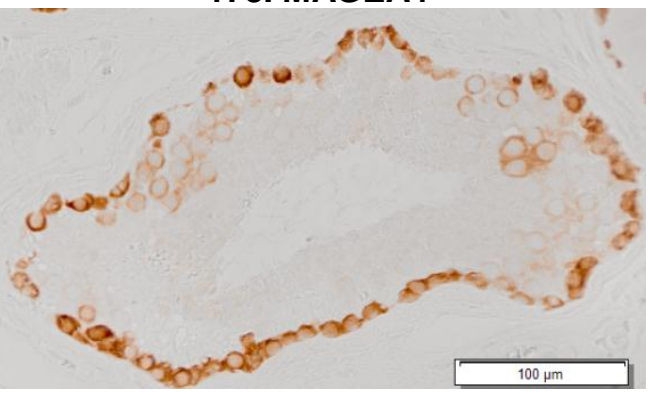




\section{Clone no. 1-2_C16}

A

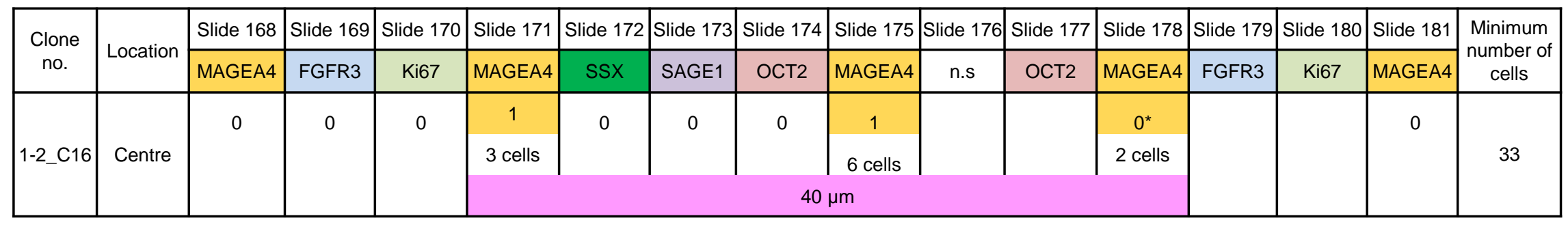

B

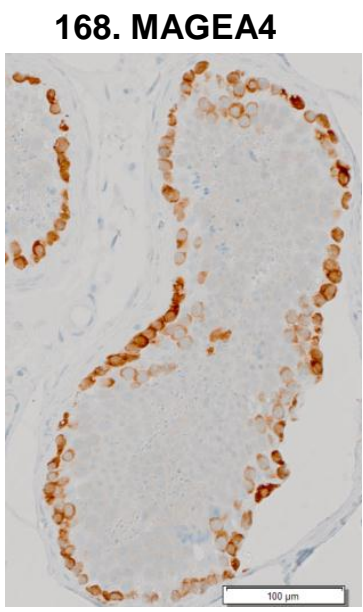

169. FGFR3

170. Ki67
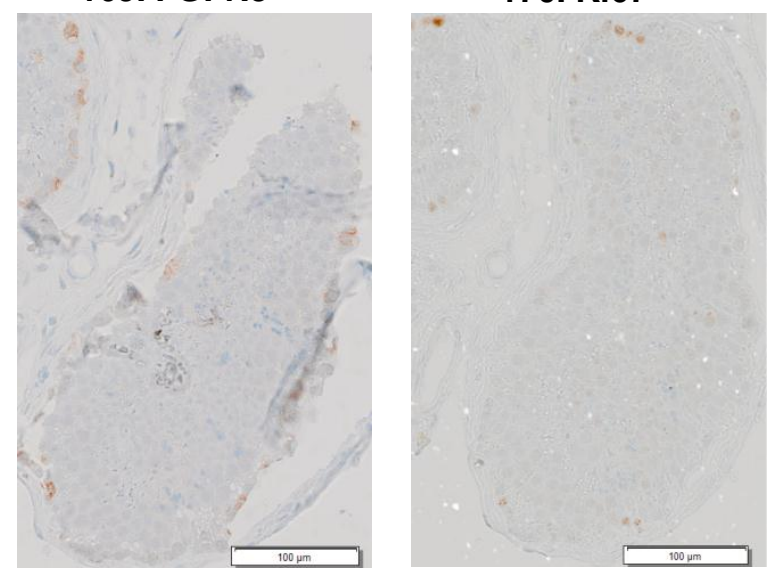

171. MAGEA4

172. SSX

173. SAGE1

174. ОСТ2
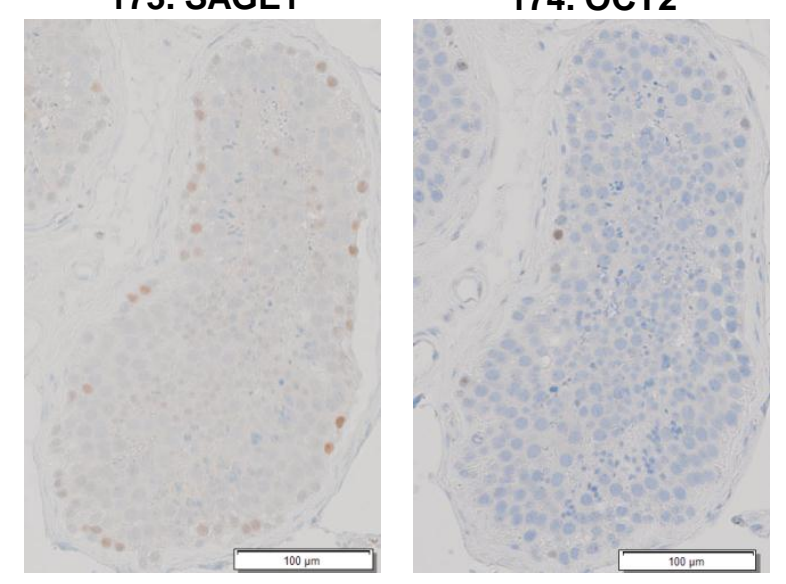

175. MAGEA4

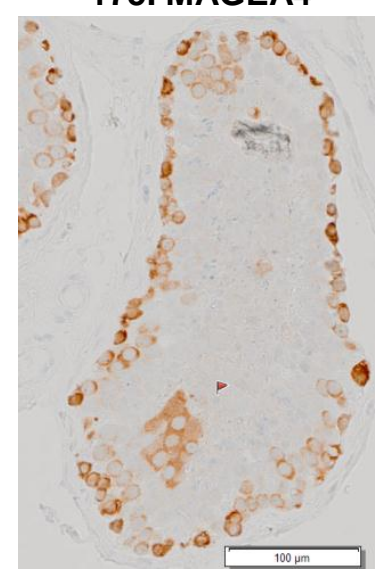

178. MAGEA4

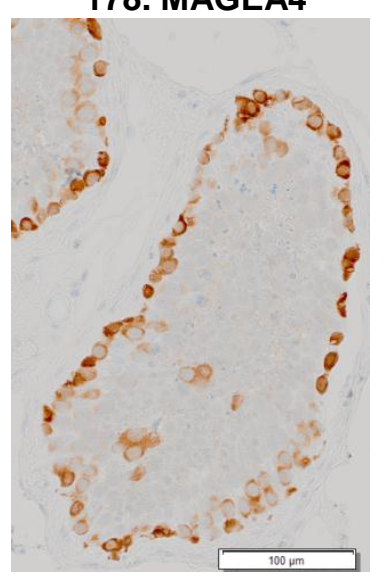

181. MAGEA4

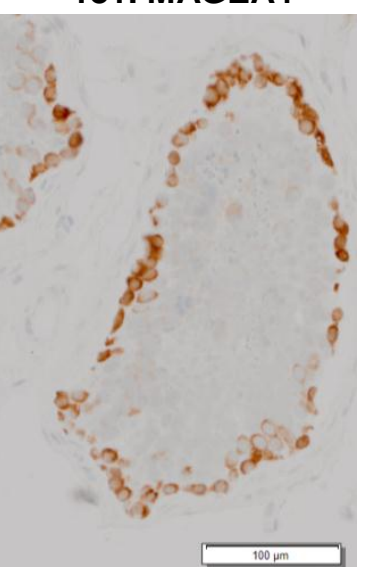




\section{Clone no. 1-2_C17}

A

\begin{tabular}{|c|c|c|c|c|c|c|c|c|c|c|c|c|c|c|c|c|c|}
\hline \multirow{2}{*}{ Clone no. } & \multirow{2}{*}{ Location } & Slide 171 & Slide 172 & Slide 173 & Slide 174 & Slide 175 & Slide 176 & Slide 177 & Slide 178 & Slide 179 & Slide 180 & Slide 181 & Slide 182 & Slide 183 & Slide 184 & Slide 185 & \multirow{2}{*}{$\begin{array}{c}\text { Minimum } \\
\text { number } 0 \\
\text { cells }\end{array}$} \\
\hline & & MAGEA4 & SSX & SAGE1 & Ост2 & MAGEA4 & n.s & Ост2 & MAGEA4 & FGFR3 & Ki67 & MAGEA4 & SSX & FGFR3 & n.s & MAGEA4 & \\
\hline \multirow{3}{*}{ 1-2_C17 } & \multirow{3}{*}{ Centre } & \multirow[t]{3}{*}{0} & \multirow[t]{3}{*}{0} & \multirow[t]{3}{*}{0} & \multirow[t]{3}{*}{0} & 1 & & \multirow[t]{2}{*}{0} & 1 & \multirow[t]{2}{*}{0} & \multirow[t]{2}{*}{0} & 1 & \multirow[t]{3}{*}{0} & & & \multirow[t]{3}{*}{0} & \multirow{3}{*}{40} \\
\hline & & & & & & 8 cells & & & 4 cells & & & 6 cells & & & & & \\
\hline & & & & & & & & & $35 \mu \mathrm{m}$ & & & & & & & & \\
\hline
\end{tabular}

B

\section{MAGEA4}

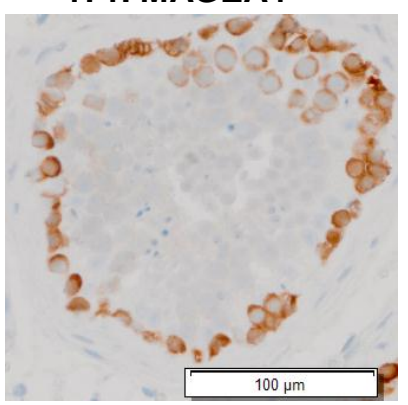

178. MAGEA4

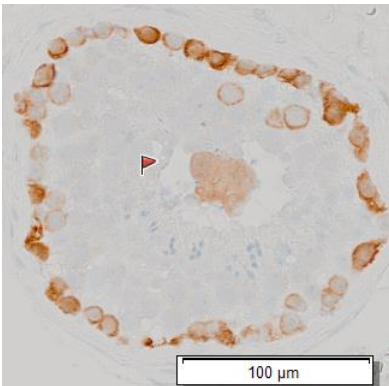

172. SSX

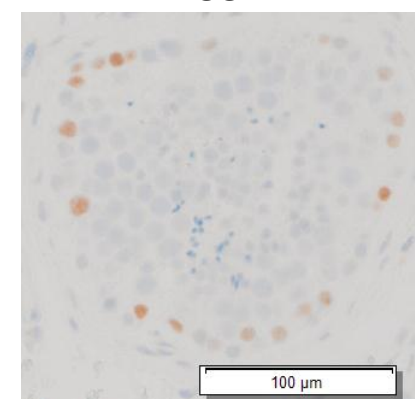

179. FGFR3

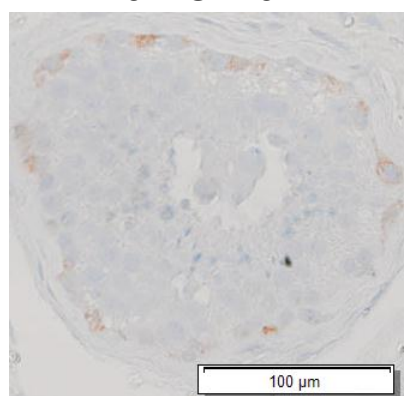

173. SAGE1

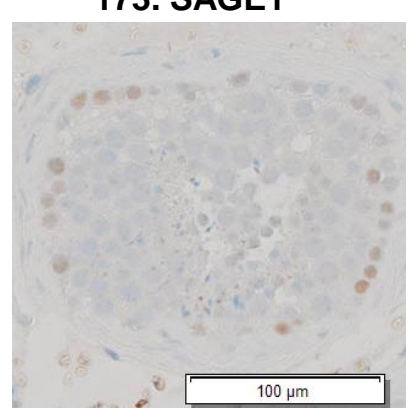

180. Ki67

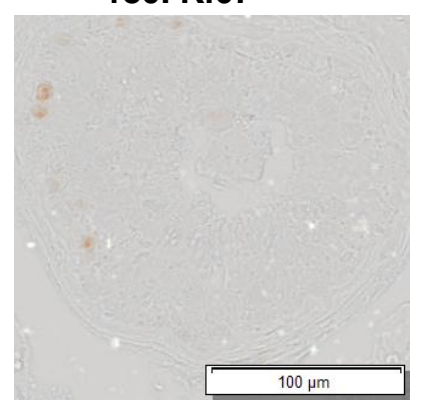

175. MAGEA4

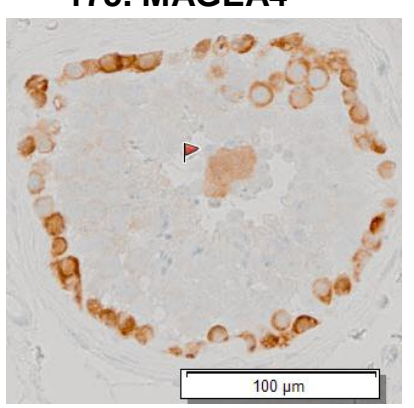

181. MAGEA4

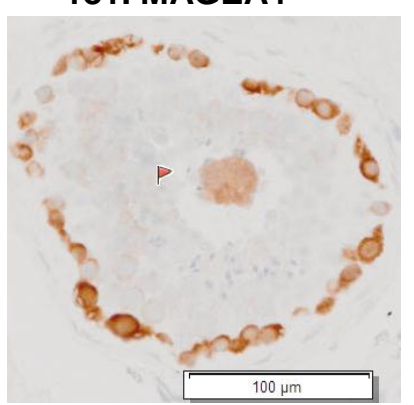

177. ОСТ2

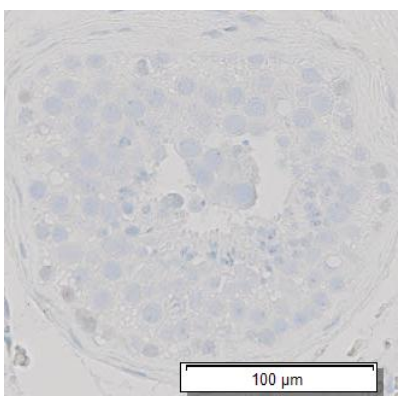

185. MAGEA4

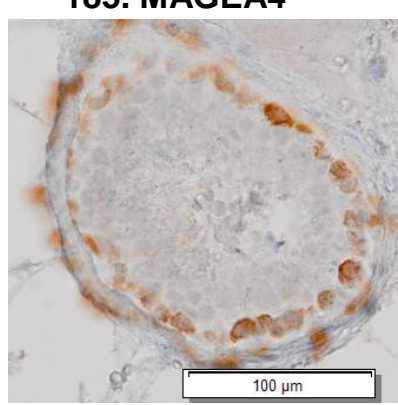




\section{Clone no. 1-2_C18}

A

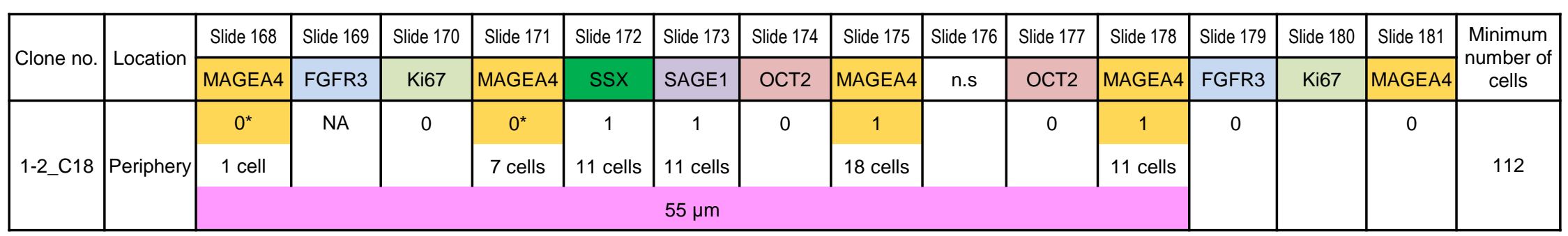

B
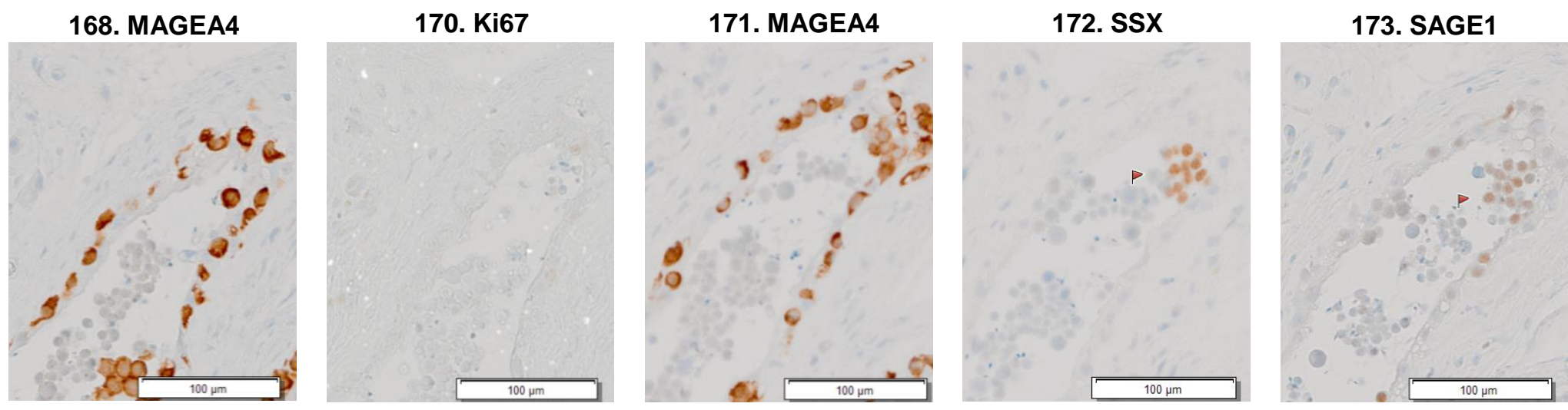

174. OCT2

175. MAGEA4
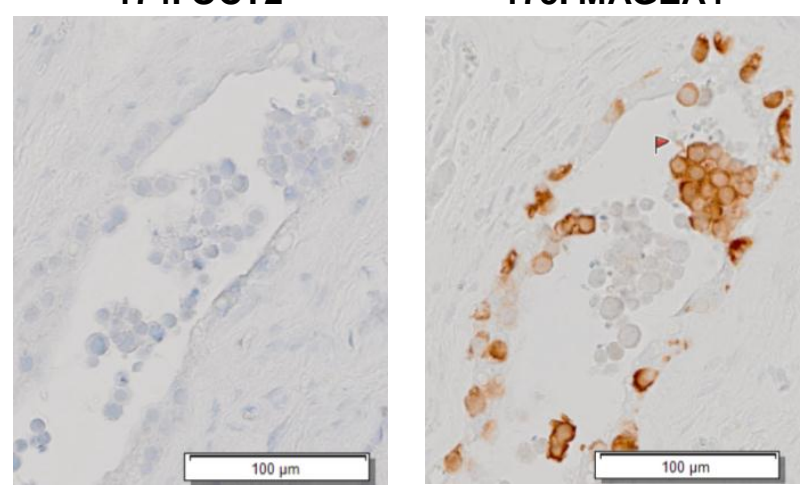

178. MAGEA4

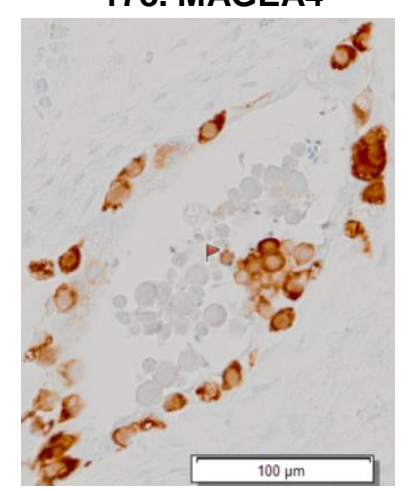

179. FGFR3

\section{MAGEA4}
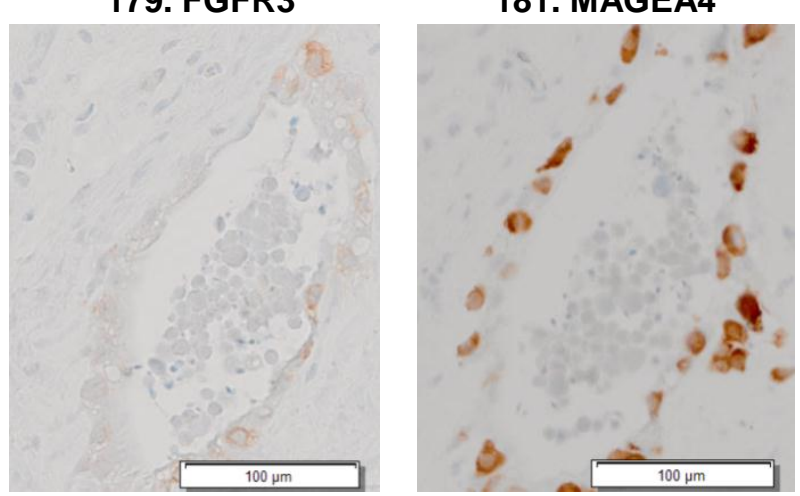


\section{Clone no. 1-2_C19}

A

\begin{tabular}{|c|c|c|c|c|c|c|c|c|c|c|c|c|c|}
\hline \multirow{2}{*}{ Clone no. } & \multirow{2}{*}{ Location } & Slide 171 & Slide 172 & Slide 173 & Slide 174 & Slide 175 & Slide 176 & Slide 177 & Slide 178 & Slide 179 & Slide 180 & Slide 181 & \multirow{2}{*}{$\begin{array}{l}\text { Minimum } \\
\text { number of } \\
\text { cells }\end{array}$} \\
\hline & & MAGEA4 & SSX & SAGE1 & ОСТ2 & MAGEA4 & n.s & ОСТ2 & MAGEA4 & FGFR3 & Ki67 & MAGEA4 & \\
\hline \multirow{3}{*}{ 1-2_C19 } & \multirow{3}{*}{$\begin{array}{l}\text { Near } \\
\text { Periphery }\end{array}$} & \multirow[t]{3}{*}{0} & \multirow[t]{3}{*}{0} & \multirow[t]{3}{*}{0} & \multirow[t]{3}{*}{0} & 1 & & \multirow[t]{2}{*}{0} & 1 & \multirow[t]{2}{*}{0} & \multirow[t]{2}{*}{0} & $0^{*}$ & \multirow{3}{*}{53} \\
\hline & & & & & & 5 cells & & & 13 cells & & & 2 cells & \\
\hline & & & & & & \multicolumn{7}{|c|}{$35 \mu \mathrm{m}$} & \\
\hline
\end{tabular}

B
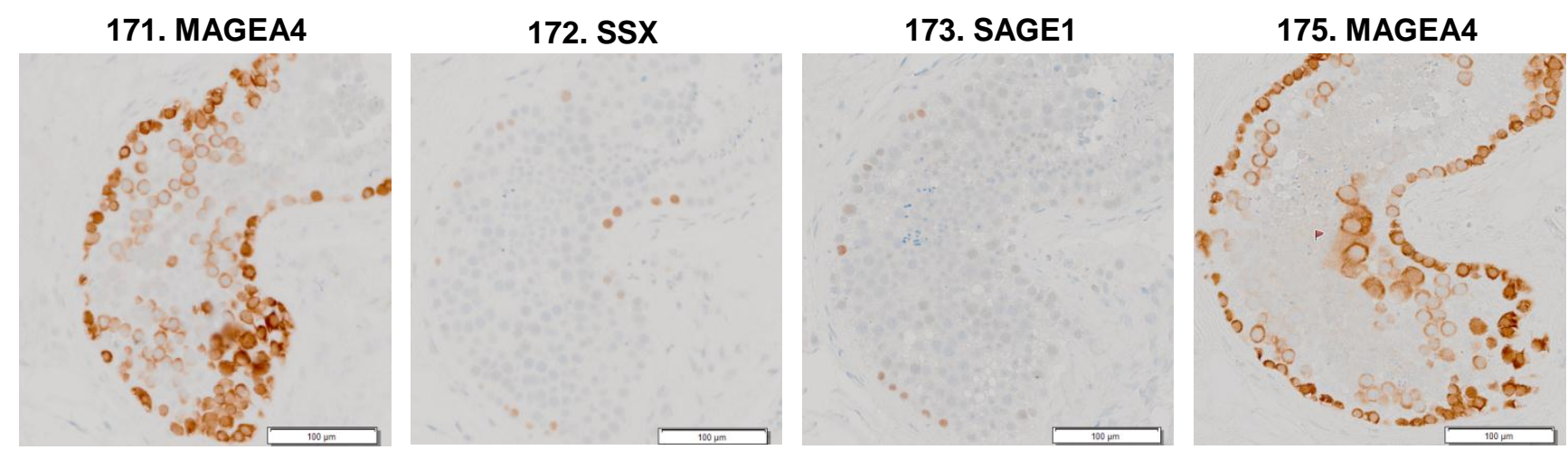

177. ОСТ2

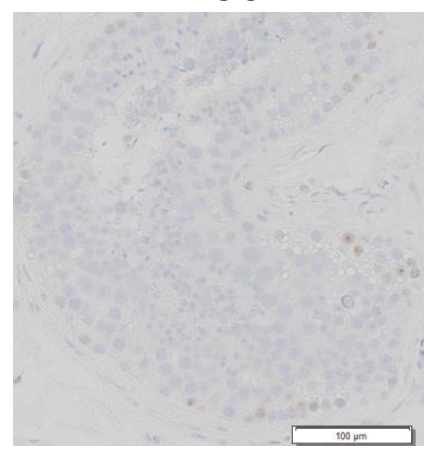

178. MAGEA4

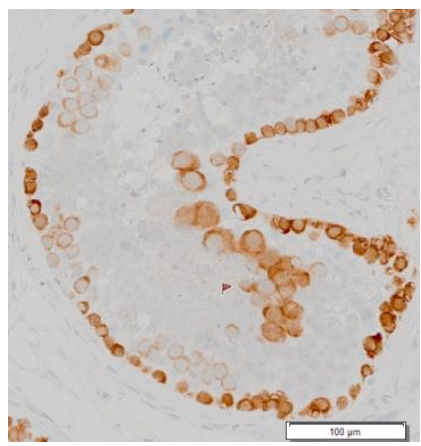

179. FGFR3

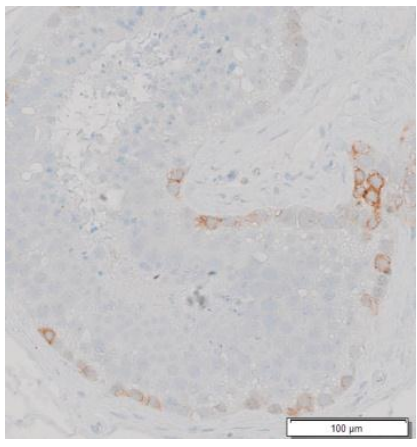

180. Ki67

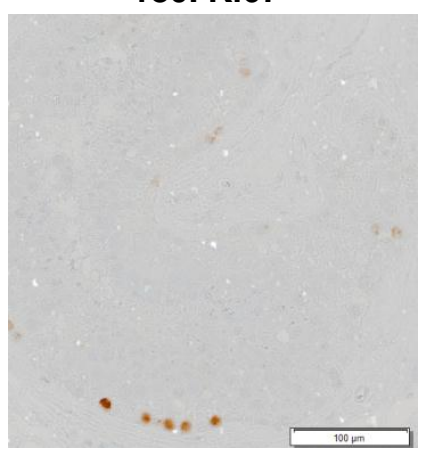

181. MAGEA4

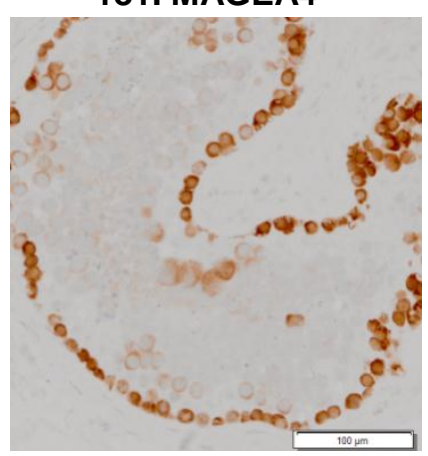




\section{Clone no. 1-2 C20}

A

\begin{tabular}{|c|c|c|c|c|c|c|c|c|c|c|c|c|c|c|c|c|c|c|c|c|c|c|c|}
\hline \multirow{2}{*}{ Clone no. } & \multirow{2}{*}{ Location } & Slide 171 & Slide 172 & Slide 173 & Slide 174 & Slide 175 & Slide 176 & Slide 177 & Slide 178 & Slide 179 & Slide 180 & Slide 181 & Slide 182 & Slide 183 & Slide 184 & Slide 185 & Slide 186 & Slide 187 & Slide 188 & Slide 189 & Slide 190 & Slide 191 & \multirow{2}{*}{$\begin{array}{c}\text { Minimum } \\
\text { number of } \\
\text { cells }\end{array}$} \\
\hline & & MAGEA4 & ssX & SAGE1 & ОСТ2 & MAGEA4 & n.s & OCT2 & MAGEA4 & FGFR3 & Ki67 & MAGEA4 & ssx & FGFR3 & n.s & MAGEA4 & n.s & n.s & n.s & n.s & n.s & MAGEA4 & \\
\hline \multirow{3}{*}{ 1-2_C20 } & \multirow{3}{*}{ Periphery } & $0^{*}$ & \multirow[t]{2}{*}{0} & \multirow[t]{2}{*}{0} & \multirow[t]{2}{*}{0} & 1 & & \multirow[t]{2}{*}{0} & 1 & \multirow[t]{2}{*}{0} & \multirow[t]{2}{*}{0} & $0^{*}$ & & & & $0^{*}$ & & & & & & NA & \multirow{3}{*}{87} \\
\hline & & 3 cells & & & & 9 cells & & & 5 cells & & & 5 cells & & & & 6cells & & & & & & & \\
\hline & & & & & & & & & $75 \mu \mathrm{m}$ & & & & & & & & & & & & & & \\
\hline
\end{tabular}

B

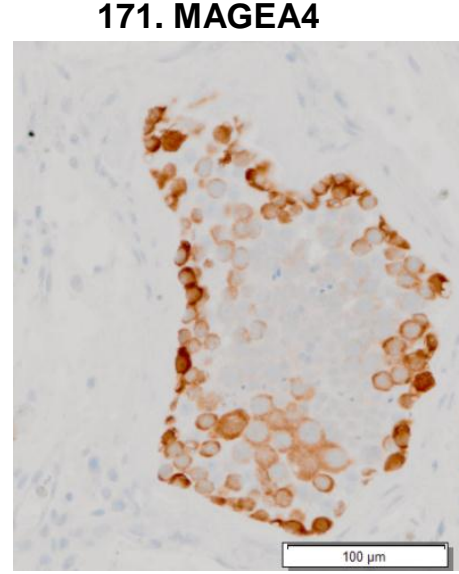

178. MAGEA4

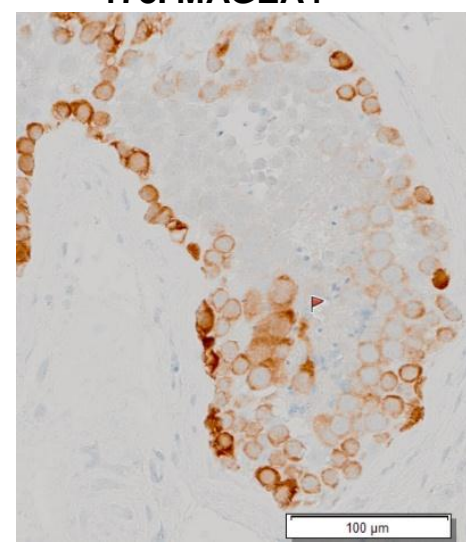

172. SSX

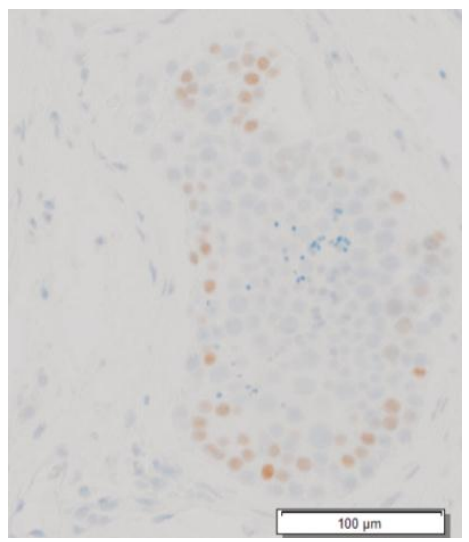

179. FGFR3

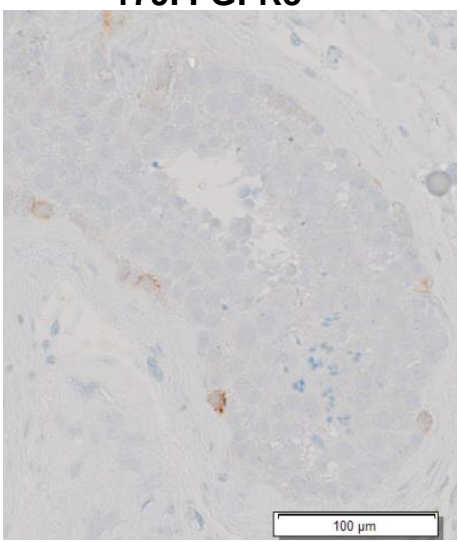

173. SAGE1

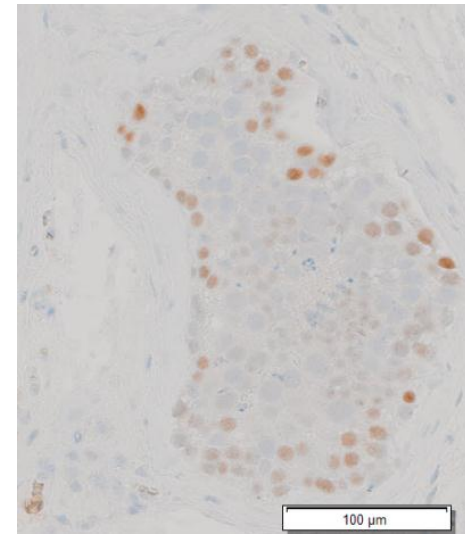

180. Ki67

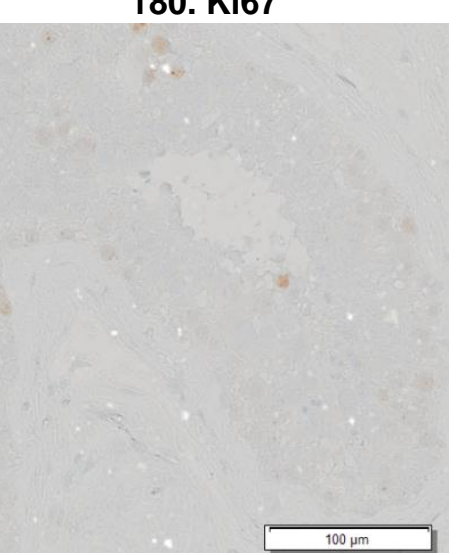

175. MAGEA4

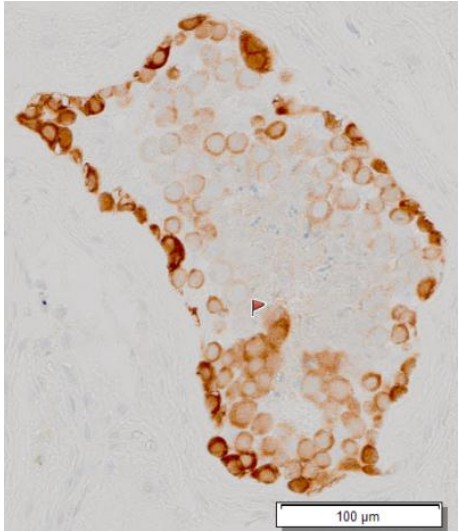

181. MAGEA4

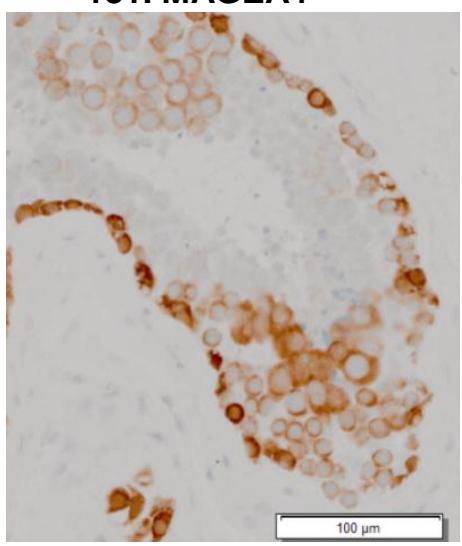

177. OCT2

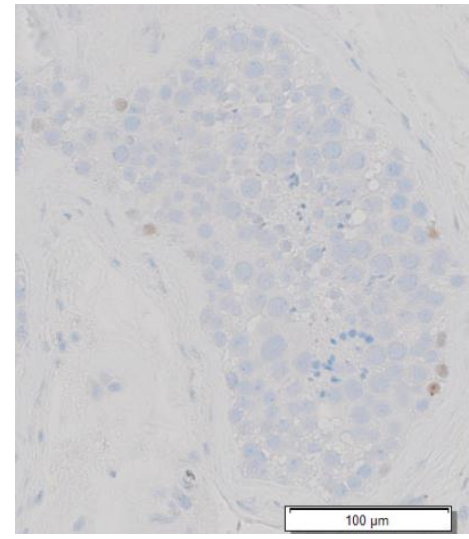

185. MAGEA4

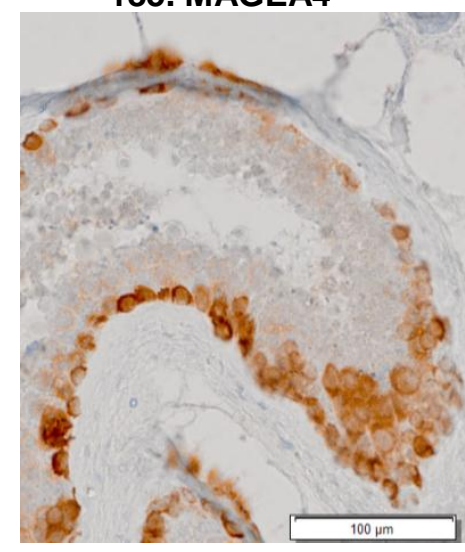




\section{Clone no. 1-2_C21}

A

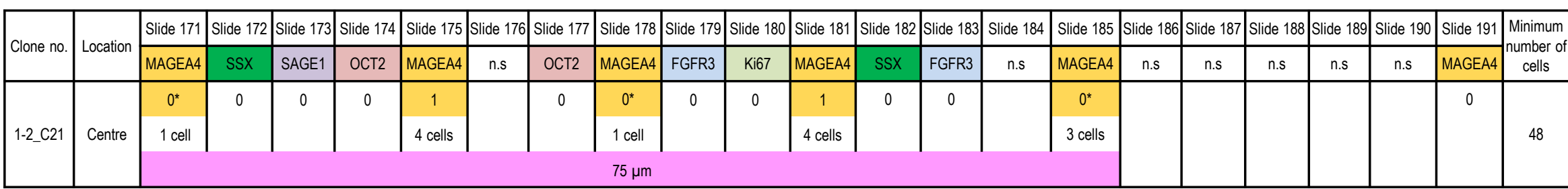

B

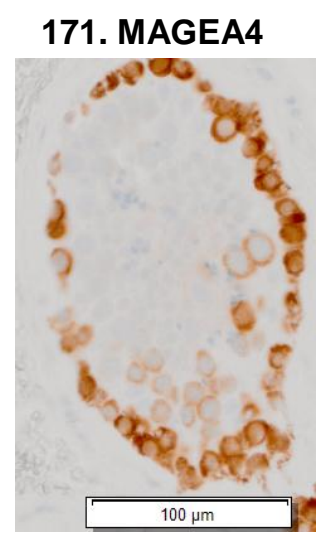

178. MAGEA4

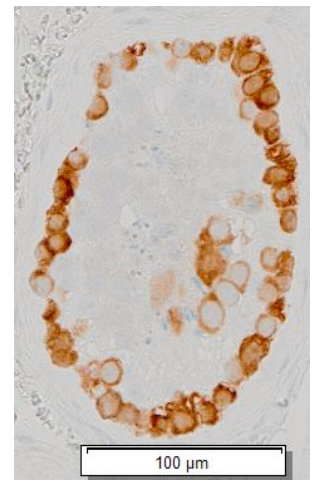

172. SSX

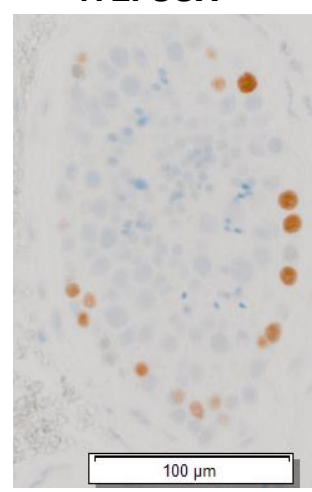

179. FGFR3

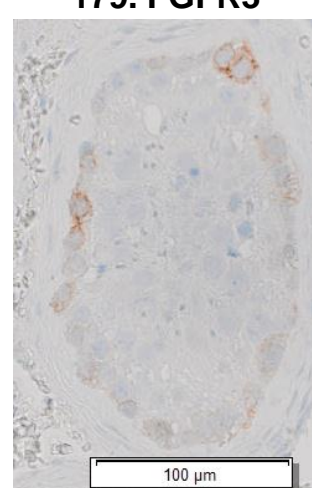

173. SAGE1

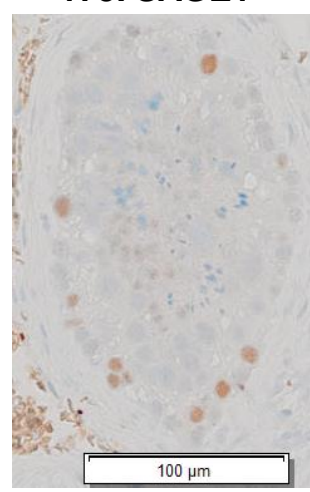

180. Ki67

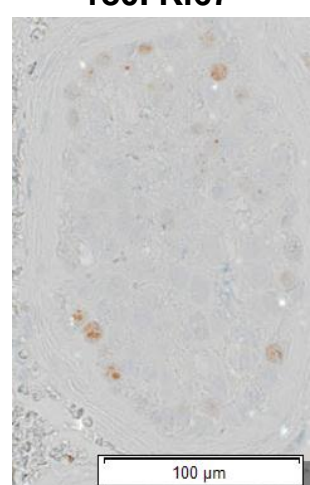

174. ОСТ2

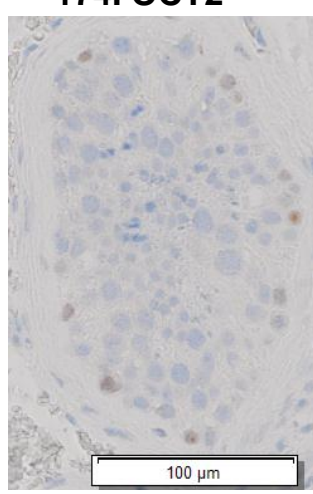

181. MAGEA4

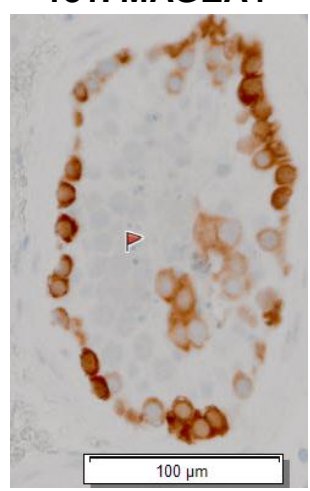

175. MAGEA4

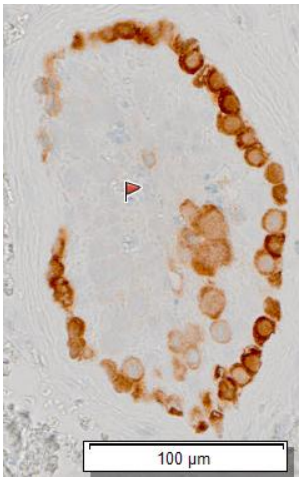

185. MAGEA4

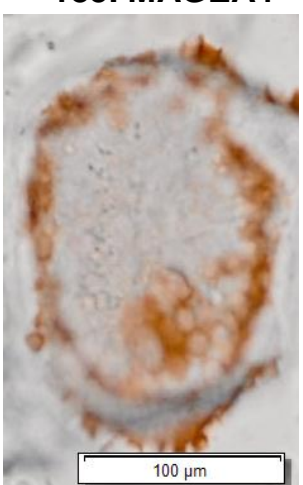




\section{Clone no. 1-2_C22}

A

\begin{tabular}{|c|c|c|c|c|c|c|c|c|c|c|c|c|c|c|c|c|c|}
\hline \multirow{2}{*}{ Clone no. } & \multirow{2}{*}{ Location } & Slide 171 & Slide 172 & Slide 173 & Slide 174 & Slide 175 & Slide 176 & Slide 177 & Slide 178 & Slide 179 & Slide 180 & Slide 181 & Slide 182 & Slide $18 ?$ & Slide 184 & Slide 185 & \multirow{2}{*}{$\begin{array}{l}\text { Minimum } \\
\text { number of } \\
\text { cells }\end{array}$} \\
\hline & & MAGEA4 & SsX & SAGE1 & ОСТ2 & MAGEA4 & n.s & Ост2 & MAGEA4 & FGFR3 & Ki67 & MAGEA4 & SSX & FGFR3 & n.s & MAGEA4 & \\
\hline \multirow{3}{*}{ 1-2_C22 } & \multirow{3}{*}{ Centre } & \multirow[t]{3}{*}{0} & \multirow[t]{3}{*}{0} & \multirow[t]{3}{*}{0} & \multirow[t]{3}{*}{0} & 1 & & \multirow[t]{2}{*}{0} & 1 & \multirow[t]{2}{*}{0} & \multirow[t]{2}{*}{0} & 1 & \multirow[t]{3}{*}{0} & & & \multirow[t]{3}{*}{ NA } & \multirow{3}{*}{57} \\
\hline & & & & & & 5 cells & & & 11 cells & & & 7 cells & & & & & \\
\hline & & & & & & \multicolumn{7}{|c|}{$35 \mu \mathrm{m}$} & & & & & \\
\hline
\end{tabular}

B

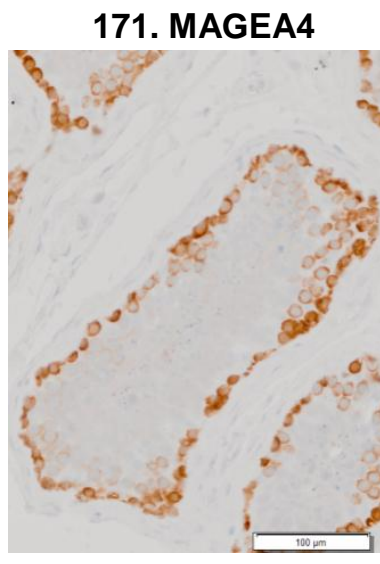

173. SAGE1

175. MAGEA4

177. OCT2

178. MAGEA4

179. FGFR3

180. Ki67

181. MAGEA4

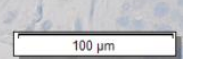

182. SSX
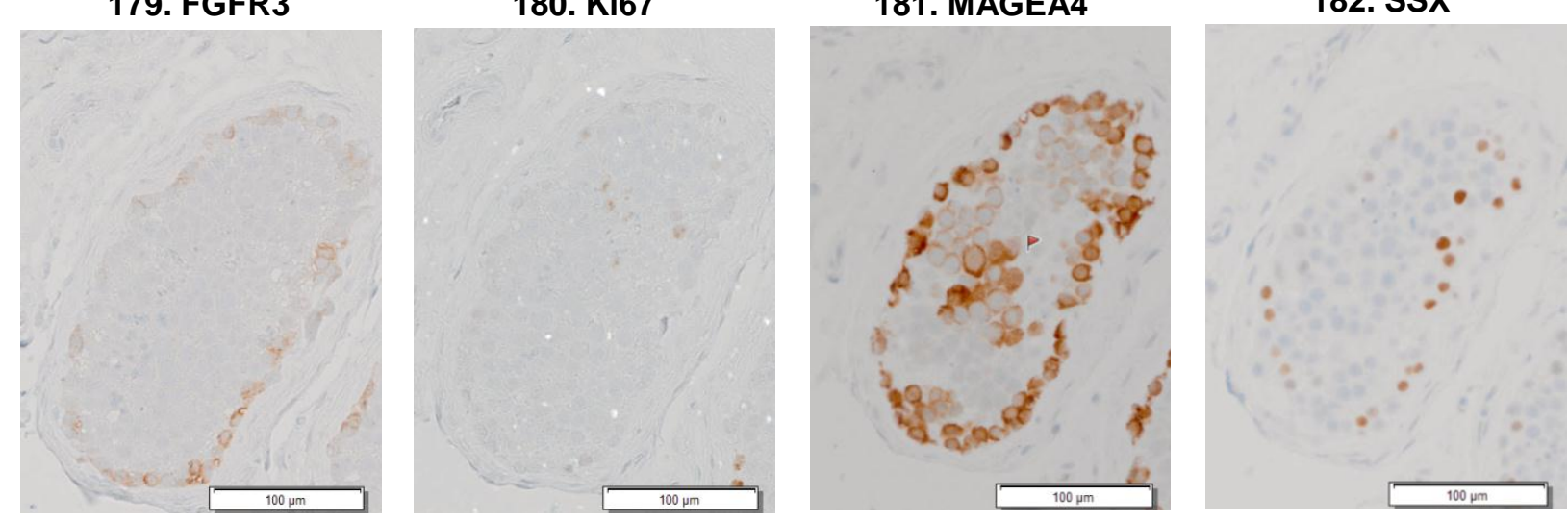
Clone no. 1-2_C23

A

\begin{tabular}{|c|c|c|c|c|c|c|c|c|c|c|c|c|c|}
\hline \multirow{2}{*}{ Clone no. } & \multirow{2}{*}{ Location } & Slide 171 & Slide 172 & Slide 173 & Slide 174 & Slide 175 & Slide 176 & Slide 177 & Slide 178 & Slide 179 & Slide 180 & Slide 181 & \multirow{2}{*}{$\begin{array}{c}\text { Minimum } \\
\text { number of cells }\end{array}$} \\
\hline & & MAGEA4 & SSX & SAGE1 & OCT2 & MAGEA4 & n.s & OCT2 & MAGEA4 & FGFR3 & Ki67 & MAGEA4 & \\
\hline \multirow{3}{*}{ 1-2_C23 } & \multirow{3}{*}{ Centre } & \multirow[t]{3}{*}{ NA } & \multirow[t]{3}{*}{ NA } & \multirow[t]{3}{*}{ NA } & \multirow[t]{3}{*}{0} & 1 & & \multirow[t]{2}{*}{0} & 1 & \multirow[t]{3}{*}{0} & \multirow[t]{3}{*}{0} & \multirow[t]{3}{*}{ NA } & \multirow{3}{*}{24} \\
\hline & & & & & & 5 cells & & & 7 cells & & & & \\
\hline & & & & & & \multicolumn{4}{|c|}{$20 \mu \mathrm{m}$} & & & & \\
\hline
\end{tabular}

B

173. SAGE1

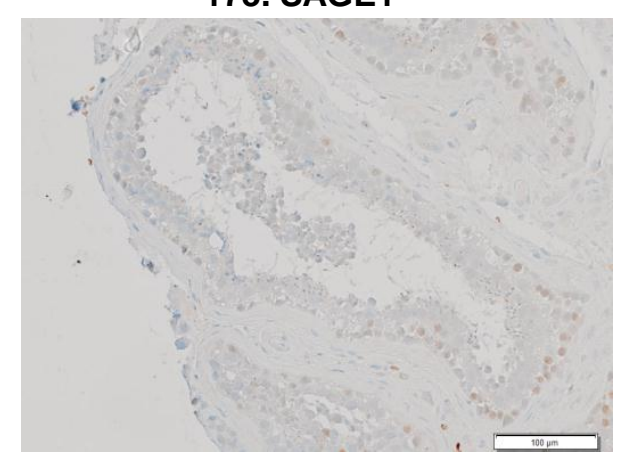

178. MAGEA4

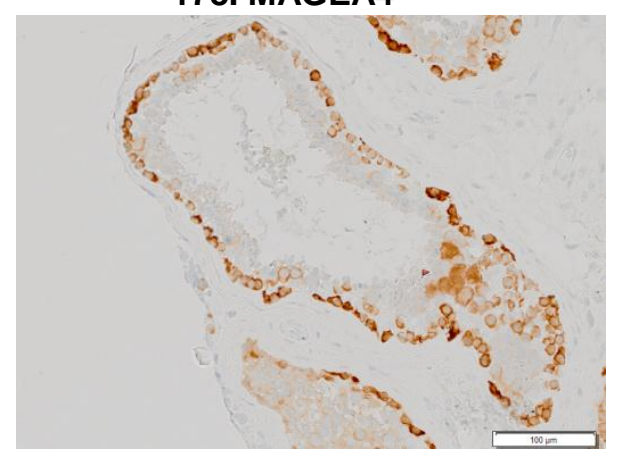

175. MAGEA4

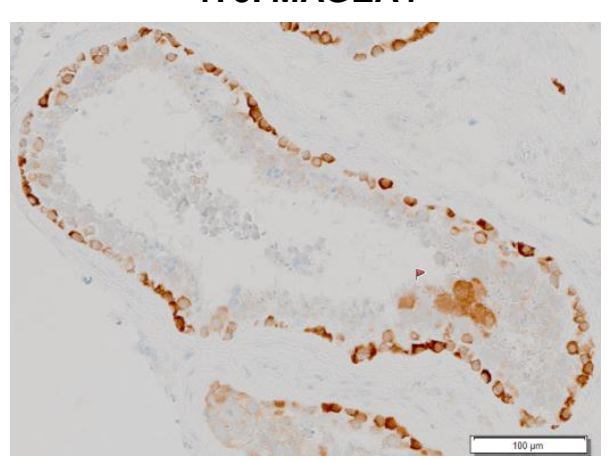

179. FGFR3

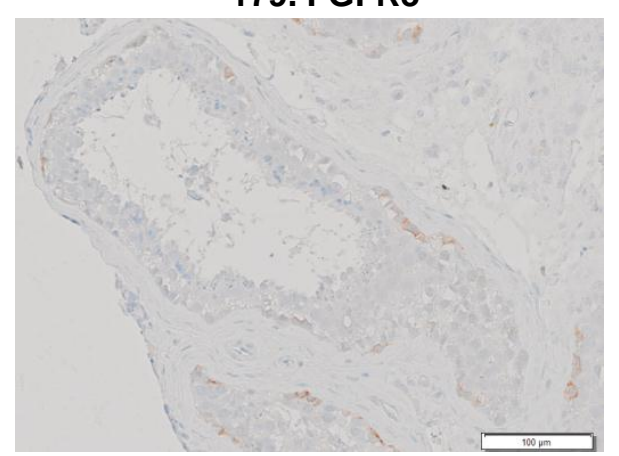

177. ОСТ2

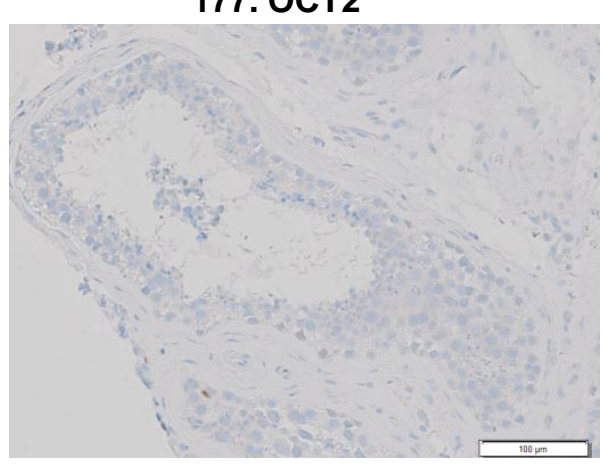

180. Ki67

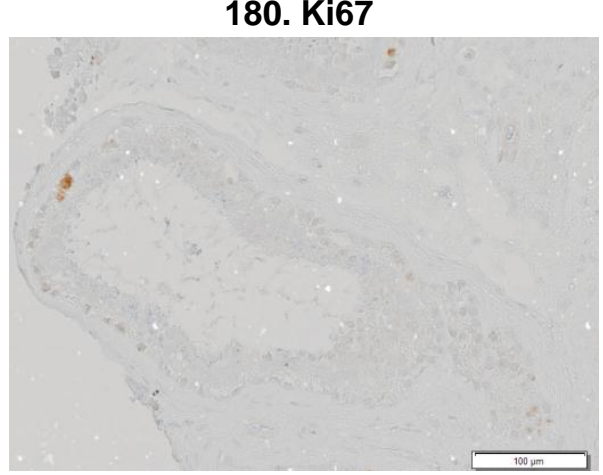


Clone no. 1-2_C24

A

\begin{tabular}{|c|c|c|c|c|c|c|c|c|c|c|c|c|c|c|c|c|c|}
\hline \multirow{2}{*}{ Clone no. } & \multirow{2}{*}{ Location } & Slide 171 & Slide 172 & Slide 173 & Slide 174 & Slide 175 & Slide 176 & Slide 177 & Slide 178 & Slide 179 & Slide 180 & Slide 181 & Slide 182 & Slide 183 & Slide 184 & Slide 185 & \multirow{2}{*}{$\begin{array}{l}\text { Minimum } \\
\text { number of } \\
\text { cells }\end{array}$} \\
\hline & & MAGEA4 & SSX & SAGE1 & Ост2 & MAGEA4 & n.s & ОСТ2 & MAGEA4 & FGFR3 & Ki67 & MAGEA4 & ssX & FGFR3 & n.s & MAGEA4 & \\
\hline \multirow{3}{*}{ 1-2_C24 } & \multirow{3}{*}{ Periphery } & \multirow[t]{3}{*}{0} & \multirow[t]{3}{*}{0} & \multirow[t]{3}{*}{0} & \multirow[t]{3}{*}{0} & 1 & & \multirow[t]{2}{*}{0} & 1 & \multirow[t]{2}{*}{0} & \multirow[t]{2}{*}{0} & 1 & \multirow[t]{3}{*}{0} & & & \multirow[t]{3}{*}{0} & \multirow{3}{*}{83} \\
\hline & & & & & & 8 cells & & & 13 cells & & & 14 cells & & & & & \\
\hline & & & & & & & & & $35 \mu \mathrm{m}$ & & & & & & & & \\
\hline
\end{tabular}

B

171. MAGEA4

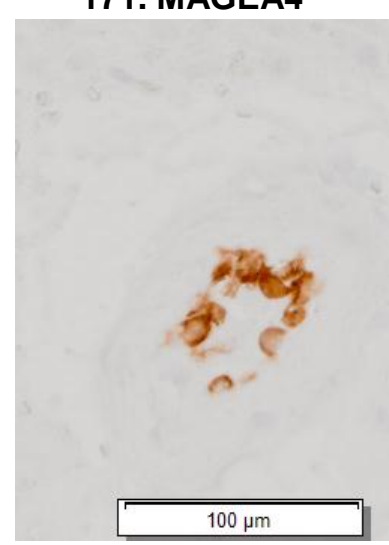

173. SAGE1

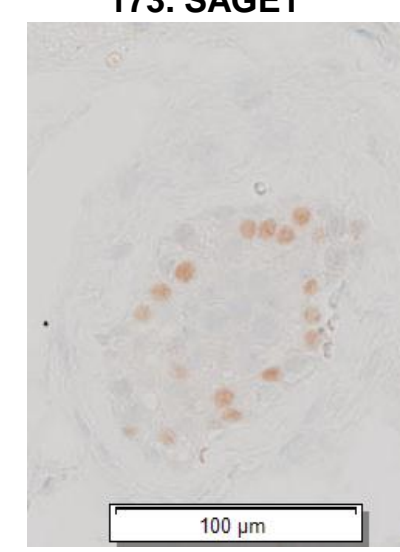

180. Ki67

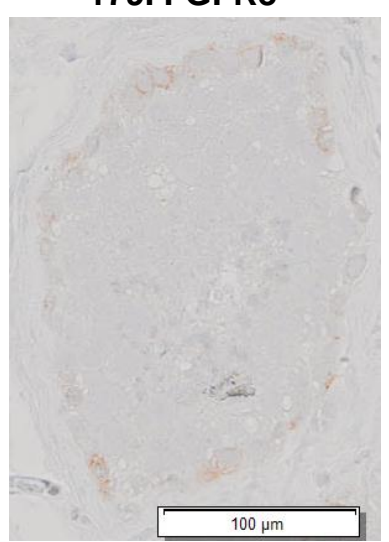

175. MAGEA4

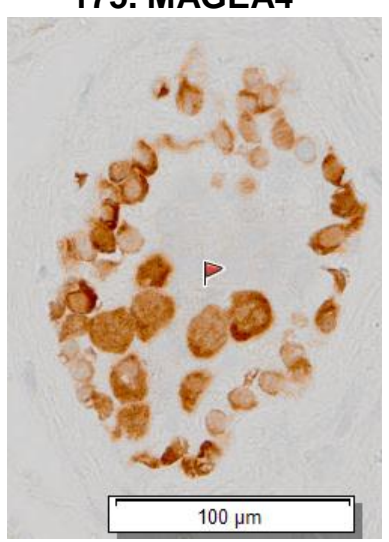

177. OCT2

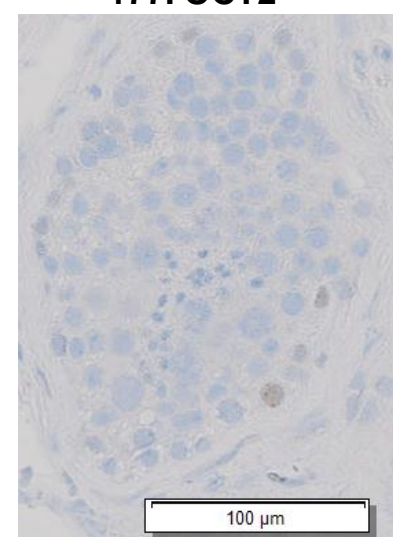

178. MAGEA4

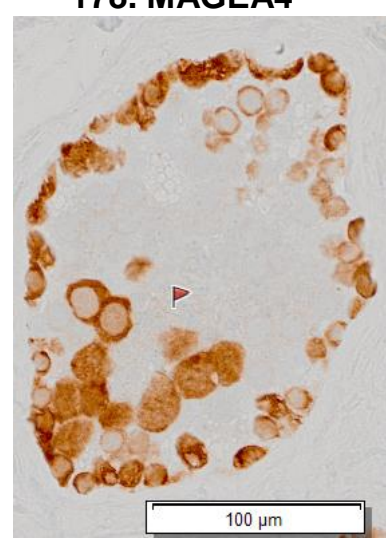

181. MAGEA4

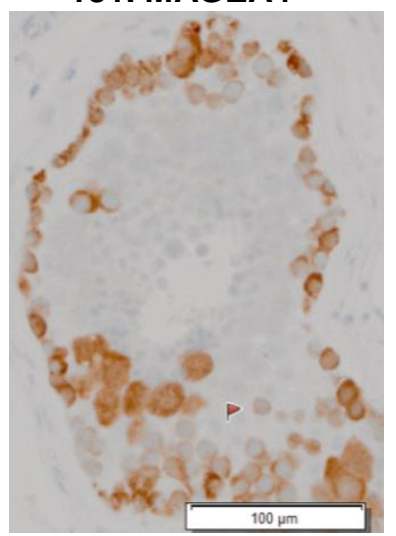

182. SSX

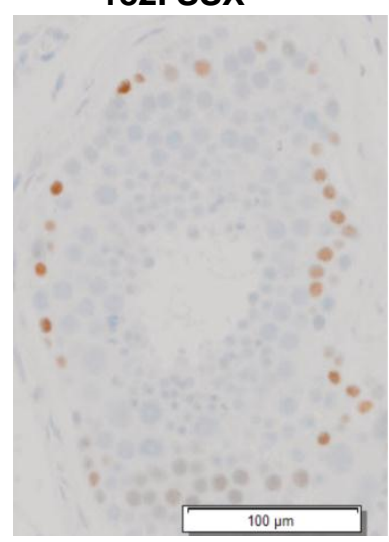


Clone no. 1-2_C25

A

\begin{tabular}{|c|c|c|c|c|c|c|c|c|c|c|c|c|c|c|}
\hline \multirow{2}{*}{ Clone no. } & \multirow{2}{*}{ Location } & Slide 170 & Slide 171 & Slide 172 & Slide 173 & Slide 174 & Slide 175 & Slide 176 & Slide 177 & Slide 178 & Slide 179 & Slide 180 & Slide 181 & \multirow{2}{*}{$\begin{array}{l}\text { Minimum } \\
\text { number of } \\
\text { cells }\end{array}$} \\
\hline & & Ki67 & MAGEA4 & ss $x$ & SAGE1 & ОСТ2 & MAGEA4 & n.s & Ост2 & MAGEA4 & FGFR3 & Ki67 & MAGEA4 & \\
\hline \multirow{3}{*}{ 1-2_C25 } & \multirow{3}{*}{ Centre } & 0 & $0^{*}$ & \multirow[t]{2}{*}{0} & \multirow[t]{2}{*}{0} & \multirow[t]{2}{*}{0} & 1 & & \multirow[t]{2}{*}{0} & 1 & \multirow[t]{3}{*}{0} & & \multirow[t]{3}{*}{0} & \multirow{3}{*}{30} \\
\hline & & & 2 cells & & & & 4 cells & & & 5 cells & & & & \\
\hline & & & \multicolumn{8}{|c|}{$40 \mu \mathrm{m}$} & & & & \\
\hline
\end{tabular}

B
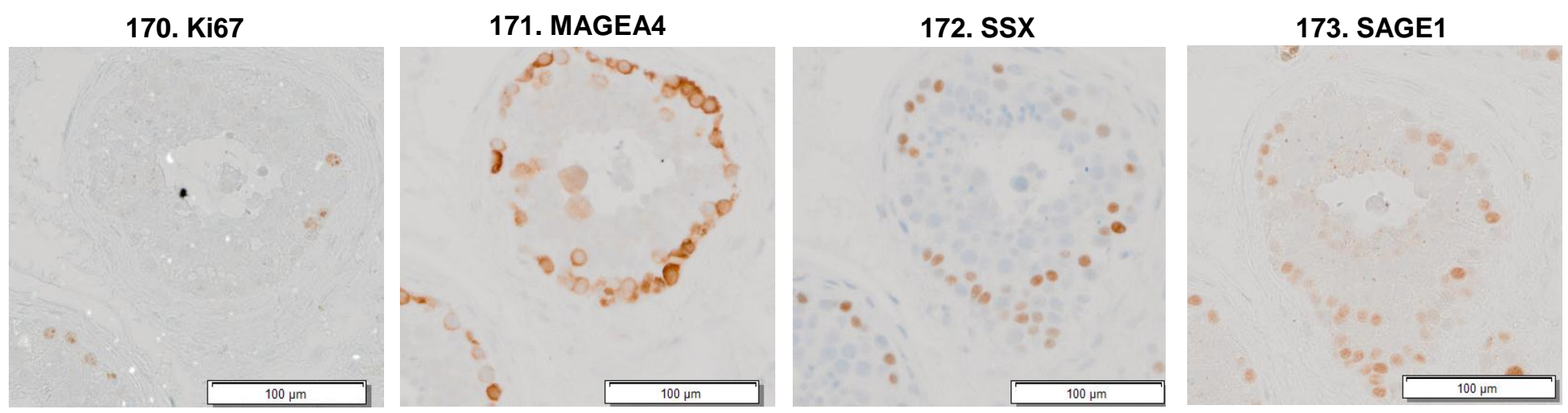

175. MAGEA4

177. ОСТ2

178. MAGEA4
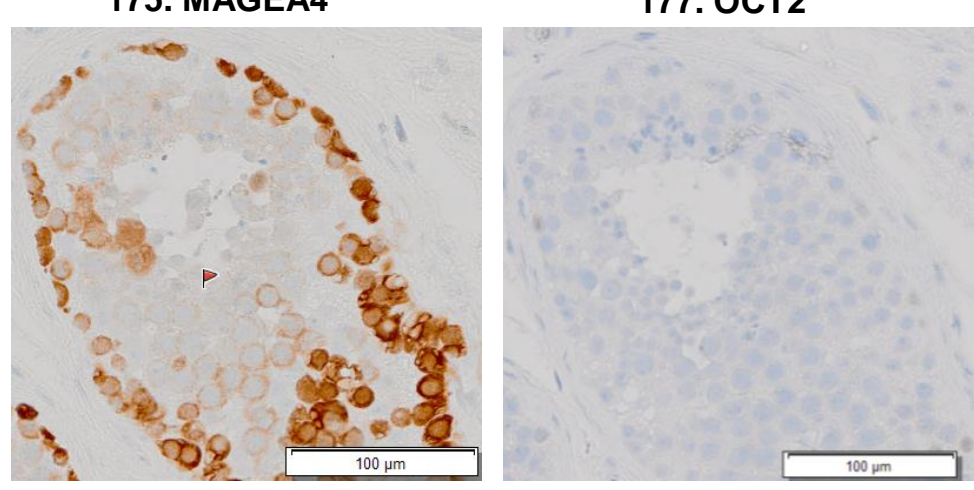

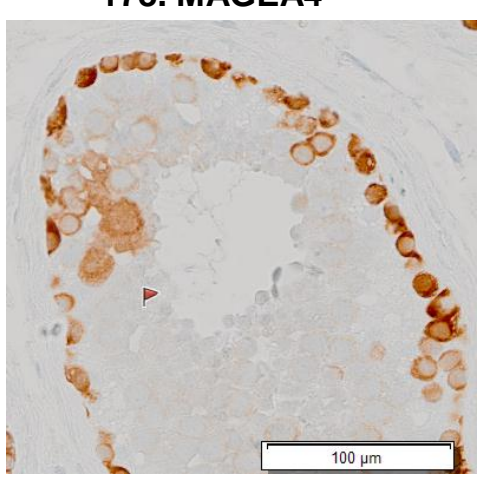

179. FGFR3

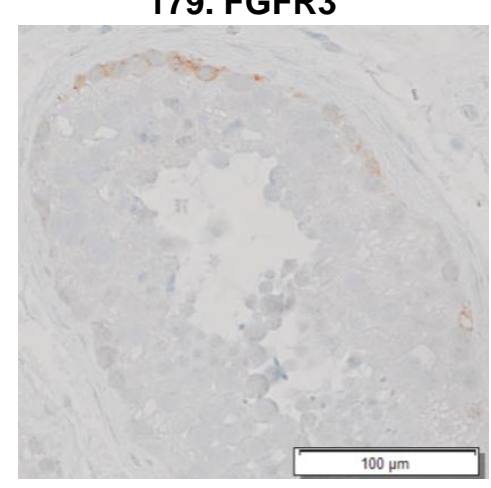


Clone no. 1-2_C26

A

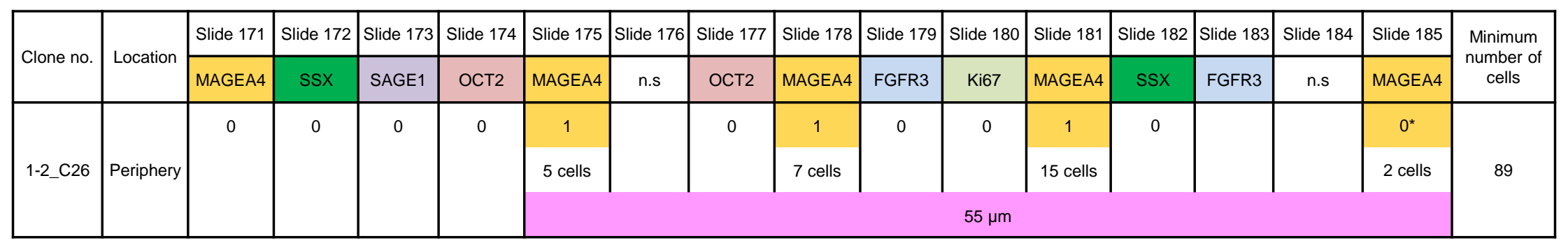

B

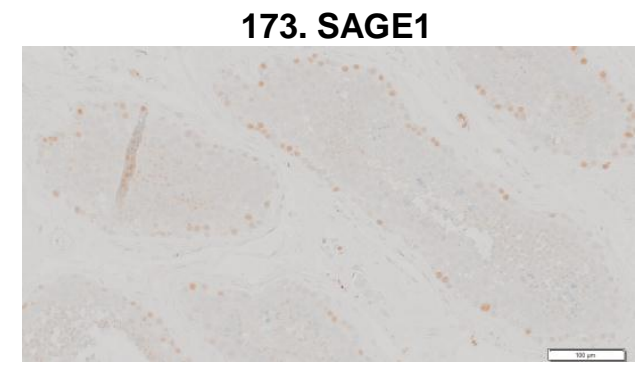

178. MAGEA4

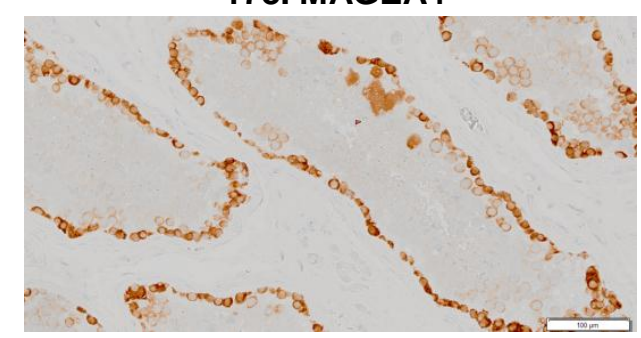

181. MAGEA4

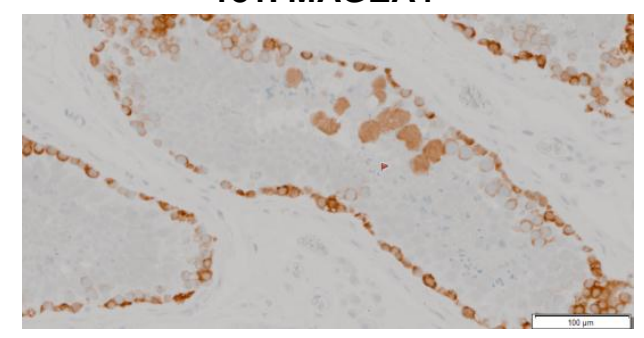

175. MAGEA4

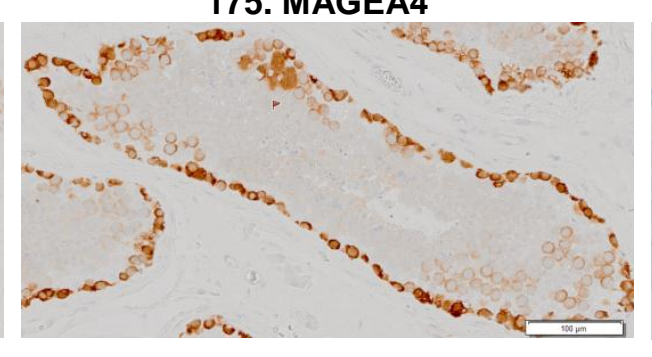

179. FGFR3

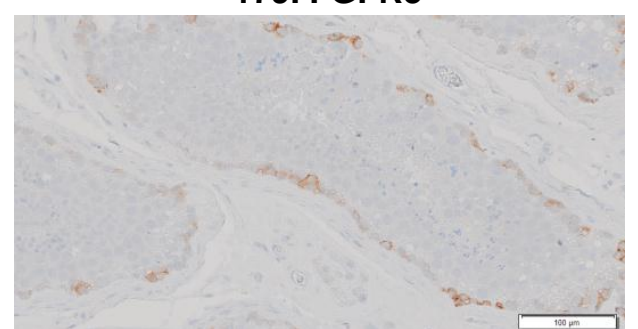

182. SSX

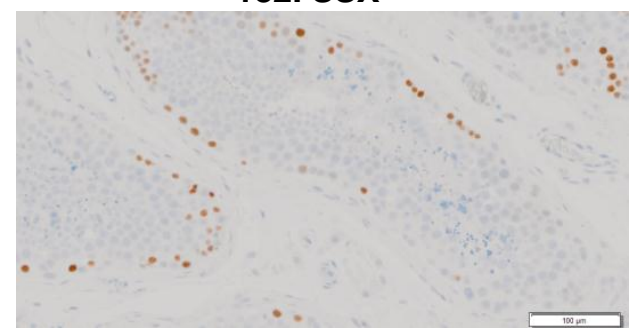

177. ОСT2

180. Ki67

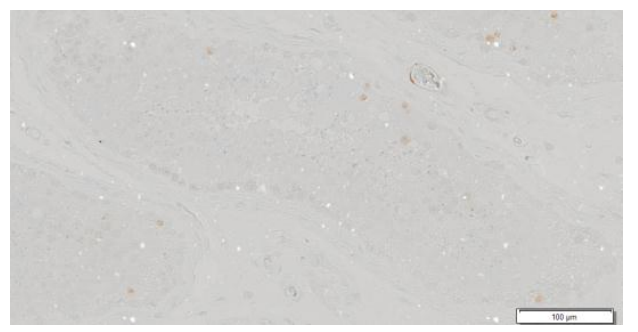

185. MAGEA4

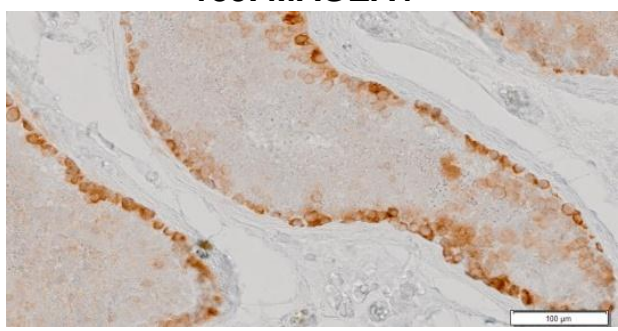




\section{Clone no. 1-2_C27}

A

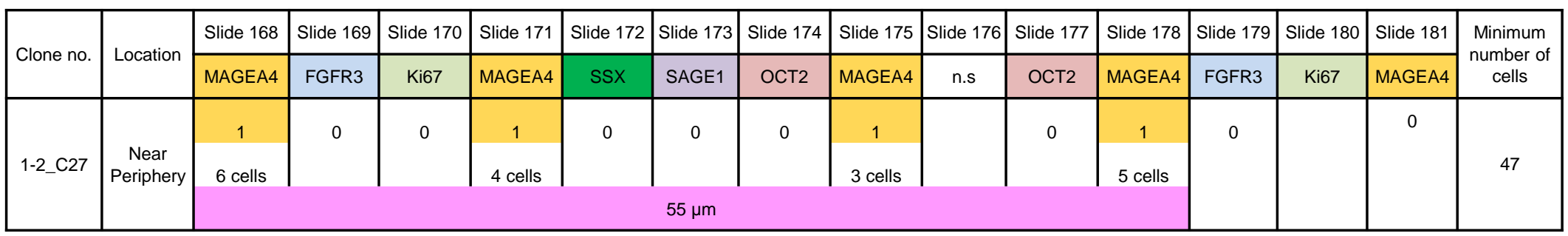

B

168. MAGEA4

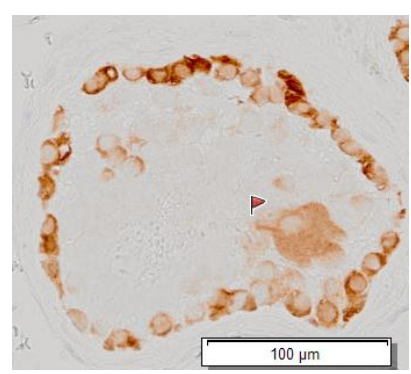

173. SAGE1

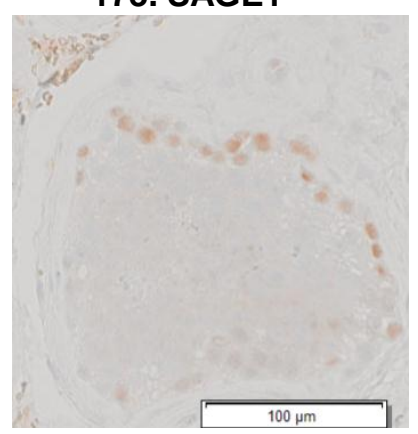

169. FGFR3

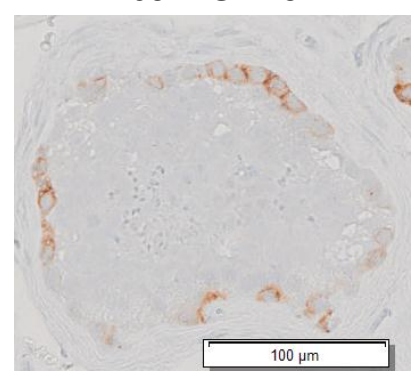

174. OCT2

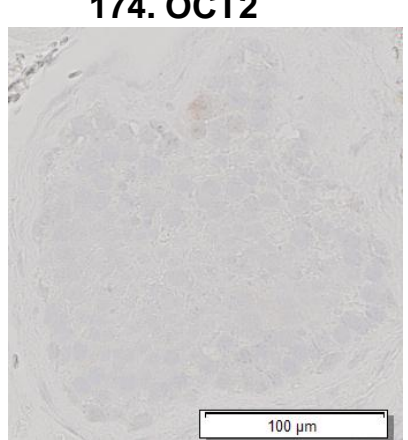

170. Ki67

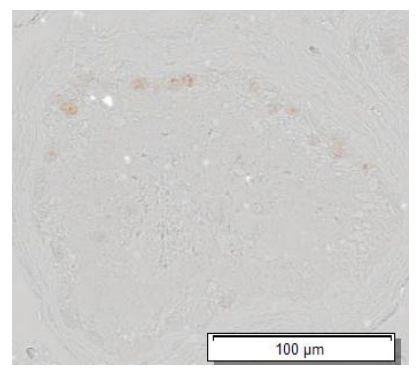

175. MAGEA4

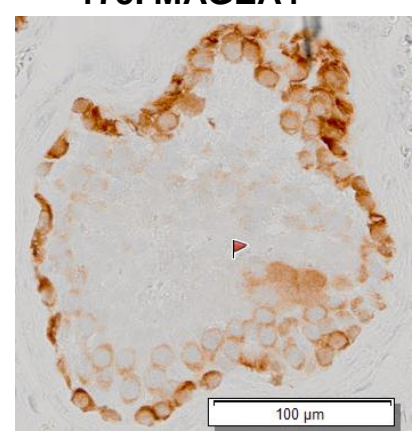

171. MAGEA4

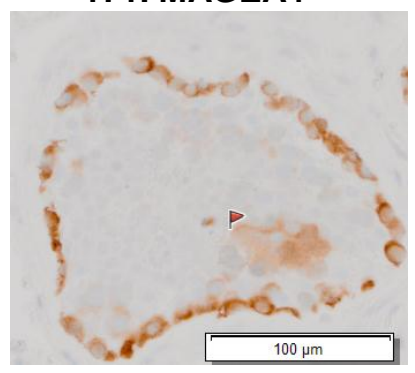

178. MAGEA4

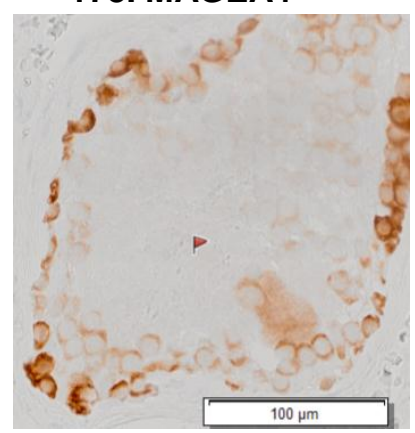

172. SSX

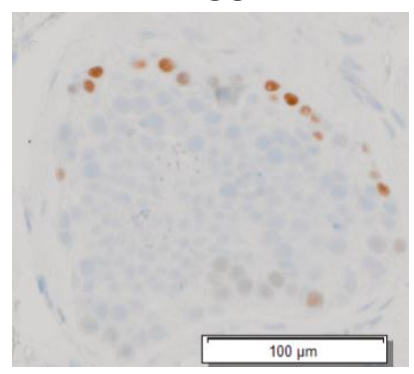

181. MAGEA4

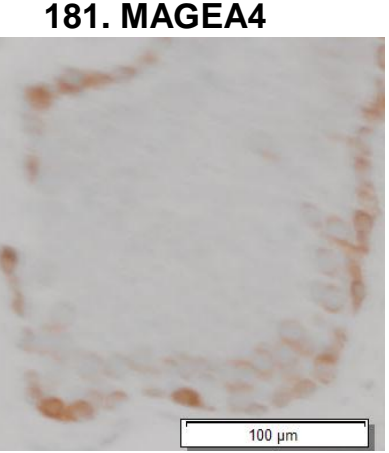




\section{Clone no. 1-2_C28}

A

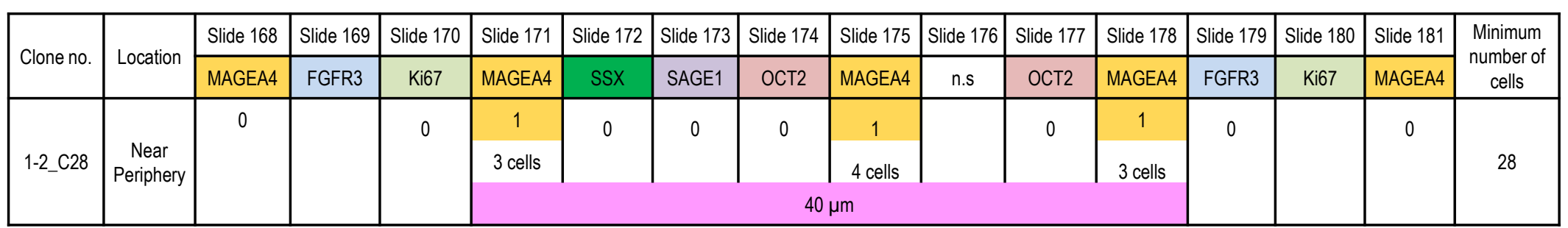

B
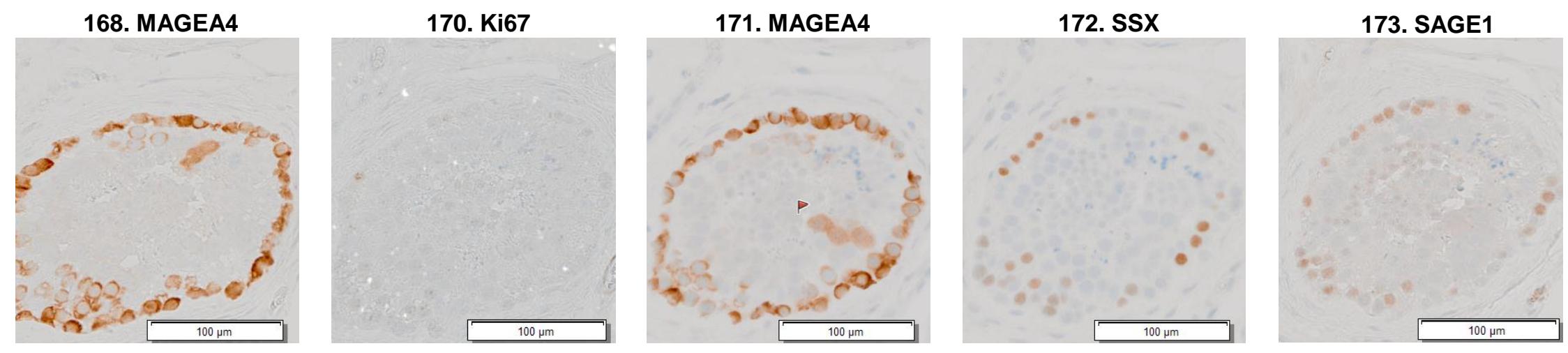

174. OCT2

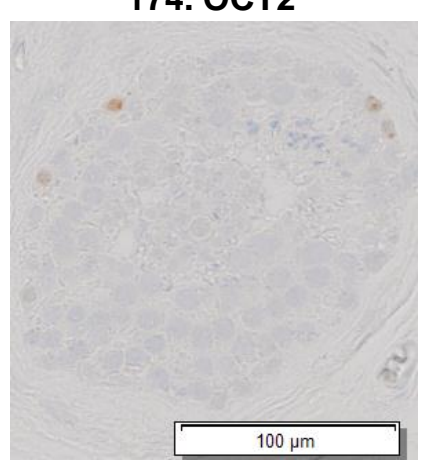

175. MAGEA4

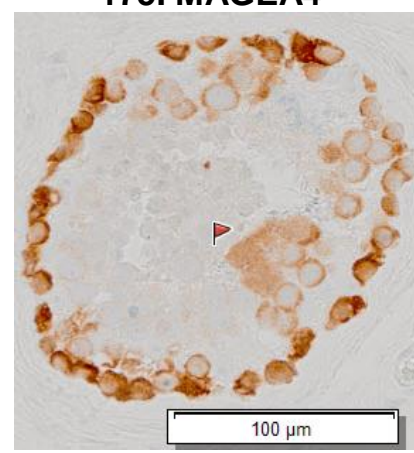

178. MAGEA4

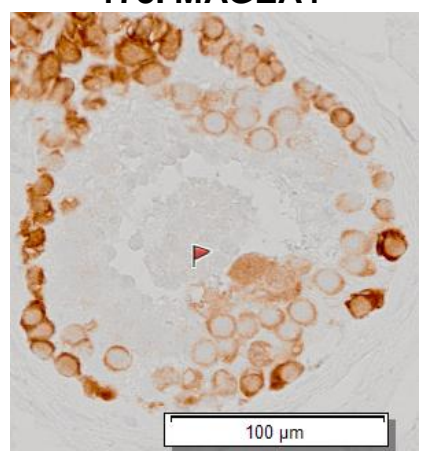

179. FGFR3

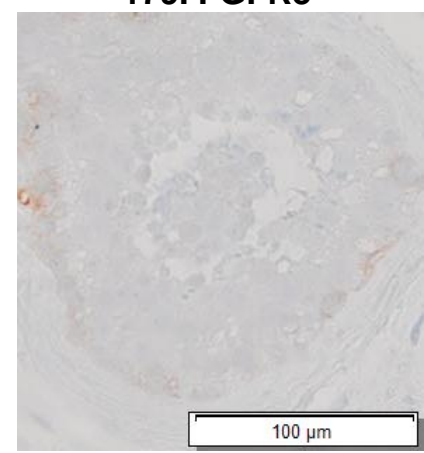


Clone no. 1-2_C29

A

\begin{tabular}{|c|c|c|c|c|c|c|c|c|c|c|c|c|c|}
\hline \multirow{2}{*}{ Clone no. } & \multirow{2}{*}{ Location } & Slide 171 & Slide 172 & Slide 173 & Slide 174 & Slide 175 & Slide 176 & Slide 177 & Slide 178 & Slide 179 & Slide 180 & Slide 181 & \multirow{2}{*}{$\begin{array}{l}\text { Minimum } \\
\text { number of } \\
\text { cells }\end{array}$} \\
\hline & & MAGEA4 & SsX & SAGE1 & Ост2 & MAGEA4 & n.s & Ост2 & MAGEA4 & FGFR3 & Ki67 & MAGEA4 & \\
\hline \multirow{3}{*}{ 1-2_C29 } & \multirow{3}{*}{$\begin{array}{c}\text { Near } \\
\text { Periphery }\end{array}$} & \multirow[t]{3}{*}{0} & \multirow[t]{3}{*}{0} & \multirow[t]{3}{*}{0} & \multirow[t]{3}{*}{0} & 1 & & 0 & 1 & \multirow[t]{3}{*}{0} & & \multirow[t]{3}{*}{0} & \multirow{3}{*}{18} \\
\hline & & & & & & 6 cells & & & 3 cells & & & & \\
\hline & & & & & & \multicolumn{4}{|c|}{$20 \mu \mathrm{m}$} & & & & \\
\hline
\end{tabular}

B
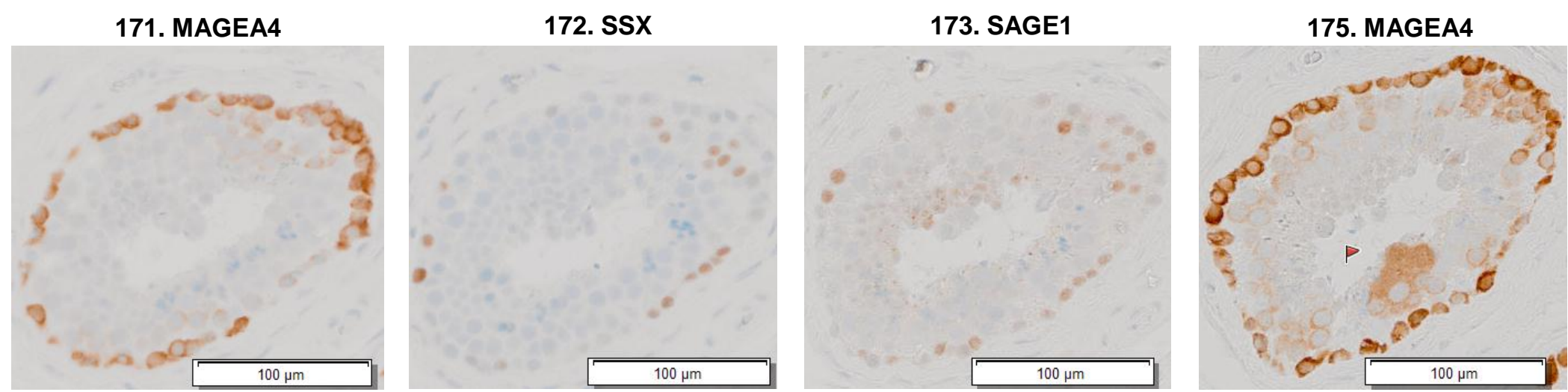

177. ОСТ2

178. MAGEA4

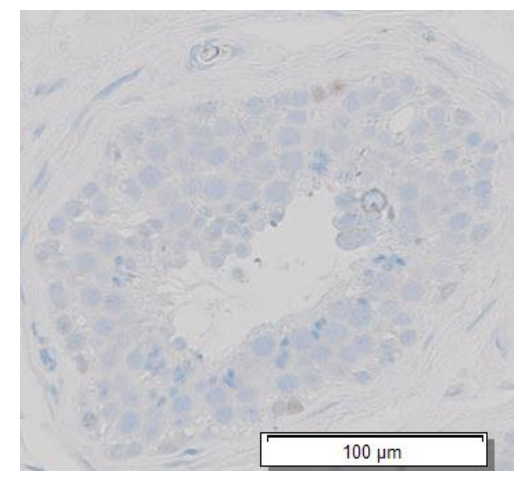

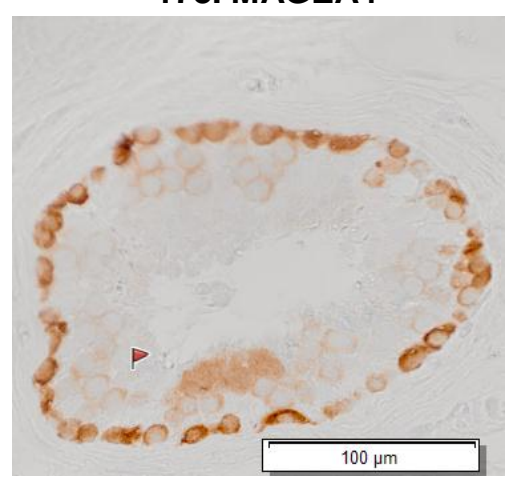

179. FGFR3

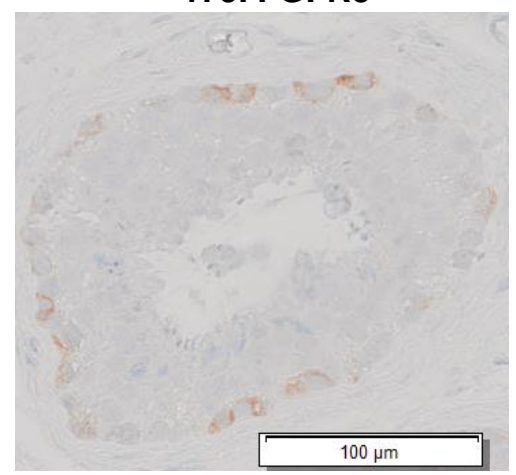

180. Ki67

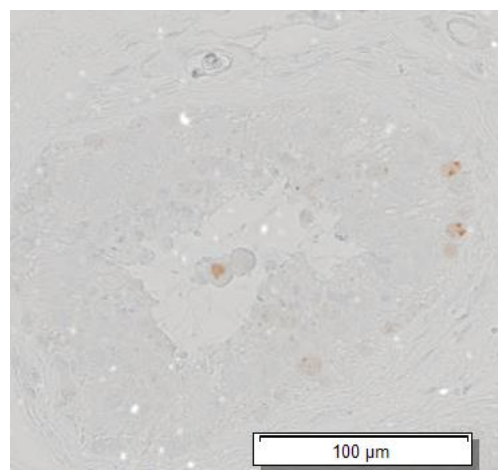




\section{Clone no. 1-2_C30}

A

\begin{tabular}{|c|c|c|c|c|c|c|c|c|c|c|c|c|c|}
\hline \multirow{2}{*}{ Clone no. } & \multirow{2}{*}{ Location } & Slide 175 & Slide 176 & Slide 177 & Slide 178 & Slide 179 & Slide 180 & Slide 181 & Slide 182 & Slide 183 & Slide 184 & Slide 185 & \multirow{2}{*}{$\begin{array}{l}\text { Minimum } \\
\text { number of } \\
\text { cells }\end{array}$} \\
\hline & & MAGEA4 & n.s & ОСТ2 & MAGEA4 & FGFR3 & Ki67 & MAGEA4 & SSX & FGFR3 & n.s & MAGEA4 & \\
\hline \multirow[b]{2}{*}{ 1-2_C30 } & \multirow[b]{2}{*}{ Centre } & \multirow[t]{2}{*}{ NA } & & \multirow[t]{2}{*}{0} & 1 & \multirow[t]{2}{*}{0} & \multirow[t]{2}{*}{0} & 1 & \multirow[t]{2}{*}{0} & & & \multirow[t]{2}{*}{ NA } & \multirow[b]{2}{*}{22} \\
\hline & & & & & 6 cells & & & 5 cells & & & & & \\
\hline
\end{tabular}

B

175. MAGEA4

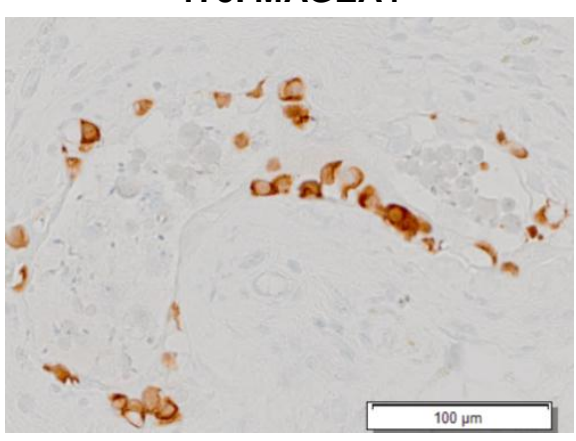

180. Ki67

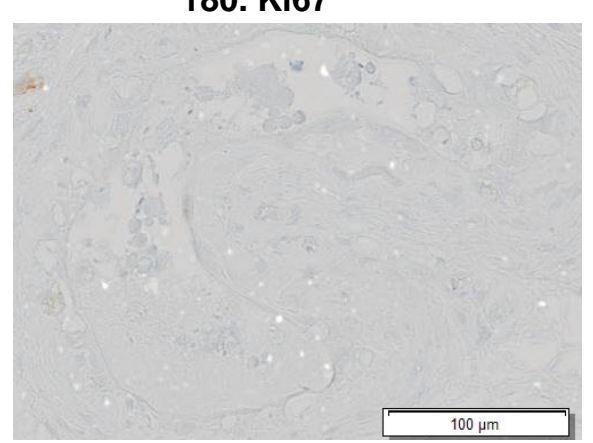

177. OCT2

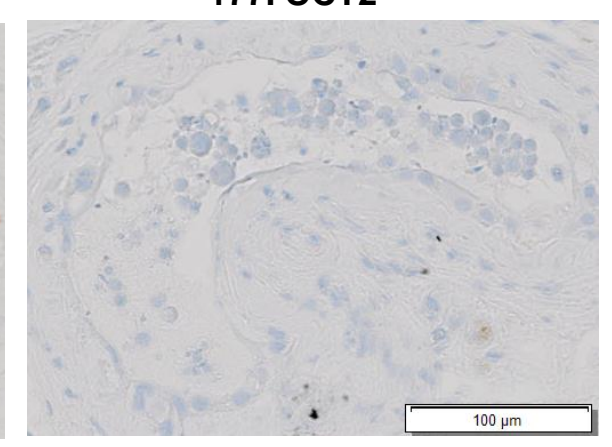

181. MAGEA4

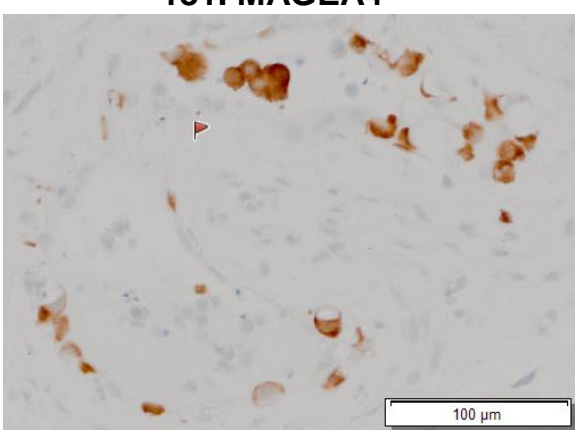

179. FGFR3

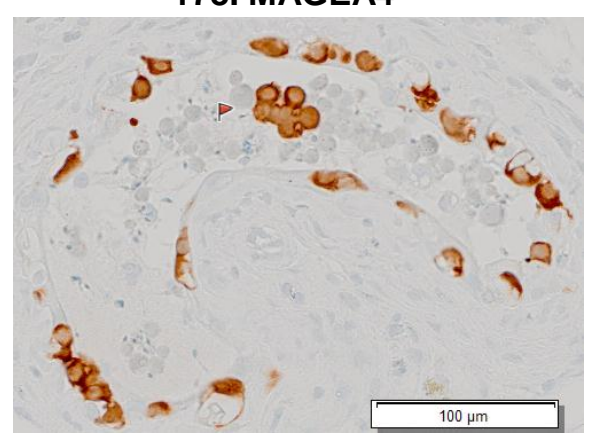

182. SSX

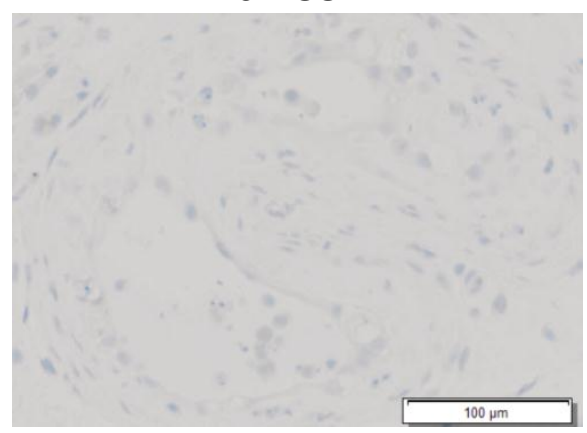




\section{Clone no. 1-2_C31}

A

\begin{tabular}{|c|c|c|c|c|c|c|c|c|c|c|c|c|c|}
\hline \multirow{2}{*}{ Clone no. } & \multirow{2}{*}{ Location } & Slide 171 & Slide 172 & Slide 173 & Slide 174 & Slide 175 & Slide 176 & Slide 177 & Slide 178 & Slide 179 & Slide 180 & Slide 181 & \multirow{2}{*}{$\begin{array}{l}\text { Minimum } \\
\text { number of } \\
\text { cells }\end{array}$} \\
\hline & & MAGEA4 & SSX & SAGE1 & ОСТ2 & MAGEA4 & n.s & ОСТ2 & MAGEA4 & FGFR3 & Ki67 & MAGEA4 & \\
\hline \multirow{3}{*}{ 1-2_C31 } & \multirow{3}{*}{ Centre } & \multirow[t]{3}{*}{0} & \multirow[t]{3}{*}{0} & \multirow[t]{3}{*}{0} & \multirow[t]{3}{*}{0} & 1 & & \multirow[t]{2}{*}{0} & 1 & \multirow[t]{3}{*}{0} & \multirow[t]{3}{*}{0} & \multirow[t]{3}{*}{0} & \multirow{3}{*}{26} \\
\hline & & & & & & 6 cells & & & 7 cells & & & & \\
\hline & & & & & & \multicolumn{4}{|c|}{$\mathrm{m}$} & & & & \\
\hline
\end{tabular}

B

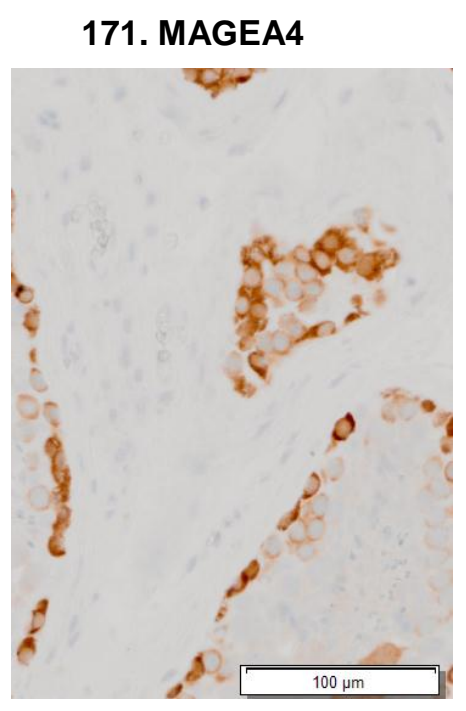

177. OCT2

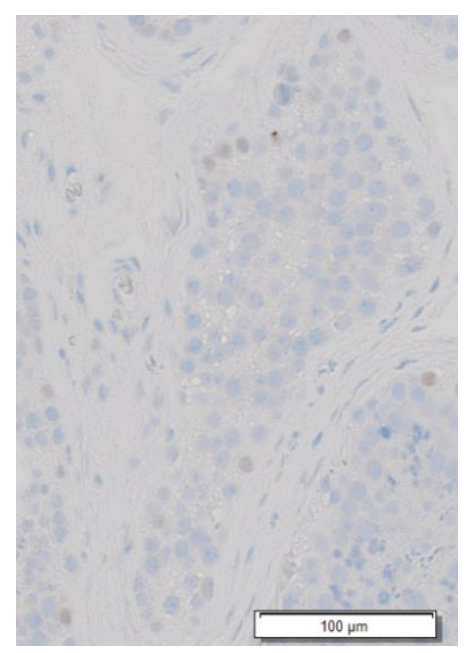

172. SSX

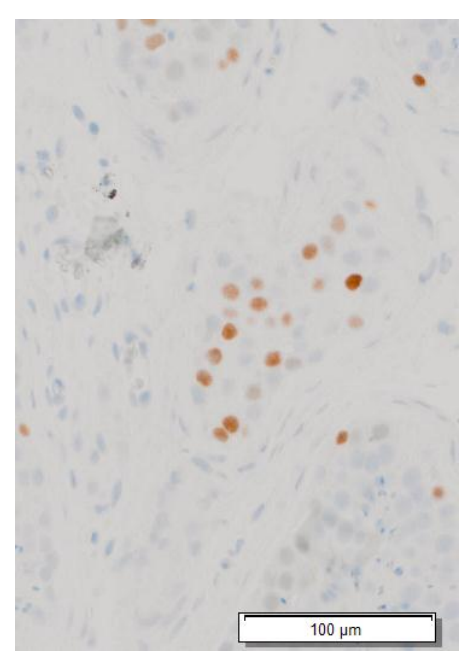

178. MAGEA4

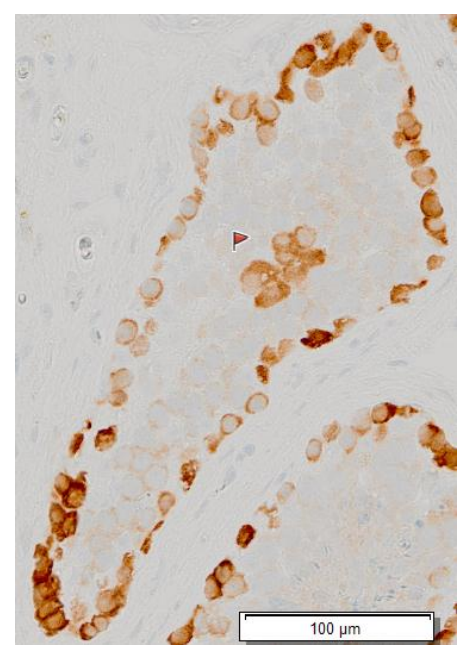

173. SAGE1

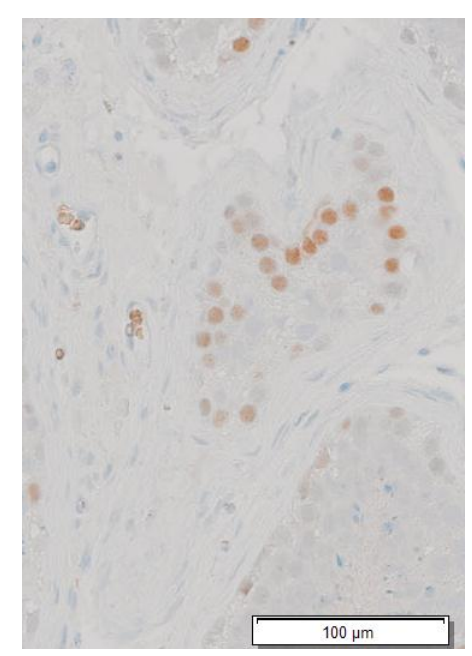

179. FGFR3
175. MAGEA4

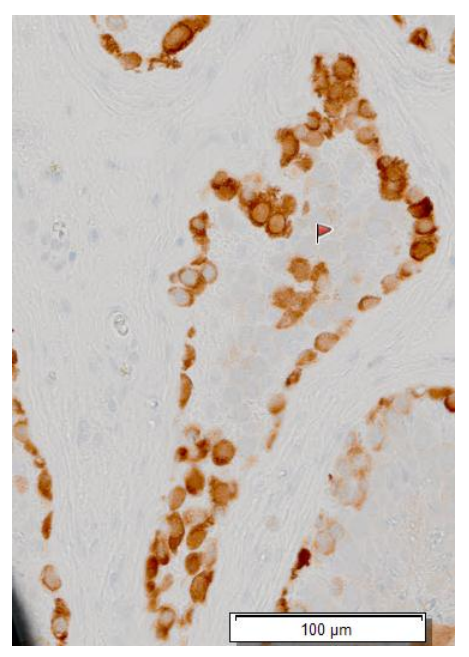

180. Ki67
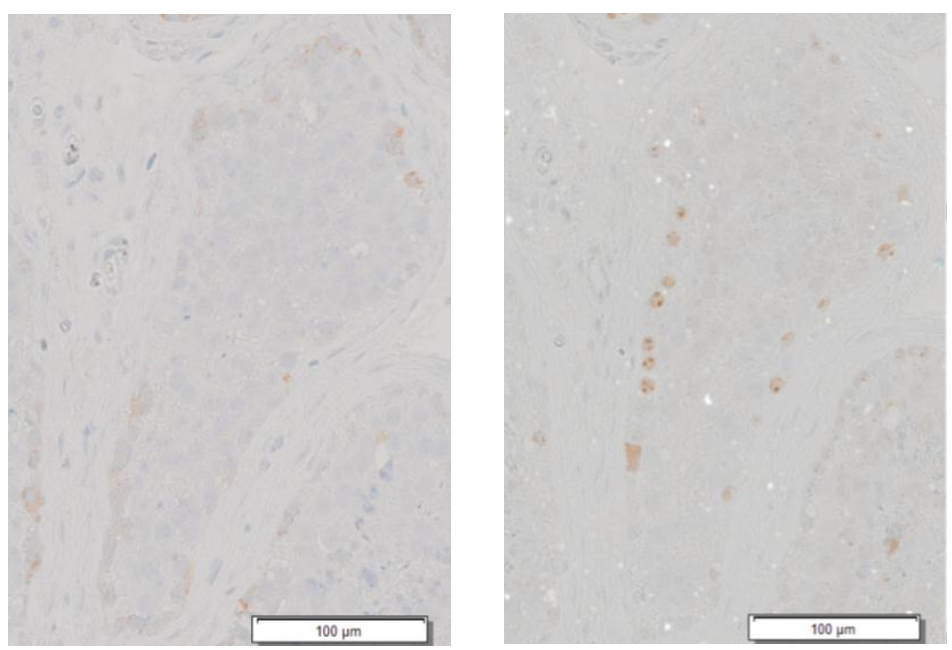


\section{Clone no. 1-2_C32}

A

\begin{tabular}{|c|c|c|c|c|c|c|c|c|c|c|c|c|c|}
\hline \multirow{2}{*}{ Clone no. } & \multirow{2}{*}{ Location } & Slide 175 & Slide 176 & Slide 177 & Slide 178 & Slide 179 & Slide 180 & Slide 181 & Slide 182 & Slide 183 & Slide 184 & Slide 185 & \multirow{2}{*}{$\begin{array}{c}\text { Minimum } \\
\text { number of } \\
\text { cells }\end{array}$} \\
\hline & & MAGEA4 & n.s & OCT2 & MAGEA4 & FGFR3 & Ki67 & MAGEA4 & SSX & FGFR3 & n.s & MAGEA4 & \\
\hline \multirow{2}{*}{ 1-2_C32 } & \multirow{2}{*}{$\begin{array}{c}\text { Near } \\
\text { Periphery }\end{array}$} & \multirow[t]{2}{*}{ NA } & & \multirow[t]{2}{*}{0} & 1 & 0 & 0 & 1 & \multirow[t]{2}{*}{0} & & & \multirow[t]{2}{*}{ NA } & \multirow{2}{*}{18} \\
\hline & & & & & \multicolumn{4}{|c|}{$20 \mu \mathrm{m}$} & & & & & \\
\hline
\end{tabular}

B

175. MAGEA4

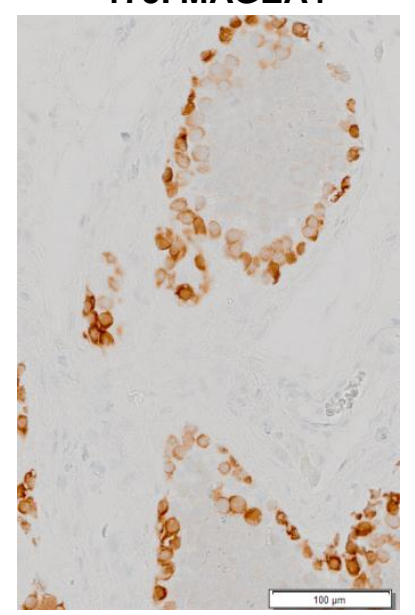

180. Ki67

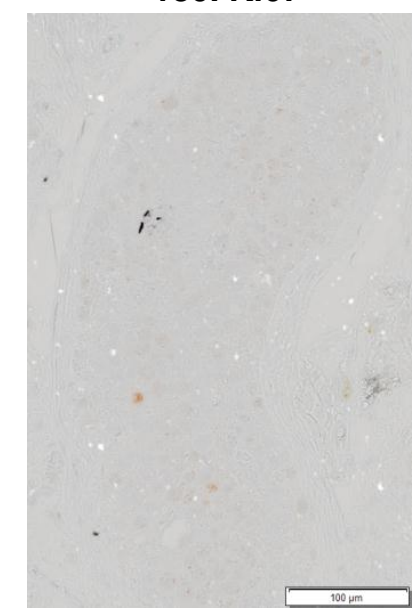

177. ОСТ2

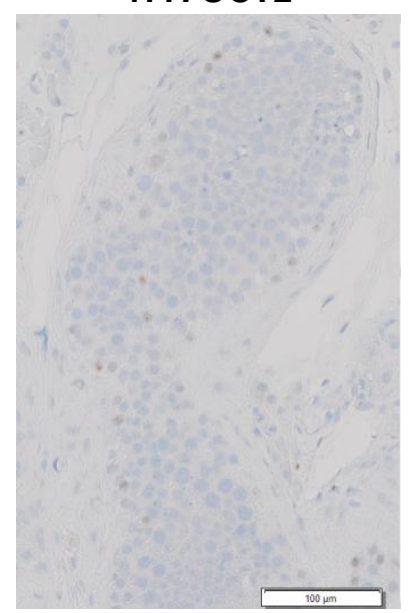

181. MAGEA4

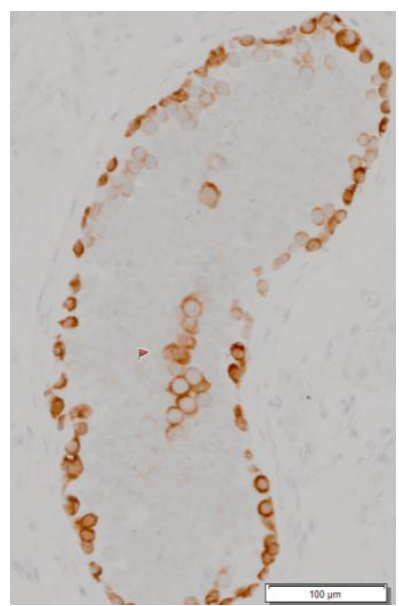

178. MAGEA4

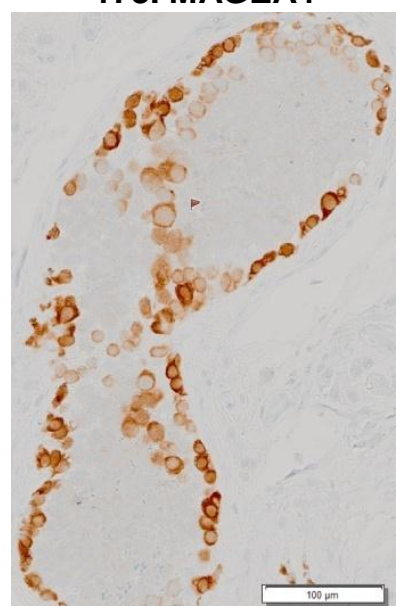

179. FGFR3

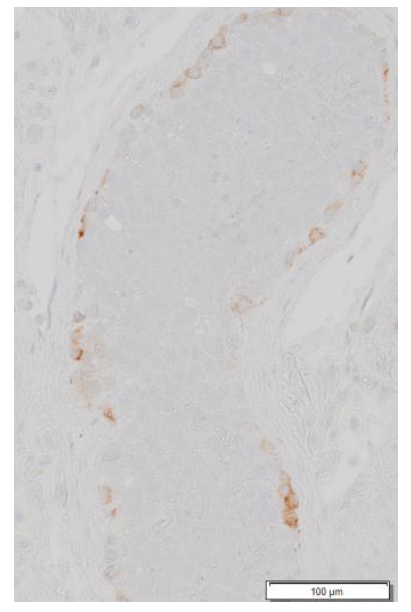

182. SSX

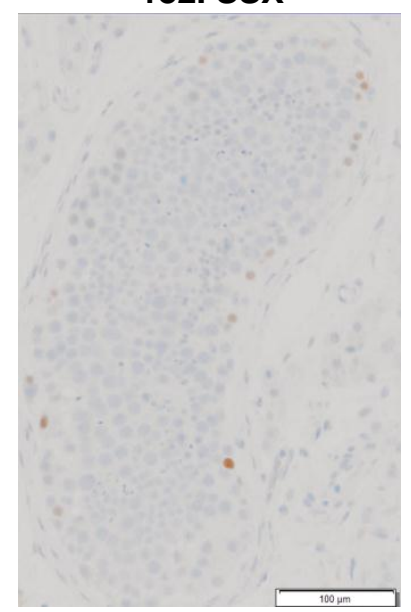




\section{Clone no. 1-2_C33}

A

\begin{tabular}{|c|c|c|c|c|c|c|c|c|c|c|c|c|c|}
\hline \multirow{2}{*}{ Clone no. } & \multirow{2}{*}{ Location } & Slide 175 & Slide 176 & Slide 177 & Slide 178 & Slide 179 & Slide 180 & Slide 181 & Slide 182 & Slide 183 & Slide 184 & Slide 185 & $\begin{array}{c}\text { Minimum } \\
\text { number of } \\
\text { cells }\end{array}$ \\
\hline & & MAGEA4 & n.s & OCT2 & MAGEA4 & FGFR3 & Ki67 & MAGEA4 & SSX & FGFR3 & n.s & MAGEA4 & M \\
\hline \multirow{2}{*}{ 1-2_C33 } & \multirow{2}{*}{ Centre } & 0 & & 0 & 1 & 0 & 0 & $0^{*}$ & 1 & & & 0 & \\
& & & & 5 cells & & & 2 cells & 3 cells & & & & 17 \\
\hline
\end{tabular}

B

175. MAGEA4

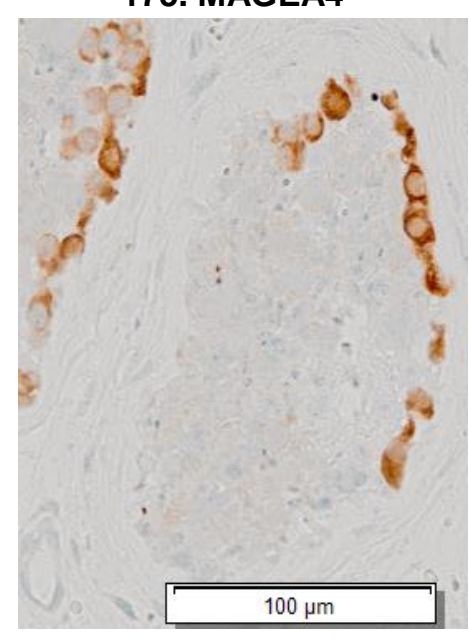

180. Ki67

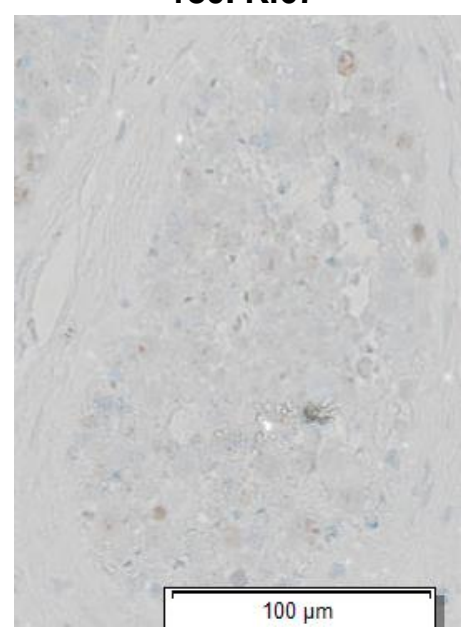

177. ОСТ2

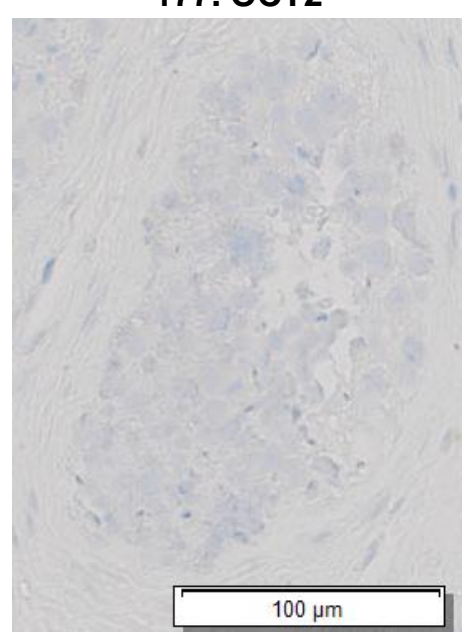

181. MAGEA4

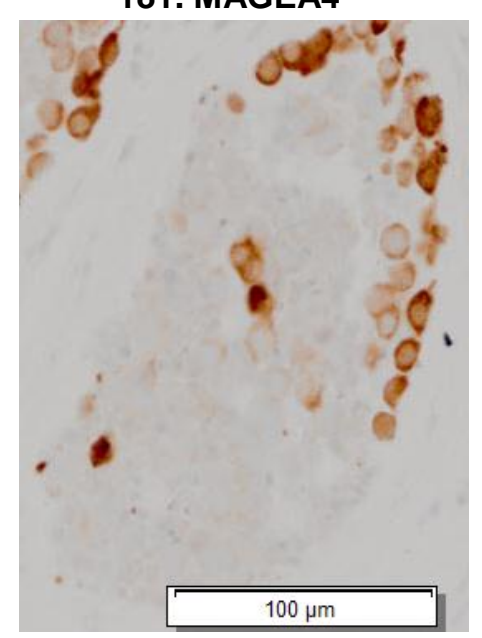

178. MAGEA4

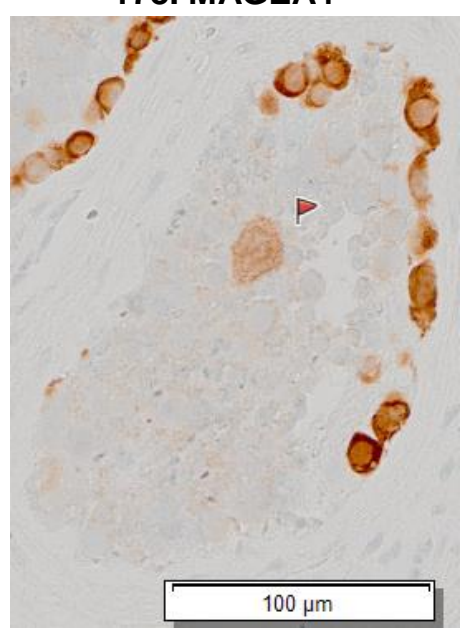

179. FGFR3

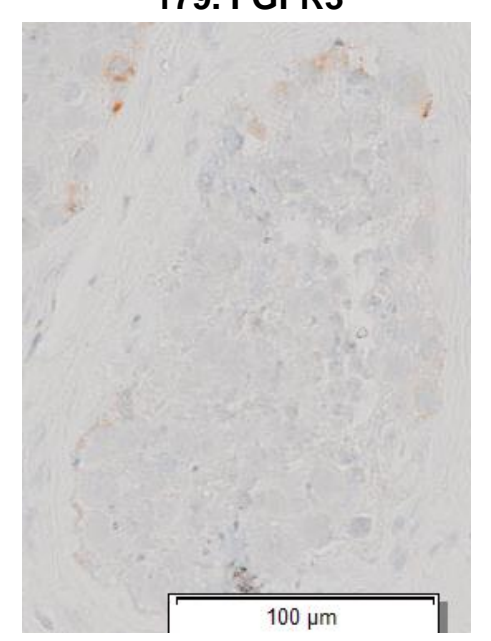

182. SSX

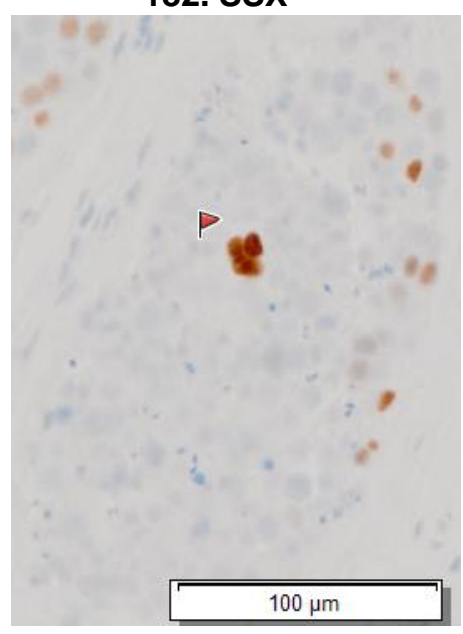




\section{Clone no. 1-2_C34}

A

\begin{tabular}{|c|c|c|c|c|c|c|c|c|c|c|c|c|c|}
\hline \multirow{2}{*}{ Clone no. } & \multirow{2}{*}{ Location } & Slide 175 & Slide 176 & Slide 177 & Slide 178 & Slide 179 & Slide 180 & Slide 181 & Slide 182 & Slide 183 & Slide 184 & Slide 185 & \multirow{2}{*}{$\begin{array}{l}\text { Minimum } \\
\text { number of } \\
\text { cells }\end{array}$} \\
\hline & & MAGEA4 & n.s & ОСТ2 & MAGEA4 & FGFR3 & Ki67 & MAGEA4 & SSX & FGFR3 & n.s & MAGEA4 & \\
\hline \multirow{3}{*}{ 1-2_C34 } & \multirow{3}{*}{ Centre } & \multirow[t]{3}{*}{0} & & \multirow[t]{3}{*}{0} & 1 & \multirow[t]{2}{*}{0} & \multirow[t]{2}{*}{0} & 1 & \multirow[t]{3}{*}{0} & & & \multirow[t]{3}{*}{0} & \multirow{3}{*}{38} \\
\hline & & & & & & & & 6 cells & & & & & \\
\hline & & & & & \multicolumn{4}{|c|}{$20 \mu \mathrm{m}$} & & & & & \\
\hline
\end{tabular}

B

175. MAGEA4

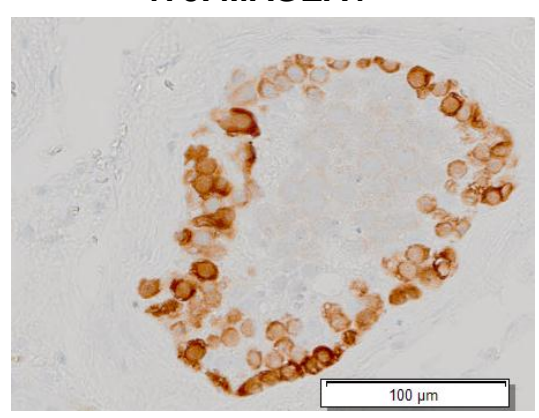

180. Ki67

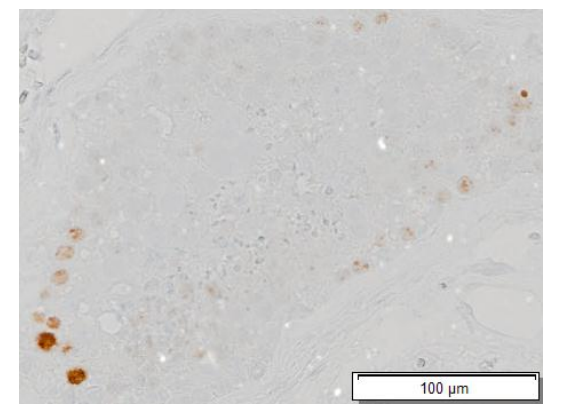

177. OCT2

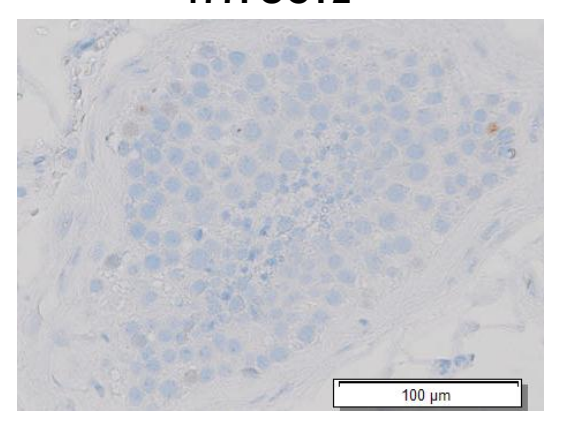

181. MAGEA4

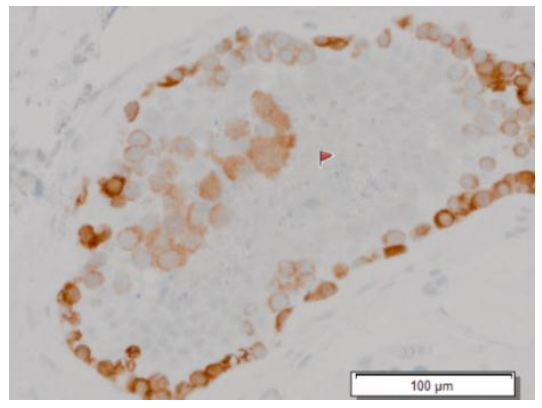

178. MAGEA4

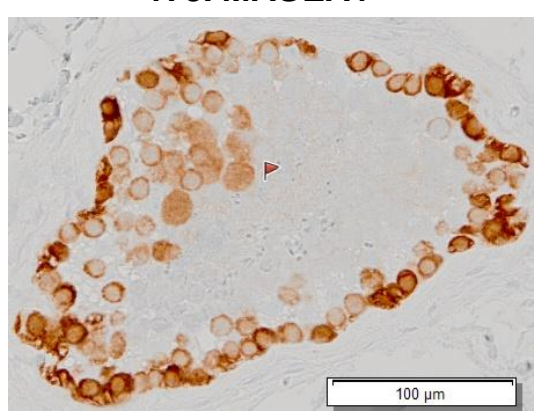

179. FGFR3

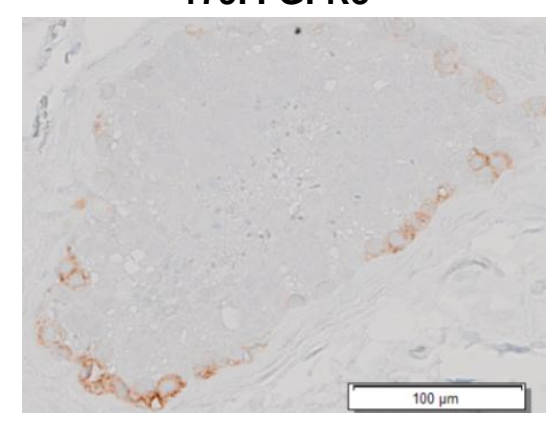

182. SSX

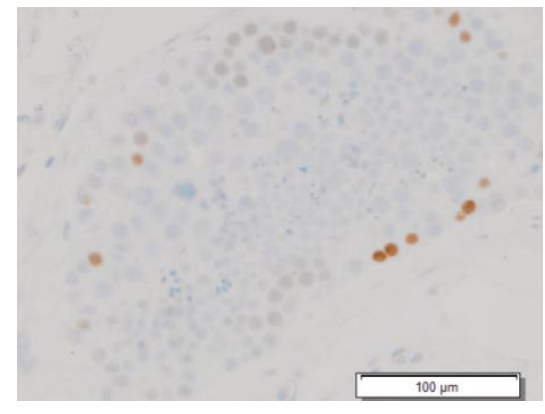


Clone no. 1-2_C35

A

\begin{tabular}{|c|c|c|c|c|c|c|c|c|c|c|}
\hline \multirow{2}{*}{ Clone no. } & \multirow{2}{*}{ Location } & Slide 178 & Slide 179 & Slide 180 & Slide 181 & Slide 182 & Slide 183 & Slide 184 & Slide 185 & \multirow{2}{*}{$\begin{array}{l}\text { Minimum } \\
\text { number of } \\
\text { cells }\end{array}$} \\
\hline & & MAGEA4 & FGFR3 & Ki67 & MAGEA4 & SSX & FGFR3 & n.s & MAGEA4 & \\
\hline \multirow{3}{*}{ 1-2_C35 } & \multirow{3}{*}{ Centre } & \multirow[t]{3}{*}{ NA } & \multirow[t]{3}{*}{0} & \multirow[t]{3}{*}{0} & 1 & 1 & \multirow[t]{3}{*}{ NA } & & \multirow[t]{3}{*}{ NA } & \multirow{3}{*}{20} \\
\hline & & & & & 13 cells & 7 cells & & & & \\
\hline & & & & & \multicolumn{2}{|c|}{$10 \mu \mathrm{m}$} & & & & \\
\hline
\end{tabular}

B

178. MAGEA4

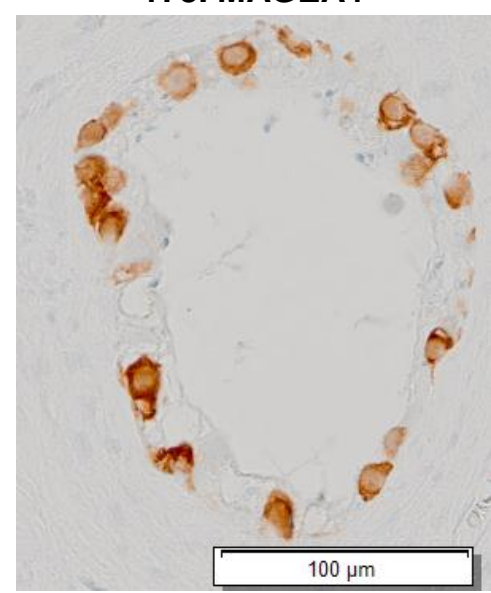

181. MAGEA4

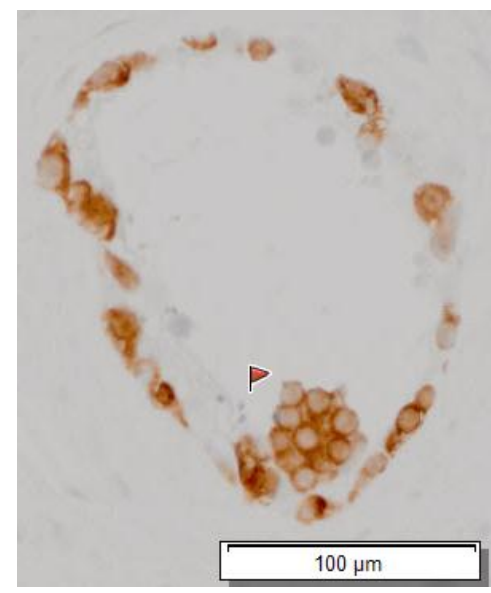

179. FGFR3

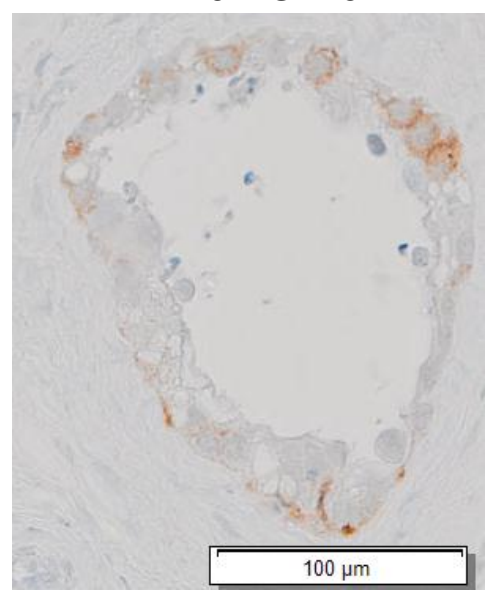

182. SSX

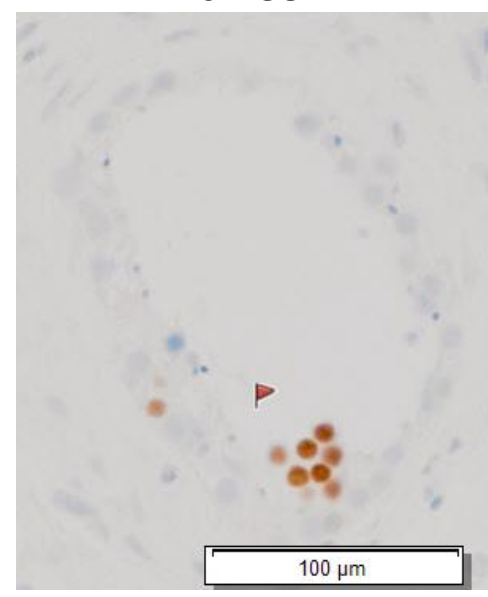

180. Ki67

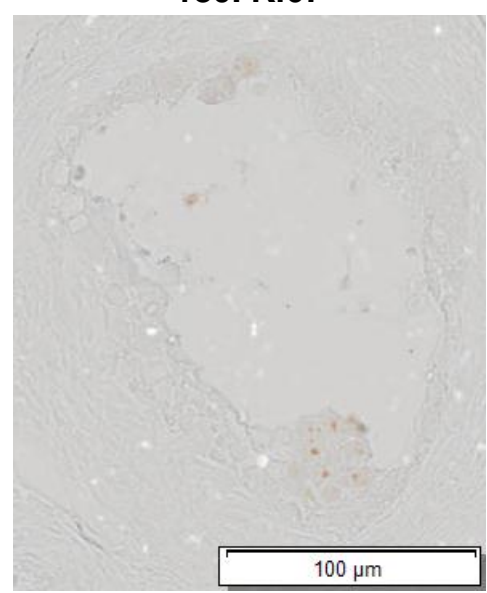

183. FGFR3

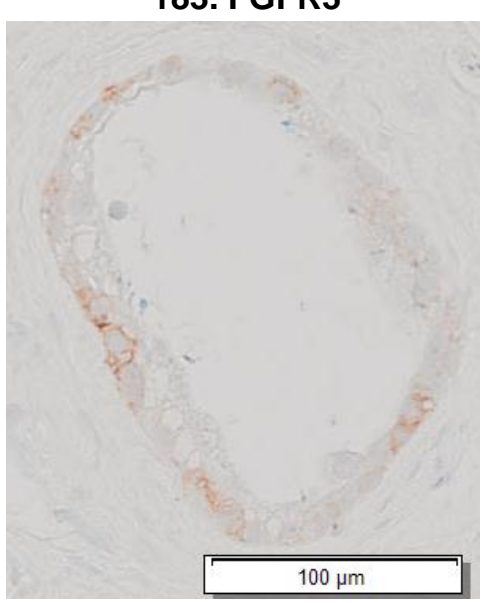




\section{Clone no. 1-2_C36}

A

\begin{tabular}{|c|c|c|c|c|c|c|c|c|c|c|c|c|c|}
\hline \multirow{2}{*}{ Clone no } & \multirow{2}{*}{ Location } & Slide 175 & Slide 176 & Slide 177 & Slide 178 & Slide 179 & Slide 180 & Slide 181 & Slide 182 & Slide 183 & Slide 184 & Slide 185 & \multirow{2}{*}{$\begin{array}{c}\text { Minimum } \\
\text { number o } \\
\text { cells }\end{array}$} \\
\hline & & MAGEA4 & n.s & ОсT2 & MAGEA4 & FGFR3 & Ki67 & MAGEA4 & SSX & FGFR3 & n.s & MAGEA4 & \\
\hline \multirow{3}{*}{ 1-2_C36 } & \multirow{3}{*}{ Periphery } & $0^{*}$ & & \multirow[t]{2}{*}{0} & 1 & \multirow[t]{2}{*}{0} & \multirow[t]{2}{*}{0} & 1 & $0^{*}$ & \multirow[t]{3}{*}{0} & & \multirow[t]{3}{*}{0} & \multirow{3}{*}{73} \\
\hline & & 3 cells & & & 14 cells & & & 10 cells & 5 cells & & & & \\
\hline & & \multicolumn{8}{|c|}{$40 \mu \mathrm{m}$} & & & & \\
\hline
\end{tabular}

B

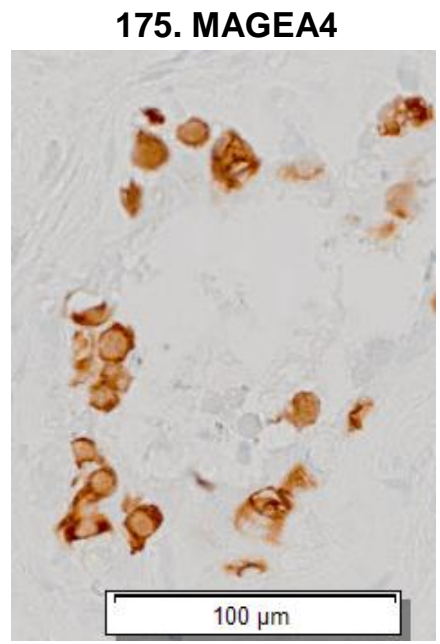

180. Ki67

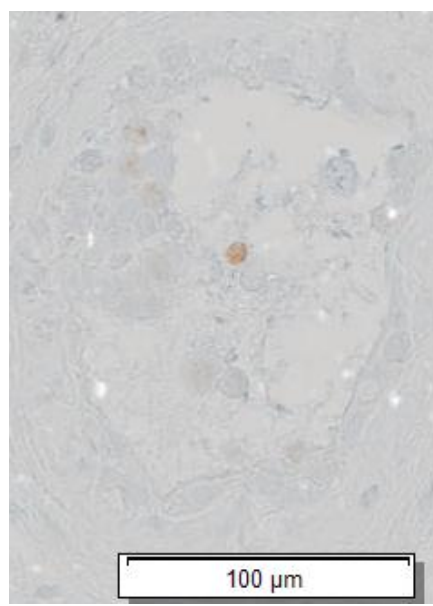

177. ОСТ2

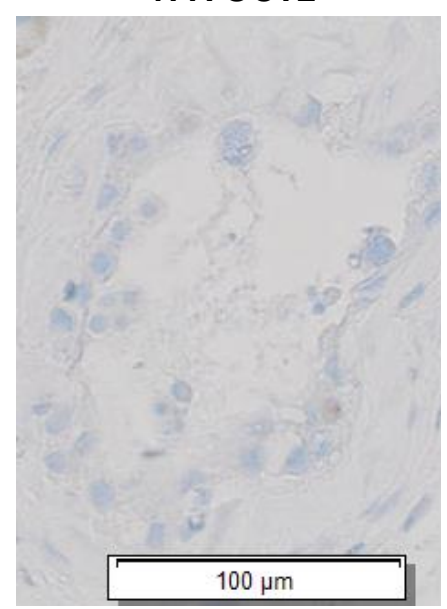

181. MAGEA4

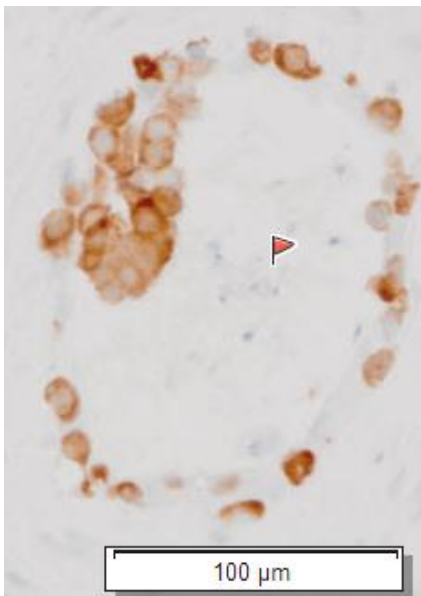

178. MAGEA4

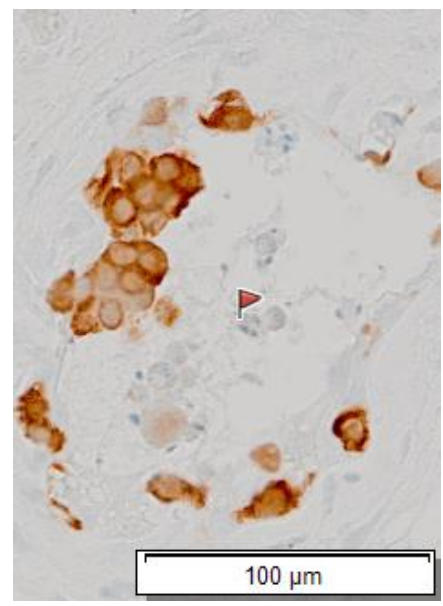

182. SSX
179. FGFR3

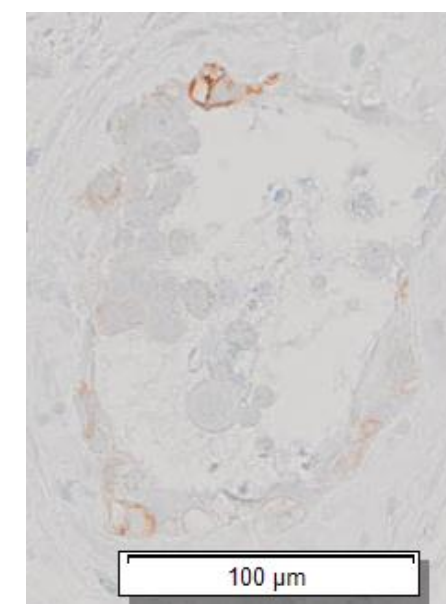

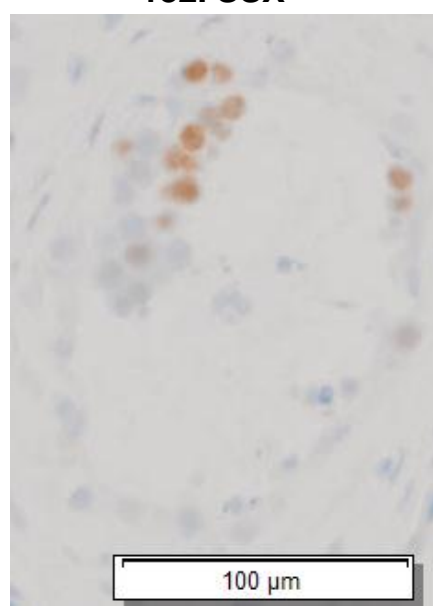




\section{Clone no.1-2_C37}

A

\begin{tabular}{|c|c|c|c|c|c|c|c|c|c|c|c|c|c|}
\hline \multirow{2}{*}{ Clone no. } & \multirow{2}{*}{ Location } & Slide 175 & Slide 176 & Slide 177 & Slide 178 & Slide 179 & Slide 180 & Slide 181 & Slide 182 & Slide 183 & Slide 184 & Slide 185 & \multirow{2}{*}{$\begin{array}{l}\text { Minimum } \\
\text { number of } \\
\text { cells }\end{array}$} \\
\hline & & MAGEA4 & n.s & ОСТ2 & MAGEA4 & FGFR3 & Ki67 & MAGEA4 & SSX & FGFR3 & n.s & MAGEA4 & \\
\hline \multirow{3}{*}{ 1-2_C37 } & \multirow{3}{*}{ Centre } & \multirow[t]{3}{*}{0} & & \multirow[t]{3}{*}{0} & 1 & \multirow[t]{2}{*}{0} & \multirow[t]{2}{*}{0} & 1 & \multirow[t]{3}{*}{0} & \multirow[t]{3}{*}{0} & & \multirow[t]{3}{*}{0} & \multirow{3}{*}{26} \\
\hline & & & & & 7 cells & & & 6 cells & & & & & \\
\hline & & & & & \multicolumn{4}{|c|}{$20 \mu \mathrm{m}$} & & & & & \\
\hline
\end{tabular}

B

175. MAGEA4

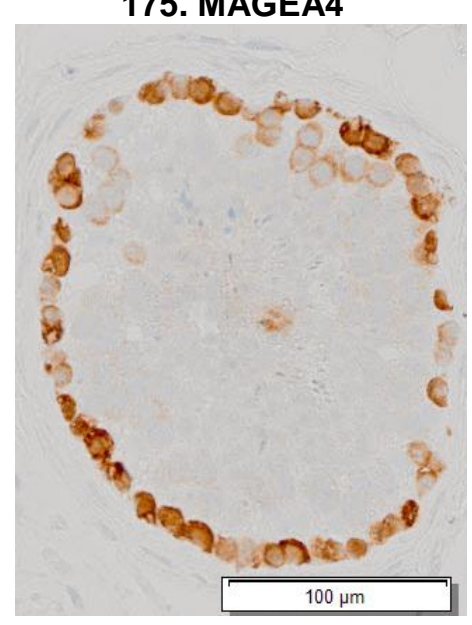

180. Ki67

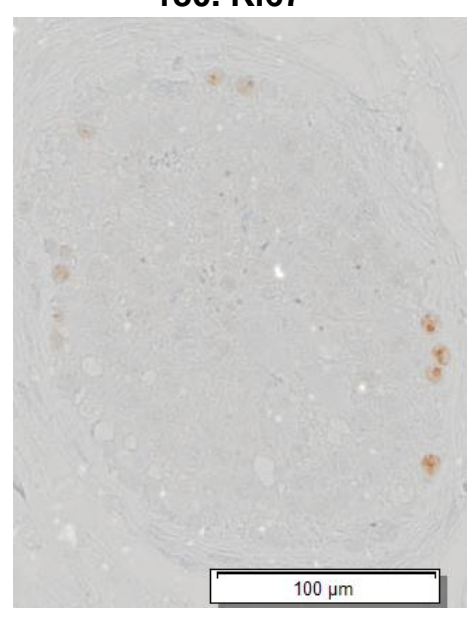

177. OCT2

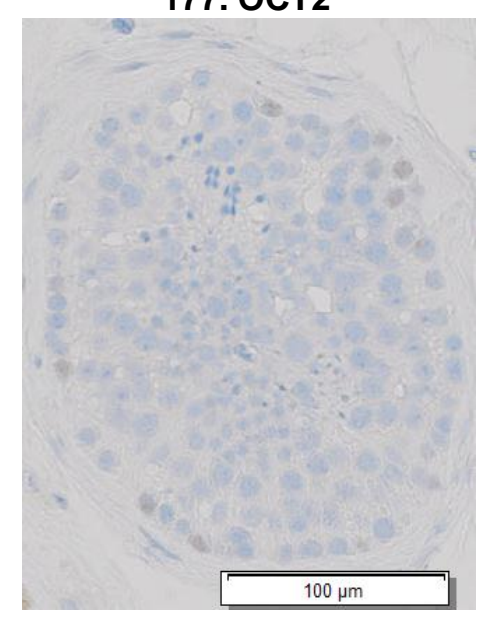

181. MAGEA4

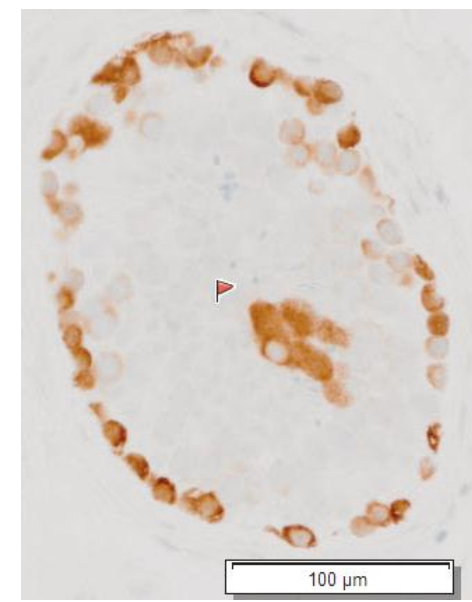

178. MAGEA4

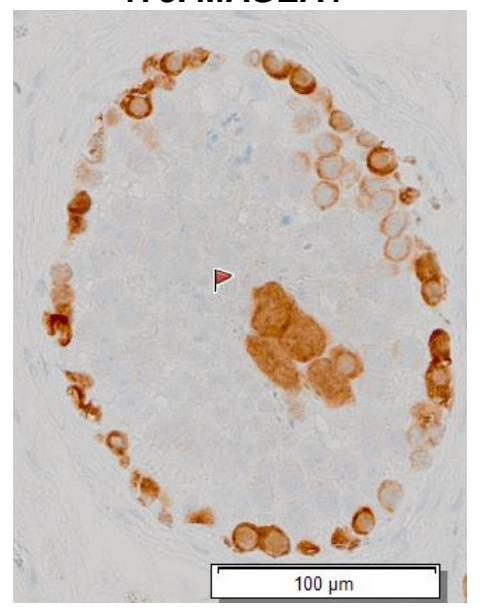

182. SSX

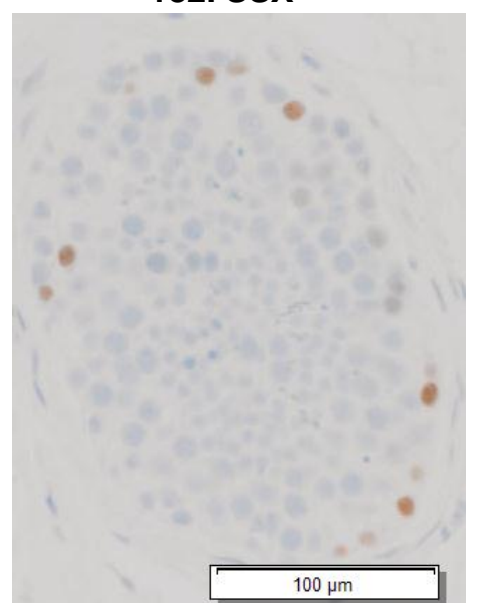

179. FGFR3

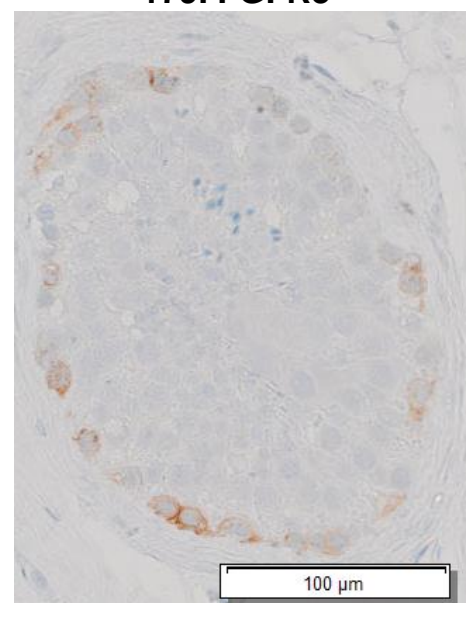

185. MAGEA4

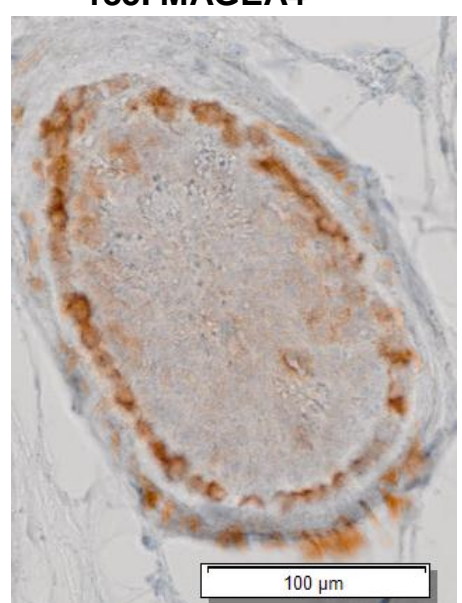


Clone no. 1-2_C38

\begin{tabular}{|c|c|c|c|c|c|c|c|c|c|c|c|c|c|c|c|c|}
\hline \multirow{2}{*}{ Clone no. } & \multirow{2}{*}{ Location } & Slide 178 & Slide 179 & Slide 180 & Slide 181 & Slide 182 & $\begin{array}{c}\text { Slide } \\
183\end{array}$ & Slide 184 & Slide 185 & $\begin{array}{c}\text { Slide } \\
186\end{array}$ & Slide 187 & Slide 188 & $\begin{array}{c}\text { Slide } \\
189\end{array}$ & Slide 190 & Slide 191 & \multirow{2}{*}{$\begin{array}{l}\text { Minimum } \\
\text { number of } \\
\text { cells }\end{array}$} \\
\hline & & MAGEA4 & FGFR3 & Ki67 & MAGEA4 & SSX & FGFR3 & n.s & MAGEA4 & n.s & n.s & n.s & n.s & n.s & MAGEA4 & \\
\hline \multirow{3}{*}{ 1-2_C38 } & \multirow{3}{*}{$\begin{array}{c}\text { Near } \\
\text { Periphery }\end{array}$} & \multirow[t]{3}{*}{0} & & \multirow[t]{3}{*}{0} & 1 & \multirow[t]{2}{*}{0} & \multirow[t]{2}{*}{0} & & 1 & & & & & & 0 & \multirow{3}{*}{33} \\
\hline & & & & & 4 cells & & & & 9 cells & & & & & & & \\
\hline & & & & & & & $25 \mu \mathrm{m}$ & & & & & & & & & \\
\hline
\end{tabular}

B

178. MAGEA4

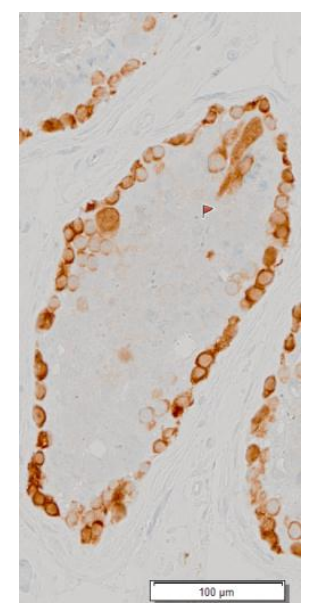

180. Ki67

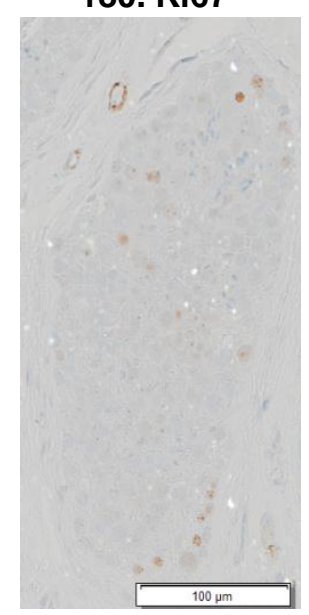

181. MAGEA4

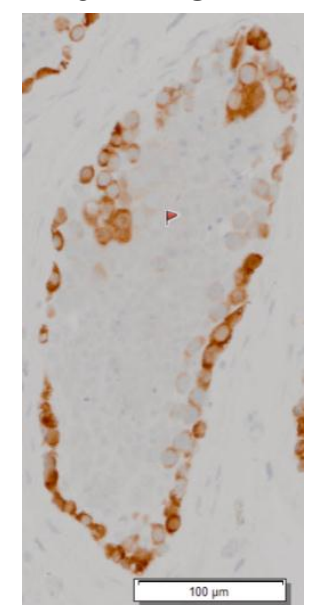

182. SSX

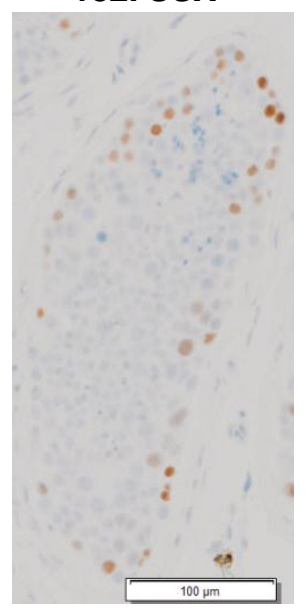

183. FGFR3

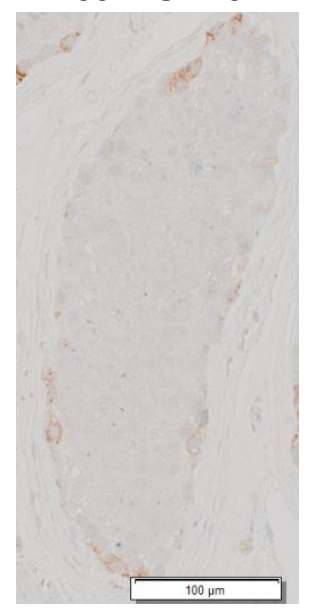

185. MAGEA4

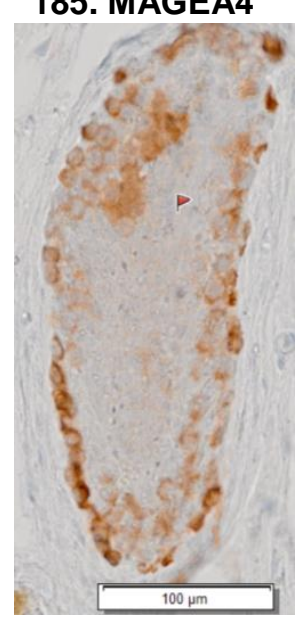

191. MAGEA4

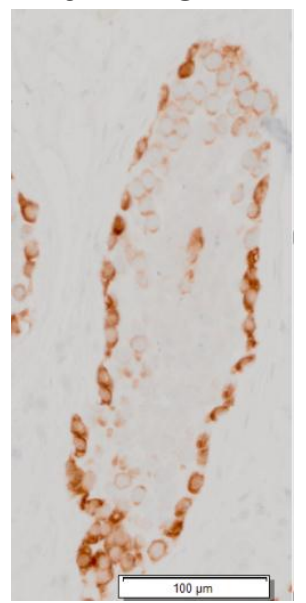




\section{Clone no. 1-2_C39}

A

\begin{tabular}{|c|c|c|c|c|c|c|c|c|c|c|c|c|c|c|c|c|}
\hline \multirow{2}{*}{ Clone no. } & \multirow{2}{*}{ Location } & Slide 178 & Slide 179 & Slide 18 & Slide 181 & Slide 182 & $\begin{array}{c}\text { Slide } \\
183 \\
\end{array}$ & Slide 184 & Slide 185 & $\begin{array}{c}\text { Slide } \\
186 \\
\end{array}$ & Slide 187 & Slide 188 & $\begin{array}{c}\text { Slide } \\
189 \\
\end{array}$ & Slide 190 & Slide 191 & \multirow{2}{*}{$\begin{array}{l}\text { Minimum } \\
\text { number of } \\
\text { cells }\end{array}$} \\
\hline & & MAGEA4 & FGFR3 & Ki67 & MAGEA4 & SSX & FGFR3 & n.s & MAGEA4 & n.s & n.s & n.s & n.s & n.s & MAGEA4 & \\
\hline \multirow{3}{*}{ 1-2_C39 } & \multirow{3}{*}{$\begin{array}{l}\text { Near } \\
\text { Periphery }\end{array}$} & \multirow[t]{3}{*}{0} & & \multirow[t]{3}{*}{0} & 1 & \multirow[t]{2}{*}{0} & \multirow[t]{2}{*}{0} & & 1 & & & & & & $0^{*}$ & \multirow{3}{*}{35} \\
\hline & & & & & 3 cells & & & & 4 cells & & & & & & 2 cells & \\
\hline & & & & & \multicolumn{11}{|c|}{$55 \mu \mathrm{m}$} & \\
\hline
\end{tabular}

B

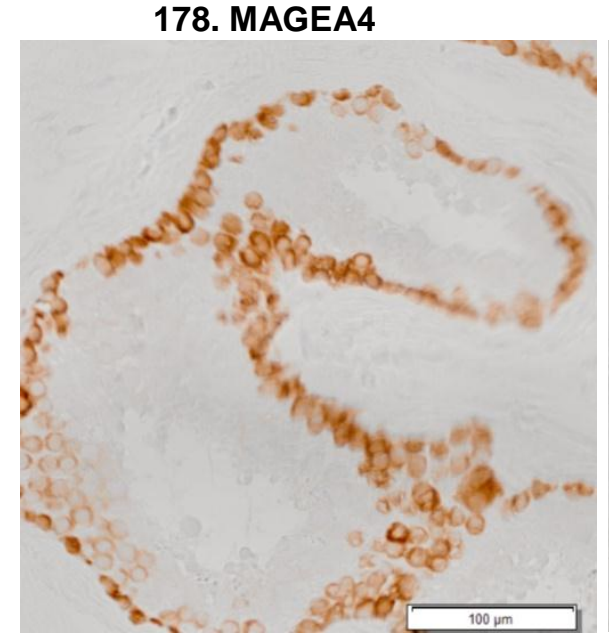

180. Ki67

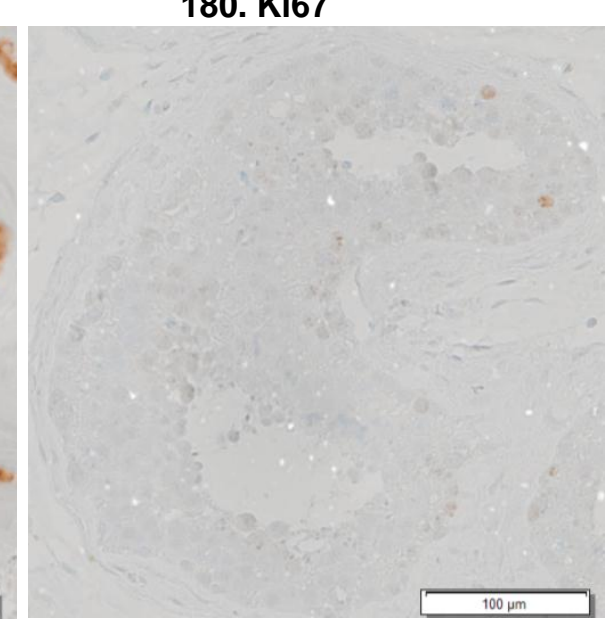

181. MAGEA4

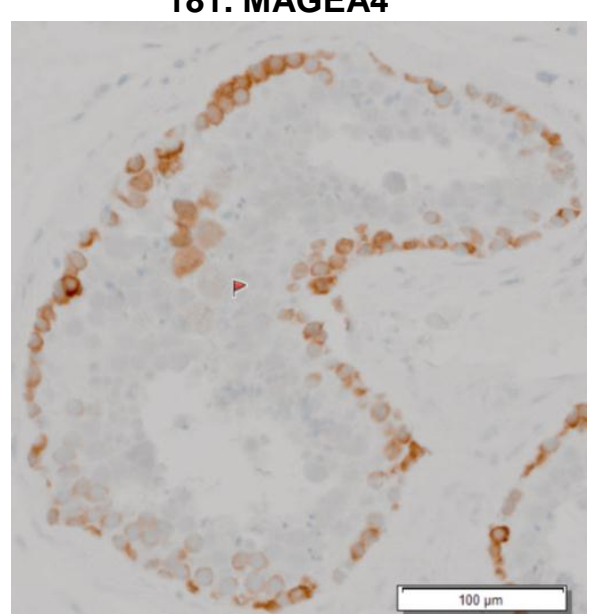

182. SSX
183. FGFR3

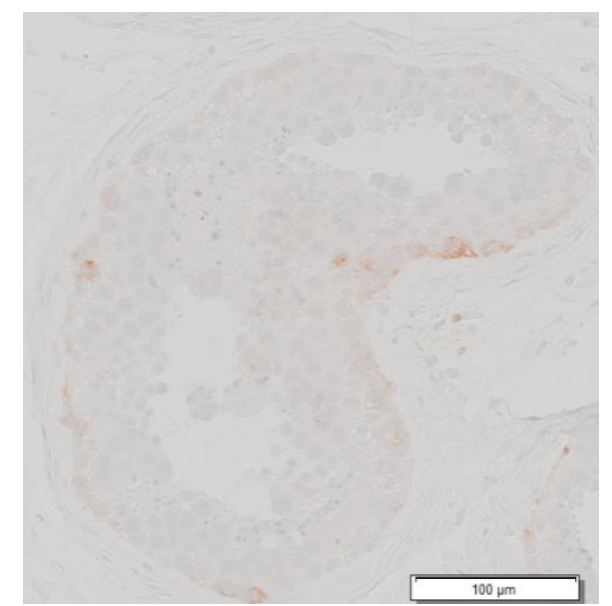

185. MAGEA4

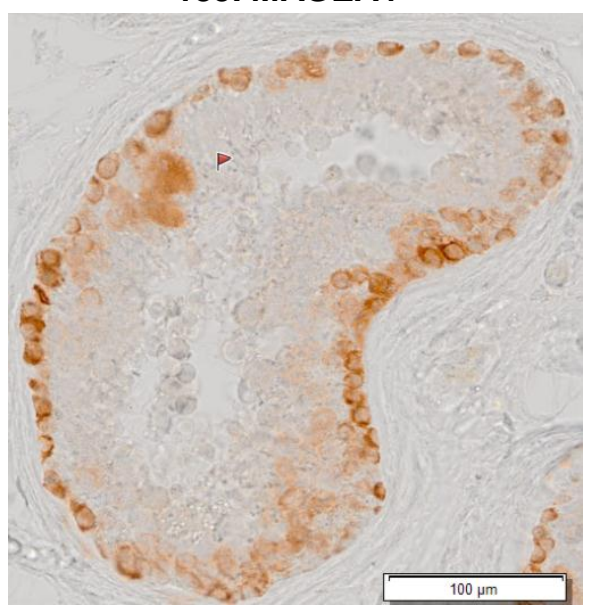

191. MAGEA4

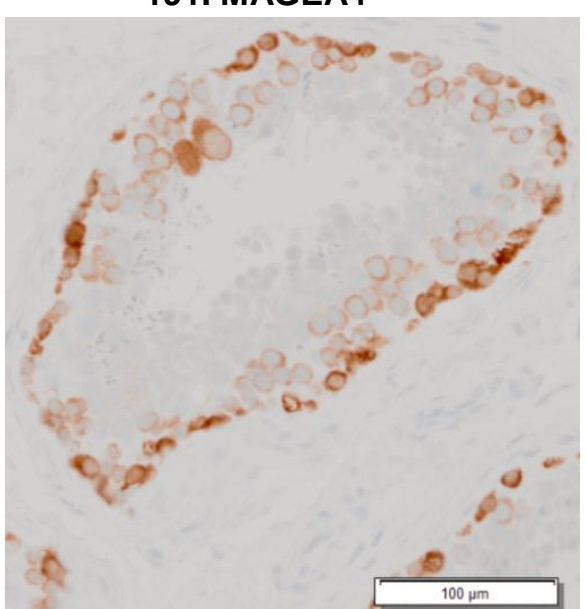

